\title{
All that looks grave is not grievous. Not all those who wince are in pain
}

Citation for published version (APA):

van Impelen, A. (2018). All that looks grave is not grievous. Not all those who wince are in pain: studies in furtherance of validity assessment. [Doctoral Thesis, Maastricht University]. Maastricht University. https://doi.org/10.26481/dis.20181025ai

Document status and date:

Published: 01/01/2018

DOI:

10.26481/dis.20181025ai

Document Version:

Publisher's PDF, also known as Version of record

\section{Please check the document version of this publication:}

- A submitted manuscript is the version of the article upon submission and before peer-review. There can be important differences between the submitted version and the official published version of record.

People interested in the research are advised to contact the author for the final version of the publication, or visit the DOI to the publisher's website.

- The final author version and the galley proof are versions of the publication after peer review.

- The final published version features the final layout of the paper including the volume, issue and page numbers.

Link to publication

\footnotetext{
General rights rights.

- You may freely distribute the URL identifying the publication in the public portal. please follow below link for the End User Agreement:

www.umlib.nl/taverne-license

Take down policy

If you believe that this document breaches copyright please contact us at:

repository@maastrichtuniversity.nl

providing details and we will investigate your claim.
}

Copyright and moral rights for the publications made accessible in the public portal are retained by the authors and/or other copyright owners and it is a condition of accessing publications that users recognise and abide by the legal requirements associated with these

- Users may download and print one copy of any publication from the public portal for the purpose of private study or research.

- You may not further distribute the material or use it for any profit-making activity or commercial gain

If the publication is distributed under the terms of Article $25 \mathrm{fa}$ of the Dutch Copyright Act, indicated by the "Taverne" license above, 


\section{All that looks grave is not grievous Not all those who wince are in pain}

Studies in furtherance of validity assessment

Alfons van Impelen 
Copyright @ 2018 Alfons van Impelen

ISBN: 978-90-829118-3-1

Title inspired by

"All that glitters is not gold"

The Merchant of Venice, William Shakespeare, 1598

"All that is gold does not glitter

Not all those who wander are lost"

The Lord of the Rings, John R. R. Tolkien, 1954

Cover image:

The Play Scene in "Hamlet", Daniel Maclise, 1842

Photo (C) Tate CC-BY-NC-ND 3.0 (Unported)

Lay-out:

Alfons van Impelen

Printing:

Ridderprint BV 


\title{
All that looks grave is not grievous Not all those who wince are in pain
}

Studies in furtherance of validity assessment

\author{
DISSERTATION
}

To obtain the degree of Doctor at Maastricht University, on the authority of the Rector Magnificus, Prof. dr. Rianne Letschert in accordance with the decision of the Board of Deans, to be defended in public on Thursday, 25 October 2018, at 10:00 hours

by

Alfons van Impelen 


\section{Supervisors}

Prof. dr. Marko Jelicic

Prof. dr. Harald Merckelbach

\section{Co-supervisor}

Prof. dr. Joost à Campo

\section{Assessment Committee}

Prof. dr. Rudolf Ponds (chair)

Prof. dr. Arjan Bos, Open University, Heerlen, the Netherlands

Dr. Brechje Dandachi-FitzGerald

Prof. dr. Gerben Meynen, Tilburg University, Vrije Universiteit Amsterdam, the Netherlands Prof. dr. Marleen Rijkeboer

The research described in this dissertation was performed at the Faculty of Psychology and Neuroscience, Department of Clinical Psychological Science, Maastricht University, Maastricht, the Netherlands, and at Radix Forensic Psychiatric Hospital, Heerlen, the Netherlands. 


\section{Contents}

Chapter 1

Chapter 2

Chapter 3

Chapter 4

Chapter 5

Chapter 6

Chapter 7

References

Biased symptom reporting and antisocial behavior in forensic samples: A weak link

Antisocial features are not predictive of symptom exaggeration in forensic patients

The Structured Inventory of Malingered Symptomatology (SIMS): A systematic review and meta-analysis

Detecting feigned cognitive impairment with Schretlen's Malingering Scale Vocabulary and Abstraction test

Differentiating factitious from malingered symptomatology: The development of a psychometric approach

General discussion 96

Publications 


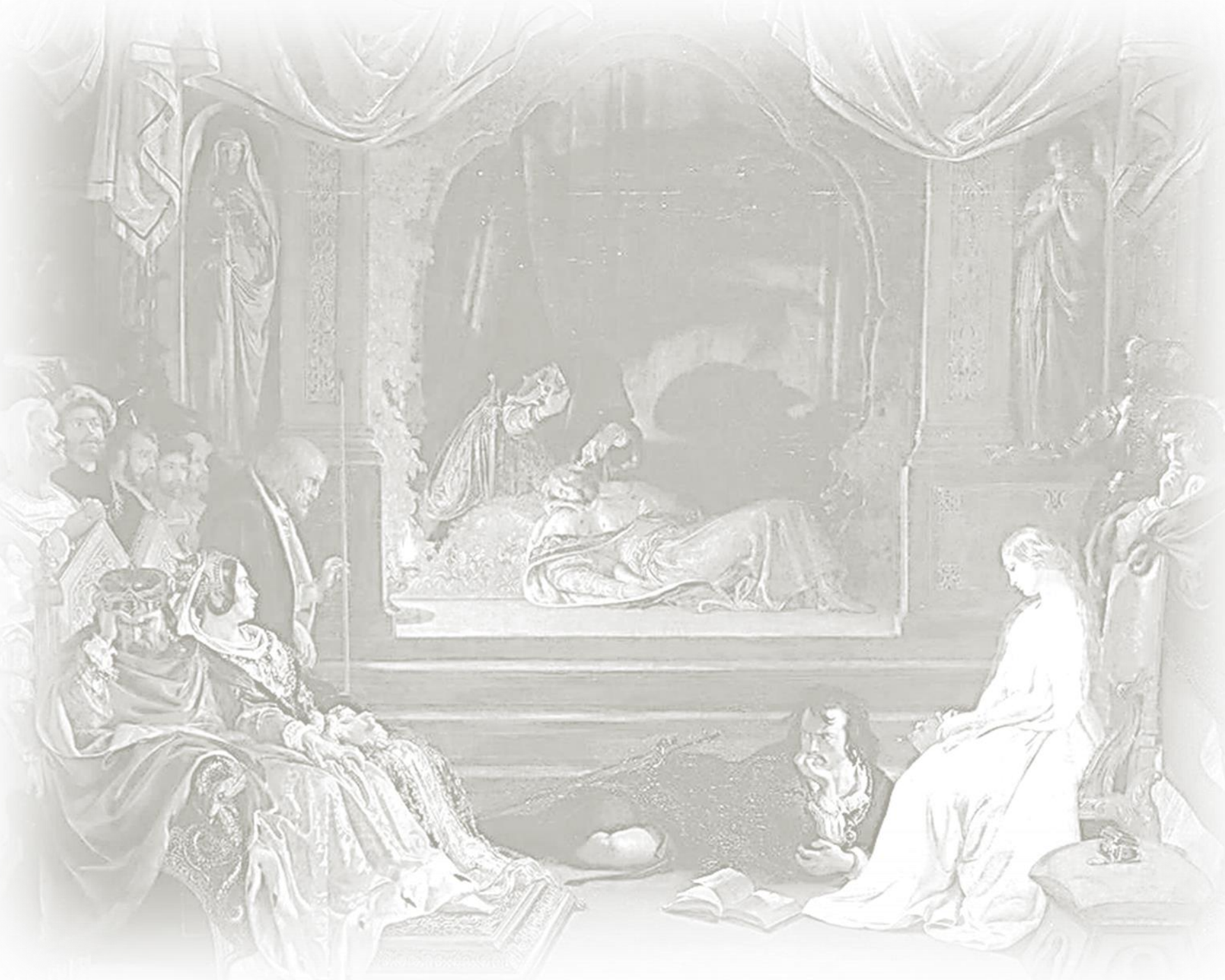




\section{Chapter 1}

\section{General introduction}

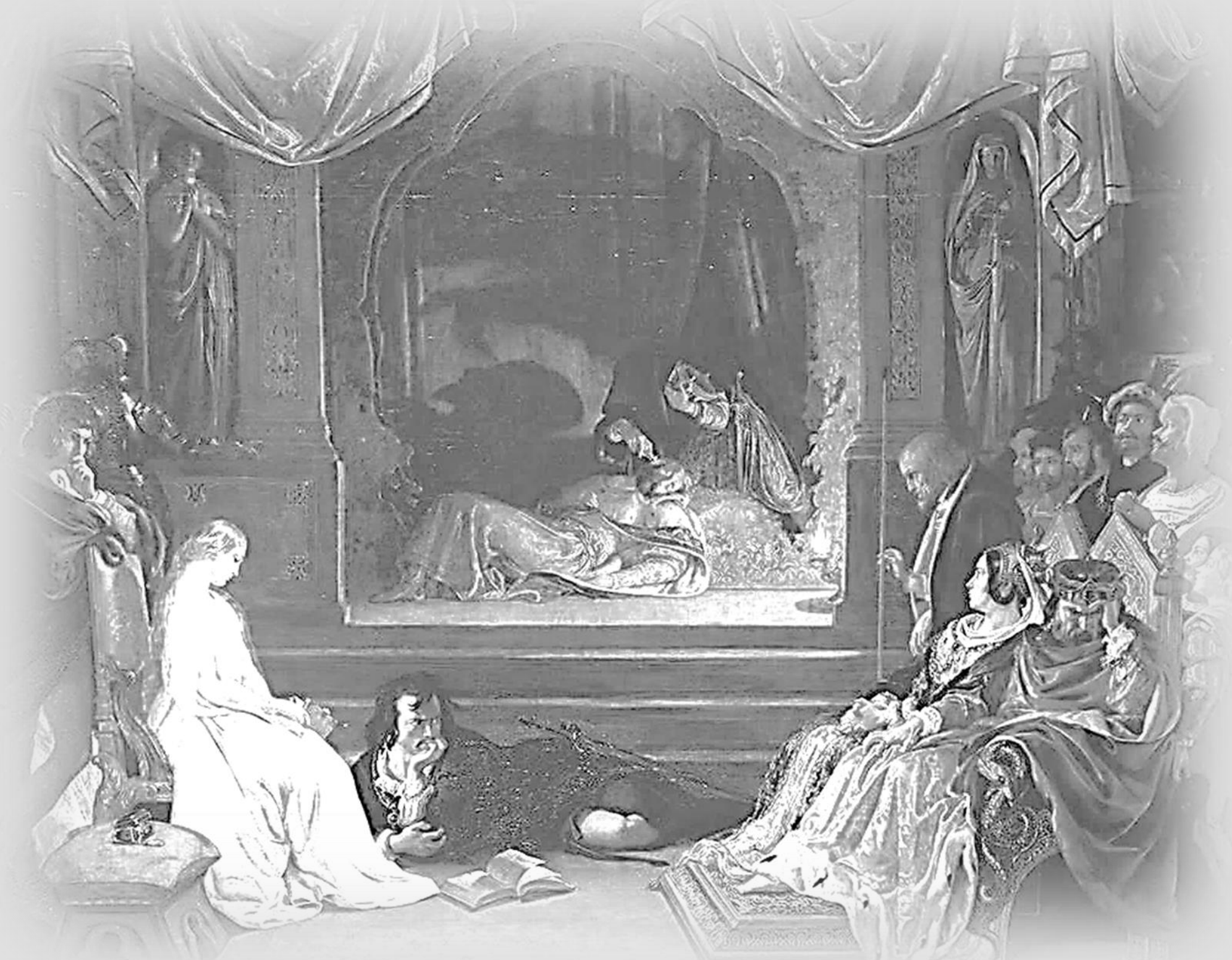

In part adapted from:

van Impelen, A., Niesten, I. J., Jelicic, M., \& Merckelbach, H. (in press). Simulatie: Enkele misvattingen nader belicht [Feigning: Shedding light on several misconceptions]. In K. Goethals, G. Meynen, A. Popma (Eds.), Leerboek forensische psychiatrie [Textbook forensic psychiatry]. De Tijdstroom Uitgeverij. 


\section{Introduction}

The aim of psychological and neuropsychological assessment is to diagnose; to investigate the cognitive, emotional, and behavioral characteristics and capacities of a person so as to establish whether, and which, pathological symptoms are present, and potentially, what disorders or conditions the symptoms constitute. In short, the goal of psychological and neuropsychological assessment is to identify the nature and cause of a person's symptoms.

There are multiple potential impediments to accurate diagnoses. Some impediments originate from diagnosticians; for example, diagnosticians may employ tests that are unreliable or inappropriate, or they may draw invalid conclusions from the data they gather. Other impediments originate from patients; for instance, patients may be unable or unwilling to describe their symptoms accurately. In formal terms, it can be stated that the accuracy of any diagnosis depends on three aspects (Larrabee, 2015); test validity (the consistency and appropriateness of diagnostic tests and procedures), assessment validity (the accuracy and openness with which patients present their symptoms), and judgment validity (i.e., the soundness of the conclusions drawn by diagnosticians). The studies in this thesis revolve around assessment validity: Some focus on the validity of specific indicators of assessment validity (e.g., antisocial behavior; Chapters 2-3) and others on tests that measure assessment validity (i.e., validity tests; Chapters 4-6).

Test validity refers to the extent to which a test measures what it is intended to measure. For instance, a short-term memory test is valid insofar as it reliably quantifies an examinee's short-term memory capacity. Assessment validity refers to the extent to which an examinee discloses their actual clinical condition during an assessment. Thus, an assessment is only valid to the degree that the examinee produces answers and test results that reflect their actual cognitive, emotional, and behavioral characteristics and capacities. The third aspect that may influence the accuracy of psychological and neuropsychological assessments is judgment validity. Judgment validity refers to the extent to which conclusions and decisions follow logically from well-grounded information.

The practice of diagnosis involves two general methods of decision-making; the "clinical" method and the "actuarial" method. The clinical method includes all decisionmaking processes that are based on human cognition, rather than on empirically derived decision rules. For example, if clinicians employ an unstructured interview to gather information about an examinee's symptoms, then they use the clinical method; if they rely on a valid psychometric test, questionnaire, or structured interview, then they use the actuarial method. Similarly, when clinicians follow their personal judgment in interpreting and combining information to arrive at a diagnosis, they employ the clinical method; if they rely exclusively on experimentally observed norms and relations to interpret and combine information, then they use the actuarial method.

The practice of medicine, including psychiatry, can be traced back to ancient history, and so can the evaluation of assessment validity. A well-known example hails from classical antique literature; the plot of Odysseus (see Gavin, 1843, for a host of historical examples). 
Odysseus, wishing to avoid the Trojan War, feigned insanity by sowing his fields with salt and plowing with a donkey and an ox (whose different stride lengths hamper plowing). Palamedes, who was send to recruit Odysseus, responded by placing Odysseus' infant son in the line of the furrow, which forced Odysseus to divert, and thus reveal the falsity of his insanity. Palamedes' test to assess the validity of Odysseus' insanity exemplifies the clinical method in validity assessment; it was conceived ad hoc and rested entirely on human intellect. The success of Palamedes' application of the clinical method is, however, not representative of its efficacy in general; on the contrary (Dawes, Faust, \& Meehl, 1989; Wedding \& Faust, 1989).

\section{Myths and misconceptions}

Most myths and misconceptions concerning validity assessment stem from clinical judgment. The reason for this is simple; the potency of clinical judgment in validity assessment is itself a myth. This is vividly illustrated by the renowned "Rosenhan study" (Rosenhan, 1973): Rosenhan and seven healthy associates each sought admission to a different psychiatric hospital by feigning auditory hallucinations. All were admitted, received a psychiatric diagnosis, and were prescribed antipsychotic drugs. Despite the cessation of feigning upon admission, the average time of hospitalization was 19 days (ranging from 9 to 52 days). In reaction to the study, one hospital administration invited Rosenhan to send more pseudo-patients, which they would then attempt to identify as such. Rosenhan assented and the hospital ended up labeling 41 out of 193 new patients (21\%) as potential pseudo-patients. Sadly, Rosenhan had refrained from sending pseudo-patients to the hospital. The Rosenhan study and 11 similar studies were compiled by Rosen and Phillips (2004): In all 12 studies, pseudo-patients were detected at very low rates, ranging from $0 \%$ to $25 \%$.

The insufficiency of clinical judgment in validity assessment has been firmly established through several decades of research, also in neuropsychology (see, for example, Faust, Hart, Guilmette, \& Arkes, 1988, and, recently, Dandachi-FitzGerald, Merckelbach, \& Ponds, 2017). Nevertheless, misguided ideas that sprang from clinical lore persist in contemporary thinking on psychiatric diagnosis. One such idea is that feigned symptom presentations are rare. Given the inadequacy of clinical judgment to detect feigned symptom presentations, it is not surprising that those who rely on it deem feigning to be an uncommon phenomenon. The assumption that feigning is rare dates back to the turn of the nineteenth century and the dawn of psychiatry as a distinct medical specialty. Eminent psychiatrists of that time discussed what they termed "die Simulationsfrage", which refers to the question whether feigned mental illness occurs at all among healthy individuals (Siemens, 1883). Carl Gustav Jung, for example, claimed to have seen thousands of people admitted to psychiatric hospitals; only 11 of which feigned their symptomatology (Jung, 1903). The prevalence of feigned symptomatology is still subject to debate among scholars, but the issue has shifted from whether or not it occurs to how common it is. For instance, 
some authors hold "40 plus or minus 10" percent to be "the new magical number" (Larrabee, Millis, \& Meyers, 2009), whereas others consider " $15 \pm 15 \%$ " to be a more accurate estimate (Young, 2015). However, there is little reason to assume that feigned psychopathology is a trivial phenomenon. Prevalence estimates depend on instruments and settings, but often they exceed the 5\% level (Greve, Ord, Bianchini, \& Curtis, 2009; McDermott, Dualan, \& Scott, 2013; Stevens, Friedel, Mehren, \& Merten, 2008), even in a pediatric samples (Araujo et al., 2014; Kirkwood \& Kirk, 2010).

Another myth that was clearly articulated throughout nineteenth- and twentiethcentury psychiatry is that those who feign symptoms are mentally ill. Illustrious figures such as Jean-Martin Charcot and later Pierre Janet and Sigmund Freud, formulated disease models for what was then called hysteria (Kanaan \& Wessely, 2010). In trying to unravel the etiology of symptoms that had no evident organic cause-ranging from amnesia and dissociation to seizures and paralysis-effort was directed at novel neurological, and later psychological, explanations. The thought that such symptoms were intentionally feigned in pursuit of incentives-obtaining material gain, for example, or avoiding duty or responsibility, or procuring attention or care-was not readily entertained. The German psychiatrist Fritz Siemens (1883, p. 42), for example, remarked; “Wie oft kommen den Irrenartz Fälle vor, die wie Simulation aussehen und doch keine sind! Daher is gewiss a priori Krankheit anzunehmen." [How often does a psychiatrist encounter cases, that look like feigning and yet are not! Therewith is certainly first of all illness to be assumed.]

The popularization of the unconscious mind as potential source of psychopathology (by Freud and Jung, for example; see Ekstrom, 2004) paved the way for what is now referred to as the "psychopathology = superordinate" position (Merten \& Merckelbach, 2013b). Proponents of this position argue, like Siemens (1883), that noncredible symptom presentations are primarily symptomatic of mental illness, rather than conscious subterfuge. The pitfall of the psychopathology = superordinate position is that it fosters circular reasoning: Patients present with noncredible pathology because they are ill, and patients are ill because they present with noncredible pathology. The point is that evidence (such as validity test scores) cannot logically be used as proof both for and against a theory or diagnosis. Put differently, the psychopathology $=$ superordinate doctrine is not falsifiable. Moreover, there is no compelling evidence against the opposite position; that a rational costbenefit analysis may precede deliberate symptom fabrication (Merten \& Merckelbach, 2013b). Although Freudian theories about the unconscious have largely been discredited (e.g., Eysenck, 1985), and the concept of hysteria abandoned as a diagnostic category, the notion of pathology originating from the unconscious mind survives in the diagnosis conversion disorder, which is conceived of as a dissociative disorder (World Health Organization, 1992) or a somatic symptom disorder (American Psychiatric Association, 2013).

The transition of the diagnosis hysteria into conversion disorder coincided with the entry of factitious disorder in the diagnostic canon (American Psychiatric Association, 1980). The modern conception of factitious disorder stems from Richard Asher's paper on what he 
dubbed "Munchausen's syndrome" (Asher, 1951), and was "included to fill the large middle ground between the hysterical disorders and malingering" (Hyler \& Spitzer, 1978, p. 1502). Factitious disorders differ from dissociative and somatic (i.e., hysterical) disorders in that patients are taken to feign or produce their symptomatology consciously, rather than subconsciously; it differs from malingering in that the incentives that prompt feigning are obscure and internal, rather obvious and external (American Psychiatric Association, 2013; World Health Organization, 1992). In factitious disorders, patients feign or produce symptoms solely to "assume the sick role" (American Psychiatric Association, 2013, p. 727) and thus acquire the attention, sympathy, and care that is typically reserved for the afflicted.

The reasoning behind the diagnosis of factitious disorders is that healthy people, in the absence of obvious external incentives (such as procurement of material benefits and evasion of responsibility) would not feign or produce pathology; and therefore, those who do must be mentally ill. The diagnostic requirement that obvious external rewards be absent in the presence of feigned symptomatology invites clinicians to erroneously infer evidence of absence from absence of evidence, which is a fallacy in informal logic known as "argument from ignorance." An argument from ignorance asserts that a proposition is true because it has not been proven false (or vice versa). This is a fallacy because it assumes a false dichotomy; the status of a proposition is not either true or false; it can also be undetermined due to insufficient information. The issue of determining the absence of external incentives is particularly problematic in clinical settings, because clinicians are tasked with salvaging the wellbeing of their patients; not with investigating their patients' personal affairs in search of potential external incentives. Research suggests that hidden motives for entering healthcare are not at all uncommon: In two studies, up to $42 \%$ of Dutch psychiatric outpatients admitted to having hopes that their patient status would further other ambitions than just the restoration of their health (e.g., disability benefits or work related privileges; van Egmond \& Kummeling, 2002; van Egmond, Kummeling, \& van Balkom, 2005).

The paradox of feigned symptoms constituting genuine symptomatology, which haunts the diagnostic categories of factitious disorders and dissociative and somatic disorders, is dispensed with in malingering, where feigned symptomatology is just that; a scam, where feigned symptoms are a stratagem to further personal gain or evade responsibility (American Psychiatric Association, 2013; World Health Organization, 1992). Malingering has traditionally been viewed as morally offensive. For example, the seminal manual "Malingering and Feigned Sickness", completed in 1913 by British physician Sir John Collie, avows: "This work deals with a dark side of human nature" (Collie, 1913, p. vi). People who act morally offensive are antisocial; they violate social norms and disrespect others. From these premises it logically follows that all malingerers are antisocial offenders; however, this mode of inference-called "denying the consequent"-does not hold in reverse; not all antisocial offenders are necessarily malingerers. The deductive fallacy of transposing premise and conclusion- "affirming the consequent" - lies at the heart of the misconception that malingering is typically perpetrated by antisocial individuals. Yet, fallaciously affirming the consequent is not the foundation. Rather, the foundation is a 
cognitive bias known as the "fundamental attribution error"; the human tendency to explain other people's behavior mainly in terms of dispositional factors, and leave situational factors erroneously out of consideration (Ross, 1977). Because the idea that antisocial behavior is associated with feigned symptomatology is perpetuated in the principal manual for psychiatric diagnoses, the Diagnostic and Statistical Manual of Mental Disorders (5th ed.; DSM5; American Psychiatric Association, 2013), we decided to investigate it empirically: Chapters 2 and 3 of this thesis address studies in which we examined whether antisocial behavior is a predictor of noncredible symptom presentations in forensic inpatients and prisoners.

The term "malingering" appears to have been coined in military circles, early in the 19th century, to denote soldiers who feigned pathology as a means to escape duty (Gavin, 1843; Brussel \& Hitch, 1943). With the advent of national insurance and workmen's compensation acts at the turn of the nineteenth century, the inquisitorial stance on feigned symptomatology carried over from military and political spheres to the medical sphere; physicians were thenceforth confronted with patients who had obvious external incentives to present as ill or impaired (Wessely, 2003). While the clinical method of assessment and the medicalized view of feigned symptomatology kept holding sway in psychiatry, the investigative approach taken by medical examiners in military and insurance settings brought about technical and experimental attempts to detect feigned symptomatology (e.g., Collie, 1913; Goldstein, 1945; Hunt \& Older, 1943; Jones \& Llewellyn, 1917). The modern era of validity assessment was pioneered in Europe by Swiss psychologist André Rey (1941, 1958) and ushered in by the development of forced-choice tests to detect hysterical syndromes (e.g., Grosz \& Zimmerman, 1965; Pankratz, Fausti, \& Peed, 1975). Yet, it began in earnest with the spreading practice and discussion of malingering assessment among American neuropsychologists in the early 1990s (e.g., see Nies \& Sweet, 1994) and the development of commercially available "malinger" tests (e.g., Structured Inventory of Malingered Symptomatology, Smith \& Burger, 1997; Test of Memory Malingering, Tombaugh, 1996).

\section{Validity tests}

The term "symptom validity testing" was originally conceived to designate two-alternative forced-choice tests that were used to identify functional neurological deficits (Pankratz, 1979). In time, however, such tests were primarily employed to detect malingering, and the epithet "symptom validity test" was applied to all techniques that aided in the investigation of malingering (Bianchini, Mathias, \& Greve, 2001). Contrary to what the names of some well-known validity tests-Structured Inventory of Malingered Symptomatology, Test of Memory Malingering-suggest, validity tests do not measure malingering. Rather, they measure only one component of malingering: Noncredible symptomatology. The other component of malingering, externally motivated intent to feign symptomatology, is not addressed. Therefore, "malinger test" is unmistakably a misnomer. 
Nowadays, the "symptom validity testing" technique and all other methods that involve cognitive testing to detect noncredible symptomatology are termed "performance validity tests" (PVTs; Larrabee, 2012). The crux of PVTs is that they are less challenging than they seem, which allows patients with authentic cognitive impairments to pass, yet leads examinees who perform below their optimal ability to produce atypical scores and response patterns. The label "symptom validity tests" (SVTs) has come to be reserved for inventories and interviews that present pseudo-pathological symptoms for examinees to endorse or reject (a methodology that actually predates the "symptom validity testing" technique; see, e.g., Cofer, Chance, \& Judson, 1949; Hunt, 1948). The idea behind SVTs is that feigners have difficulties distinguishing bogus symptomatology from authentic symptomology, and are thus inclined to endorse rare, extreme, atypical, or outright false symptoms; symptoms that genuine patients would not endorse.

PVTs can be derived from actual cognitive tests via the identification of atypical performance levels or patterns, or they can be embedded in standard cognitive tests, or they can be stand-alone instruments that mimic cognitive tests. Similarly, SVTs can be incorporated in standard symptom inventories or interviews, or they can be free-standing measures. To evaluate assessment validity, PVTs and SVTs should be used conjointly, because both tap different domains of assessment (Egeland, Andersson, Sundseth, \& Schanke, 2015), and because the use of multiple tests can decrease the risk of false-positive identifications, provided that the tests are independent (i.e., weakly correlated) and that only failure of two or more tests constitutes a positive identification of invalid assessment validity (Meyers et al., 2014).

The interpretation of validity tests is straightforward; PVTs offer insight into whether an examinee's performance is an accurate reflection of their cognitive abilities, and SVTs provide information on whether an examinee's symptom report is a precise representation of their symptomatology (Larrabee, 2015). Yet, where exactly to draw the line between valid and invalid cognitive performance or symptom report is a more intricate issue, which is, of course, subject to considerable debate (e.g., Bilder, Sugar, \& Hellemann, 2014). Perhaps even more complicated is the determination of malingering and the diagnosis of factitious disorder, for both require the establishment of motivation and intent. Intent can be assessed through the original forced-choice testing technique, which allows for the calculation that a given test score is obtained by intentional avoidance of correct answers rather than by chance (Merten \& Merckelbach, 2013a). The evaluation of motivation, however, rests entirely on methods other than validity tests. To gauge the reasons behind insufficient assessment validity (be it internal incentives, external incentives, or simply disengagement or carelessness), diagnosticians have to resort to behavioral observations or reach out to thirdparty sources for information about an examinee's personal affairs and activities of daily life. Nevertheless, the intricacies of secondary inferences for test behavior should never be a barrier to employ validity tests, because the most important information that validity tests yield is whether assessment validity is insufficient; not why it is insufficient. 
Aims and outline of this thesis

The overarching aim of this thesis is the furtherance of validity assessment. This is achieved in various ways: First, by investigating the utility of antisocial behavior as indicator of assessment validity (Chapters 2-3); second, by meta-analytically quantifying the diagnostic merits of a widely-used SVT (the SIMS; Chapter 4); third, through examining the qualities of a PVT that has yet to gain widespread use (the Malingering Scale Vocabulary and Abstraction test; MSVA; Schretlen \& Arkowitz, 1990; Chapter 5); fourth, by developing and testing an SVT with the unprecedented aspiration to distinguish between factitious and malingered symptom presentations (the Symptom and Disposition Interview; SDI; Chapter 6); and last, by illustrating an actuarial technique for interpreting and combining validity test data (the likelihood ratio; Chapter 7).

In Chapter 2, we take stock of the empirical literature about the potential association between antisocial behavior and noncredible symptom presentations, and present two studies investigating this association in forensic inpatients and prisoners, respectively. Antisocial behavior was quantified through behavioral observations, self-report measures, and psychiatric diagnoses. According to the DSM-5, antisocial behavior is an indicator of malingering, and as such, it should have predictive value for distorted symptom endorsement.

Chapter 3 continues down the investigative path taken in Chapter 2, and shifts the focus from general antisocial behavior to specific features that may underlie the possible link between antisocial personality disorder and noncredible symptom presentations, namely deceitfulness, lack of remorse, and blame externalization. As in Chapter 2, a signal detection theory approach is used to discern the diagnostic utility of antisocial features for noncredible symptom endorsement.

Chapter 4 moves away from clinical guidelines on validity assessment and takes on psychometric methods. It presents a meta-analysis of all published data on the SIMS and offers diagnostic accuracy indices and normative scores of patients, claimants, defendants, nonclinical adults, and various experimental feigners. We evaluate the strengths and weaknesses of the SIMS, and put forward guidelines for clinical practice.

Chapter 5 details the resurrection of a PVT that faded into obscurity after a few publications in the early 1990s: We translated the Vocabulary and Abstraction tests from the Malingering Scale (MgS; Schretlen \& Arkowitz, 1990), dubbed them "MSVA", and examined their diagnostic potential through experiments among children, forensic inpatients with intellectual disability, forensic inpatients with psychiatric symptoms, and undergraduate students. The initial appeal of the MSVA lies in its use of the original symptom validity testing technique-which permits identification of below-chance performances-and in the rarity of the cognitive domains that is taps (semantic knowledge and perceptual reasoning, as opposed to memory, which is what the vast majority of PVTs target).

In Chapter 6, we chronicle our development of the SDI; an SVT that seeks not only to detect noncredible symptom presentations, but also to differentiate between factitious and 
malingered symptom presentations. The latter function is realized by incorporating strategies to gauge internal incentives that are associated with factitious disorder (i.e., the "need to assume the sick role"). The qualities of the SDI were explored and compared with a traditional SVT (the SIMS) in two simulation studies, each with factitious and malingering conditions and a clinical control group.

The final Chapter, 7, discusses the main findings and conclusions that are presented in the foregoing chapters, and highlights important methodological issues, clinical implications, and directions for future research. To raise the practical usefulness of this thesis, and showcase the value of the studies reported herein, Chapter 7 also includes an exposition of likelihood ratios as an actuarial technique for interpreting and combining validity test data. 


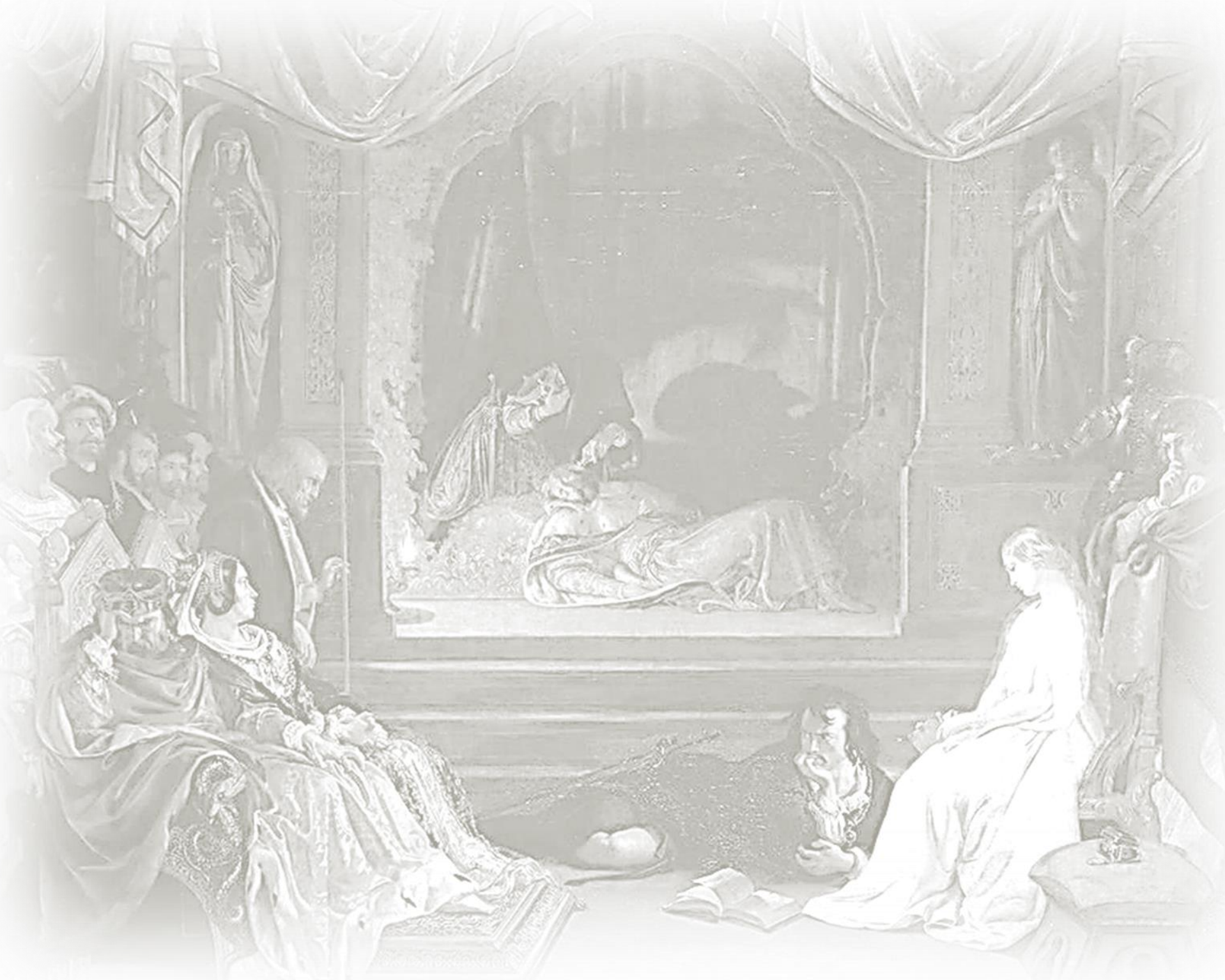




\section{Chapter 2}

\section{Biased symptom reporting and antisocial behavior in forensic samples: A weak link}

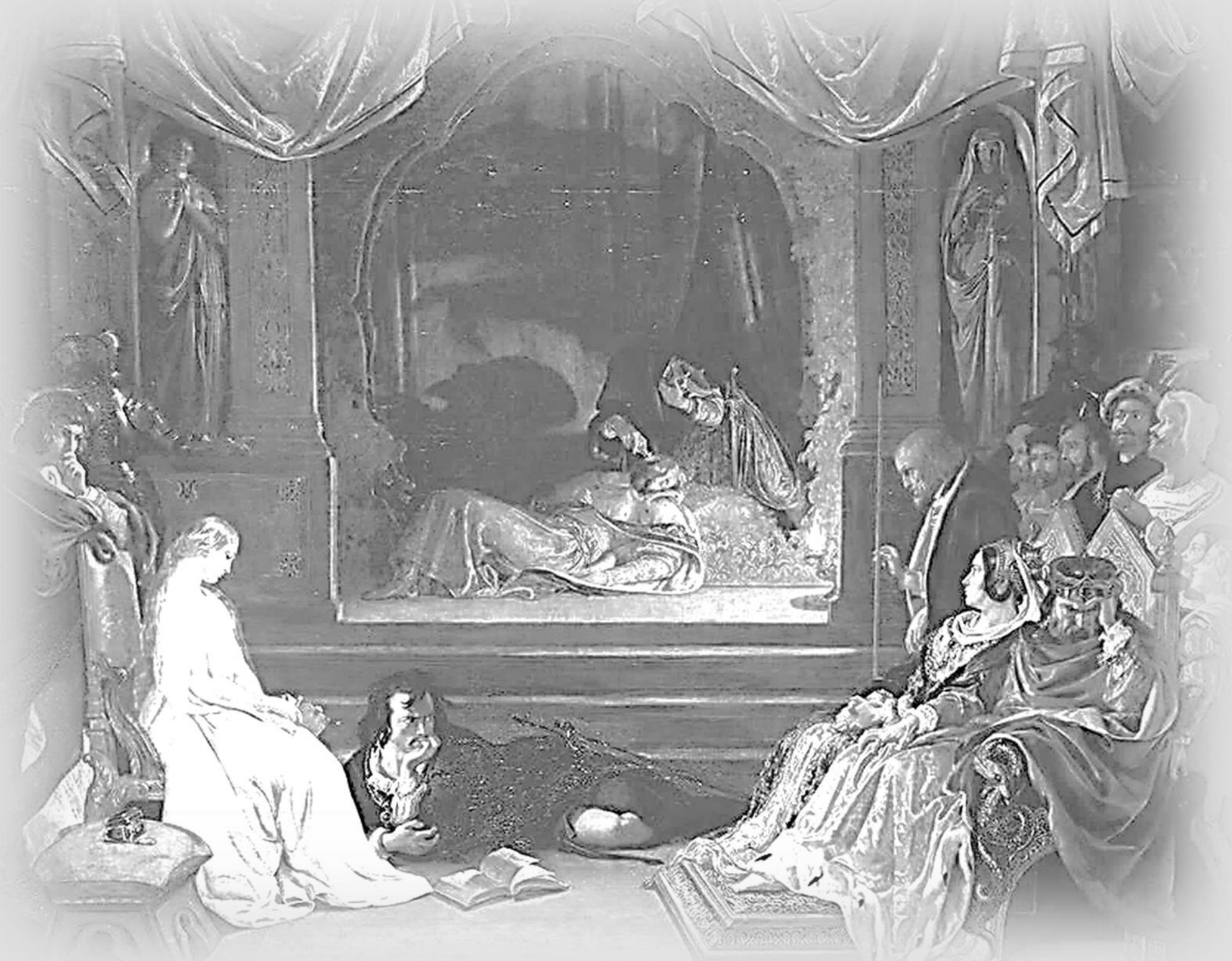

Published as:

van Impelen, A., Merckelbach, H., Niesten, I. J., Jelicic, M., Huhnt, B., \& à Campo, J. (2017). Biased symptom reporting and antisocial behaviour in forensic samples: A weak link. Psychiatry, Psychology and Law, 24, 530-548. 


\begin{abstract}
In two studies (one with 57 forensic inpatients and one with 45 prisoners) the connection between biased symptom reporting and antisocial behavior is explored. The findings are as follows: 1) the association between symptom overreporting and antisocial features is a) present in self-report measures, but not in behavioral measures, and b) stronger in the punitive setting than in the therapeutic setting; and 2) participants who overreport symptoms a) are prone to attribute blame for their offense to mental disorders, and b) tend to report heightened levels of antisocial features, but the reverse is not true. The data provide little support for the inclusion of antisocial behavior (i.e., antisocial personality disorder) as a signal of symptom overreporting (i.e., malingering) in the Diagnostic and Statistical Manual of Mental Disorders (5th ed.; DSM-5). The empirical literature on symptom overreporting and antisocial/psychopathic behavior is discussed and it is argued that the utility of antisocial behavior as an indicator of biased symptom reporting is unacceptably low.
\end{abstract}




\section{Introduction}

Antisocial behavior and deceptive tendencies are considered to be core characteristics of both antisocial personality disorder (ASPD; American Psychiatric Association, 1980, 2000, 2013) and psychopathy (Cleckley, 1941, 1988; Hare, 1991, 2003; Hare, Forth, \& Hart, 1989). A specific variant of deceptive behavior is referred to in the Diagnostic and Statistical Manual of Mental Disorders (5th ed.; DSM-5; American Psychiatric Association, 2013) as malingering: "The intentional production of false or grossly exaggerated physical or psychological symptoms, motivated by external incentives" (American Psychiatric Association, 2013, p. 726).

Precisely because malingering is a form of deception-and because such behavior infringes social norms - the idea that malingering is strongly associated with ASPD and psychopathy has great intuitive appeal. Accordingly, the DSM-from its third edition onwards-assumes that antisocial behavior is intimately linked to malingering. Indeed, the DSM-5 lists the presence of ASPD among the indications that warrant heightened suspicion of malingering. However, in contrast to its prima facie plausibility, the empirical support for this idea is weak. In fact, early reviews (Clark, 1997; DeMatteo \& Edens, 2006) concluded that there is a paucity of studies demonstrating the link between antisocial behavior and malingering. More recently, Niesten, Nentjes, Merckelbach, and Bernstein (2015) conducted a systematic search by means of several databases and confirmed the mixed findings in this domain: of the seven studies found that explore whether psychopathic and antisocial behavior are related to symptom overreporting, four found an association-albeit a relatively weak one-(e.g., Heinze \& Vess, 2005; Kucharski, Duncan, Egan, \& Falkenbach, 2006), one did not find a relation (Pierson, Rosenfeld, Green, \& Belfi, 2011), and two produced conflicting results (Cima \& van Oorsouw, 2013; Sumanti, Boone, Savodnik, \& Gorsuch, 2006). Furthermore, a recent meta-analysis of the relation between distorted response styles and self-reported psychopathic traits revealed a medium association between symptom overreporting (i.e., malingering) and the antisocial lifestyle factor (95\% CI of weighted mean effect size: $[.23, .40])$, but not the manipulative, callous personality factor (95\% CI: [.00, .14]) of psychopathy (Ray et al., 2013).

Some authors (e.g., MacNeil \& Holden, 2006) have speculated that high levels of psychopathy are associated with greater proficiency in successful (i.e., undetected) faking. Even if psychopathic traits would confer no aptitude for malingering directly, they could still lead to gains in proficiency through practice, as they may prompt individuals to engage in malingering more frequently. However, there is hardly any support for the hypothesis that antisocial and psychopathic traits foster the ability to malinger (e.g., Marion et al., 2013; for an overview, see Niesten et al., 2015).

Distorted symptom reports during clinical assessment are not limited to the exaggeration of symptoms; they may also take the form of the denial of such symptoms, as well as the exaggeration of positive qualities or indicators of good health (i.e., social desirability). Much like malingering, symptom underreporting and social desirability are 
principally deceptive and manipulative in nature. Hence, it stands to reason that if antisocial and psychopathic traits predispose to symptom overreporting (i.e., malingering), these features may also predispose to symptom underreporting.

The extant literature about the relation between symptom underreporting and social desirability, on the one hand, and antisocial and psychopathic traits, on the other, is even scarcer than that on symptom overreporting and antisocial or psychopathic traits. The investigation of Niesten et al. (2015) only yielded two studies that are directly relevant: Cima, van Bergen, and Kremer (2008), who found no association, and Freeman and Samson (2012), who found psychopathy to be associated with less symptom underreporting. Additionally, the meta-analysis of Ray et al. (2013) showed that the antisocial lifestyle factor $(95 \%$ CI of weighted mean effect size: $[-.25,-.06])$, but not the manipulative, callous personality factor (95\% CI: $[-.06, .05])$ of psychopathy is negatively related to symptom underreporting and social desirability.

One explanation for the conflicting findings in this research domain is that the links between biased symptom reporting and antisocial features are context dependent. Thus, prison inmates may feign psychiatric symptoms in an attempt to be transferred from prison to the relatively mild conditions of a forensic psychiatric hospital. Once in a psychiatric hospital, they may exaggerate their mental fitness to reduce mandatory treatment. Similarly, defendants may feign symptoms in an attempt to reduce their criminal responsibility, yet employ symptom underreporting and social desirability post-conviction to obtain privileges, probation, or parole. Likewise, plaintiffs may feign particular symptom constellations (e.g., posttraumatic stress, burnout, chronic pains) in the service of a compensation claim, while simultaneously denying genuine problems (e.g., substance use, impulsivity, compulsivity) to make a favorable impression on judicial decision-makers (e.g., Cima \& van Oorsouw 2013; Niesten et al., 2015).

The idea - as endorsed by the DSM-5-that antisocial behavior is associated with symptom overreporting is further examined in two studies. Unlike other studies in this field, symptom underreporting (Study 1) and social desirability (Study 2) are also examined, because such behavior is no less deceptive than symptom overreporting, and thus-at face value-it is equally plausible for it to be related to antisocial and psychopathic behavior. To explore the idea that the relations between biased symptom reporting and antisocial features are context dependent, a therapeutic forensic setting (Study 1) is contrasted with a punitive forensic setting (Study 2). 


\section{Study 1}

The aim of Study 1 is to investigate the relation between biased symptom reporting (i.e., overreporting and underreporting) and antisocial behavior (measured by institutional misbehavior and ASPD diagnoses) in a forensic psychiatric context. Given the mixed findings in the literature mentioned earlier, it was expected that little to no relation between antisocial behavior and biased symptom reporting would be found. The therapeutic environment of the psychiatric hospital (in which treatment progress leads to privileges such as furloughs and access to accommodation for recreational activities) created the anticipation of a higher rate of symptom underreporting than symptom overreporting. Prior to data collection, ethical approval was obtained from the standing Ethics Committee of the Faculty of Psychology and Neuroscience, Maastricht University, and from Radix Forensic Psychiatric Hospital, Heerlen, the Netherlands.

\section{Method}

\section{Participants}

Participants were recruited from Radix, a medium security forensic psychiatric hospital in the Netherlands that admits patients post-trial. Confinement there is in lieu of regular punishment, but not mandatory; patients can opt for incarceration in a penitentiary (and also opt for this during their stay). All patients undergo psychological and neuropsychological assessment upon admission to establish diagnoses as laid out in the DSM-5. In addition to individually tailored treatment for their psychopathology, patients are obliged to partake in group therapies aimed at resocialization and recidivism risk reduction. Patients remain in treatment until they are ready to re-enter society or until their prison term ends.

Treatment supervisors provided the names of patients they deemed fit to participate and these patients were then invited to take part in the study. Exclusion criteria (as determined by treatment supervisors) included insufficient command of the Dutch language, extreme symptoms of drug withdrawal, severe mental instability due to psychosis, or deficient mental abilities owing to severe intellectual disability. On these grounds, 25 patients were not approached. The majority of these patients were found to be unfit to participate because of substance withdrawal symptoms, severe intellectual disability, or psychosis. Furthermore, as participation was voluntary and did not yield any rewards, 13 eligible patients chose not to participate. Another 3 patients absconded before behavioral observations were completed, and 1 patient chose to terminate his participation shortly after starting the first test.

In total, 57 male inpatients aged 19 to 54 years $(M=40.0, S D=9.1)$ completed the study. The mean IQ was 88.2 ( $S D=14.6$, IQ range: $61-140$; IQ scores are missing for 2 participants). IQ data were gathered from patient records, which contained Wechsler Adult Intelligence Scale (4th ed.; WAIS-IV; Wechsler, 2008) protocols. The majority of participants are Caucasian $(79 \%, n=45)$ and all except one $(98 \%, n=56)$ had been diagnosed with one or 
multiple substance disorders. Furthermore, 28\% $(n=16)$ had received a diagnosis of other specified personality disorder, 16\% $(n=9)$ had been diagnosed with ASPD, 14\% $(n=8)$ had been diagnosed with autism spectrum disorder, $7 \%(n=4)$ had been diagnosed with attention deficit hyperactivity disorder (ADHD), 7\% $(n=4)$ had been diagnosed with schizophrenia, and 19\% $(n=11)$ received no diagnosis other than substance disorder.

\section{Measures}

Structured Inventory of Malingered Symptomatology (SIMS).

The SIMS (Smith \& Burger, 1997; see Merckelbach \& Smith, 2003 for the Dutch translation) is a symptom validity test that assesses a broad spectrum of feigned and exaggerated symptoms. The SIMS consists of 75 true-false items, which constitute five subscales that target feigned depression, psychosis, neurologic impairment, memory dysfunction, and low intelligence. The items mostly refer to bizarre experiences and atypical symptoms such as "I have difficulty recognizing written and spoken words" and "When I can't remember something, hints do not help." The number of endorsed symptoms is summed so as to obtain a total SIMS score. The SIMS does not require a high reading level (i.e., Flesch-Kincaid Scale 5.3 suffices; Smith, 2008). The internal consistency of the SIMS is reasonable (Cronbach's alpha coefficients of .72 found by Merckelbach \& Smith, 2003, and .92 to .94 by Rogers, Robinson, \& Gillard, 2014). Both studies with experimental simulators and studies with identified malingerers (i.e., known-groups studies) have yielded acceptable diagnostic accuracy parameters, with sensitivity circling around .91 and specificity around .65 for a cutoff of $>16$ (for a detailed overview, see Chapter 4 ).

Supernormality Scale (SS).

The SS (Cima, Merckelbach, et al., 2003) is a self-report instrument that has been developed as a research tool for assessing symptom underreporting. It consists of 37 true-false items, of which 21 items comprise a supernormality subscale (measuring minimization of mild psychopathological phenomena), 11 items comprise a social desirability scale, and 5 items are bogus. An illustrative supernormality item is "I have my problems under full control," and an example of a social desirability item is "I try to help everybody who has problems." Endorsement of supernormality and social desirability items is summed so as to obtain a total SS score. While the internal consistency (Cronbach's alpha $=.86$ ) and test-retest reliability $(r=.90)$ of the SS are satisfactory, the diagnostic accuracy indices are meagre, with the sensitivity and specificity being .74 and .42 for a $>14$ cutoff score, .58 and .67 for a $>17$ cutoff score, and .28 and .93 for a $>21$ cutoff score, respectively (Cima, Merckelbach, et al., 2003). However, the SS does possess moderate predictive validity, as undergraduate students instructed to imagine that they were offenders who opted for parole and who therefore engaged in faking good exhibited statistically higher scores compared with control individuals (Cima, Merckelbach, et al., 2003). 
Levenson Self-Report Psychopathy Scale (LSRPS).

The LSRPS (Levenson, Kiehl, \& Fitzpatrick, 1995) is a 26-item self-report instrument that assesses traits associated with a callous and manipulative orientation towards others (i.e., primary psychopathy) and with a disinhibited and antisocial lifestyle (i.e., secondary psychopathy). Items are scored on 4-point Likert scales ranging from 1 (strongly disagree) to 4 (strongly agree). A total score that is reflective of psychopathic traits can be calculated by recoding some items and then summing all scores. Total scores of $>57$ are considered to be "high" (Brinkley, Schmitt, Smith, \& Newman, 2001). A representative item from the primary psychopathy scale is "In today's world, I feel justified in doing anything I can get away with to succeed," whereas an illustrative item from the secondary psychopathy scale is "I have been in a lot of shouting matches with other people." While the LSRPS was originally designed to assess psychopathic traits in non-institutionalized samples, it has been employed successfully in large forensic samples (Brinkley et al., 2001; Walters, Brinkley, Magaletta, \& Diamond, 2008). The internal consistency of the total and primary psychopathy scale is adequate (Cronbach's alpha $=.82-.84$ ), whereas that of the secondary psychopathy scale is moderate (Cronbach's alpha $=.63-.68$; Levenson et al., 1995; Lynam, Whiteside, \& Jones, 1999).

Social Dysfunction and Aggression Scale-11 (SDAS-11).

The SDAS-11 (Wistedt et al., 1990) is an 11-item behavioral observation scale that was developed to measure social dysfunction and aggression in psychiatric inpatients. The SDAS-11 is scored over a longer time interval, with one-week intervals between successive ratings. It consists of 9 items covering outward aggression and social dysfunction (e.g., irritability, negativism, verbal and physical aggression) and 2 items covering inward aggression (i.e., self-harm), with each item including a 5-point scoring scale ranging from 0 (not present) to 4 (severe). The outward and inward items are not inter-correlated and the internal consistency is acceptable (Cronbach's alpha = .79; Wistedt et al., 1990). In the current study, SDAS-11 items were used to evaluate the daily nurse observation records of each participant. More specifically, for each participant, all records of a six-week period were selected and scored in terms of indications for the presence of SDAS-11 items. To explore the reliability of this procedure, a random set of ten one-week records from 10 patients were selected and evaluated by the first author and another rater who was also blind to the symptom validity status associated with each record. The Spearman rank order correlation between the two raters is .79 .

\section{Procedure}

Seated in a small therapy room on their own ward, participants first gave written informed consent that was also verbally communicated to them. Next, participants completed the test battery, which included-in counterbalanced order-the SIMS, the SS, and for a subsample $(n=25)$ also the LSRPS. The test battery also included an instrument that is not addressed in 
the current study: the Vocabulary and Abstraction subtests of the Malingering Scale (Schretlen \& Arkowitz, 1990), which are cognitive paper-and-pencil tasks that measure underperformance. After participants had completed the test battery, their engagement in institutional misbehavior was monitored for a period of six weeks. The monitoring of participants was achieved through the close examination of patient records, which were maintained on a daily basis by nursing staff, therapists, psychologists, physicians, and treatment supervisors. The patient records that were used for the present study contain reports of daily activities and detailed accounts of clinically relevant activities and behavior, such as social functioning, treatment progress, and physical and emotional wellbeing. As such, the patient records contain ample information for completing the SDAS-11 items. For each participant, the scores on the test battery were calculated only after scores on the SDAS11 had been obtained, thus reducing experimenter bias during the evaluation of patient records with SDAS-11 items.

\section{Results}

Table 2.1 summarizes the mean scores on the psychometric instruments and also gives the proportion of patients who scored above cutoff points, as well as the prevalence of the most frequent diagnoses among these patients. As can be seen, symptom underreporting (as indexed by the SS) is more than twice as prevalent as symptom overreporting (as indexed by the SIMS).

\section{Table 2.1}

Summary of means, corresponding $95 \%$ confidence intervals, standard deviations, and prevalence rates of diagnoses and cutoff failures in a forensic patient sample

\begin{tabular}{lccccc}
\hline $\begin{array}{l}\text { Measure } \\
(\text { min-max })\end{array}$ & $n$ & $M(S D)$ & $95 \%$ CI & $\%(n)>$ cutoff & $\begin{array}{l}\% \text { most frequent diagnoses } \\
\text { of patients scoring }>\text { cutoff }\end{array}$ \\
\hline $\begin{array}{l}\text { SIMS } \\
(0-75)\end{array}$ & 57 & $8.6(6.6)$ & {$[6.8,10.3]$} & $9 \%(5)>16$ & $60 \%$ IQ $<75,40 \%$ OSPD \\
$\begin{array}{l}\text { SS } \\
(0-32)\end{array}$ & 57 & $16.4(6.5)$ & {$[14.7,18.2]$} & $23 \%(13)>21$ & $38 \%$ OSPD, 23\% IQ $<75$ \\
$\begin{array}{l}\text { LSRPS } \\
(0-104)\end{array}$ & 25 & $52.6(9.6)$ & {$[48.6,56.6]$} & $28 \%(7)>57$ & No diagnoses with count $>1$ \\
$\begin{array}{l}\text { SDAS-11 } \\
(0-264)\end{array}$ & 57 & $17.1(12.5)$ & {$[13.8,20.4]$} & $16 \%(8)>1.5 S D$ & $38 \%$ IQ $<75,25 \%$ OSPD
\end{tabular}

Note. $\mathrm{CI}=$ confidence interval; SIMS = Structured Inventory of Malingered Symptomatology; SS = Supernormality Scale; LSRPS = Levenson Self-Report Psychopathy Scale; SDAS-11 = Social Dysfunction and Aggression Scale-11; OSPD = other specified personality disorder; IQ = intelligence quotient. 
The most frequent diagnoses among participants who failed the SIMS cutoff score ( $n$ $=5,9 \%)$ are an IQ of $<75(60 \%)$ and other specified personality disorders (OSPDs; $40 \%$ ). Among participants who failed the SS cutoff score $(n=13,23 \%)$, the most frequent diagnoses are OSPDs $(38 \%)$ and an IQ of $<75(23 \%)$. Furthermore, two participants produced a significantly outlying score ( $>2$ SDs) on the LSRPS; they were diagnosed with ASPD and autism spectrum disorder, respectively. The group of participants who scored beyond 1.5 SDs on the SDAS-11 $(n=8,14 \%)$ is diverse with regard to diagnoses: three participants $(38 \%)$ had an IQ of $<75$ and two (25\%) had an OSPD diagnosis. There is no overlap between the group of participants who exceeded the cutoff score of the SIMS and the group who exceeded the cutoff scores of the SS or the LSRPS. Of the thirteen participants who scored above the cutoff on the SS, three (23\%) have SDAS-11 scores of 1.5 SDs above the mean and two have an LSRPS score that surpasses the cutoff of $>57$. Interestingly, the mean SDAS-11 score of patients with ASPD does not differ statistically from that of the other patients (15.4 vs. 17.3), $t(55)=0.3, p=.75$, a result that squares with the recent finding of Edens, Kelley, Lilienfeld, Skeem, and Douglas (2015) that ASPD has no predictive value for institutional misconduct.

To examine the relation between antisocial features and biased symptom reporting, binary contingency tables were computed for all antisocial behavior indices (i.e., psychopathic traits; LSRPS scores $>57$, institutional misbehavior; SDAS-11 scores $>1.5$ SDs above the mean, and ASPD diagnoses) and biased symptom reports (i.e., symptom overreporting; SIMS scores $>16$, and symptom underreporting; SS scores $>21$ ). Fisher's exact tests indicate that biased symptom reporting is not associated with psychopathic traits, institutional misbehavior, or ASPD diagnoses (all $p \mathrm{~s}>.05$ ).

As another approach to data analysis, Pearson product-moment correlations among the various measures were calculated (Table 2.2). Institutional misbehavior (SDAS-11) was unrelated to symptom overreporting (SIMS) or underreporting (SS). Self-reported psychopathic traits (LSRPS) were not associated with symptom underreporting (SS), yet seem to be moderately associated with symptom overreporting (SIMS); the correlation is .31 $[-.09, .63]$, yet it did not reach statistical significance ( $p=.13$, two-tailed), possibly due to the small sample size $(n=25)$. Age is not related to any of the measures; IQ is related only to symptom underreporting, with those with higher IQs predisposed towards less underreporting, $r=-.30[-.52,-.04], p=.03$, two-tailed.

Consistent with the correlational analyses, multiple linear regression analyses indicate that neither self-reported psychopathic traits (LSRPS) nor institutional misbehavior (SDAS-11) are predictive of symptom overreporting (SIMS), $F(2,22)=1.70, p=.21$, or symptom underreporting (SS), $F(2,22)=0.40, p=.67$. Analyses including the scores on the subscales of the SIMS, SS, and LSRPS did not yield additional information. In sum, no association was found between institutional misbehavior and either form of biased symptom reporting, nor was there a relation between biased symptom reporting and ASPD or selfreported psychopathy. 
Chapter 2

\section{Table 2.2}

Pearson product-moment correlations and corresponding 95\% confidence intervals among Structured Inventory of Malingered Symptomatology, Supernormality Scale, Levenson Self-Report Psychopathy Scale, and Social Dysfunction and Aggression Scale-11 scores

\begin{tabular}{llll}
\hline Measure & 1. SIMS & 2 & 3
\end{tabular}

\begin{tabular}{|c|c|}
\hline 2. SS & $\begin{array}{c}-.28^{*} \\
{[-.50,-.02]}\end{array}$ \\
\hline
\end{tabular}

3. LSRPSa

$.31^{\mathrm{a}}$ $[-.09, .63]$

4. SDAS-11

$$
-.04
$$

$[-.30, .22]$

$$
\begin{gathered}
-.10^{a} \\
{[-.30, .48]}
\end{gathered}
$$

.00

$[-.26, .26]$
.27

$[-14, .60]$

Note. SIMS = Structured Inventory of Malingered Symptomatology; SS = Supernormality Scale; LSRPS $=$ Levenson Self-Report Psychopathy Scale; SDAS-11 = Social Dysfunction and Aggression Scale-11. aBased on $n=25$.

${ }^{*} p<.05$, two-tailed.

Finally, groups were formed based on the temporal trends of the SDAS-11 scores; one group had scores that increased over time $(n=23)$, one group had scores that remained relatively stable $(n=26)$, and one group had scores that decreased over time $(n=8)$. The three groups were then compared with regard to biased symptom-reporting (i.e., frequency of individuals scoring above the SIMS or SS cutoffs). Table 2.3 shows the patterns. Fisher's exact tests yielded no significant results (all $p \mathrm{~s}>.05$ ), which implies that institutional misbehavior is in no way related to symptom overreporting or underreporting.

\section{Table 2.3}

Number and percentage of forensic patients $(N=57)$ with increasing, constant, or decreasing Social

\begin{tabular}{|c|c|c|c|c|}
\hline \multirow[b]{2}{*}{$\begin{array}{l}\text { SDAS-11 } \\
\text { score pattern }\end{array}$} & \multicolumn{2}{|c|}{$\begin{array}{c}\text { SIMS score } \\
n(\%)\end{array}$} & \multicolumn{2}{|c|}{$\begin{array}{c}\text { SS score } \\
n(\%) \\
\end{array}$} \\
\hline & $\begin{array}{l}\text { Below cutoff } \\
\qquad(\leq 16)\end{array}$ & $\begin{array}{l}\text { Above cutoff } \\
\qquad(>16)\end{array}$ & $\begin{array}{l}\text { Below cutoff } \\
\qquad(\leq 21)\end{array}$ & $\begin{array}{l}\text { Above cutoff } \\
\quad(>21)\end{array}$ \\
\hline Increasing & $21(37 \%)$ & $2(4 \%)$ & $18(32 \%)$ & $5(9 \%)$ \\
\hline Constant & $24(42 \%)$ & $2(4 \%)$ & $20(35 \%)$ & $6(11 \%)$ \\
\hline Decreasing & $7(12 \%)$ & $1(2 \%)$ & $6(11 \%)$ & $2(4 \%)$ \\
\hline
\end{tabular}
Dysfunction and Aggression Scale-11 scores who overreport symptoms (Structured Inventory of Malingered Symptomatology) or underreport symptoms (Supernormality Scale)

Note. SDAS-11 = Social Dysfunction and Aggression Scale-11; SIMS = Structured Inventory of Malingered Symptomatology; SS = Supernormality Scale. 


\section{Discussion}

The prevalence of symptom overreporting in this sample of forensic psychiatric inpatients is relatively low (9\%) compared with estimates that can be found in the literature (cf. 19\%: Mittenberg, Patton, Canyock, \& Condit, 2002; 32\%: Pollock, Quigley, Norley, \& Bashford, 1997). The participants in the present study were recruited from a forensic psychiatric hospital where patients are admitted once their sentences have been passed, and in which patients have relatively few apparent external incentives to overreport symptoms-in fact, doing so may even result in delayed furloughs and prolonged stays. This might explain why symptom underreporting was more than twice as prevalent as symptom overreporting in the present sample (23\% vs. $9 \%$ ). Additionally, the prevalence of symptom overreporting might have been low because of selection bias: treatment supervisors prohibited the inclusion of patients they deemed too disordered to participate. It might be that a portion of these patients exaggerated their pathology (and would have overreported symptoms had they participated).

The prevalence of ASPD (16\%) and antisocial behavior is low as well. A large portion of patients' SDAS-11 scores are explained by irritability, negativism, mild resentment, and moderate verbal aggression. Thus, participants engaged almost exclusively in mild disruptive behavior; none engaged in serious physical violence, self-harm, or severe verbal aggression. The relative absence of gravely disruptive behavior is likely due to several factors. First, it might have to do with the focus on treatment and the consequently comprehensive and constant implementation of a zero tolerance policy on all wards, which have a staff to patient ratio of at least 1:6 (usually 1:4). Second, it might be related to the considerable weight of the consequences of misbehavior, which typically include delayed or revoked furloughs, prolonged stays, or - in severe cases-relocation to a penal institution. 


\section{Study 2}

This study examines the relation between biased symptom reporting and antisocial behavior in a punitive forensic setting. Additionally, several types of blame attribution and excusemaking are assessed. Niesten et al. (2015) report an interesting difference between forensic psychiatric patients and prisoners with respect to symptom overreporting and underreporting. More specifically, they found that both types of distorted symptom reporting are higher in the latter group, presumably because the incentives to distort symptoms are higher in that context. With this in mind, more symptom overreporting was expected in the punitive setting of Study 2 than in the therapeutic setting of Study 1, yet it was also predicted that the relation between biased symptom reporting and antisocial behavior would be similarly small. Cima, Merckelbach, et al. (2003) observe that symptom underreporting in a forensic sample is related to the tendency to blame external conditions or others for their crimes. To extend this work, it was decided to test whether symptom overreporting is associated with excuse-making and blame attribution to mental disorders. Approval was obtained from the standing Ethics Committee of the faculty of Psychology and Neuroscience, Maastricht University, and the Youth Prison of Berlin (Jugendstrafanstalt Berlin), Germany.

\section{Method}

\section{Participants}

Inmates of an all-male youth prison in Berlin were proffered a brief description of the study and invited to participate in two test sessions without compensation. Insufficient literacy and command of the German language are the only exclusion criteria. A total of 65 inmates agreed to participate and completed the first session, but only 45 of those completed the second session, which took place two to three weeks later. Reasons for dropping out included completion of the prison sentence, relocation to another facility, and lack of interest in the second session. The majority of the final sample $(n=45)$ were sentenced prisoners, and $4(9 \%)$ were on remand. The mean age was 20.7 years (age range: $18-24)$.

\section{Measures}

Antisocial and delinquent behavior was measured with several proxies: length of prison sentences (in years), number of incurred disciplinary actions (coded as a continuous variable), and classification as "intensive offender" (yes or no). Intensive offender (Intensivtäter) is a term used in Germany to designate juveniles whose delinquency is serious and repetitive. Although there are no formal definitions or criteria to establish intensive offending, the term is commonplace in the German justice system. The SIMS and the LSRPS were used (see Study 1 for details), along with two other instruments. The test battery also included a measure of symptom overreporting that was not used in the analyses 
below (the recently developed Self-Report Symptom Inventory; SRSI; Merten, Merckelbach, Giger, \& Stevens, 2016).

Social Desirability Scale-5 (SDS-5).

The SDS-5 consists of five modified items from the Social Desirability Scale-17 (SDS-17; Stöber, 2001). The internal consistency (Cronbach's alpha $=.80)$ and test-retest reliability $(r=$ .82) of the SDS-17 are adequate. The SDS-5 was embedded in the LSRPS. Therefore, the original true-false format is replaced with a 4-point scale ranging from 0 ( $I$ do not at all agree) to 3 (I fully agree).

Revised Gudjonsson Blame Attribution Inventory (BAI).

The BAI (Gudjonsson \& Singh, 1989; for the German translation, see Cima et al., 2006) contains 42 items that tap into three independent dimensions of blame attribution for criminal offenses: external attribution (i.e., blaming transgressions on social environments, victims, or society; Cronbach's alpha $=.77$ ), mental-element attribution (i.e., placing blame on mental disorders or insufficient self-control; Cronbach's alpha $=.79$ ), and guilt-feeling attribution (i.e., feeling remorse or regret about offenses; Cronbach's alpha $=.81$ ). Items consist of first-person statements that are evaluated on a 5-point scale ranging from 0 ( $I$ do not at all agree) to 4 (fully agree). Representative items include "I did not deserve to be caught for the crime I committed" (external attribution), "I would certainly not have committed the crime I did if I had been mentally well" (mental-element attribution), and "I have no serious regrets about what I did" (guilt-feeling attribution).

\section{Procedure}

Two sessions were undertaken, the first containing the informed consent form followed by administration of the SRSI. The second session (which took place two to three weeks later) consisted of administration of the SIMS, the BAI, and the LSRPS with the SDS-5 items. Participants were told that the instruments measured personality characteristics and psychological problems.

\section{Results}

Table 2.4 presents means scores of the sample on the various measures, as well as the proportion of prisoners whose scores exceed the associated cutoffs. As can be seen, $13 \%$ ( $n=$ 6) of the participants failed the SIMS, which is only slightly higher than the failure rate in Study 1 (9\%). More than half of the sample scored above the cutoff on the LSRPS (56\%), which is considerably higher than the proportion with extreme LSRPS scores in Study 1 (28\%). 
Chapter 2

Table 2.4

Summary of means, corresponding 95\% confidence intervals, standard deviations, and prevalence rates of cutoff failures in a forensic sample $(N=45)$

\begin{tabular}{|c|c|c|c|}
\hline $\begin{array}{l}\text { Measure } \\
\text { (min-max) }\end{array}$ & $M(S D)$ & $95 \% \mathrm{CI}$ & $\%(n)>$ cutoff \\
\hline $\begin{array}{l}\text { SIMS } \\
(0-75)\end{array}$ & $10.6(5.2)$ & {$[9.1,12.2]$} & $13 \%(6)>16$ \\
\hline $\begin{array}{l}\text { SDS-5 } \\
(0-15)\end{array}$ & 12.7 (2.7) & {$[11.9,13.5]$} & $\mathrm{N} / \mathrm{A}$ \\
\hline $\begin{array}{l}\text { LSRPS } \\
(0-104)\end{array}$ & $58.9(9.3)$ & {$[56.1,61.7]$} & $56 \%(25)>57$ \\
\hline $\begin{array}{l}\text { BAI Guilt } \\
(0-72)\end{array}$ & 54.6 (11.7) & {$[51.1,58.2]$} & $\mathrm{N} / \mathrm{A}$ \\
\hline $\begin{array}{l}\text { BAI External } \\
(0-60)\end{array}$ & $29.5(8.5)$ & {$[26.9,32.0]$} & $\mathrm{N} / \mathrm{A}$ \\
\hline $\begin{array}{l}\text { BAI Mental } \\
(0-36)\end{array}$ & $25.0(6.6)$ & {$[23.0,27.0]$} & $\mathrm{N} / \mathrm{A}$ \\
\hline $\begin{array}{l}\text { Prison term } \\
\text { (in years) }\end{array}$ & $2.5(1.4)$ & {$[2.1,2.9]$} & $\mathrm{N} / \mathrm{A}$ \\
\hline $\begin{array}{l}\text { Punitive actions } \\
(0.0-1.0)\end{array}$ & $.5(.9)$ & {$[.3, .8]$} & $\mathrm{N} / \mathrm{A}$ \\
\hline $\begin{array}{l}\text { Intensive offender } \\
\text { (yes/no) }\end{array}$ & $\mathrm{N} / \mathrm{A}$ & N/A & $22 \%(10)$ \\
\hline
\end{tabular}

Note. $\mathrm{CI}$ = confidence interval; SIMS = Structured Inventory of Malingered Symptomatology; SDS-5 = five items of the Social Desirability Scale-17; N/A = not applicable; LSRPS = Levenson Self-Report Psychopathy Scale; BAI Guilt = revised Gudjonsson Blame Attribution Inventory, Guilt scale; BAI External = revised Gudjonsson Blame Attribution Inventory, External scale; BAI Mental = revised Gudjonsson Blame Attribution Inventory, Mental scale; Prison term = length of prison sentence in years; Punitive actions = relative number of punitive actions taken against participants.

Table 2.5 displays the correlations among the various measures. Symptom overreporting (SIMS) correlates positively with self-reported psychopathic traits as measured by the LSRPS and negatively with social desirability as indexed by the SDS-5. 


\section{Table 2.5}

Pearson product-moment correlations and corresponding 95\% confidence intervals among Structured Inventory of Malingered Symptomatology, Social Desirability Scale-5, Levenson Self-Report Psychopathy Scale, and revised Gudjonsson Blame Attribution Inventory scale scores, length of prison sentences, relative number of incurred punitive actions, and classification as intensive offender

\begin{tabular}{|c|c|c|c|c|c|c|c|c|}
\hline & 1. SIMS & 2 & 3 & 4 & 5 & 6 & 7 & 8 \\
\hline 2. SDS-5 & $\begin{array}{c}-.42^{* *} \\
{[-.63,-.14]}\end{array}$ & - & & & & & & \\
\hline 3. LSRPS & $\begin{array}{c}.60^{* *} \\
{[.37, .76]}\end{array}$ & $\begin{array}{c}-.50^{* *} \\
{[-.69,-.24]}\end{array}$ & - & & & & & \\
\hline $\begin{array}{l}\text { 4. BAI } \\
\text { Guilt }\end{array}$ & $\begin{array}{c}-.09 \\
{[-.38, .21]}\end{array}$ & $\begin{array}{c}.21 \\
{[-.10, .47]}\end{array}$ & $\begin{array}{c}-.26 \\
{[-.52, .04]}\end{array}$ & - & & & & \\
\hline $\begin{array}{l}\text { 5. BAI } \\
\text { External }\end{array}$ & $\begin{array}{c}.35^{*} \\
{[.06, .59]}\end{array}$ & $\begin{array}{c}-.27 \\
{[-.53, .03]}\end{array}$ & $\begin{array}{c}.41^{* *} \\
{[.13, .63]}\end{array}$ & $\begin{array}{c}-.50^{* *} \\
{[-.70,-.24]}\end{array}$ & - & & & \\
\hline $\begin{array}{l}\text { 6. BAI } \\
\text { Mental }\end{array}$ & $\begin{array}{c}.43^{* *} \\
{[.16, .65]}\end{array}$ & $\begin{array}{c}-.12 \\
{[-.40, .18]}\end{array}$ & $\begin{array}{c}.24 \\
{[-.06, .50]}\end{array}$ & $\begin{array}{c}.33^{*} \\
{[.04, .57]}\end{array}$ & $\begin{array}{c}.18 \\
{[-.12, .46]}\end{array}$ & - & & \\
\hline $\begin{array}{l}\text { 7. Prison } \\
\text { term }\end{array}$ & $\begin{array}{c}.23 \\
{[-.08, .49]}\end{array}$ & $\begin{array}{c}-.17 \\
{[-.45, .13]}\end{array}$ & $\begin{array}{c}.09 \\
{[-.21, .38]}\end{array}$ & $\begin{array}{c}-.01 \\
{[-.31, .29]}\end{array}$ & $\begin{array}{c}-.11 \\
{[-.39, .19]}\end{array}$ & $\begin{array}{c}.22 \\
{[-.09, .48]}\end{array}$ & - & \\
\hline $\begin{array}{l}\text { 8. Punitive } \\
\text { actions }\end{array}$ & $\begin{array}{c}-.05 \\
{[-.34, .25]}\end{array}$ & $\begin{array}{c}.16 \\
{[-.15, .43]}\end{array}$ & $\begin{array}{c}.01 \\
{[-.28, .30]}\end{array}$ & $\begin{array}{c}.08 \\
{[-.22, .36]}\end{array}$ & $\begin{array}{c}-.05 \\
{[-.34, .25]}\end{array}$ & $\begin{array}{c}-.01 \\
{[-.30, .28]}\end{array}$ & $\begin{array}{c}.13 \\
{[-.17, .41]}\end{array}$ & - \\
\hline $\begin{array}{l}\text { 9. Intensive } \\
\text { offender }\end{array}$ & $\begin{array}{c}-.14 \\
{[-.42, .16]}\end{array}$ & $\begin{array}{c}.02 \\
{[-.28, .31]}\end{array}$ & $\begin{array}{c}.02 \\
{[-.28, .31]}\end{array}$ & $\begin{array}{c}.04 \\
{[-.26, .33]}\end{array}$ & $\begin{array}{c}-.02 \\
{[-.31, .28]}\end{array}$ & $\begin{array}{c}-.03 \\
{[-.32, .27]}\end{array}$ & $\begin{array}{c}.33^{*} \\
{[-.04, .57]}\end{array}$ & $\begin{array}{c}-.02 \\
{[-.31, .28]}\end{array}$ \\
\hline
\end{tabular}

Note. SIMS = Structured Inventory of Malingered Symptomatology; SDS-5 = five items of the Social Desirability Scale-17; LSRPS = Levenson Self-Report Psychopathy Scale; BAI Guilt = revised Gudjonsson Blame Attribution Inventory, Guilt scale; BAI External = revised Gudjonsson Blame Attribution Inventory, External scale; BAI Mental = revised Gudjonsson Blame Attribution Inventory, Mental scale; Prison term = length of prison sentence in years; Punitive actions = relative number of punitive actions taken against participants.

${ }^{*} p<.05 .{ }^{* *} p<.01$.

Table 2.5 also shows that symptom overreporting is related to blame attribution to external factors such as social environments, victims, or society (BAI External) and to mental disorders (BAI Mental). However, symptom overreporting is not statistically related to behavioral proxies of antisocial behavior (i.e., sentence length, number of incurred disciplinary actions, or classification as intensive offender). Also, the four participants on remand did not produce SIMS or LSRPS scores above the respective cutoffs, despite two of them being considered intensive offenders. Analyses containing subscale scores of the SIMS and LSRPS revealed that primary psychopathy scores are moderately related to age; older 
participants reported more callous and manipulative demeanor, $r=.38[.10, .61], p<.01$, twotailed.

Multiple linear regression analyses revealed that self-reported psychopathic traits (LSRPS; $B=.30, p<.01$ ), and to a lesser extent blame attribution to mental disorders (BAI Mental; $B=.24, p=.01$ ), are predictive of symptom overreporting, $R^{2}=.46, F(2,41)=17.69, p<$ .01 . Self-reported psychopathic traits (LSRPS; $B=-.14, p<.01$ ) are moderately predictive of a less socially desirable response style (SDS-5), $R^{2}=.24, F(1,42)=13.58, p<.01$.

\section{Discussion}

Analogous to Study 1, the second study relies on a self-report instrument to assess psychopathy. Self-report measures, however, may not be suitable for quantifying psychopathic traits because such traits include the inclination to deceive and manipulate (for a meta-analytic review, see Ray et al., 2013; for a qualitative review, see Kelsey, Rogers, \& Robinson, 2014). This concern is addressed through the inclusion of a concise measure of socially desirable responding (i.e., the SDS-5). A substantial negative correlation was found between self-reported psychopathy and socially desirable response bias: participants who scored higher on the LSRPS generally scored lower on the SDS-5. This result is reminiscent of Niesten et al. (2015), who found a negative correlation between faking good and psychopathy in their forensic sample. Arguably, the most salient interpretation is that participants with more psychopathic traits and/or more severe psychopathic traits hold (and report) attitudes that are less socially desirable.

An alternative explanation is that many participants who answered in a highly socially desirable manner underreported psychopathic attitudes and behaviors. A Pearson's chi-square analysis of the SDS-5 (>14) and LSRPS (>57) groups revealed that $50 \%$ of participants who produced LSRPS scores below the cutoff displayed a highly socially desirable response bias, whereas this is the case for only $12 \%$ of the participants who scored above the cutoff on the LSRPS. Put differently, the participants who answered in a highly socially desirable manner were 7.3 times more likely (compared with participants who had a less socially desirable response bias) to score low on psychopathic attitudes and behaviors. Thus, the relatively low psychopathy scores of some participants might be the result of an intentionally distorted response style (but see Watts et al., 2015). Unfortunately, this drawback extends to all measures that rely on self-report (e.g., the BAI), although measures that are less transparent (e.g., the SIMS) may be more robust.

A socially desirable response style also correlates negatively with symptom overreporting (SIMS scores). It can be argued that this is counterintuitive by appealing to the common denominator of socially desirable response bias and symptom overreporting; both behaviors amount to deception. On the other hand, psychopathology is not typically perceived as socially desirable (unless it constitutes grounds for excuse-making) and, as such, it may be expected that participants who are keen to make a good impression will not overreport psychopathological symptoms. This is exactly what the data show; there is a 
subgroup of participants $(n=8)$ who seem particularly determined to make a good impression by answering in a socially desirable way. This group scored low on both the LSRPS and the BAI External scale (which both comprise socially undesirable items) and refrained from excessive endorsement of psychopathology as measured by the SIMS.

One could argue that the number of incurred disciplinary actions, classification as intensive offender, and particularly the length of prison sentences are questionable as proxies for antisocial behavior-let alone for ASPD. While such criticism is well founded (Edens et al., 2015), it does not detract from the aura of antisocial attitudes that these proxies possess, or from the relevance of these proxies to clinical and legal decision-making about inmates and forensic patients. When forming professional opinions of individuals (i.e., opinions that have to be substantiated), decision-makers-from psychiatrists and clinical psychologists to judges and probation officers-rely on quantitative indicators, such as the number of disciplinary actions and classification as an intensive offender. Therefore, these indicators warrant inclusion when testing the idea that antisocial demeanor predisposes to biased symptom reporting.

\section{General discussion}

The findings of the present studies cast doubt on the intuitive assumption that antisocial behavior is invariably related to biased symptom reporting. Moreover, they call into question two heuristic rules that-according to the DSM, since its third edition-give grounds for strong suspicion of malingering, namely, the presence of ASPD and a lack of compliance with treatment regimens. In Study 1, neither ASPD nor institutional misbehavior (which included transgressions of treatment regimens) was found to be related to symptom overreporting. In Study 2, symptom overreporting was not linked to proxies of antisocial behavior-notably length of prison sentence, number of institutional disciplinary actions, and classification as intensive offender.

In contrast to behavioral indices of antisocial features, in Study 2, self-report measures of such features were found to be related to symptom overreporting. Analysis of the aggregated data of Studies 1 and $2(n=70)$ yields a correlation between symptom overreporting (SIMS) and self-reported psychopathic traits (LSRPS) of $r=.55[.36, .70], p<.01$, two-tailed. Endorsement of primary (i.e., callous and manipulative orientation toward others) as well as secondary (i.e., a disinhibited and antisocial lifestyle) psychopathic traits are related to heightened SIMS scores, $r=.46[.25, .63]$ and $r=.49,[.29, .65]$, respectively, $p<$ .01 , two-tailed. This pattern seems to provide support for antisocial behavior as an indicator of malingering. A comparison of actual test scores, however, reveals that the predictive value of self-reported psychopathic traits is limited: only 19\% (6 out of 32) of those with elevated levels of psychopathic traits (LSRPS score $>57$ ) engaged in overreporting of symptoms (SIMS score $>16)$.

As previously stated, the association between symptom overreporting and selfreported psychopathic traits is evident in Study 2, but not in Study 1. A possible reason for 
this discrepancy may be the limited number of LSRPS protocols that were obtained $(n=25)$ and the resulting lack of statistical power in Study 1, which is .34 ( $\alpha=.05, r=.31, n=25)$. This means that, when the correlation between symptom overreporting and self-reported psychopathic traits is indeed moderate (i.e., .31), the probability of obtaining a significant result (i.e., $p<.05$ ) is only .34.

Another contributory factor to the discrepant results in the two studies might be the different frequencies of self-reported psychopathic traits. While the prevalence of symptom overreporting is low in both studies ( $9 \%$ and 13\%), the prevalence of self-reported psychopathic traits is substantially higher in Study 2 than in Study 1 (56\% vs. 28\%). This may well be the result of contextual differences; the therapeutic setting of Study 1 is geared towards positive behavioral change and recidivism reduction, and actively suppresses the antisocial "survival of the toughest" attitudes that typically exist within penal institutions such as the one investigated in Study 2 (Butler, 2008). Thus, a therapeutic climate may reduce antisocial features and/or deter disclosure of such features, which might curb the relation between self-reported psychopathic traits and symptom overreporting.

In Study 2, the participants who overreported symptoms attributed their offenses more to external factors such as social environments, victims, or society, and reported less remorse and regret for their wrongdoings relative to those who did not engage in symptom overreporting. This is consistent with the positive relation between symptom overreporting and self-reported psychopathic traits that also emerged in Study 2. Note, however, that these correlations all rely on self-report, and contradict the findings that are based on behavioral indices. For example, in Study 2, all participants whose SIMS score exceeded the cutoff $(>16)$ produced a high LSRPS score $(>57)$, yet none were deemed an intensive offender (pointbiserial $r$ SIMS intensive offender $=-.14[-.42, .16], p>.05$, two-tailed). Moreover, these participants did not differ from the rest of the participants with regard to length of prison sentence and relative frequency of institutional disciplinary actions.

In Study 2, the attribution of criminal behavior to mental disorders is associated with symptom overreporting, $r=.43,[.16, .65] p<.01$, two-tailed, which lends some support to the hypothesis that symptom exaggeration can be a form of post hoc excuse-making for offenses (Maruna \& Mann, 2006). However, there is no difference in blame attribution to mental disorders between participants who scored beyond the SIMS cutoff (i.e., >16) and those who did not, $t(42)=-1.41, p>.05$. This suggests that symptom reporting generally coincides with attributions of blame to psychopathology, but that excessive symptom reporting does not necessarily coincide with excessive attributions of blame to psychopathology.

Given that the present studies only evaluated if participants engaged in symptom overreporting and not why participants engaged in symptom overreporting (i.e., the presence of external gains was not assessed), its findings are not a direct contradiction of those reported by, for example, Gacono, Meloy, Sheppard, Speth, and Roske (1995), who observed that offenders who malinger insanity exhibit more antisocial and psychopathic behavior. It might be that relationships exist between specific forms of antisocial behavior (e.g., aggressive narcissism and predatory violence) and specific forms of symptom 
overreporting (e.g., successful malingering to obtain a "not guilty by reason of insanity" verdict). However, the current findings suggest that the relation between symptom overreporting and antisocial behavior is at best a specific one that does not hold for symptom overreporting in general (i.e., as found in heterogeneous forensic populations).

It must be noted that the small sample sizes of the present studies prohibit the detection of subtle effects and small associations. While certainly interesting and worth investigating, such effects and associations are not relevant to the detection of symptom exaggeration and malingering. For scores of a certain index (e.g., the LSRPS, the SDAS-11, number of punitive actions) to be diagnostically relevant with regard to a dichotomous condition (e.g., symptom exaggeration ${ }^{1}$ ), the overlap between the index score distributions of the two conditions (e.g., honest and feigning) must be $<50 \%$. For example, if SDAS-11 scores are used as predictor of symptom exaggeration and the overlap between SDAS-11 scores of honest patients and feigning patients is $40 \%$, then $60 \%$ of the patients can be classified correctly (i.e., $60 \%$ obtained scores that are unique to their group). Percentages of overlap between score distributions correspond to the magnitude of difference between the means of the score distributions (i.e., to Cohen's $d$; see Table 1 in Zakzanis, 2001). The sample size required for the conventional .80 statistical power to detect an effect that produces a diagnostic accuracy of at least $60 \%$ (i.e., $d \geq 1.2$ ) is 54 when the base rate of symptom exaggeration is set at $10 \%(\alpha=.05$, one-tailed). The smallest groups in Studies 1 and 2 are the ones based on high SIMS scores (i.e., SIMS score $>16 ; n=5$ and $n=6$ ). The achieved power in comparisons of these groups with the groups that responded credibly to the SIMS is .81 for Study 1 and .85 for Study 2 ( $\alpha=.05$, one-tailed). Thus, the modest sample sizes of the present studies suffice to detect effects that are sufficiently large to be diagnostically relevant.

The considerable disparities among research findings should suffice to dissuade clinicians from using antisocial behavior as a red flag for symptom overreporting, as propagated by the DSM-5. Although some studies have found statistically significant correlations between symptom overreporting and antisocial behavior (Niesten et al., 2015), only one study yielded findings that are of a high predictive value (Gacono et al., 1995 found psychopathy to be a strong predictor of malingering insanity). The studies by Kucharski and colleagues are illustrative in this regard, observing a moderate effect of ASPD (Kucharski, Falkenbach, Egan, \& Duncan, 2006) and psychopathy (Kucharski, Duncan, Egan, \& Falkenbach, 2006) on symptom overreporting (Cohen's $d=.89$ and .86, respectively, calculated using available information), but this does not produce satisfactory diagnostic values (accuracy $=.52$ and .43 , respectively, calculated using available information). The point is that a positive relation between a predictor and a target condition does not constitute evidence for the utility of that predictor; it is the strength of the relation that determines the utility of the predictor.

\footnotetext{
1 Symptom exaggeration is in fact not a dichotomous phenomenon; rather, it is dimensional, with feigned psychopathology stretched out along a continuum (Walters, Berry, Rogers, Payne, \& Granacher, 2009; Walters, Rogers, et al., 2008). Nevertheless, practical decision-making often demands the assessment of feigned psychopathology to produce dichotomous outcomes (e.g., the honesty-feigning dichotomy).
} 
The stronger the relation between a predictor and a target condition, the higher the predictive value of the predictor. The relational strength depends on two factors: joint occurrence and concurrent absence. That is, for a predictor to be predictively valuable, it must be present when the target condition is present (this corresponds to a positive predictive value) and absent when the target condition is absent (this corresponds to a negative predictive value). Considering the empirical literature, this is clearly not the case with symptom overreporting and antisocial behavior. For instance, in the study that found the strongest relation between symptom overreporting and antisocial behavior (Gacono et al., 1995), the prevalence of ASPD in the sample of malingerers was $100 \%$, whereas the prevalence of ASPD in the sample of non-malingerers was 55\%. Thus, all who engaged in malingering were diagnosed with ASPD, but not all who were diagnosed with ASPD engaged in malingering (only $64 \%$ did). The omnipresence of ASPD in the sample of malingerers may foster the intuitive allure of ASPD as a good predictor of malingering. Succumbing to this allure, however, amounts to committing the logical fallacy known as "affirming the consequent." In the sample of Gacono et al. (1995), malingering is perfectly predictive of ASPD, yet the converse is not true; ASPD is only moderately predictive of malingering (64\%).

A high prevalence of malingering among patients who are diagnosed with ASPD or psychopathy heightens vigilance with regard to malingering when patients have a record of antisocial behavior, yet it may also decrease alertness when patients have no history of antisocial behavior. While the former is warranted, the latter is tantamount to taking absence of evidence for evidence of absence (i.e., to committing the logical fallacy known as "denying the antecedent"). For example, in the forensic sample of Delain, Stafford, and Ben-Porath (2003), ASPD is fairly predictive of malingering (83\%), but malingering is not predictive of ASPD (17\%, calculated using available information).

In terms of diagnostic accuracy, affirming the consequent leads to false-positive classifications (i.e., individuals who display antisocial behavior but do not overreport symptoms are incorrectly considered to be malingerers). Similarly, denying the antecedent leads to false-negative classifications (i.e., individuals who do not display antisocial behavior but do engage in symptom overreporting are incorrectly considered to be honest). The quantities of these errors depend on the prevalence of both symptom overreporting among antisocial patients and antisocial behavior among overreporting patients. Few studies have assessed these prevalence rates, and even fewer still have looked into both prevalence rates among their samples. Table 2.6 displays prevalence rates of symptom overreporting among patients with ASPD or psychopathy (and vice versa) and corresponding percentages of incorrect predictions when antisocial behavior is used as predictor of symptom overreporting. In addition to the two present studies, only studies that found a statistically significant relation between symptom overreporting and antisocial behavior are included in 
Table 2.6.2 In studies other than the present, the prevalence of symptom overreporting among antisocial patients ranges from $11 \%$ to $90 \%$, whereas the prevalence of antisocial behavior among overreporting patients varies between $17 \%$ and $100 \%$.

\section{Table 2.6}

Prevalence rates of symptom overreporting among patients with antisocial personality disorder or psychopathy (and vice versa) and corresponding percentages of incorrect predictions when antisocial behavior is used as predictor of symptom overreportinga

\begin{tabular}{|c|c|c|c|c|}
\hline Authors & $\begin{array}{l}\text { Prevalence of symptom } \\
\text { overreporting among } \\
\text { antisocial patients }\end{array}$ & $\begin{array}{l}\text { False- } \\
\text { positive } \\
\text { predictions }\end{array}$ & $\begin{array}{l}\text { Prevalence of antisocial } \\
\text { behavior among } \\
\text { overreporting patients }\end{array}$ & $\begin{array}{l}\text { False- } \\
\text { negative } \\
\text { predictions }\end{array}$ \\
\hline \multirow[t]{3}{*}{ Study 1} & 0\% (ASPD) & $100 \%$ & 0\% (ASPD) & $100 \%$ \\
\hline & 0\% (SDAS-11 >1.5 SD) & $100 \%$ & 0\% (SDAS-11>1.5 SD) & $100 \%$ \\
\hline & 0\% (LSRPS > 57) & $100 \%$ & 0\% (LSRPS > 57) & $100 \%$ \\
\hline \multirow[t]{2}{*}{ Study 2} & $0 \%$ (Intensive offender) & $100 \%$ & $0 \%$ (Intensive offender) & $100 \%$ \\
\hline & $24 \%($ LSRPS >57) & $76 \%$ & $100 \%($ LSRPS > 57) & $0 \%$ \\
\hline Delain et al. (2003) & $83 \%(\mathrm{ASPD})^{\mathrm{b}}$ & $17 \%$ & $17 \%(A S P D)^{b}$ & $83 \%$ \\
\hline \multirow[t]{2}{*}{ Gacono et al. (1995)c } & $64 \%(\mathrm{ASPD})^{\mathrm{b}}$ & $36 \%$ & $100 \%(\mathrm{ASPD})^{\mathrm{b}}$ & $0 \%$ \\
\hline & 90\% (Psychopathy) ${ }^{\mathrm{b}}$ & $10 \%$ & 100\% (Psychopathy) ${ }^{\mathrm{b}}$ & $0 \%$ \\
\hline Heinze \& Vess (2005) & 11\% (Psychopathy) & $89 \%$ & 33\% (Psychopathy) & $67 \%$ \\
\hline $\begin{array}{l}\text { Kucharski, Duncan } \\
\text { et al. (2006) }\end{array}$ & 33\% (Psychopathy) & $67 \%$ & 52\% (Psychopathy) & $48 \%$ \\
\hline $\begin{array}{l}\text { Kucharski, Falkenbach } \\
\text { et al. (2006) }\end{array}$ & $31 \%$ (ASPD) & $69 \%$ & $72 \%(\mathrm{ASPD})$ & $28 \%$ \\
\hline
\end{tabular}

Note. ASPD = antisocial personality disorder; SDAS-11 = Social Dysfunction and Aggression Scale-11; LSRPS = Levenson Self-Report Psychopathy Scale.

aStudies gathered from Niesten et al. (2015), and via a thorough search through Google Scholar with the search terms "psychopathy" and "antisocial personality disorder" combined with "malingering," "feigning," "simulation," and "dissimulation." Aside from the present studies, only studies that found a statistically significant relation between symptom overreporting and antisocial behavior are included. bCalculated using available information. 'Employed two samples: malingerers and nonmalingerers.

The vast variation in prevalence rates severely limits the predictive value of antisocial behavior for symptom overreporting. The lower the prevalence of symptom overreporting relative to the prevalence of antisocial behavior, the higher the false-positive rate; and conversely, the lower the prevalence of antisocial behavior relative to the prevalence of

\footnotetext{
2 Studies were gathered from Niesten et al. (2015), and via a thorough search via Google Scholar with the search terms "psychopathy" and "antisocial personality disorder" combined with "malingering," "feigning," "simulation," and "dissimulation."
} 
symptom overreporting, the higher the false-negative rate. As can be seen from Table 2.6, the employment of antisocial behavior as a predictor of symptom overreporting rarely yields acceptably low proportions of false-positive and false-negative predictions.

The weight of the evidence against the predictive utility of generic antisocial behavior for symptom overreporting is such that future research in this regard is uncalled for. Symptom overreporting (including malingering) is better conceptualized as a contextdependent variable than as a trait that is associated with an antisocial disposition. Subsequent research should address specific forms of antisocial behavior (e.g., subtypes of psychopathy or ASPD), particular contextual factors (e.g., subcategories of criminal or civil cases), and explicit patient characteristics (e.g., certain types of crime). For example, the present studies assess symptom overreporting in post-trial settings where there are no incentives to feign symptoms that may affect the outcome of a trial (such as crime-related amnesia, dissociative fugue, command hallucinations, etc.). It might be that relations between malingering and antisocial or psychopathic behavior are more pronounced among defendants than among convicts. Also, it may well be that associations exist between biased symptom reporting and antisocial or psychopathic behavior by way of a third variable. For example, it is possible that antisocial and psychopathic individuals engage in more activities (e.g., criminal acts) that put them in situations (e.g., criminal trials) in which biased symptom-reporting is an appealing course of action. Furthermore, research could be strengthened by looking into multiple response styles (i.e., symptom overreporting as well as underreporting). While symptom overreporting has often been discussed in relation to ASPD and psychopathy, symptom underreporting has-undeservedly-received less attention.

Exaggerating symptoms to realize a transfer from prison to a psychiatric hospital is no less self-serving and deceptive than it is to conceal symptoms to secure an early release from a psychiatric ward. Thus, even if it is true that the occurrence of response bias is heavily dependent on certain character traits (e.g., psychopathic and antisocial traits), the form of response bias (i.e., positive or negative) remains largely dependent on contextual factors. A priori, then, an association with ASPD and psychopathy is as plausible for a positive response bias (e.g., symptom underreporting) as it is for a negative response bias (e.g., symptom overreporting). Hence, any assessment of the relation between malingering and psychopathic and antisocial traits is incomplete if it does not also address positive response bias. This should be a focus of subsequent research.

Study 2 found symptom overreporting to be related to self-reported antisocial features, yet neither study found symptom overreporting to be related to actual antisocial behavior. This incongruity might be a clue to the discrepancies within the empirical literature about the association between symptom overreporting and antisocial features, where a sizable portion found no association and an equally large portion found a small yet predictively trivial association.

The upshot of the preceding discussion is that antisocial behavior is not a clinically useful indicator of symptom overreporting or malingering. The DSM-5 entry in this regard is scientifically untenable and its use leads to unacceptable rates of false-positive 
identifications of malingering in ill-disposed patients, and biases clinicians to miss cases of malingering among socially-accomplished individuals. Clinicians are strongly advised to refrain from using antisocial behavior as a risk factor or indicator of symptom exaggeration. Instead, clinicians are urged - whether or not a patient presents with antisocial demeanor or meets criteria for ASPD or psychopathy - to always check for biased symptom-reporting by routinely including screening measures of symptom and performance validity in clinical assessments (Bush, Heilbronner, \& Ruff, 2014). 


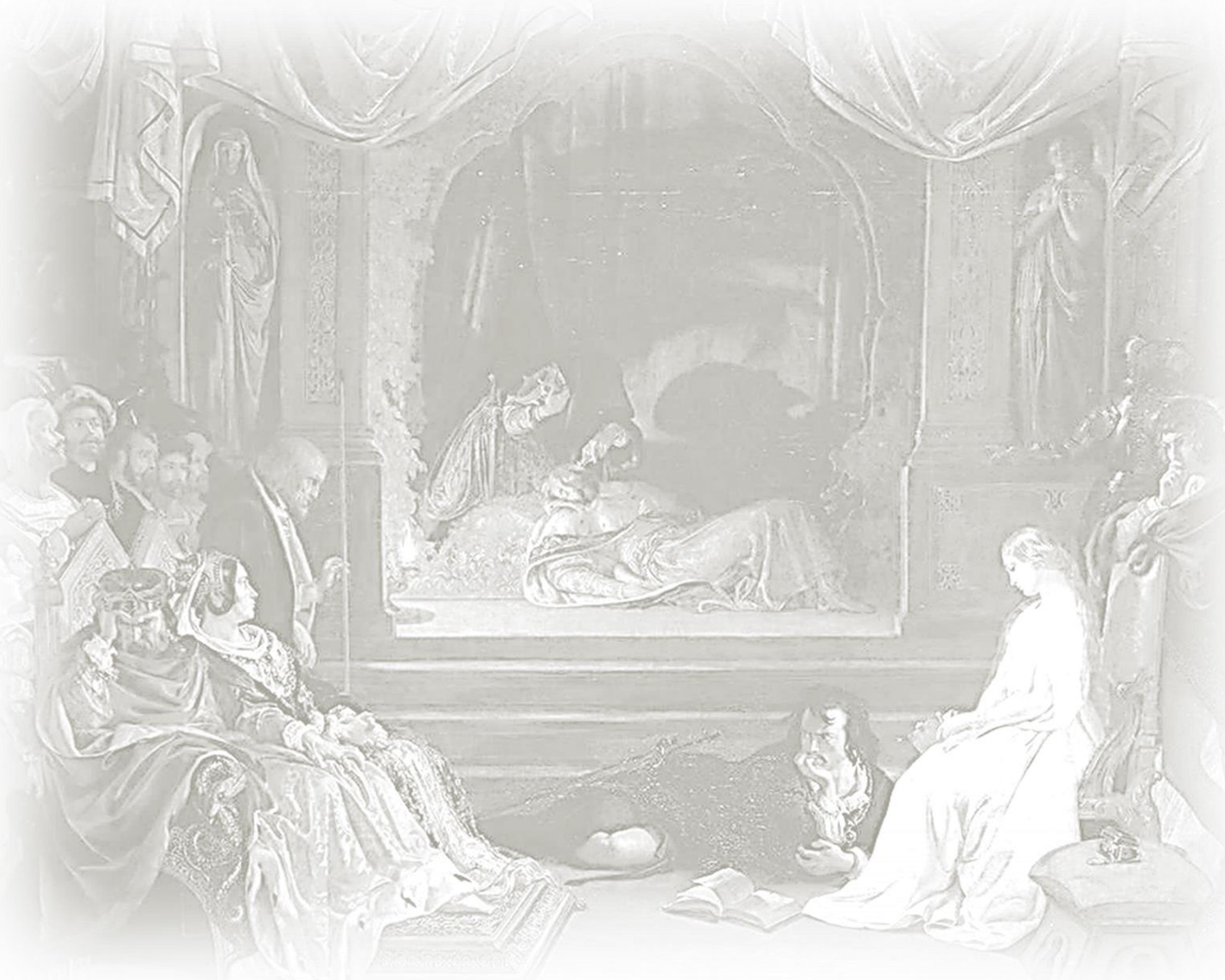




\section{Chapter 3}

\section{Antisocial features are not predictive of}

\section{symptom exaggeration in forensic patients}

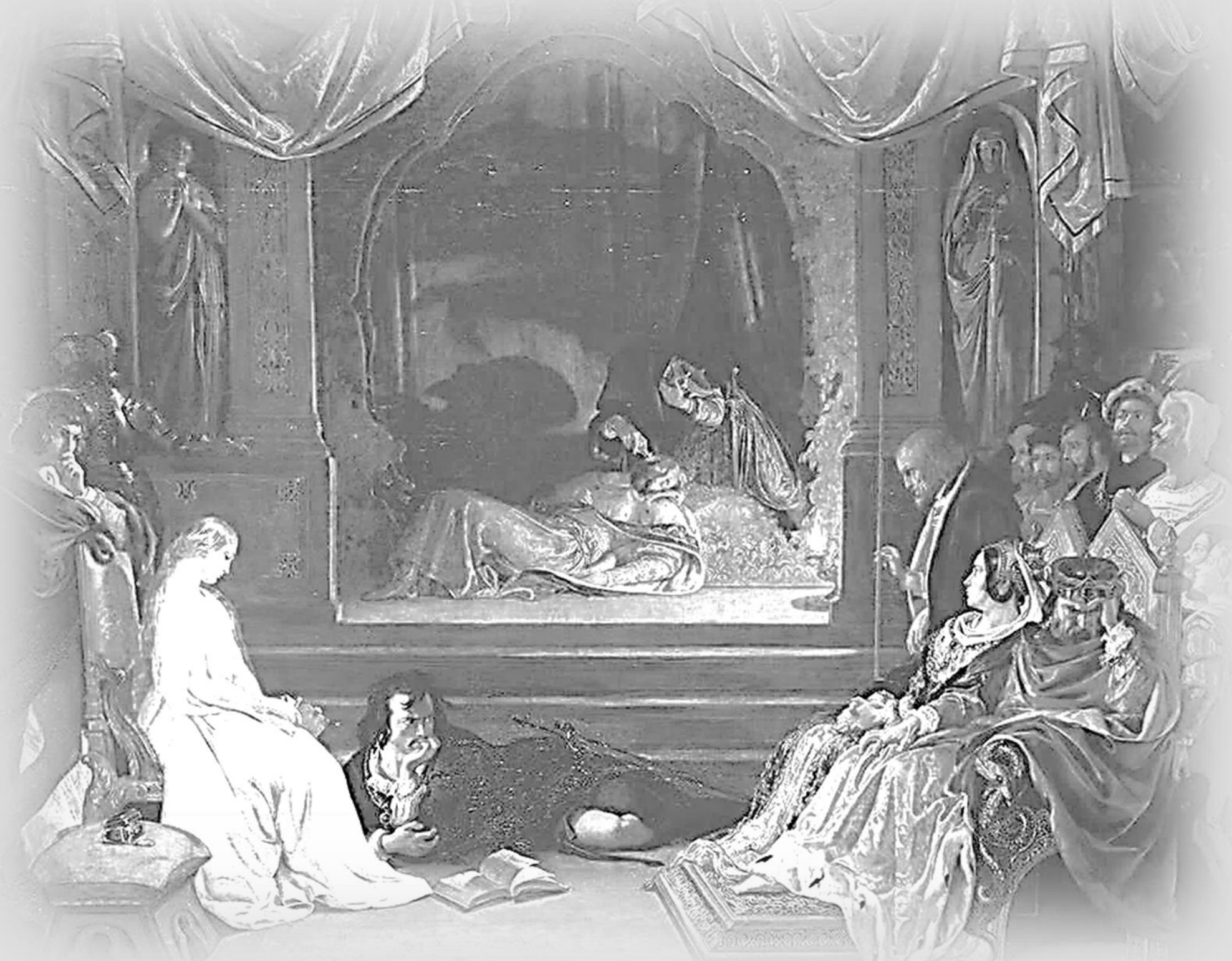

Published as:

van Impelen, A., Merckelbach, H., Jelicic, M., \& à Campo, J. (2018). Antisocial features are not predictive of symptom exaggeration in forensic patients. Legal and Criminological Psychology, 23, 135-147. 


\begin{abstract}
We investigated the predictive value of antisocial personality disorder (ASPD) for symptom exaggeration in a sample of forensic patients $(N=57)$. We focused on three features that may underlie the potential link between ASPD and symptom exaggeration, namely deceitfulness, lack of remorse, and blame externalization. Participants were asked to complete several selfreport instruments and a semi-structured interview about their most recent offense. To quantify patients' deceitfulness, the information collected via the semi-structured interview was checked against the official records of patients' offenses. The main results are that ASPD was not a useful indicator of symptom exaggeration. Also, patients who were inaccurate when reporting their delinquency, or who showed little regret for their offenses, or who tended to blame their offenses on external factors, had similar levels of symptom exaggeration as those without these tendencies. We conclude that antisocial traits, including deceitfulness, lack of remorse, and blame externalization, are not meaningfully related to symptom exaggeration and therefore should have no place in the assessment of symptom validity or the detection of malingering. On the contrary; focusing on antisocial traits as indicators of symptom exaggeration is likely to result in large portions of misclassifications.
\end{abstract}




\section{Introduction}

A core concern in forensic psychiatric and psychological evaluations is the accuracy of examinees' self-reported information. Primary concerns in this respect are distorted symptom presentations and biased accounts of crimes or misconduct. At first blush, such concerns seem more appropriate in some cases than in others, depending on the personality of the examinee and the psycho-legal issue that is assessed. Because "deceit and manipulation are central features of antisocial personality disorder" (ASPD; American Psychiatric Association, 2013, p. 659), it stands to reason that those with antisocial personality traits tend to misrepresent psycho-legally relevant information. Consistent with the notion that antisocial personalities are prone to deceitfulness, and that symptom exaggeration is a form of deceit, the Diagnostic and Statistical Manual of Mental Disorders (5th ed.; DSM-5; American Psychiatric Association, 2013) adheres to the idea that symptom exaggeration (e.g., malingering) is an act typically committed by individuals with ASPD. Thus, the DSM-5 states that individuals with ASPD "may repeatedly lie, use an alias, con others, or malinger (American Psychiatric Association, 2013, p. 660, italics added). This typology of symptom exaggeration - dubbed "the criminological model" by Rogers, Sewell, and Goldstein (1994)-has remained unchanged through four revisions since its first appearance in the DSM-III (American Psychiatric Association, 1980).

Nearly three decades ago, Rogers (1990a) found the empirical evidence to justify the use of ASPD as an indicator of symptom exaggeration to be meager. Since then, Rogers' continued criticism (e.g., Rogers, 2008a; Rogers \& Shuman, 2005) has been corroborated by multiple empirical studies (e.g., Kucharski, Falkenbach, Egan, \& Duncan, 2006; Pierson, Rosenfeld, Green, \& Belfi, 2011; Sumanti, Boone, Savodnik, \& Gorsuch, 2006). While some studies did find ASPD to be associated with symptom exaggeration (e.g., Delain, Stafford, \& Ben-Porath, 2003; Gacono, Meloy, Sheppard, Speth, \& Roske, 1995), the magnitude of the associations is insufficient to be of any diagnostic value (see Chapter 2).

In two previous studies, we investigated the predictive value of antisocial behavior for symptom exaggeration in a medium security forensic psychiatric hospital and a youth prison, respectively, and found it to be nonexistent (Chapter 2). This squares with the review by Niesten, Nentjes, Merckelbach, and Bernstein (2015), who concluded that a general predisposition to disregard and violate rules and social norms has little predictive value for symptom exaggeration. It may well be, however, that other features of ASPD drive the modest associations that some studies find between symptom exaggeration and ASPD (e.g., Delain et al., 2003), but also between symptom exaggeration and psychopathy (e.g., Gacono et al., 1995; Heinze \& Vess, 2005; Kucharski, Duncan, Egan, \& Falkenbach, 2006).

Arguably, the feature of ASPD that is most likely to be associated with symptom exaggeration is deceitfulness. Indeed, the assumption that individuals who are deceitful in one domain (e.g., offense reporting), are more prone to be deceitful in other domains (e.g., symptom reporting) has ample intuitive allure. In contrast to earlier research, we explicitly tested this assumption in the present study by comparing the accuracy of patients' self- 
reported symptoms with the accuracy of their self-reported offense descriptions, and by quantifying the degree to which patients denied or minimized their delinquency.

Another feature of ASPD that may seem to predispose to symptom misrepresentation is lack of remorse and the tendency to rationalize transgressions. We addressed this hypothesis by assessing the extent to which patients felt remorse for their offenses and blamed their offenses on external factors (such as social environments, victims, or society) and on mental disorders or insufficient self-control. Thus, in addition to testing the strength of ASPD as indicator of symptom exaggeration directly, we investigated underlying features that potentially link ASPD to symptom exaggeration.

\section{Method}

The present study followed a correlational design in which self-report measures were administered to forensic psychiatric patients (see below). Symptom exaggeration, lack of remorse, and blame externalization were measured with validated instruments (the Structured Inventory of Malingered Symptomatology, SIMS; Smith \& Burger, 1997, and the revised Gudjonsson Blame Attribution Inventory, BAI; Gudjonsson \& Singh, 1989). To address deceitfulness, we utilized several proxies; offense report inaccuracy, denial of offense, denial of aggression, and offense minimization. Offense report inaccuracy was quantified by contrasting the information that participants reported during a semi-structured interview with the information in the official records of their offenses. Denial of offense was determined by gathering patients' therapists' and treatment supervisors' judgment on this matter from patient records. Offense minimization and denial of aggression were measured through a brief questionnaire that we developed for that purpose. To assess the relation between symptom exaggeration, on the one hand, and potential predictors of symptom exaggeration (i.e., offense report inaccuracy, denial of offense, offense minimization, denial of aggression, lack of remorse, and blame externalization), on the other hand, we conducted a correlational analysis and we cross-tabulated prevalence rates of symptom exaggeration with prevalence rates of the potential predictors. Based on the results of our previous studies (see Chapter 2) and the review by Niesten et al. (2015), we did not expect symptom exaggeration to be related to biased offense reporting (i.e., offense report inaccuracy, denial of offense, offense minimization, and denial of aggression), lack of remorse, or external blame attribution.

\section{Participants}

Participants were recruited from three outpatient units and one inpatient unit of Radix Forensic Psychiatric Hospital, located in the Netherlands. All participants had a history of delinquent behavior and were in treatment for psychiatric symptoms; 65\% was being treated on a mandatory basis (i.e., compulsory treatment imposed by the Dutch probation services) and 35\% had voluntarily applied for treatment to avoid escalation of criminal behavior and contact with the justice system. Crimes that patients were convicted for included arson, 
assault, battery, burglary, drug-related offenses, robbery, and sexual assault. The therapies and interventions that patients were enrolled in aimed to improve mental health and reduce recidivism risk. Patients who were suffering from acute drug withdrawal or psychosis were not eligible for participation. Fifty-seven patients completed the study; 4 women ( $M_{\text {age }}=40.3$ years, age range: $30-49)$ and 53 men (Mage $=36.5$ years, age range: $22-57)$. Most patients $(67 \%$; $n=38)$ identified themselves as being of Dutch descent, $18 \%(n=10)$ originated from a state within the European Union, and 16\% $(n=9)$ hailed from a state outside the European Union.

Before patients are to receive treatment at Radix, they must have undergone a comprehensive psychological evaluation, which includes, for example, cognitive tests, personality assessment, clinical interviews, behavioral observations, and background checks. The results of the psychological evaluations are weighed and integrated according to the criteria set forth in the DSM-5 and culminate in concomitant diagnoses. We retrieved the diagnoses of participants from their patient records at Radix. The majority of patients were diagnosed with a substance-related disorder $(68 \% ; n=39)$ and roughly half of the patients with a personality disorder $(53 \% ; n=30)$. Other mental disorders included depression $(12 \%$; $n=7)$, intellectual disability $(9 \% ; n=5)$, anxiety disorder $(7 \% ; n=4)$, and attention deficit hyperactivity disorder $(7 \% ; n=4)$. The prevalence of ASPD was $18 \%(n=10)$. Thus, the ASPD subsample consisted of 10 patients and the non-ASPD subsample consisted of 47 patients.

\section{Measures}

Structured Inventory of Malingered Symptomatology (SIMS).

The SIMS (Smith \& Burger, 1997; for the Dutch translation, see Merckelbach \& Smith, 2003) is a self-report screen for exaggerated symptomatology. It comprises 75 true-false statements, which are evenly distributed over five scales that target exaggerated depression, psychosis, neurologic impairment, memory dysfunction, and low intelligence, respectively. The statements refer to extreme and atypical symptoms, such as "I have difficulty recognizing written and spoken words" and "When I can't remember something, hints do not help." The number of endorsed statements is used as an indicator of symptom exaggeration, with a cut score of $>16$ being associated with a sensitivity of about .91 and a specificity of around .65 (see Chapter 4). The internal consistency of the SIMS is adequate (Cronbach's alpha coefficient $=.88$, Widows \& Smith, 2005).

\section{Offense report inaccuracy.}

To assess the inaccuracy with which patients described their most recent offense, we developed a semi-structured interview and a coding scheme to compare the self-report version of the offense with the official file version of the offense (for a similar approach, see Porter \& Woodworth, 2007). The interview served to gather information that was important to understanding how the offense happened. Such information was coded as distinct pieces of "main information." Examples of main information are the type and severity of the 
offense, the nature of the weapon or violence that was used, the relationship with the victim, characteristics of the victim and the location, involvement of drugs, and the motive for the offense. After coding the information that was gathered from the interview into pieces of main information, all pieces of main information were checked against the official documents about the offense (i.e., documents of the Netherlands Institute of Forensic Psychiatry and Psychology). For each piece of main information it was determined whether or not the patient omitted or altered the information during the interview (0: main information accurately reported; 1: main information inaccurately reported). The data of sixteen patients were excluded because the official documentation of their offense did not suffice to verify at least five pieces of main information. The mean number of pieces of main information of the remainder of the sample $(n=41)$ was $8.0(S D=2.3$, range: $5-13)$. To account for differences in the number of pieces of main information that could be verified, offense report inaccuracy was calculated as the proportion of verifiable pieces of main information that was inaccurately reported.

Denial of offense.

An essential component of treatment at Radix Forensic Psychiatric Hospital revolves around patients' ability to recognize and constrain their delinquent behavior and accept responsibility for past delinquency. The extent to which patients acknowledge the offenses they committed is judged by therapists and treatment supervisors and recorded in patient records. We collected this information from participants' patient records and coded it as 0 (no offense denial), 1 (partial offense denial and/or minimization) or 2 (complete offense denial).

\section{Offense minimization.}

We measured patients' minimization of their most recent offense with six items based on those constructed by Henning and Holdford (2006). Minimization was quantified by having patients indicate on a 5-point scale ranging from 0 (none of it is true) to 4 (all of it is true) "How much of what the police said about this incident is true" and by five statements that were to be responded to via a 4-point scale ranging from 0 (strongly disagree) to 3 (strongly agree), such as "This situation got blown way out of proportion" and "The police made this incident sound much worse than it is." After reversing the score on the first item, the scores on the items were summed to obtain a total score that ranges from 0 to 19 , with higher scores indicating greater offense minimization. The reliability of the offense minimization scale, as quantified by Cronbach's alpha, was .52, which is questionable and suggests that the items vary in the type of minimization they tap (Tavakol \& Dennick, 2011).

Denial of aggression.

Denial of aggression during their most recent offense was probed by asking patients whether they agreed or disagreed with the following two statements: "There was no argument between me and the victim" and "There was no physical violence between me and the 
victim." For each patient, the actual occurrence of verbal aggression or physical violence during their most recent offense was verified through the official file information about their offense, as documented in reports drawn up by the Netherlands Institute of Forensic Psychiatry and Psychology, which is part of the Dutch Ministry of Justice. The data of sixteen patients were excluded because their most recent offense did not involve an argument or physical violence. Responses were summed, such that the overall index varied between 0 (no denial) and 2 (complete denial).

Revised Gudjonsson Blame Attribution Inventory (BAI).

The BAI (Gudjonsson \& Singh, 1989) is a self-report measure of blame attribution for criminal transgressions. It consists of 42 first-person statements that are responded to via 5point scales ranging from 0 (I do not at all agree) to 4 (I fully agree). The BAI probes three separate dimensions of blame attribution for offenses: Guilt-feeling attribution (i.e., feeling remorse or regret for offenses; 18 items, score range: 0-72, Cronbach's alpha $=.81$ ); External attribution (i.e., blaming offenses on social environments, victims, or society; 15 items, score range: $0-60$, Cronbach's alpha $=.77$ ); and Mental-element attribution (i.e., placing blame on mental disorders or insufficient self-control; 9 items, score range: 0-36, Cronbach's alpha = .79). Typical items are "I feel very ashamed of the crime(s) I committed" (Guilt-feeling attribution), "I did not deserve to be caught for the crime I committed" (External attribution), and "I would certainly not have committed the crime I did if I had been mentally well" (Mental-element attribution).

\section{Procedure}

Prior to data collection, approval was obtained from Radix Forensic Psychiatric Hospital in Heerlen, the Netherlands, and from the standing Ethics Committee of the Faculty of Psychology and Neuroscience of Maastricht University. Data were collected solely for research purposes and were not relayed to staff or treatment personnel. Tests were administered by two graduate psychology students who were acquainted with test protocols.

At the inpatient location, recruitment was initiated via brief announcements during morning gatherings. Interested patients were asked if they agreed to be approached by one of the researchers, from whom they could receive additional information on an individual basis. A similar procedure was followed at the outpatient locations, except that the initial brief announcements were made by therapists to their patients individually. Before being asked for their written informed consent, patients received both verbal and written information about the study.

Because knowledge of the research design could influence patients' responses to the self-report measures, we veiled the purpose of the study by telling patients that the study was about the relation between personality characteristics and symptomatology, but leaving out that we were specifically interested in exaggerated symptomatology and antisocial 
personality characteristics. To safeguard the design of the study, the debriefing of patients took place after all data had been collected.

We stimulated patients' openness and honesty by imploring them to be completely truthful in answering all questions and by stressing the importance of the research and the potential profits that it might yield in general (i.e., more accurate diagnostic procedures and thereby better allocation of treatment resources). Participation in the study was completely voluntary; no rewards or incentives were offered for participation. To protect the privacy of the patients, test sessions took place in secluded rooms and none of the study materials, except the informed consent, were signed with information other than participant numbers.

Test sessions lasted approximately 45 minutes. Patients were at liberty to take a break at any time. After giving written informed consent, patients completed, in fixed order, the SIMS, the semi-structured interview about their offense, the denial and minimization questionnaire, and the BAI.

\section{Results}

The difference in settings-three outpatient units and one inpatient unit-did not affect scores on any of the measures; $F(24,63)=0.88, p=.63$, which permits pooling of the data. Table 3.1 summarizes sample sizes and mean scores on the various measures. The mean SIMS score $(9.8,95 \%$ CI $[8.2,11.5])$ is typical for clinical populations (see Chapter 4$)$. Patients with ASPD produced a mean SIMS score that was nearly equivalent to that of the other patients (10.0 vs. $9.8 ; t(55)=-0.9, p=.93)$. SIMS scores above the recommended cutoff that signals symptom exaggeration were equally prevalent among patients with ASPD and other patients (cut score $>16 ; 10 \%$ vs. $13 \%$ ). Several patients $(n=5)$ were diagnosed with intellectual disability - a disorder that may cause false-positive validity test results (Victor \& Boone, 2007) - but none of these patients scored beyond the cutoff on the SIMS.

The mean proportion of inaccurately reported pieces of main information that patients reported about their most recent offense was .17 (95\% CI [.11, .23]). Proportions inaccurately reported offense information between .10 and .25 occurred in eleven patients (27\%), proportions between $.25-.50$ occurred in seven patients $(17 \%)$, and proportions above .50 in five patients $(12 \%)$. The mean denial of offense score-based on clinicians' judgment as recorded in patient records-was 0.7 (range: $0-2,95 \%$ CI [0.6, 0.9]). The denial of aggression score averaged 0.9 (range: $0-2,95 \%$ CI $[0.6,1.1]$ ), with five patients (12\%) falsely denying the occurrence of an argument during their most recent offense, seven patients (17\%) falsely denying physical violence, and twelve patients (29\%) falsely denying both an argument and violence. Offense minimization scores-based on self-report-ranged from 1 to 18 (of the possible 0-19), with the mean score being 9.2 (95\% CI [8.3, 10.1]). Six patients (12\%) scored higher than 13 , which is $68 \%$ of the maximum score, and signals serious minimization. 


\section{Table 3.1}

Summary of means, corresponding 95\% confidence intervals, and standard deviations of Structured Inventory of Malingered Symptomatology, offense report inaccuracy, denial of offense, offense minimization, denial of aggression, and revised Gudjonsson Blame Attribution Inventory scores

\begin{tabular}{|c|c|c|c|c|}
\hline $\begin{array}{l}\text { Measure } \\
\text { (min-max) }\end{array}$ & $n$ & $M(S D)$ & $95 \% \mathrm{CI}$ & $\%(n)>$ cutoff \\
\hline $\begin{array}{l}\text { SIMS } \\
(0-75)\end{array}$ & 57 & $9.8(6.3)$ & {$[8.2,11.5]$} & $12 \%(7)>16$ \\
\hline $\begin{array}{l}\text { Offense report inaccuracy } \\
(0.00-1.00)\end{array}$ & 41 & $.17(.19)$ & {$[.11, .23]$} & $\begin{array}{l}27 \%(11)=.10-.24 \\
17 \%(7)=.25-.49 \\
12 \%(5) \geq .50\end{array}$ \\
\hline $\begin{array}{l}\text { Denial of offense } \\
(0-2)\end{array}$ & 52 & $0.7(0.7)$ & {$[0.6,0.9]$} & $\begin{array}{l}50 \%(26)=1 \\
12 \%(6)=2\end{array}$ \\
\hline $\begin{array}{l}\text { Offense minimization } \\
(0-19)\end{array}$ & 52 & $9.2(3.3)$ & {$[8.3,10.1]$} & $12 \%(6)>13$ \\
\hline $\begin{array}{l}\text { Denial of aggression } \\
(0-2)\end{array}$ & 41 & $0.9(0.8)$ & {$[0.6,1.1]$} & $\begin{array}{l}29 \%(12)=1 \\
29 \%(12)=2\end{array}$ \\
\hline $\begin{array}{l}\text { BAI Guilt } \\
(0-72)\end{array}$ & 57 & $34.7(11.1)$ & {$[31.8,37.6]$} & \\
\hline $\begin{array}{l}\text { BAI External } \\
(0-60)\end{array}$ & 57 & $21.4(8.8)$ & {$[19.1,23.8]$} & \\
\hline $\begin{array}{l}\text { BAI Mental } \\
(0-36)\end{array}$ & 57 & $19.4(7.3)$ & {$[17.4,21.3]$} & \\
\hline
\end{tabular}

Note. $\mathrm{CI}=$ confidence interval; SIMS = Structured Inventory of Malingered Symptomatology; BAI Guilt = revised Gudjonsson Blame Attribution Inventory, Guilt scale; BAI External = revised Gudjonsson Blame Attribution Inventory, External scale; BAI Mental = revised Gudjonsson Blame Attribution Inventory, Mental scale.

The mean score on the BAI guilt-feeling attribution scale was 34.7 (95\% CI [31.8, 37.6]), which indicates that, on average, patients expressed only modest remorse or regret for their offenses. The mean BAI external attribution scale score was 21.4 (95\% CI [19.1, 23.8]), signifying that patients' blame attribution styles were moderately externalizing, with substantial proportions of blame for offenses being ascribed to social environmental factors, victims, or society. The mean BAI mental-element attribution scale score was 19.4 (95\% CI $[17.4,21.3])$, suggesting that patients were typically inclined to blame their offenses at least in part on psychological symptoms or insufficient self-control.

To examine the relation between symptom exaggeration, ASPD, and bias in offenserelated self-report, we computed Pearson product-moment correlation coefficients (except where noted) between SIMS scores, ASPD diagnoses (point-biserial correlations), and the 
indices of offense report inaccuracy, denial of offense, offense minimization, denial of aggression, and criminal blame attribution (BAI). Table 3.2 displays the results.

\section{Table 3.2}

Pearson product-moment and point-biserial correlations and corresponding 95\% confidence intervals among Structured Inventory of Malingered Symptomatology, antisocial personality disorder, offense report inaccuracy, denial of offense, offense minimization, denial of aggression, and revised Gudjonsson Blame Attribution Inventory scores

\begin{tabular}{|c|c|c|c|c|c|c|c|c|}
\hline & 1. SIMS & 2 & 3 & 4 & 5 & 6 & 7 & 8 \\
\hline 2. ASPD $\left(r_{\mathrm{pb}}\right)$ & $\begin{array}{c}.01 \\
{[-.25, .27]}\end{array}$ & - & & & & & & \\
\hline $\begin{array}{l}\text { 3. Offense } \\
\text { report } \\
\text { inaccuracy }\end{array}$ & $\begin{array}{c}.15 \\
{[-.17, .44]}\end{array}$ & $\begin{array}{c}-.05 \\
{[-.35, .26]}\end{array}$ & - & & & & & \\
\hline $\begin{array}{l}\text { 4. Denial of } \\
\text { offense }\end{array}$ & $\begin{array}{c}.24 \\
{[-.04, .48]}\end{array}$ & $\begin{array}{c}-.12 \\
{[-.38, .16]}\end{array}$ & $\begin{array}{c}-.09 \\
{[-.39, .22]}\end{array}$ & - & & & & \\
\hline $\begin{array}{l}\text { 5. Offense } \\
\text { minimization }\end{array}$ & $\begin{array}{c}.11 \\
{[-.17, .37]}\end{array}$ & $\begin{array}{c}-.02 \\
{[-.29, .25]}\end{array}$ & $\begin{array}{c}-.05 \\
{[-.32, .23]}\end{array}$ & $\begin{array}{c}.17 \\
{[-.11, .42]}\end{array}$ & - & & & \\
\hline $\begin{array}{l}\text { 6. Denial of } \\
\text { aggression }\end{array}$ & $\begin{array}{c}.03 \\
{[-.28, .34]}\end{array}$ & $\begin{array}{c}.22 \\
{[-.10, .50]}\end{array}$ & $\begin{array}{c}.16 \\
{[-.16, .45]}\end{array}$ & $\begin{array}{c}-.13 \\
{[-.42, .19]}\end{array}$ & $\begin{array}{c}-.42^{* *} \\
{[-.62,-.17]}\end{array}$ & - & & \\
\hline 7. BAI Guilt & $\begin{array}{c}-.02 \\
{[-.28, .24]}\end{array}$ & $\begin{array}{c}-.11 \\
{[-.36, .16]}\end{array}$ & $\begin{array}{c}-.05 \\
{[-.35, .26]}\end{array}$ & $\begin{array}{c}.08 \\
{[-.20, .35]}\end{array}$ & $\begin{array}{c}-.17 \\
{[-.41, .10]}\end{array}$ & $\begin{array}{c}-.10 \\
{[-.40, .21]}\end{array}$ & - & \\
\hline 8. BAI External & $\begin{array}{c}.31^{*} \\
{[.05, .53]}\end{array}$ & $\begin{array}{c}-.10 \\
{[-.35, .17]}\end{array}$ & $\begin{array}{c}.13 \\
{[-.19, .42]}\end{array}$ & $\begin{array}{c}.21 \\
{[-.07, .46]}\end{array}$ & $\begin{array}{c}.28^{*} \\
{[.02, .50]}\end{array}$ & $\begin{array}{c}.11 \\
{[-.21, .40]}\end{array}$ & $\begin{array}{c}-.44^{* *} \\
{[-.63,-.20]}\end{array}$ & - \\
\hline 9. BAI Mental & $\begin{array}{c}.02 \\
{[-.24, .28]}\end{array}$ & $\begin{array}{c}-.37^{* *} \\
{[-.58,-.12]}\end{array}$ & $\begin{array}{c}.23 \\
{[-.08, .50]}\end{array}$ & $\begin{array}{c}.05 \\
{[-.23, .32]}\end{array}$ & $\begin{array}{c}-.01 \\
{[-.28, .26]}\end{array}$ & $\begin{array}{c}-.32^{*} \\
{[-.54,-.07]}\end{array}$ & $\begin{array}{c}.57^{* *} \\
{[.36, .72]}\end{array}$ & $\begin{array}{c}-.07 \\
{[-.33, .19]}\end{array}$ \\
\hline
\end{tabular}

Note. SIMS = Structured Inventory of Malingered Symptomatology; ASPD = antisocial personality disorder; BAI Guilt = revised Gudjonsson Blame Attribution Inventory, Guilt scale; BAI External = revised Gudjonsson Blame Attribution Inventory, External scale; BAI Mental = revised Gudjonsson Blame Attribution Inventory, Mental scale. Values in bold font are correlations with symptom exaggeration (i.e., SIMS scores).

${ }^{*} p<.05 .{ }^{* *} p<.01$.

As can be seen in Table 3.2, symptom exaggeration was moderately associated with the attribution of criminal blame to external factors (such as social economic environment, victims, or society; $r=.31[.05, .53] p<.05$, two-tailed), but neither related to ASPD, nor to any index of bias in offense-related self-report, feelings of guilt or regret, or attribution of criminal blame to psychopathology. Antisocial personality disorder was inversely related to the attribution of criminal blame to psychopathology $\left(r_{\mathrm{pb}}=-.37[-.58,-.12] p<.01\right.$, two-tailed $)$; compared with other patients, patients with ASPD tended to ascribe less criminal blame to psychopathological symptoms. The attribution of criminal blame to psychopathology also correlated negatively with denial of aggression $(r=-.32[-.54,-.07] p<.05$, two-tailed); 
patients who more strenuously falsely denied having had an argument or a physical fight with the victim of their offense, generally attributed less criminal blame to psychopathology.

The diagnostic value of an indicator (e.g., ASPD) for a target condition (e.g., symptom exaggeration) depends on the prevalence of the indicator among those with the condition as well as the prevalence of the condition among those with the indicator. Table 3.3 presents such data for several potential indicators of symptom exaggeration, including offense report inaccuracy, denial of offense, offense minimization, denial of aggression, lack of remorse, externalization of criminal blame, attribution of blame to psychopathology, and ASPD. We employed two thresholds for considering whether or not an indicator was present in a patient: The first thresholds were scores at or beyond the $80^{\text {th }}$ percentile of the score distribution of an indicator (or $\leq 20^{\text {th }}$ percentile if the indicator was hypothesized to correlate negatively with symptom exaggeration) and the second thresholds were scores $\geq 90^{\text {th }} / \leq 10^{\text {th }}$ score percentiles.

As shown in Table 3.3, all of the potential indicators of symptom exaggeration produce unacceptable error rates: False-positive predictions range from $60 \%$ to $100 \%$ and false-negative predictions range from $50 \%$ to $100 \%$. Fisher's exact tests computed for these data confirmed that symptom exaggeration was not associated with any of the potential indicators (all $p \mathrm{~s}>.09)$.

Table 3.3

Prevalence rates of symptom exaggeration (Structured Inventory of Malingered Symptomatology score >16) among patients with potential indicators of symptom exaggeration, and vice versa

\begin{tabular}{|c|c|c|c|c|}
\hline $\begin{array}{l}\text { Indicator of symptom } \\
\text { exaggeration (if score } \\
\geq 80^{\text {th-90 }}{ }^{\text {th }} \text { centile) }\end{array}$ & $\begin{array}{l}\text { Prevalence of symptom } \\
\text { exaggeration among } \\
\text { patients with indicator }\end{array}$ & $\begin{array}{l}\text { False } \\
\text { positive } \\
\text { predictions }\end{array}$ & $\begin{array}{l}\text { Prevalence of indicator } \\
\text { among patients who } \\
\text { exaggerate symptoms }\end{array}$ & $\begin{array}{l}\text { False } \\
\text { negative } \\
\text { predictions }\end{array}$ \\
\hline ASPD (if present) & $10 \%$ & $90 \%$ & $14 \%$ & $86 \%$ \\
\hline $\begin{array}{l}\text { Offense report } \\
\text { inaccuracy }\end{array}$ & $11-0 \%$ & $89-100 \%$ & $50-0 \%$ & $50-100 \%$ \\
\hline $\begin{array}{l}\text { Denial of offense } \\
\text { (if denial is complete) }\end{array}$ & $33 \%$ & $67 \%$ & $40 \%$ & $60 \%$ \\
\hline Offense minimization & $14-17 \%$ & $86-83 \%$ & $33-17 \%$ & $67-83 \%$ \\
\hline $\begin{array}{l}\text { Denial of aggression } \\
\text { (if denial is complete) }\end{array}$ & $8 \%$ & $92 \%$ & $25 \%$ & $75 \%$ \\
\hline $\begin{array}{l}\text { BAI Guilt (if score } \\
\leq 20^{\text {th }}-10^{\text {th }} \text { centile) }\end{array}$ & $9-0 \%$ & $91-100 \%$ & $14-0 \%$ & $86-100 \%$ \\
\hline BAI External & $25-40 \%$ & $75-60 \%$ & $43-29 \%$ & $57-71 \%$ \\
\hline BAI Mental & $9-0 \%$ & $91-100 \%$ & $14-0 \%$ & $86-100 \%$ \\
\hline
\end{tabular}

Note. ASPD $=$ antisocial personality disorder; BAI Guilt $=$ revised Gudjonsson Blame Attribution Inventory, Guilt scale; BAI External = revised Gudjonsson Blame Attribution Inventory, External scale; BAI Mental = revised Gudjonsson Blame Attribution Inventory, Mental scale. 


\section{Discussion}

Because deceitfulness is a core feature of ASPD, it may be attractive to consider ASPD a useful indicator of symptom exaggeration. The current findings do not support this notion: ASPD had no predictive value for symptom exaggeration. The predictive values of three features of ASPD that may link it with symptom exaggeration, namely deceitfulness (i.e., offense report inaccuracy, denial of offense, offense minimization, and denial of aggression), lack of remorse, and blame externalization, were trivial as well. Thus, the present data dispute the inclusion of ASPD among conditions that signal symptom exaggeration, and cast doubt on the assumptions that underlie the hypothesized relation between ASPD and malingering.

The data in Table 3.3 show that each of the potential indicators of symptom exaggeration is ineffective when used in isolation. To test whether the predictive value of the indicators increases when they are used jointly, we employed them in concert through a discriminant function analysis. This yielded a detection rate of symptom exaggeration of $29 \%$, which corresponds to a $71 \%$ false-negative rate. The average detection rate of the indicators individually is $29 \%$ at the $\geq 80^{\text {th }} / \leq 20^{\text {th }}$ percentile threshold and $16 \%$ at the $\geq 90^{\text {th }} / \leq$ $10^{\text {th }}$ percentile threshold (corresponding to $71 \%$ and $84 \%$ false-negative rates, respectively). Thus, there is little gain in detection rate when using the indicators in a joint analysis. This underscores the inefficacy of these variables (i.e., ASPD, offense report inaccuracy, denial of offense, offense minimization, denial of aggression, lack of remorse, externalization of criminal blame, and attribution of blame to psychopathology) as potential indicators of symptom exaggeration.

The only potential indicator that we found to be statistically significantly associated with symptom exaggeration is the attribution of criminal blame to external factors (such as social economic environment, victims, or society; $r=.31[.05, .53])$. This result mirrors that of an earlier study (Chapter 2, Study 2), where we found a modest relation between blame externalization and symptom exaggeration among internees of a youth prison $(N=45, r=.35$, $[.06, .59])$. Nevertheless, the strength of this association does not suffice to produce a satisfactory predictive value (43-29\% detection rate, $75-60 \%$ false-positive rate; see Table 3.3).

The most prominent limitation of the present study is arguably the small sample size: Of the 57 patients, 10 were diagnosed with ASPD, and seven produced SIMS scores suggestive of symptom exaggeration, only one of whom was diagnosed with ASPD. However, testifying to the reliability of these findings is that they echo the results that we reported earlier based on similar data we gathered at the same forensic psychiatric hospital (see Chapter 2, Study 1$)$. In that study $(N=57)$ there was no overlap between patients with ASPD $(n=9)$ and patients who engaged in symptom exaggeration $(n=5)$. In Chapter 2 we also point out that associations or effects need to be fairly large in order to be diagnostically relevant (i.e., Cohen's $d s \geq 1.2$ ). Small sample sizes (down to 54) are sufficient to detect such large effects, even if the prevalence of symptom exaggeration is low (e.g., 10\%). For example, 
in the present study, the achieved power in the comparison of SIMS scores between patients with ASPD $(n=10)$ and other patients $(n=47)$ is $.96(\alpha=.05$, one-tailed); in the same comparison between patients who denied aggression $(n=12)$ and other patients $(n=29)$ the attained power is also .96 ( $\alpha=.05$, one-tailed). Thus, the sample size of the present study, while small, suffices to detect any associations or effects that would be diagnostically useful.

Another limitation is that the causes of offense report inaccuracy cannot be determined. It could be that a portion of the offense report inaccuracies are genuine errors of memory (e.g., confabulations) rather than the intentional, goal-directed distortions (e.g., lies) that are hypothesized to be associated with ASPD. To differentiate deception from memory errors, future studies could employ deception detection techniques such as the Comparison Question Test and the Concealed Information Test (for more information, see, e.g., Meijer, Verschuere, Gamer, Merckelbach, \& Ben-Shakhar, 2016).

The results of the present study fit into the cadre of empirical research that dispels the notion of malingering or symptom exaggeration as a disposition that is related to antisocial traits. The "criminological model" of symptom exaggeration, as perpetuated in the DSM-5, does not hold against the mounting data that malingering, feigning, or exaggerating symptomatology is not driven by personality characteristics, antisocial or otherwise. For example, Young, Jacobson, Einzig, Gray, and Gudjonsson (2016) assessed 63 claimants of personal injury compensation, and found personality traits to lack any predictive value for feigned cognitive deficits.

Future research into the potential link between antisocial traits and symptom exaggeration may be worthwhile if, like the present study, it focusses on specific features of ASPD (and, by extension, psychopathy) rather than ASPD in general. However, the extant research weighs against personality characteristics being causal to symptom exaggeration such that it would arguably be more interesting to explore alternative avenues of research. One such avenue could be to explicitly examine the "adaptational model" proposed by Rogers (1990b), which posits that malingering is typically the result of a cost-benefit analysis prompted by situational variables (e.g., particular opportunities to obtain financial gain or escape responsibilities). Other angles that may be worth exploring are to conceptualize potential relationships between antisocial features and malingering in terms of socialcognitive processes that constitute malingering (e.g., Walczyk, Harris, Duck, \& Mulay, 2014) or beliefs characteristics that typify ASPD (e.g., Beck et al., 2001).

The take-home message of this study is that antisocial traits, including deceitfulness (which we assessed through offense report inaccuracy, denial of offense, offense minimization, and denial of aggression), lack of remorse, and blame externalization, are not meaningfully related to symptom exaggeration and therefore have no place in the assessment of symptom validity or the detection of malingering. In fact, employment of antisocial traits as indicators of symptom exaggeration should be eschewed, because the proportion of correct classifications will likely be heavily outweighed by the proportions of false-positive and false-negative results. In closing, we assert that the present study adds to the body of data that prove the DSM wrong to disregard decades of progress in symptom 
Chapter 3

validity assessment (e.g., see Merten et al., 2013) and ignore substantiated calls for change in the malingering criteria, such as that of Rogers (1992) for the DSM-IV, and Berry and Nelson (2010) for the DSM-5. 


\section{Chapter 4}

\section{The Structured Inventory of Malingered Symptomatology (SIMS): A systematic review and meta-analysis}

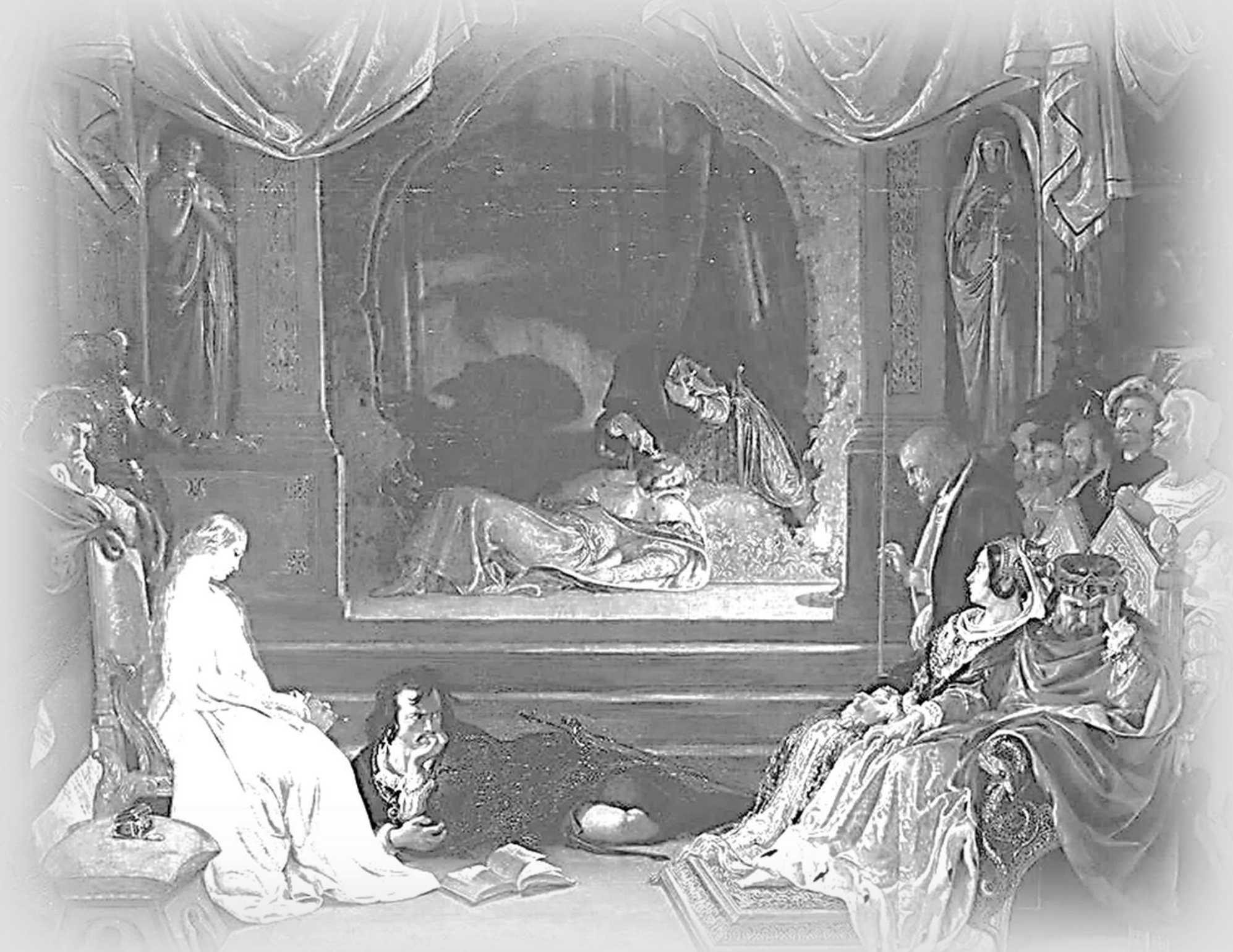

Published as:

van Impelen, A., Merckelbach, H., Jelicic, M., \& Merten, T. (2014). The Structured Inventory of Malingered Symptomatology (SIMS): A systematic review and meta-analysis. The Clinical Neuropsychologist, 28, 1336-1365. 


\begin{abstract}
We meta-analytically reviewed studies that used the Structured Inventory of Malingered Symptomatology (SIMS) to detect feigned psychopathology. We present weighted mean diagnostic accuracy and predictive power indices in various populations, based on 31 studies, including 61 subsamples and 4009 SIMS protocols. In addition, we provide normative data of patients, claimants, defendants, nonclinical adults, and various experimental feigners, based on 41 studies, including 125 subsamples and 4810 SIMS protocols. We conclude that the SIMS (1) is able to differentiate well between instructed feigners and honest responders; (2) generates heightened scores in groups that are known to have a raised prevalence of feigning (e.g., offenders who claim crime-related amnesia); (3) may overestimate feigning in patients who suffer from schizophrenia, intellectual disability, or psychogenic non-epileptic seizures; and (4) is fairly robust against coaching. The diagnostic power of the traditional cut scores of the SIMS (i.e., $>14$ and $>16$ ) is not so much limited by their sensitivity - which is satisfactory-but rather by their substandard specificity. This, however, can be worked around by combining the SIMS with other symptom validity measures and by raising the cut score, although the latter solution sacrifices sensitivity for specificity.
\end{abstract}




\section{Introduction}

In 1997 Smith and Burger introduced their Structured Inventory of Malingered Symptomatology (SIMS). Its name is misleading, but clearly reveals the ambition of the authors: The SIMS aims to detect feigned psychopathology. Its construction was guided by the idea that naïve respondents are likely to endorse bizarre, rare, atypical, or extreme symptoms on a questionnaire when they attempt to feign or exaggerate symptoms. Thus, the SIMS presents patients, claimants, defendants, or research participants with a list of 75 implausible symptoms or statements that are to be endorsed or rejected.

The SIMS covers a broad spectrum of pseudo-psychopathology. Its items allude to atypical depression, improbable memory problems, pseudo-neurological symptoms, doubtful claims of psychotic experiences, and hyperbolic signs of mental retardation. Each of these five categories is represented by a scale comprising 15 items. People may endorse some items, but those who claim to suffer from an abundance of SIMS items are thought to feign psychopathology. Smith and Burger (1997) recommended a cut score of $>14$ (i.e., scores exceeding 14 are considered to be positive test outcomes). The authors warned that the SIMS subscales are not suitable for detecting feigned psychopathology, and only serve to evaluate what type of psychopathology the respondent is trying to feign, once it has been established that the total SIMS score exceeds the cutoff.

In 2005, after the SIMS had been in use for a number of years, its manual was published (Widows \& Smith, 2005). Studies that had employed the SIMS to that date were summarized in the manual. Boone (2013), Wisdom, Callahan, and Shaw (2010; Table 1), and Smith (2008; Table 19.3) presented qualitative reviews of studies using the SIMS. In this article we take a meta-analytical approach to the extant SIMS literature. In contrast to previous reviews, we present a meta-analysis of diagnostic accuracies and predictive powers, and offer normative data of patients, claimants, defendants, nonclinical adults, and various experimental feigners. We focus on what these data tell us about the ability of the SIMS to discriminate between feigners and honest responders. We also discuss implications for the clinical utility of the SIMS and offer guidelines for clinical practice. Before doing so, we put the term "malinger test" (as the SIMS is often understood) into context.

Malingerers overreport pathological symptoms. They do so in a calculated attempt to obtain material gain or to escape formal duty or responsibility (see Diagnostic and Statistical Manual of Mental Disorders, 5th ed.; DSM-5; American Psychiatric Association, 2013). However, not everyone who overreports symptoms is a malingerer. Hence, there is no such thing as a "malinger test". While a test may indicate that a person overreports symptoms, it cannot clarify why he or she does so (see also Boone, 2007). Thus, the name of the SIMS is based on a misconception. It is more accurate to refer to the SIMS as a symptom validity test (SVT).

How proficient is the SIMS in detecting symptom over-endorsement? Several authors (e.g., Hartman, 2002) have commented on the qualities that SVTs such as the SIMS should possess. First and foremost, an SVT should differentiate accurately between honest 
respondents and people who are known to feign their symptoms. This requires high sensitivity (i.e., ability to identify feigners) as well as high specificity (i.e., ability to classify honest responders correctly). A second and related point is that an SVT should be sensitive to differential prevalence. That is, the SVT should generate higher scores for populations in which feigning is common, and lower scores for populations in which feigning is rare. A third requisite for SVTs is insensitivity to genuine psychopathology: Honest patients should not attain red flag scores on an SVT. A fourth quality indicator is robustness against coaching by, for example, lawyers. Other criteria stress that SVTs should be easy to administer and interpret, and that they ought to cover disabilities or symptoms that are likely targets for feigning. Ideally, an SVT resembles measures of genuine psychopathology (i.e., it should not be readily identifiable as an SVT). Lastly, the efficacy of an SVT should be based on reliable, up-to-date norms for nonclinical controls, honest patients, and known feigners (Hartman, 2002).

Below we review the SIMS literature and match the SIMS against these criteria. We conclude that while the SIMS might be a useful SVT, certain guidelines should be adopted. These include using optimal cut scores, exercising extra caution when administering the SIMS to certain clinical groups, and combining the SIMS with other SVTs and, ideally, with performance validity tests (PVTs), which measure underperformance in cognitive domains.

\section{Method}

Published studies that employed the SIMS were located by means of a computerized literature search with Google Scholar and EBSCO Discovery Service (PsycINFO). This search was conducted with "Structured Inventory of Malingered Symptomatology" and "SIMS" as entries. Studies published since the introduction of the SIMS (1997) up to the writing of this article (August 2014) were inspected. In addition to Anglo-Saxon articles, Dutch, German, and Spanish papers were included. Unpublished papers (e.g., dissertations) were not considered because they are not readily accessible to readers. Accordingly, five dissertations were not included. Additional studies were identified by contacting researchers who attended the Third European Symposium on Symptom Validity Assessment (see Plohmann \& Merten, 2013).

All identified studies that reported data concerning the diagnostic accuracy and/or predictive power of the SIMS in detecting symptom overreporting were included (i.e., no exclusions were made). These studies are listed in Table 4.1 (known-groups studies) and Table 4.2 (simulation studies). Weighted mean diagnostic accuracy and predictive power indices for both known-groups and simulation studies are presented in Table 4.3. Table 4.6 gives mean SIMS scores and effect sizes, based on studies that reported mean SIMS scores. In order to test whether language had a moderating effect, all studies were coded with respect to their language background. The effect sizes shown in Table 4.6 were calculated by employing a single pooled standard deviation. Data were analyzed with IBM SPSS Statistics 21 and Exploratory Software for Confidence Intervals (ESCI; see Cumming, 2012). 


\section{Results}

\section{Known-groups studies}

Table 4.1 summarizes SIMS data from 10 studies in which an external criterion was used to define samples of feigners and honest responders.

\section{Table 4.1}

Diagnostic accuracy of the Structured Inventory of Malingered Symptomatology in known-groups studies

\begin{tabular}{|c|c|c|c|c|c|c|c|c|}
\hline Authors & Sample & $N$ & Criterion & $\begin{array}{l}\text { Prevalence } \\
\text { of feigning }\end{array}$ & Cutoff & SN & SP & $\begin{array}{c}\text { Cohen's } \\
d\end{array}$ \\
\hline \multirow{2}{*}{$\begin{array}{l}\text { Alwes et al. } \\
(2008)\end{array}$} & Claimants & 308 & SIRS & $7 \%$ (psych.) & $>16$ & .96 & .67 & 2.6 \\
\hline & & & $\begin{array}{l}\text { TOMM, } \\
\text { VSVT, LMT }\end{array}$ & $24 \%$ (cogn.) & $>16$ & .75 & .60 & 1.1 \\
\hline \multirow{3}{*}{$\begin{array}{l}\text { Clegg et al. } \\
(2009)\end{array}$} & Claimants & 56 & SIRS & $31 \%$ & $>14$ & 1.00 & .37 & 1.6 \\
\hline & & & & & $>16$ & .95 & .51 & \\
\hline & & & & & $>19$ & .90 & .69 & \\
\hline \multirow[t]{2}{*}{$\begin{array}{l}\text { Edens et al. } \\
(2007)\end{array}$} & $\begin{array}{l}\text { Prisoners in } \\
\text { mental }\end{array}$ & 56 & SIRS & $45 \%$ & $>14$ & 1.00 & .52 & NR \\
\hline & health unit & & $\begin{array}{l}\text { CJ based on } \\
\text { SIRS strategies }\end{array}$ & $46 \%$ & $>14$ & .85 & .40 & \\
\hline \multirow{2}{*}{$\begin{array}{l}\text { G. Ordi, } \\
\text { S. Fernández, } \\
\text { B. Saiz et al. (2008) }\end{array}$} & Claimants & 305 & MMPI-2 & $10 \%$ & $>14$ & 1.00 & .61 & 2.1 \\
\hline & & & $\begin{array}{l}(F-K \geq 5 \text { or } \\
T \text { and } F>70)\end{array}$ & & $>16$ & .97 & .75 & \\
\hline \multirow{2}{*}{$\begin{array}{l}\text { G. Ordi } \\
\text { et al. (2010) }\end{array}$} & Patients on & 61 & \multirow{2}{*}{\multicolumn{2}{|c|}{ CJ based on Slick 56\% }} & $>14$ & .88 & .81 & 1.6 \\
\hline & sick leave & & & & $>16$ & .82 & .93 & \\
\hline $\begin{array}{l}\text { Heinze \& Purisch } \\
\text { (2001) }\end{array}$ & $\begin{array}{l}\text { Defendants } \\
\text { (IST) }\end{array}$ & 57 & $\begin{array}{l}\text { CJ by multi- } \\
\text { disciplinary team }\end{array}$ & $13 \%$ & $>13$ & .87 & $\mathrm{~N} / \mathrm{A}$ & $\mathrm{N} / \mathrm{A}$ \\
\hline $\begin{array}{l}\text { Lewis et al. } \\
(2002)\end{array}$ & Defendants & 55 & SIRS & $44 \%$ & $>16$ & 1.00 & .61 & 3.0 \\
\hline $\begin{array}{l}\text { Vitacco et al. } \\
(2007)\end{array}$ & Defendants & 100 & SIRS & $21 \%$ & $>14$ & 1.00 & .65 & 3.1 \\
\hline \multirow{3}{*}{$\begin{array}{l}\text { Vossler-Thies } \\
\text { et al. (2013) }\end{array}$} & Claimants & 95 & Slick & 31\% (def.) & $>16$ & NR & NR & $1.5^{\mathrm{b}}$ \\
\hline & & & & $22 \%$ (prob.) & $>16$ & & & $1.1^{\mathrm{b}}$ \\
\hline & & & & $53 \%$ (total) & & & & $1.3^{\mathrm{b}}$ \\
\hline \multirow{3}{*}{$\begin{array}{l}\text { Wisdom et al. } \\
(2010)\end{array}$} & Claimants & 33 & Slick & $67 \%$ & $>14$ & .96 & .64 & $2.0^{\mathrm{b}}$ \\
\hline & & & & (15\% def., & $>21$ & .68 & .73 & $1.5^{\mathrm{b}}$ \\
\hline & & & & $52 \%$ prob.) & $>24$ & .55 & 1.00 & $1.5^{\mathrm{b}}$ \\
\hline
\end{tabular}

Note. SN = sensitivity; SP = specificity; SIRS = Structured Interview of Reported Symptoms (Rogers et al., 1992); TOMM = Test of Memory Malingering (Tombaugh, 1996); VSVT = Victoria Symptom Validity Test (Slick, Hopp, Strauss, \& Thomson; 1997); LMT = Letter Memory Test (Inman et al., 1998); $\mathrm{NR}=$ not reported, insufficient data to calculate; $\mathrm{CJ}=$ clinical judgment; MMPI-2 = Minnesota Multiphasic Personality Inventory-Second Edition (Butcher et al., 2001); Slick = criteria for malingering as formulated by Slick, Sherman, and Iverson (1999); IST = incompetent to stand trial; $\mathrm{N} / \mathrm{A}=$ not applicable.

aBased on an initial sample of 438 defendants who were found incompetent to stand trial. ${ }^{\mathrm{b} C a l c u l a t e d}$ using available information. 
With the exception of González Ordi, Santamaría Fernández, and Fernández Marín (2010), samples consisted of individuals who were involved in legal procedures, be it as claimants in compensation cases, as defendants in criminal procedures, or as prisoners within a penal institution. In most studies, scores on the Structured Interview of Reported Symptoms (SIRS; Rogers, Bagby, \& Dickens, 1992) served as external criteria. The SIRS consists of 172 questions that cover multiple strategies to detect feigned psychopathology, such as absurd symptoms, unlikely combinations of symptoms, reported versus observed symptoms, and abnormal severity of symptoms. The SIRS has been well studied; the metaanalysis by Green and Rosenfeld (2011) yielded a sensitivity (i.e., the likelihood of a positive SVT result in feigners) of .49 and a specificity (i.e., likelihood of a negative SVT result in honest responders) of .95 for the SIRS.

The overall conclusion that can be drawn from Table 4.1 is that the SIMS is fairly effective in discriminating between feigning and honest responding groups: Effect sizes (Cohen's $d$ s) range from 1.1 to 3.0. The sensitivity for the commonly employed cutoffs (i.e., $>14$ and $>16$ ) is adequate, ranging from .75 to 1.00 . The corresponding specificity rates are highly divergent (range: .37 to .93), yet often alarmingly low; a serious point to which we will return below.

\section{Simulation studies}

Table 4.2 provides an overview of 24 simulation studies. Samples consisted predominantly of undergraduate students. In the majority of these studies participants were either asked to feign psychopathology or to respond honestly. In the feigning conditions participants were typically presented with a case vignette describing an individual with a salient and strong motive to feign pathological symptoms. Before being administered the SIMS, participants were prompted to identify with the main character in the case scenario and were asked to feign psychiatric or cognitive symptoms convincingly.

In most studies participants feigned symptoms on the basis of their own naïve views. However, some studies employed conditions in which participants were informed about credible and noncredible symptoms. Still other studies recruited participants who already possessed such knowledge by virtue of their professional or psychiatric background. A number of studies explicitly added a warning about validity tests and information about the rationale behind tests such as the SIMS. Providing participants with such technical information amounts to coaching, an issue that we will consider below.

The general conclusion that can be drawn from Table 4.2 is, again, that the SIMS does a reasonably good job in differentiating between experimental feigners and honest responders: Effect sizes (Cohen's $d \mathrm{~s}$ ) vary between .5 and 4.7 . The range of effect sizes is remarkably wide. This is in large part due to differences in type of control groups. Some studies employed patients as controls (e.g., González Ordi \& Santamaría Fernández, 2008; Graue et al., 2007; Peters, Jelicic, Moritz, Hausschildt, \& Jelinek, 2013), whereas others resorted to nonclinical controls. This variety in symptomatological levels will have 
contributed to differences in SIMS scores between control groups. Additionally, some conditions may render patients particularly susceptible to produce raised SIMS scores (e.g., intellectual disability; Graue et al., 2007; see below).

\section{Table 4.2}

Diagnostic accuracy of the Structured Inventory of Malingered Symptomatology in simulation studies

\begin{tabular}{|c|c|c|c|c|c|c|c|}
\hline Authors & Sample & $\begin{array}{l}\text { Experim. } \\
\text { feigners }\end{array}$ & $\begin{array}{l}\text { Honest } \\
\text { responders }\end{array}$ & Cutoff & $\mathrm{SN}$ & SP & $\begin{array}{l}\text { Cohen's } \\
\quad d\end{array}$ \\
\hline \multirow{2}{*}{$\begin{array}{l}\text { Cima, Hollnack, } \\
\text { et al. (2003) }\end{array}$} & Patients & - & 62 & $>16$ & $\mathrm{~N} / \mathrm{A}$ & .73 & $1.5^{\mathrm{a}}$ \\
\hline & Undergraduates & 135 & 69 & $>16$ & .87 & 1.00 & $2.0^{\mathrm{a}}$ \\
\hline $\begin{array}{l}\text { Dandachi-F. \& } \\
\text { Merckelbach (2013) }\end{array}$ & Undergraduates & 42 & 20 & $>16$ & .91 & 1.00 & $3.2^{\mathrm{a}}$ \\
\hline Edens et al. (1999) & Undergraduates & 196 & $196^{\mathrm{b}}$ & $>14$ & .96 & .91 & $3.0^{\mathrm{a}}$ \\
\hline Edens et al. (2007) & Nonclinical prisoners & 29 & 30 & $>14$ & .90 & .97 & NR \\
\hline \multirow[t]{3}{*}{ Giger et al. (2010) } & Nonclinical adults: & & & & & & \\
\hline & - Naïve & 20 & 20 & $>16$ & .95 & .95 & $2.9^{a}$ \\
\hline & - Warned of SVTs & 20 & - & $>16$ & .65 & $\mathrm{~N} / \mathrm{A}$ & $1.5^{\mathrm{a}}$ \\
\hline G. Ordi \& & Patients & - & 152 & $>14$ & .92 & .40 & 1.4 \\
\hline S. Fernández (2008) & Undergraduates & $326^{c}$ & - & $>16$ & .96 & .48 & \\
\hline G. Ordi, & Undergraduates & $326^{c}$ & 147 & $>14$ & .96 & .95 & 3.0 \\
\hline $\begin{array}{l}\text { S. Fernández, \& } \\
\text { M. Veiga (2008) }\end{array}$ & & & & $>16$ & .92 & .97 & \\
\hline \multirow[t]{2}{*}{ Graue et al. (2007) } & Intellectually disabled & - & 26 & $>16$ & $\mathrm{~N} / \mathrm{A}$ & .23 & .5 \\
\hline & Matched controls & 25 & 10 & $>16$ & .88 & NR & $1.3^{\mathrm{a}}$ \\
\hline \multirow[t]{5}{*}{ Jelicic et al. (2006) } & Undergraduates: & & & & & & \\
\hline & - Naïve & $15^{\mathrm{d}}$ & 15 & $>16$ & .93 & 1.00 & $3.2^{\mathrm{a}}$ \\
\hline & - Clinical knowledge & $15^{\mathrm{d}}$ & - & $>16$ & 1.00 & $\mathrm{~N} / \mathrm{A}$ & $3.0^{\mathrm{a}}$ \\
\hline & - Knowledge \& Warned & $15^{\mathrm{d}}$ & - & $>16$ & .80 & N/A & $2.6^{\mathrm{a}}$ \\
\hline & (Total) & $(45)$ & (15) & & $(.91)$ & $(1.00)$ & $(2.9)^{\mathrm{a}}$ \\
\hline \multirow[t]{4}{*}{ Jelicic et al. (2011) } & Undergraduates: & & & & & & \\
\hline & - Clinical knowledge & $29 \mathrm{~d}$ & 29 & $>16$ & .93 & 1.00 & $3.0^{\mathrm{a}}$ \\
\hline & - Knowledge \& Warned & $28^{d}$ & - & $>16$ & .86 & N/A & $3.2^{\mathrm{a}}$ \\
\hline & (Total) & $(47)$ & $(29)$ & & $(.89)$ & $(1.00)$ & $(3.1)^{\mathrm{a}}$ \\
\hline Jelicic, & Undergraduates: & & & & & & \\
\hline \multirow{2}{*}{$\begin{array}{l}\text { Merckelbach, } \\
\text { et al. (2007) }\end{array}$} & - Naïve & 30 & 30 & $>14$ & .90 & 1.00 & $2.8^{\mathrm{a}}$ \\
\hline & - Knowledge \& Warned & 30 & - & $>14$ & .90 & $\mathrm{~N} / \mathrm{A}$ & $2.3^{\mathrm{a}}$ \\
\hline
\end{tabular}

Note. $\mathrm{SN}$ = sensitivity; $\mathrm{SP}=$ specificity; $\mathrm{N} / \mathrm{A}=$ not applicable; $\mathrm{NR}=$ not reported, insufficient data to calculate; SVTs = symptom validity tests.

aCalculated using available information; bWithin-subjects (i.e., test-retest) design; ${ }^{\mathrm{c} T h e}$ data of this group were employed by both González Ordi and Santamaría Fernández (2008) and González Ordi, Santamaría Fernández, and Matalobos Veiga (2008); dThe difference in mean SIMS scores between these groups was not statistically significant $(p>.05)$. 
Chapter 4

Table 4.2 (continued)

Diagnostic accuracy of the Structured Inventory of Malingered Symptomatology in simulation studies

\begin{tabular}{|c|c|c|c|c|c|c|c|}
\hline Authors & Sample & $\begin{array}{l}\text { Experim. } \\
\text { feigners }\end{array}$ & $\begin{array}{l}\text { Honest } \\
\text { responders }\end{array}$ & Cutoff & SN & SP & $\begin{array}{c}\text { Cohen's } \\
d\end{array}$ \\
\hline $\begin{array}{l}\text { Jelicic, Peters, } \\
\text { et al. (2007) }\end{array}$ & $\begin{array}{l}\text { Undergraduates: } \\
\text { - Naïve } \\
\text { - Clinical knowledge }\end{array}$ & $\begin{array}{l}30 \\
31\end{array}$ & $\begin{array}{l}30^{\mathrm{a}} \\
31^{\mathrm{a}}\end{array}$ & $\begin{array}{l}>16 \\
>16\end{array}$ & $\begin{array}{r}.97 \\
1.00\end{array}$ & $\begin{array}{l}1.00 \\
1.00\end{array}$ & $\begin{array}{l}4.1^{\mathrm{b}} \\
3.4^{\mathrm{b}}\end{array}$ \\
\hline Jelicic et al. (2013) & $\begin{array}{l}\text { Clinical experts } \\
\text { Undergraduates }\end{array}$ & $\begin{array}{l}23 \\
24\end{array}$ & $\begin{array}{l}23^{\mathrm{a}} \\
24^{\mathrm{a}}\end{array}$ & $\begin{array}{l}>16 \\
>16\end{array}$ & $\begin{array}{l}.87 \\
.96\end{array}$ & $\begin{array}{l}1.00 \\
1.00\end{array}$ & $\begin{array}{l}2.4^{\mathrm{b}} \\
3.7^{\mathrm{b}}\end{array}$ \\
\hline $\begin{array}{l}\text { Merckelbach \& } \\
\text { Collaris (2012) }\end{array}$ & $\begin{array}{l}\text { Undergraduates: } \\
\text { - Naïve } \\
\text { - Warned of SVTs } \\
\text { - Primed for honesty } \\
\text { (Total) }\end{array}$ & $\begin{array}{c}15^{\mathrm{c}} \\
15^{\mathrm{c}} \\
15^{\mathrm{c}} \\
(45)\end{array}$ & $\begin{array}{c}15 \\
15 \\
15 \\
(45)\end{array}$ & $\begin{array}{l}>16 \\
>16 \\
>16\end{array}$ & $\begin{array}{l}\text { NR } \\
\text { NR } \\
\text { NR } \\
(.76)\end{array}$ & $\begin{array}{c}\text { NR } \\
\text { NR } \\
\text { NR } \\
(1.00)\end{array}$ & $\begin{array}{c}2.1^{\mathrm{b}} \\
2.3^{\mathrm{b}} \\
2.3^{\mathrm{b}} \\
(2.2)^{\mathrm{b}}\end{array}$ \\
\hline $\begin{array}{l}\text { Merckelbach \& } \\
\text { Smith (2003) }\end{array}$ & $\begin{array}{l}\text { Patients } \\
\text { Undergraduates } \\
\text { (Total) }\end{array}$ & $\begin{array}{l}- \\
57 \\
(57)\end{array}$ & $\begin{array}{c}10 \\
231 \\
(241)\end{array}$ & $\begin{array}{l}>16 \\
>16\end{array}$ & $\begin{array}{l}\mathrm{N} / \mathrm{A} \\
.93 \\
(.93)\end{array}$ & $\begin{array}{l}\mathrm{NR} \\
\mathrm{NR} \\
(.98)\end{array}$ & $\begin{array}{l}2.1^{\mathrm{b}} \\
4.7^{\mathrm{b}} \\
(4.7)\end{array}$ \\
\hline Merten et al. (2008) & $\begin{array}{l}\text { Nonclinical adults: } \\
\text { - Naïve } \\
\text { - Warned of SVTs }\end{array}$ & $\begin{array}{l}16 \\
16\end{array}$ & $\begin{array}{l}- \\
-\end{array}$ & $\begin{array}{l}>16 \\
>16\end{array}$ & $\begin{array}{l}.94 \\
.63\end{array}$ & $\mathrm{~N} / \mathrm{A}$ & $\mathrm{N} / \mathrm{A}$ \\
\hline
\end{tabular}

Note. $\mathrm{SN}=$ sensitivity; $\mathrm{SP}=$ specificity; $\mathrm{NR}=$ not reported, insufficient data to calculate; SVTs = symptom validity tests; N/A = not applicable.

aWithin-subjects (i.e., test-retest) design; ${ }^{b}$ Calculated using available information; ${ }^{c}$ The difference in mean SIMS scores between these groups was not statistically significant $(p>.05)$.

As can be seen in Table 4.6 later, nonclinical controls tend to produce significantly lower SIMS scores than patient controls, meaning that the SIMS is sensitive to genuine psychopathology. This inflates effect sizes and specificity values (see also Table 4.3). In nonclinical control groups specificity rates of commonly used cutoffs (i.e., $>14$ and $>16$ ) vary from .88 to 1.00 , whereas in patient controls they range from .23 to .83 . Compared with specificity rates, sensitivity rates are more satisfactory and less diverse across studies. Table 4.2 lists sensitivity rates for simulation studies, which ranged from .87 to 1.00 for naïve (i.e., noncoached) groups.

\section{Robustness against coaching}

Several studies tested whether the sensitivity of the SIMS to detect feigning is undermined by knowledge about psychopathology and/or advise to beware of symptom validity testing. These studies are also listed in Table 4.2, and their accumulated data are displayed in Table 4.3 .

The general finding is that being knowledgeable about psychopathology does little to undermine the sensitivity of the SIMS. In contrast, forewarning of symptom validity testing or advice against excessive feigning undermines sensitivity: When individuals were 
forewarned about SVTs, a cut score of $>16$ yielded a sensitivity of only .72 . Furthermore, clinical knowledge interacts significantly with forewarning, but in a counterintuitive way. That is, knowledge about psychopathology reduces the sensitivity-undermining effect of forewarning by approximately one third.

The SIMS attempts to detect overreporting of psychopathology, which is radically different from the type of symptom validity assessed by PVTs. PVTs such as the Amsterdam Short-Term Memory test (ASTM; Schagen, Schmand, de Sterke, \& Lindeboom, 1997), the Test of Memory Malingering (TOMM; Tombaugh, 1996), and the Word Memory Test (WMT; Green, 2003) focus on cognitive dysfunction and measure underperformance on cognitive tests. Nonetheless, SIMS scores are significantly elevated in groups that are instructed to feign cognitive deficits. For example, the SIMS attained a higher sensitivity than the ASTM among respondents who were coached and asked to feign cognitive impairment (detection rates of .90 and .70, respectively; Jelicic, Merckelbach, Candel, \& Geraerts, 2007). The sensitivity of the SIMS matched that of the ASTM in a study on the effects of forewarning among experimental feigners of cognitive dysfunction (Giger, Merten, Merckelbach, \& Oswald, 2010). In addition, Jelicic, Ceunen, Peters, and Merckelbach (2011) found the SIMS to be as sensitive as the TOMM when coached feigners simulated cognitive problems (detection rates of .87 and .86 , respectively). In a simulation study by Merten, Diederich, and Stevens (2008), the SIMS was more sensitive in detecting feigned whiplash injury symptoms than the WMT. Yet, in forewarned participants it showed a drop of .31 in detection rate, while the WMT was largely resistant against forewarning. Moreover, $69 \%$ of research participants were able to identify the SIMS as an instrument that assesses symptom validity, as opposed to $56 \%$ who were able to identify the WMT as such (Merten et al., 2008). In another study, however, only $16 \%$ of the participants suspected the SIMS to be a measure of symptom validity, while $28 \%$ voiced such suspicion about the WMT (Merten, Lorenz, \& Schlatow, 2010)

These divergent findings illustrate that estimates of sensitivity, transparency, and robustness against coaching depend on the experimental procedures that participants are subjected to. The sensitivity of the SIMS to feigned cognitive dysfunction might be largely due to the tendency of some feigners to overgeneralize and simulate psychopathology in addition to cognitive deficits. However, except for low intelligence, the SIMS does not address specific feigned cognitive deficits. Thus, regardless of its potential sensitivity, the SIMS cannot be relied upon to detect feigned cognitive impairment.

\section{Diagnostic accuracy}

Table 4.3 shows weighted mean diagnostic accuracy and predictive power of the SIMS for known-groups research (Table 4.1) and simulation studies (Table 4.2). Table 4.3 allows for the following conclusions. To begin with, using a cut score of $>14$ (as recommended by Smith \& Burger, 1997) results in a sensitivity that circles around .97. Even when the cutoff is raised to $>16$, the sensitivity of the SIMS to detect feigned symptoms, such as displayed by 
defendants attempting to feign insanity or incompetency to stand trial, remains excellent (i.e., above .90). The sensitivity rates in experimental feigners (Table 4.2) are similar to those in claimants (Table 4.1). This suggests that experimental feigners are a valid model for claimants and defendants who feign symptoms; a point that is further elaborated upon below.

Second, specificity rates in samples of honest patients, claimants, and defendants using cut scores of $>14$ and $>16$ varied extensively ( .37 to .70 ) and indicate that the SIMS can yield high false-positive rates in these groups (i.e., misclassify honest responders as feigners). Specificity rates in groups of nonclinical controls are high, but not perfect, which is disappointing given that these respondents presumably do neither feign nor experience any form of psychopathology. The marked difference in specificity rates between clinical and nonclinical controls underscores the importance of employing samples of honest patients, claimants, or defendants as control groups when estimating diagnostic accuracy indices of SVTs.

Third, although some studies found that control patients with psychotic symptoms score relatively low on the SIMS (e.g., Vitacco, Rogers, Gabel, \& Munizza 2007), other studies noted that the diagnostic accuracy of the SIMS appears to be limited in patients with schizophrenia (Peters et al., 2013) and individuals who suffer from psychogenic non-epileptic seizures (Benge et al., 2012) or intellectual disability (Graue et al., 2007). The nontrivial proportion of patients with scores above the cutoff suggests that the lack of specificity is overly pronounced in these clinical groups.

Estimates of the diagnostic accuracy of the SIMS are dependent on the criteria that are employed to compose groups of feigners and honest responders. The majority of knowngroups studies employed the SIRS as sole external criterion, but this instrument possesses suboptimal sensitivity. Because of this, groups of honest responders may contain a substantial proportion of false negatives (i.e., feigners who are erroneously classified as honest responders; on average 51\%; Green \& Rosenfeld, 2011). This may lead to an overestimation of the sensitivity of the SIMS (because the SIMS is not faulted for failing to label false negatives of the SIRS as hits) and an underestimation of specificity (as the SIMS is considered to be incorrect when it does identify false negatives of the SIRS as hits).

A related problem with using the SIRS as a criterion is the similarity in detection strategies between the SIMS and the SIRS. Both instruments focus on the endorsement of bizarre, extreme, or atypical symptoms, which is reflected in the significant correlations between the SIMS and the SIRS (e.g., $r=.54$, Freeman, Powell, \& Kimbrell, 2008; and $r=.81$, Edens, Poythress, \& Watkins-Clay, 2007). Thus, the diagnostic errors of the SIMS may mirror those of the SIRS, which might lead to an overestimation of the diagnostic accuracy of the SIMS. 


\section{Predictive power}

Diagnostic accuracy (i.e., sensitivity and specificity) is only one part of the equation that describes the efficacy of a diagnostic instrument. The other part is predictive power, which depends on both diagnostic accuracy and the prior probability (i.e., prevalence, or base rate) of test results. Where diagnostic accuracy denotes the probability of a certain test outcome given the true status of an individual, predictive power refers to the probability of the true status of an individual given a certain test outcome. Thus, the practical implications of particular SIMS cutoffs cannot be evaluated without taking the base rate of feigning into account.

Table 4.3 shows predictive power for base rates of $10 \%, 30 \%$, and $50 \%$.

\section{Table 4.3}

Weighted mean diagnostic accuracy and predictive power of the Structured Inventory of Malingered Symptomatology (SIMS) in various samples, based on 31 studies, including 61 subsamples and 4009 SIMS protocols

\begin{tabular}{|c|c|c|c|c|c|c|c|c|c|c|c|}
\hline \multirow[t]{2}{*}{ Population } & \multirow[t]{2}{*}{ Samples } & \multirow[t]{2}{*}{$N$} & \multirow[t]{2}{*}{ Cutoff } & \multirow[t]{2}{*}{ SN } & \multirow[t]{2}{*}{ SP } & \multicolumn{3}{|c|}{$\begin{array}{c}\text { PPP } \\
\text { at base rate: }\end{array}$} & \multicolumn{3}{|c|}{$\begin{array}{c}\text { NPP } \\
\text { at base rate: }\end{array}$} \\
\hline & & & & & & $10 \%$ & $30 \%$ & $50 \%$ & $10 \%$ & $30 \%$ & $50 \%$ \\
\hline Claimants & 4 & 455 & $>14$ & .98 & .61 & .22 & .52 & .72 & 1.00 & .99 & .97 \\
\hline (Known-groups) & 4 & 730 & $>16$ & .91 & .70 & .25 & .57 & .75 & .99 & .95 & .89 \\
\hline Defendants & 2 & 156 & $>14$ & 1.00 & .60 & .22 & .52 & .71 & 1.00 & 1.00 & 1.00 \\
\hline (Known-groups) & 2 & 108 & $>16$ & $1.00^{\mathrm{a}}$ & .67 & .25 & .56 & .75 & 1.00 & 1.00 & 1.00 \\
\hline Honest patients & $\begin{array}{l}2 \\
5^{c}\end{array}$ & $\begin{array}{l}206 \\
377\end{array}$ & $\begin{array}{l}>14 \\
>16\end{array}$ & N/A & $\begin{array}{l}.37 \\
.59\end{array}$ & $\begin{array}{l}.15^{\mathrm{b}} \\
.20^{\mathrm{d}}\end{array}$ & $\begin{array}{l}.40^{\mathrm{b}} \\
.49^{\mathrm{d}}\end{array}$ & $\begin{array}{l}.61^{\mathrm{b}} \\
.69^{\mathrm{d}}\end{array}$ & $\begin{array}{l}.99^{\mathrm{b}} \\
.99^{\mathrm{d}}\end{array}$ & $\begin{array}{l}.97^{\mathrm{b}} \\
.95^{\mathrm{d}}\end{array}$ & $\begin{array}{l}.93^{\mathrm{b}} \\
.88^{\mathrm{d}}\end{array}$ \\
\hline Nonclinical adults & 10 & $1222^{\mathrm{e}}$ & $>14$ & .96 & .93 & .60 & .85 & .93 & 1.00 & .98 & .96 \\
\hline (Experimental groups) & 25 & $1487^{\mathrm{f}}$ & $>16$ & .92 & .99 & .91 & .98 & .99 & .99 & .97 & .93 \\
\hline $\begin{array}{l}\text { Experimental feigners: } \\
\text { - Clinical knowledge }\end{array}$ & 6 & 171 & $>16$ & .87 & N/A & $.22 \mathrm{~g}$ & $.52 \mathrm{~g}$ & $.72 \mathrm{~g}$ & $.98 \mathrm{~s}$ & $.92 \mathrm{~g}$ & $.84 \mathrm{~g}$ \\
\hline $\begin{array}{l}\text { Experimental feigners: } \\
\text { - Warned of SVTs }\end{array}$ & 3 & 56 & $>16$ & .72 & N/A & $.19 \mathrm{~g}$ & $.48 \mathrm{~g}$ & $.68^{g}$ & $.95 \mathrm{~g}$ & $.85 \mathrm{~g}$ & $.70 \mathrm{~g}$ \\
\hline $\begin{array}{l}\text { Experimental feigners: } \\
\text { - Knowledge + Warned }\end{array}$ & 4 & 88 & $>16$ & .82 & N/A & $.21 \mathrm{~g}$ & $.51^{\mathrm{g}}$ & $.71 \mathrm{~g}$ & $.97 \mathrm{~g}$ & $.90 \mathrm{~g}$ & $.79 g$ \\
\hline
\end{tabular}

Note. $\mathrm{SN}=$ sensitivity; $\mathrm{SP}=$ specificity; $\mathrm{PPP}=$ positive predictive power; $\mathrm{NPP}=$ negative predictive power; N/A = not applicable; SVTs = symptom validity tests. The data summarized in this table are based on 3652 individuals who-due to within-subject (i.e., test-retest) designs - contributed 4009 SIMS protocols. The studies by Heinze and Purisch (2001) and Rogers, Jackson, and Kaminski (2005) could not be included in this table: The former because it reported only data for a cutoff of $>13$; the latter for the reason that it did not report diagnostic accuracy data.

aBased on 1 sample, 55 subjects. ${ }^{b}$ Calculated by assuming a sensitivity for feigning responders of .97 (the weighted mean sensitivity of cut score $>14$ for experimental feigners and feigning claimants and defendants). ${ }^{c}$ The honesty of these patients is assumed, but not established through symptom validity testing. ${ }^{\mathrm{d} C a l c u l a t e d}$ by assuming a sensitivity for feigning responders of .92 (the weighted mean sensitivity of cut score $>16$ for experimental feigners and feigning claimants and defendants). ${ }^{\text {eThis }}$ sample includes 789 SIMS protocols of experimental feigners and 433 SIMS scores of nonclinical

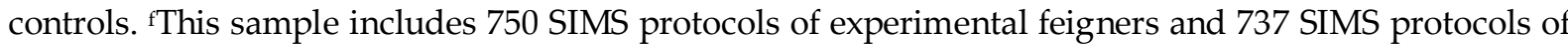

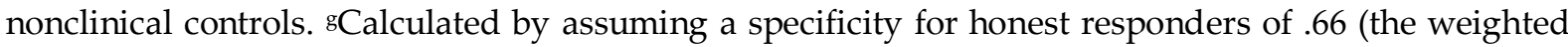
mean specificity of cut score $>16$ for honest patients, claimants, and defendants). 
As evidenced in Table 4.3, higher base rates lead to greater positive predictive power (i.e., probability of feigning if SVT outcome is positive) for a given cutoff, whereas lower base rates lead to a greater negative predictive power (i.e., probability of honest responding if SVT outcome is negative). The negative predictive power for cut scores of $>14$ and $>16$ is excellent, even at base rates of up to $50 \%$. That is, the likelihood that an individual does not feign symptoms if his or her SIMS score remains below the cutoff is very high. What is more, negative predictive power decreases only slightly as base rate increases, especially if a cutoff of $>14$ is employed. On the other hand, the likelihood that an individual feigns symptoms if his or her SIMS score exceeds the cutoff varies considerably depending on the base rate of feigning in his or her population. Overall, the positive predictive power for cut scores of $>14$ and also $>16$ is rather low, and drops quickly as base rates fall. This implies that in populations where feigning is rare, the probability of false-positive identifications is high, even when a cut score of $>16$ is employed. Note that positive predictive power is markedly higher among nonclinical respondents than in patient populations. As said earlier, the SIMS is sensitive to genuine psychopathology, and can overestimate feigning in patients.

\section{Sensitivity to differential prevalence}

Table 4.4 provides an overview of five studies that employed a differential design to explore the qualities of the SIMS.

\section{Table 4.4}

Differential prevalence of Structured Inventory of Malingered Symptomatology scores in clinical and forensic samples

\begin{tabular}{|c|c|c|c|c|c|c|}
\hline Authors & Sample & $N$ & Cutoff & $\begin{array}{l}\text { Prevalence of } \\
\text { SIMS scores } \\
\text { beyond cutoff }\end{array}$ & $\begin{array}{l}\text { Mean } \\
\text { SIMS } \\
\text { score }\end{array}$ & $\begin{array}{l}\text { Cohen's } \\
\quad d\end{array}$ \\
\hline \multirow[t]{2}{*}{$\begin{array}{l}\text { Benge et al. } \\
(2012)\end{array}$} & $\begin{array}{l}\text { Patients with psychogenic } \\
\text { nonepileptic seizures }\end{array}$ & 91 & $>16(>19)$ & $71 \%(59 \%)$ & 22.4 & \multirow[t]{2}{*}{$.8^{* * * a}$} \\
\hline & $\begin{array}{l}\text { Patients with epileptic } \\
\text { seizures }\end{array}$ & 29 & & $31 \%(17 \%)$ & 14.4 & \\
\hline \multirow{3}{*}{$\begin{array}{l}\text { Cima \& van } \\
\text { Oorsouw } \\
\text { (2013) } \\
\text { Chen et al. } \\
(2011)\end{array}$} & $\begin{array}{l}\text { Prisoners claiming crime- } \\
\text { related amnesia }\end{array}$ & 12 & $>16$ & $33 \%$ & 12.5 & \multirow[t]{2}{*}{$.8^{* *}$} \\
\hline & Nonamnestic prisoners & 19 & & $5 \%$ & 6.9 & \\
\hline & $\begin{array}{l}\text { Successful vs. unsuccessful } \\
\text { placebo-induced seizures in } \\
\text { patients with psychogenic } \\
\text { nonepileptic seizures }\end{array}$ & 51 & $>14$ & $\begin{array}{l}\text { Successful 80\%* } \\
\text { Unsuccessful 33\%* }\end{array}$ & NR & NR \\
\hline \multirow{2}{*}{$\begin{array}{l}\text { Capilla Ramírez } \\
\text { et al. (2008) }\end{array}$} & Fibromyalgia claimants & 30 & \multirow[t]{2}{*}{$>16$} & $80 \%$ & 25.5 & $2.5^{* * * a}$ \\
\hline & $\begin{array}{l}\text { Chronic pain claimants } \\
\text { Chronic pain nonclaimants }\end{array}$ & $\begin{array}{l}30 \\
25\end{array}$ & & $\begin{array}{l}\text { NR } \\
\text { NR }\end{array}$ & $\begin{array}{r}14.1 \\
6.9\end{array}$ & $1.0^{* * * a}$ \\
\hline $\begin{array}{l}\text { van Beilen et al. } \\
\text { (2009) }\end{array}$ & $\begin{array}{l}\text { Psychogenic patients } \\
\text { Neurological patients } \\
\text { Nonclinical controls }\end{array}$ & $\begin{array}{l}26 \\
26 \\
18\end{array}$ & $>16$ & $\begin{array}{r}23 \% \\
4 \% \\
0 \%\end{array}$ & $\begin{array}{r}11.5 \\
7.8 \\
4.6\end{array}$ & $\begin{array}{r}1.3^{* * a} \\
.6^{* * * a}\end{array}$ \\
\hline
\end{tabular}

Note. $\mathrm{NR}=$ Not reported, insufficient data to calculate.

${ }^{a}$ Calculated using available information.

${ }^{*} p<.05 .{ }^{* *} p<.01 .{ }^{* * *} p<.001$. 
The samples displayed in Table 4.4 vary from neurological patients and fibromyalgia litigants to prisoners who claim crime-related amnesia. The idea that feigned psychopathology is more prevalent among patients who report psychogenic complaints than among patients with neurological symptoms is prima facie plausible. The same holds for the assumption that feigning is more common among defendants who claim crime-related amnesia than it is among defendants without such claims. Similarly, it is safe to assume that feigning occurs more frequently among litigants than among nonlitigants.

Table 4.4 illustrates that the mean SIMS score of litigants is substantially higher than that of nonlitigating patients (Capilla Ramírez, González Ordi, \& Santamaría Fernández, 2008). Furthermore, SIMS scores above the cutoff are more prevalent in samples of patients with psychogenic complaints or crime-related amnesia by an average factor of 4.9 in comparison with relevant control groups. Taken together, the data suggest that the SIMS is sensitive to differential prevalence. Moreover, this sensitivity seems to manifest itself more strongly as the cutoff is raised (Benge et al., 2012).

\section{Correlations with clinical scales and other SVTs}

Table 4.5 lists Pearson product-moment correlations between SIMS scores and scores on other psychological instruments. It warrants the following conclusions. First, respondents who endorse many symptoms on the SIMS also report many symptoms on standard clinical inventories: There are moderate correlations ( $r \mathrm{~s}=.50$ to .72$)$ between the SIMS and symptom measures such as the Symptom Checklist-90-Revised (SCL-90-R; Derogatis, 1994) and the Beck Depression Inventory (BDI; Beck, Ward, Mendelson, Mock, \& Erbaugh, 1961).

Second, the correlations between the SIMS and PVTs (ASTM; Schagen et al., 1997; Morel Emotional Numbing Test, MENT; Morel, 1998; WMT; Green, 2003) are weak to moderate ( $r$ s vary from .22 to .49). Assessment of symptom validity should ideally include multiple SVTs, and preferably SVTs that are independent (i.e., correlate weakly with each other; Larrabee, 2008, 2014; Victor, Boone, Serpa, Buehler, \& Ziegler, 2009). With this in mind, the correlations listed in Table 4.5 suggest that the combination of SIMS and ASTM is less redundant compared with that of SIMS and WMT.

A final point is the interpretation of SIMS scores that exceed the cutoff. In the studies listed in Tables 4.4 and 4.5, two extremes can be found. Some authors employ the SIMS as a definitive "malinger test" and treat scores above the cutoff as conclusive evidence of feigned psychopathology (e.g., Kunst, Winkel, \& Bogaerts, 2011). Others consider heightened SIMS scores to be a manifestation of somatization (e.g., Benge et al., 2012). Both interpretations are questionable. The first position is dubious because heightened SIMS scores do not necessarily reflect malingering. Elevated SIMS scores may also signal feigned psychopathology as found in factitious disorder or they might be the result of yea-saying to the test items. Such irrelevant responding can stem from frustration, boredom, defiance, or fatigue, without flagging feigning per se (see Meade \& Craig, 2012). 
The second interpretation assumes that somatoform disorders are superordinate in relation to feigning. There is no empirical evidence for this assumption, and the opposite idea-intentional feigning eventually contributing to somatoform symptoms-can be defended equally forcefully (Merten \& Merckelbach, 2013b; see also Rogers, Jackson, \& Kaminski, 2005).

\section{Table 4.5}

Pearson product-moment correlations between Structured Inventory of Malingered Symptomatology scores and scores of other instruments

\begin{tabular}{|c|c|c|c|c|c|c|}
\hline Authors & Sample & $N$ & $\begin{array}{l}\text { Prevalence } \\
\text { of feigning }\end{array}$ & Measure & $r$ SIMS & $\begin{array}{l}\text { Shared } \\
\text { variance }\end{array}$ \\
\hline \multirow[t]{2}{*}{$\begin{array}{l}\text { Cima \& van } \\
\text { Oorsouw (2013) }\end{array}$} & $\begin{array}{l}\text { Prisoners claiming } \\
\text { crime-related amnesia }\end{array}$ & 12 & $33 \%$ & \multirow[t]{2}{*}{ PPI } & \multirow[t]{2}{*}{.44} & \multirow[t]{2}{*}{$19 \%$} \\
\hline & Nonamnestic prisoners & 19 & $5 \%$ & & & \\
\hline $\begin{array}{l}\text { Dandachi-F. et al. } \\
\text { (2011) }\end{array}$ & Psychiatric outpatients & 183 & $21 \%$ & ASTM & $-.22^{a}$ & $5 \%$ \\
\hline Edens et al. (2007) & $\begin{array}{l}\text { Prisoners in Mental } \\
\text { Health Unit }\end{array}$ & 56 & $45 \%$ & SIRS & .81 & $66 \%$ \\
\hline $\begin{array}{l}\text { Freeman et al. } \\
\text { (2008) }\end{array}$ & Veterans with PTSD & 74 & $53 \%$ & SIRS & .54 & $29 \%$ \\
\hline Kunst et al. (2011) & $\begin{array}{l}\text { Claimants victim } \\
\text { services }\end{array}$ & 125 & $18 \%$ & PTSD & .67 & $45 \%$ \\
\hline \multirow{2}{*}{$\begin{array}{l}\text { Merten, Friedel, } \\
\text { Mehren, \& Stevens } \\
\text { (2007) }\end{array}$} & \multirow{2}{*}{$\begin{array}{l}\text { Claimants workers' } \\
\text { compensation }\end{array}$} & \multirow[t]{2}{*}{93} & \multirow[t]{2}{*}{$26 \%$} & BDI & .72 & $52 \%$ \\
\hline & & & & WMT & $-.44^{a}$ & $19 \%$ \\
\hline \multirow[t]{2}{*}{ Merten et al. (2009) } & \multirow{2}{*}{$\begin{array}{l}\text { Claimants workers' } \\
\text { compensation }\end{array}$} & \multirow[t]{2}{*}{61} & \multirow[t]{2}{*}{$51 \%$} & MENT & .36 & $13 \%$ \\
\hline & & & & WMT & $-.49^{a}$ & $24 \%$ \\
\hline \multirow{3}{*}{$\begin{array}{l}\text { van Beilen et al. } \\
\text { (2009) }\end{array}$} & Psychogenic patients & 26 & $23 \%$ & \multirow[t]{3}{*}{ SCL-90-R } & .70 & $49 \%$ \\
\hline & Neurological patients & 26 & $4 \%$ & & .50 & $25 \%$ \\
\hline & Nonclinical controls & 18 & $0 \%$ & & $n s$ & \\
\hline
\end{tabular}

Note. PPI = Psychopathic Personality Inventory (Lilienfeld \& Andrews, 1996); ASTM = Amsterdam Short-Term Memory test (Schagen et al., 1997); SIRS = Structured Interview of Reported Symptoms (Rogers et al., 1992); PTSD = Posttraumatic Stress Disorder symptoms; BDI = Beck Depression Inventory (Beck et al., 1961); WMT $=$ Word Memory Test $($ Green, 2003). MENT $=$ Morel Emotional Numbing Test (Morel, 1998); SCL-90-R = Symptom Checklist-90-Revised (Derogatis, 1994); $n s=$ not statistically significant.

aNegative correlation is due to the inverse scoring direction of the two instruments.

\section{SIMS subscales}

Feigning may take on many forms. One advantage of the SIMS is that it comprises five nonoverlapping scales that cover diverse types of pseudo-psychopathology: Psychosis, Neurological impairment, Amnestic disorders, Low intelligence, and Affective disorders. 
However, the diagnostic accuracy indices of these subscales are inferior to that of the SIMS Total score. Among various experimental samples, the original cutoffs of the subscales produced sensitivity rates between .66 and 1.00 and specificity rates between .73 and .93, with two notable exceptions: The sensitivity of the Psychosis scale, the lowest of which was .57 and the specificity of the Low intelligence scale, the lowest of which was .52 (Edens, Otto, \& Dwyer, 1999; Smith \& Burger, 1997). However, these diagnostic accuracy rates are based on nonclinical controls and therefore overestimate specificity values as found in clinical samples.

The sensitivity of the subscales seems to be largely dependent on the type of symptoms that are feigned. The closer the match between the type of psychopathology a respondent tries to feign and the type of pseudo-psychopathology that a subscale targets, the higher the sensitivity of the subscale (Merckelbach \& Smith, 2003; Smith \& Burger, 1997; but see Edens et al., 1999, Table 3). While the sensitivity of a SIMS subscale might thus benefit from certain contexts, it rarely exceeds that of the SIMS Total score. Subscales that attain high sensitivity when confronted with their target psychopathology are Affective disorders, Neurological impairment, and Amnestic disorders (Benge et al., 2012; Clegg, Fremouw, \& Mogge, 2009; Giger et al., 2010). The Low intelligence scale remains relatively insensitive to explicit attempts to mimic poor intellectual abilities (Clegg et al., 2009).

Cronbach's alpha coefficients (taken to be measures of internal consistency, but see Sijtsma, 2009) of the subscales depend on sample characteristics. Smith and Burger (1997) obtained alpha coefficients ranging from .80 to .86 in a sample in which the majority $(87 \%)$ was instructed to feign symptoms ( $N=476$ undergraduates), whereas Merckelbach and Smith (2003) found coefficients that varied between .24 (Low intelligence) and .59 (Affective disorders) in a sample where the majority $(81 \%)$ was asked to respond honestly $(N=298$ undergraduates). Alpha values are higher in feigning than in honest conditions; a pattern that is also evident in the data reported by Rogers, Robinson, and Gillard (2014). The influence of sample characteristics is further illustrated by the discrepancies between the results of Merckelbach and Smith (2003) and Vitacco et al. (2007; $N=100$ competency to stand trial patients, $21 \%$ malingering). The alpha coefficients for the Affective disorders scale in these studies were .59 and .61 , respectively. Yet in the former study it was the highest coefficient for subscales, while in the latter it was the lowest. Poor alphas for the Affective disorders scale (.31-.37) were also found by Rogers et al. (2014) in their clinical samples. Studies uniformly find that the alpha coefficients of the subscales are lower than that of the Total scale, which is to be expected given that internal reliability is a function of item number. The internal consistency of the SIMS Total scale is generally satisfactory (e.g., $\alpha=.80$ in Cima, Hollnack, et al., 2003; .72 in Merckelbach \& Smith, 2003; .92-.94 in Rogers et al., 2014; and .96 in Vitacco et al., 2007).

All in all, the subscales do not lend themselves to detect feigned psychopathology. Still, the subscales are sensitive enough to their target psychopathology to justify qualitative use (i.e., tentative assessment of the type of psychopathology that a person is trying to feign, 
once it has been established that the total score exceeds the cutoff), as originally proposed by Smith and Burger (1997).

The SIMS covers a wide variety of (spurious) psychopathology. Nonetheless, it exhibits sufficient internal consistency (e.g., Vitacco et al., 2007). This might reflect a common strategy among feigners - the tendency to overgeneralize when reporting symptoms. Studies involving experimental feigners typically find that, in spite of instructions to feign specific symptoms, participants are inclined to overgeneralize and report a diversity of symptoms (e.g., Giger et al., 2010; Merten et al., 2010).

Clegg et al. (2009) noted that experimental feigners who were instructed to feign depression and patients who were suspected of feigning a mood disorder were just as likely to fail the SIMS as they were to fail the Affective disorders scale. This finding illustrates three related points: Experimental feigners are comparable to real-world feigners; feigners are prone to overgeneralizing when reporting symptoms; and the accuracy of the subscales of the SIMS is at best equal to its total score.

A study by Rogers et al. (2005) suggests that subscales might be useful to discriminate between malingering and factitious disorder. In their simulation experiment, these authors instructed undergraduates to role-play individuals who feign symptoms for financial reasons or individuals who feign for intrapsychic reasons (e.g., medical attention). Those with the first set of instructions (malingering condition) were found to score particularly high on the Neurological impairment scale $(N)$, whereas those with the second set of instructions (factitious condition) scored especially high on the Affective disorders scale $(A F)$. Rogers et al. (2005) concluded that the $A F$ minus $N$ index might provide a basis for differentiating between the two types of feigning. Obviously, this interesting finding needs independent replication.

Another promising development is the attempt by Rogers and co-workers (2014; see Chapter 6) to design new SIMS indexes that are based on the established detection strategies of rare symptoms (RS) and unlikely symptom combinations (SC). Rogers and colleagues employed a simulation design in an inpatient sample and found the $R S$ and SC indices to produce very large ${ }^{3}$ effect sizes: Cohen's $d$ s of 2.0 and 1.6, respectively.

Aggregated data

An analysis of the effect of language on SIMS scores revealed that Dutch nonclinical controls score lower than English, German, and Spanish nonclinical controls (weighted means of 4.7 and 7.6, respectively; $p<.001$, two tailed; $d=-.8$ ). We have no plausible explanation for this finding, but it means that data generated by Dutch nonclinical controls might not generalize well to other cultures. In all other groups, language effects are absent ( $p \mathrm{~s}>.05)$. Therefore, the results of these groups were pooled in Table 4.6. This table aggregates the data of 41

\footnotetext{
${ }^{3}$ We followed the recommendation of Rogers et al. (2008) for the qualification of effect sizes: moderate $(\geq .75)$, large ( $\geq 1.25)$, and very large $(\geq 1.50)$.
} 
studies-comprising 125 subsamples and 4810 SIMS protocols ${ }^{4}$-in which mean SIMS scores are reported. Table 4.6 shows weighted means, standard deviations, Cohen's $d s$ when various samples are compared with the pooled scores of honest patients, claimants, and defendants, the corresponding 95\% confidence intervals for $d s$, and the non-overlap of score distributions that the $d s$ imply. This non-overlap is an upper bound estimate of the diagnostic accuracy of the SIMS: The greater the non-overlap between scores of feigners and honest patients, the higher the potential diagnostic accuracy.

It can be argued that studies involving experimental feigners are of little use because such feigners have other motives than real-world feigners. Moreover, the outcomes of experimental feigning research depend highly on the specific procedures employed in a study, such as quality and elaboration of the scenario with which participants are instructed (Nies \& Sweet, 1994; Merckelbach, Smeets, \& Jelicic, 2009). Still, experimental feigners might serve as a proxy for feigners in a real-world situation. For instance, Brennan and Gouvier (2006) and Clegg et al. (2009) contrasted experimental feigners with feigning claimants. Neither study found significant differences between the SIMS scores of both groups. A similar correspondence between SIMS scores of experimental and real-life feigners was evident in the preliminary findings of Santamaría Fernández (2013). The data displayed in Table 4.6 corroborate the overlap between SIMS scores of experimental feigners and at least some categories of real-world feigners. As can be seen, SIMS scores of experimental feigners fall within a range that is typical for feigning defendants.

In contrast to experimental feigners, experimental honest responders (i.e., nonclinical controls) are poor substitutes for their real-world counterparts ${ }^{5}$ : Table 4.6 shows that honest claimants, defendants, and patients score higher than nonclinical controls. The effect size of genuine psychopathology on SIMS scores ${ }^{6}$ is moderate $(d=.9$ in English, German, and Spanish samples; $d=1.2$ in Dutch samples). Thus, as stated earlier, studies that rely on nonclinical controls overestimate the specificity and positive predictive power of the SIMS.

Table 4.6 also reveals that feigning claimants score significantly lower than feigning defendants ( $d=1.1$ vs. $d=2.8$ ). The non-overlap between the distributions of SIMS scores of honest and feigning defendants is $91 \%$ whereas the non-overlap between scores of honest and feigning claimants is only $59 \%$. This suggests that the diagnostic accuracy of the SIMS is better in criminal law settings than in civil law settings. Feigning defendants usually aim for reduced criminal responsibility, which arguably requires more radical symptoms than the typical disability that is needed for the compensation that claimants commonly seek.

Another conclusion that can be drawn from Table 4.6 is that experimental feigners who feign psychiatric symptoms produce total SIMS scores that are similar to those of experimental feigners who fake cognitive deficits $(d=2.5$ vs. $d=2.4$; non-overlap of $88 \%$ and

\footnotetext{
${ }^{4}$ The data summarized in Table 4.6 are based on 4562 individuals who-due to within-participant (i.e., testretest) designs - contributed 4810 SIMS protocols. The studies used are marked with * in the references.

${ }^{5}$ Note that, in clinical practice, the SIMS will never be administered to nonclinical honest responders, because they, by definition, do not claim to suffer from psychopathology.

${ }^{6}$ Calculated by contrasting the weighted mean SIMS score of nonclinical respondents with that of honest patients, claimants, and defendants.
} 
$87 \%$, respectively). This implies that the sensitivity of the SIMS to feigned cognitive deficits is roughly equivalent to its sensitivity to feigned psychiatric symptoms.

\section{Table 4.6}

Weighted means, standard deviations, Cohen's ds, corresponding 95\% confidence intervals, and non-overlap between distributions of Structured Inventory of Malingered Symptomatology (SIMS) scores in various samples, based on 41 studies, including 125 subsamples and 4810 SIMS protocols

\begin{tabular}{|c|c|c|c|c|c|c|c|}
\hline Population & Samples & $N$ & $\begin{array}{l}\text { Weighted } \\
M(S D)\end{array}$ & $95 \% \mathrm{Cl}$ & $\begin{array}{l}\text { Cohen's } \\
d^{a}\end{array}$ & $95 \% \mathrm{CI}$ & $\begin{array}{l}\text { Non- } \\
\text { overlap }\end{array}$ \\
\hline $\begin{array}{l}\text { Nonclinical controls } \\
\text { (English, German, } \\
\text { Spanish) }^{\mathrm{b}}\end{array}$ & 12 & 648 & $7.6(4.1)$ & [5.9-9.2] & -.9 & {$[-1.2--.6]$} & $52 \%$ \\
\hline $\begin{array}{l}\text { Nonclinical controls } \\
\text { (Dutch) }^{\mathrm{b}}\end{array}$ & $19 c$ & $688^{\mathrm{d}}$ & $4.7(3.4)$ & [3.5-5.9] & -1.2 & {$[-1.5--.9]$} & $62 \%$ \\
\hline Honest patientse & 17 & 742 & $16.1(8.8)$ & [13.4-18.9] & N/A & N/A & N/A \\
\hline Honest claimants & 6 & 563 & $13.5(6.3)$ & [11.9-15.1] & N/A & N/A & N/A \\
\hline Honest defendants & 3 & 141 & $13.2(8.4)$ & [10.9-15.5] & N/A & N/A & N/A \\
\hline Feigning claimants & 9 & 238 & $23.7(8.7)$ & [20.4-27.0] & 1.1 & [0.8-1.4] & $59 \%$ \\
\hline Feigning defendants & 3 & 102 & $38.2(14.6)$ & {$[33.6-42.8]$} & 2.8 & [2.4-3.2] & $91 \%$ \\
\hline $\begin{array}{l}\text { Experimental feigners } \\
\text { (Psychiatric symptoms) }\end{array}$ & 17 & 615 & $35.8(12.3)$ & [31.3-40.3] & 2.5 & [2.1-2.9] & $88 \%$ \\
\hline $\begin{array}{l}\text { Experimental feigners } \\
\text { (Cognitive symptoms) }\end{array}$ & 15 & 526 & $34.5(12.2)$ & [29.8-39.2] & 2.4 & {$[2.0-2.8]$} & $87 \%$ \\
\hline $\begin{array}{l}\text { Experimental feigners } \\
\text { (Miscellaneous) }\end{array}$ & 10 & 212 & $29.6(10.1)$ & [25.1-34.1] & 1.8 & {$[1.5-2.1]$} & $77 \%$ \\
\hline $\begin{array}{l}\text { Experimental feigners } \\
\text { (Clinical knowledge) }\end{array}$ & 6 & 171 & $35.5(11.8)$ & [31.3-39.7] & 2.5 & [2.1-2.9] & $88 \%$ \\
\hline $\begin{array}{l}\text { Experimental feigners } \\
\text { (Warned of SVTs) }\end{array}$ & 4 & 71 & $23.3(10.7)$ & [18.4-28.2] & 1.0 & {$[.7-1.3]$} & $55 \%$ \\
\hline $\begin{array}{l}\text { Experimental feigners } \\
\text { (Knowledge + Warned) }\end{array}$ & 4 & 93 & $26.5(10.1)$ & [22.1-30.9] & 1.4 & [1.1-1.7] & $68 \%$ \\
\hline
\end{tabular}

Note . $\mathrm{CI}=$ confidence interval; Non-overlap $=$ Non-overlap between the distributions of scores of the specified populations and the scores of honest patients, claimants, and defendants; N/A = not applicable. The data summarized in this table are based on 4562 individuals who-due to withinsubject (i.e., test-retest) designs - contributed 4810 SIMS protocols.

aCalculated using the weighted mean score of honest patients, claimants, and defendants. ${ }^{b}$ Aside from the significant difference $(p<.001$, two tailed; Cohen's $d=-.8)$ between Dutch nonclinical controls and English, German, and Spanish nonclinical controls, there were no significant differences between the mean scores of Dutch, English, German, and Spanish respondents to the SIMS. Including 1 within subjects (i.e., test-retest) sample. ${ }^{\text {Including }} 24$ within-subjects (i.e., test-retest) SIMS protocols. ${ }^{\text {The }}$ honesty of the vast majority of these patients is assumed, but not established by symptom validity testing. 
In the majority of simulation studies, participants were explicitly asked to feign certain types of symptoms (i.e., either cognitive or psychiatric symptoms). Samples in which it was left to the participants to decide which type of psychopathology they would attempt to feign are brought together in Table 4.6 under the caption "Experimental feigners (Miscellaneous)." The greater freedom to choose which type of symptoms to feign has a mitigating effect on SIMS scores of experimental feigners: It reduces the effect of experimental feigning $(d)$ from 2.5 to 1.8 .

Furthermore, Table 4.6 confirms that SIMS scores of experimental feigners can be subdued considerably by forewarning of symptom validity testing ( $d$ drops from 2.5 to 1.0 ), but not by relevant knowledge about psychopathology ( $d$ remains 2.5$)$. However large the effect of forewarning, it still falls short of enabling coached feigners to produce scores that fall completely within the range of honest claimants and patients. More specifically, forewarning decreases the non-overlap between distributions of SIMS scores of experimental feigners and honest patients from approximately $87 \%$ to $55 \%$. Also evident from Table 4.6 is that the effects of forewarning and relevant clinical knowledge do not interact to produce a greater moderating effect on SIMS scores of feigners. As mentioned before, clinical knowledge curbs the effect of forewarning on the sensitivity of the SIMS.

\section{Discussion}

\section{Limitations of the SIMS}

Despite its solid internal consistency and broad coverage of (bogus) psychopathology, the SIMS suffers from several limitations. These are inherent to the rationale behind its construction. Smith and Burger (1997) developed the SIMS for the purpose of forensic screening. As a consequence, the SIMS covers a number of extreme dysfunctions (in particular with regard to claimed mental retardation and amnestic syndrome) that defendants might feign in the context of, for example, pleas of diminished criminal responsibility. However, such extremes will have lower base rates outside criminal settings. Milder, less disabling cognitive impairments are not addressed by the SIMS items. Therefore, the sensitivity of the SIMS might be limited in civil forensic assessment, where claims of moderate or even mild impairment are much more common.

A related point is that the SIMS items focus mainly on bizarre and atypical symptoms (but see below for exceptions). This capitalization on bizarre symptoms renders the SIMS readily recognizable as an SVT, (e.g., Merten et al., 2008). More importantly, the lack of alternative (i.e., other than pseudo-symptom) items constrains the diagnostic possibilities of the SIMS. The absence of items that cover genuine symptoms makes it difficult to determine whether heightened SIMS scores might be potentially related to genuine psychopathology. Similarly, without control items it is not possible to identify irrelevant response patterns such as indiscriminate affirmation or rejection of items (resulting from, e.g., recalcitrance or indifference). Thus, its exclusive reliance on pseudo-psychopathology prevents the SIMS from differentiating between feigning and aberrant test behavior. 
The presence of authentic symptoms within SIMS subscales is a fourth shortcoming. The Affective disorders scale has been criticized particularly for this reason (Widder, 2011). Illustrative examples of moot items from this subscale are items \#32 ("I have trouble ...") and \#52 ("I do not seem ..."). The overlap of this subscale with genuine depressive symptoms might bias honest patients toward the cutoff. For example, Kobelt, Göbber, Bassler, and Petermann (2012) found that the prevalence of SIMS failure (i.e., SIMS Total score >16) among patients with depression was disproportionally high relative to other clinical groups (57\% vs. $4-24 \%$ ).

There are other SIMS items that might tap into authentic psychopathology, notably items \#15 (memory problems), \#20 (head injury), and \#44 (tinnitus). Furthermore, Widder (2011) opined that items \#5 (changed taste of food), \#6 (laughing rarely), \#10 (changing body shape), \#43 (difficulties maintaining sleep), and \#66 (being inactive) might reflect genuine psychopathology.

Another source of measurement error might be the wording of some items: In particular item \#65 ("When I hear ..."), which contains a double negation, is difficult to understand for some persons. As well, item \#21 ("There are six ...") is strictly speaking logically correct reasoning, although endorsing it would count as an indication for feigning. This item is of the "there-are-living-100-people-in-the-US" type. One could imagine an autistic patient with a tendency toward concretism endorsing this item. A better way of formulating this type of item would be, "There are exactly 100 people living in the US."

An asset of the SIMS is its low comprehension difficulty; it does not require a high reading level (i.e., Flesch-Kincaid Scale 5.3 suffices; Smith, 2008). Nevertheless, in a sample of nonclinical controls $(N=100)$, SIMS scores were found to be slightly dependent on verbal intelligence $\left(B=0.11, R^{2}=.18, p<.05\right)$, but not on age, gender, or education (although the dependence on education was significant when verbal intelligence was not controlled for; Giger \& Merten, 2013). Indeed, the SIMS has yielded low specificity rates among individuals with intellectual disability and care is warranted in making determinations of feigning in this group based on the traditional cutoffs. It could be that individuals with intellectual disability produce heightened SIMS scores because of their diminished capacity to comprehend SIMS items. However, it might also be that low intelligence predisposes individuals to engage in more transparent forms of feigning (e.g., Solomon et al., 2010).

A limitation of the literature on the SIMS is the lack of test-retest reliability data. The stability of SIMS scores over time has been assessed only in small, nonclinical control samples. Merckelbach and Smith (2003) gave the Dutch version of the SIMS twice to 24 female undergraduate students, using a 3-week test interval. They obtained a test-retest correlation coefficient of .72, which can be regarded as satisfactory. Cima, Hollnack, and colleagues (2003) administered the German version of the SIMS to 18 undergraduates (4 women, 14 men) twice, with a 6-week interval in between, and found an outstanding testretest correlation: .97 . 
Suboptimal specificity

When the traditional cut scores (i.e., $>14$ and $>16$ ) are employed, the SIMS meets several requirements for a sound SVT (Hartman, 2002): Its hit rate (sensitivity) is acceptable; it is sensitive to differential prevalence; and it is robust against coaching. These qualities generalize across gender (e.g., Alwes, Clark, Berry, \& Granacher, 2008; Wisdom et al., 2010), race (Edens et al., 2007; Vitacco et al., 2007), and language (i.e., Dutch: Merckelbach \& Smith, 2003; German: Cima, Hollnack, et al., 2003; and Spanish: González Ordi \& Santamaría Fernández, 2009). In addition, the SIMS is relatively easy to administer and interpret, and it measures a wide range of symptoms that are likely targets for feigning (see DandachiFitzGerald \& Merckelbach, 2013).

However, the ability of the original SIMS cutoffs to classify honest responders with psychopathology correctly is not satisfactory: Cut scores of $>14$ and $>16$ have generally yielded low specificity rates in honest patient samples. In patients with schizophrenia, individuals with intellectual disability, and patients suffering from psychogenic nonepileptic seizures, the SIMS generates many positive results (Benge et al., 2012; Graue et al., 2007; Peters et al., 2013). Certain characteristics of schizophrenia, such as deficits in reality monitoring (Radaelli, Benedetti, Cavallaro, Colombo, \& Smeraldi, 2013), lack of illness insight (Shad, Tamminga, Cullum, Haas, \& Keshaven, 2006), and cognitive impairment (Schaefer, Giangrande, Weinberger, \& Dickinson, 2013; but see Stevens et al., 2014), may predispose patients to produce high SIMS scores. Similarly, intellectual disability may contribute to heightened SIMS scores due to, for example, deficiencies in verbal comprehension, abstract thinking, and judgment (American Psychiatric Association, 2013). Psychogenic disorders such as psychogenic movement disorder and non-epileptic seizures (PNES) may involve cognitive biases (e.g., "jumping to conclusions"; Pareés, Kassavetis, et al., 2012) and abnormalities in attention and perception (Pareés, Saifee, et al., 2012) that might lead patients to experience and report peculiar symptoms. This might explain why these patients sometimes fail on PVTs (Drane et al., 2006; Heintz et al., 2013) and SVTs such as the SIMS (Benge et al., 2012).

Although specific deficits inherent to schizophrenia, intellectual disability, and psychogenic disorder can put patients at risk of generating raised SIMS scores, high SIMS scores should not be dismissed lightly. Studies that employed the SIMS in these populations (Benge et al., 2012; Graue et al., 2007; Peters et al., 2013) did not conform to known-groups designs, which complicates the interpretation of their results. The authors of these studies noted that their patients were not involved in legal proceedings and were not bent on gaining benefits in any way. Yet, obvious external incentives are not a prerequisite for dubious scores on SVTs (e.g., Fox, 2011). Also, absence of evidence for external incentives should not be taken as evidence for the absence of such incentives. In fact, research into hidden agendas of patients drives home the point that a substantial portion of patients (up to $42 \%$ ) have covert motives for obtaining secondary gains associated with their patient status (e.g., financial support, help or attention from others, stimulant medication, work or study 
related privileges, or evasion of responsibilities; van Egmond \& Kummeling, 2002; van Egmond, Kummeling, \& van Balkom, 2005).

Clinicians should be circumspect in explaining high SIMS scores as a "cry for help": Such an interpretation might be valid, but it requires evidence that is independent from methods that rely on self-report. Furthermore, there is some evidence that feigning psychopathology is associated with reduced rather than increased treatment intensity, which runs counter to the notion of "cry for help" (Greene, 1988).

Given that the SIMS is (mainly) composed of noncredible symptoms, it stands to reason that prominent scores (e.g., >21) imply that respondents are either unwilling or unable to report their symptoms accurately, which means that diagnostic follow-up examinations are warranted. Just as the honesty of patients should not be discredited solely on the basis of elevated SIMS scores, so excessively raised SIMS scores should not be dismissed only because salient external incentives are absent and/or the patient has a diagnosis of, say, schizophrenia. Not only would such an approach ignore factitious motives to feign psychopathology (e.g., sympathy, attention, and care that come with the "sick role"), it would also disregard the possibility that patients may engage in feigning or exaggeration of symptoms.

Besides genuine inability and feigning, there are many reasons why patients might score above the SIMS cutoff. For example, patients might respond arbitrarily to a test in an attempt to obstruct the assessment or in order to be done with it as quickly as possible. Or they might fail to comprehend complex sentences (e.g., item \#13 “There is nothing ..."). Obviously, obstruction, rashness, and insufficient language comprehension bear no direct relation to feigning. Thus, the inference that a heightened SIMS score represents feigning is a secondary clinical inference; the primary clinical inference is "noncredible symptom report." This primary inference means that other test scores and self-reports of the patient cannot be accepted at face value either. Indeed, a recurrent finding in the literature is that heightened SIMS scores explain a considerable part of other test scores (Dandachi-FitzGerald, Ponds, Peters, \& Merckelbach, 2011; Merten, Friedel, \& Stevens, 2007; van Beilen, Griffioen, Gross, \& Leenders, 2009).

Optimal cutoff

In light of the considerable consequences of discrediting authentic psychopathology, the conclusion that patients, claimants, or defendants feign symptoms should only be drawn when there is solid evidence. Surely, any diagnostic decision criterion that lacks specificity (i.e., that carries a significant false-positive risk) will have difficulties generating such evidence. The SIMS has poor specificity when cut scores of $>14$ and $>16$ are employed (see also Rogers et al., 2014). How problematic this is depends on the purpose for which the SIMS is utilized. When it is used as a global screening measure of symptom validity such that scores exceeding the cutoff lead to conclusive follow-up testing, suboptimal specificity is defensible. If, on the other hand, the SIMS is employed as part of a multi-method SVT battery 
that is utilized for conclusive assessment of feigned psychopathology, then the substandard specificity associated with cut scores of $>14$ or $>16$ is perilous. In that case, a cut score of $>19$ (Clegg et al., 2009) or - when even more diagnostic certainty is required $->24$ (Wisdom et al., 2010) would be more appropriate. Of course, gains in specificity due to raising the cutoff come at the cost of sensitivity. Thus, setting the cutoff at $>19$ or $>24$ will result in safer yet fewer identifications of feigned psychopathology, such that the SIMS will only identify the most blatant forms of feigning, and hence lose its quality as a screening instrument.

Another approach would be to use a cutoff of $>19$ and define a zone of less certainty as to individual classifications. Table 4.7 shows a tentative taxonomy. A similar procedure has been proposed by Rogers et al. (1992) for the SIRS. Its advantage is that a strict and artificial dichotomy between feigning and honest responding is avoided.

Thus, the optimal cutoff varies depending on the rationale for using the SIMS (i.e., screening versus conclusive assessment). The trade-off between the power to detect feigned psychopathology (i.e., sensitivity) and the ability to avoid false positives (i.e., specificity) forces clinicians to decide in advance whether specificity should take precedence over sensitivity. If the goal is to screen for possible cases of invalid symptom reporting, then a cut score of $>16$ suffices. If, however, it is crucial to avoid false positives (as would be the case in many instances of clinical or forensic assessment), then a cut score of at least $>19$ is called for. In populations with particularly heightened SIMS scores due to genuine psychopathology (e.g., schizophrenia, intellectual disability), cut scores of $>19$ for screening and $>24$ for conclusive assessment would be highly recommendable. In sum, selection of a particular cutoff should be considered carefully and in advance: The data in Table 4.6 and the taxonomy in Table 4.7 might be helpful in this regard.

\section{Table 4.7}

Possible cut scores of the Structured Inventory of Malingered Symptomatology and corresponding interpretations and recommendations as to their use

\begin{tabular}{ll}
\hline Cut score & Considerations \\
\hline$>16$ & $\begin{array}{l}\text { Recommended when the SIMS is employed as a screen for feigned psychopathology. } \\
\text { Carefully investigate and possibly exclude false-positive classifications. }\end{array}$ \\
$>19$ & $\begin{array}{l}\text { Recommended when the SIMS is employed as part of a test battery that is utilized for } \\
\text { conclusive assessment of feigned psychopathology. It yields lower sensitivity, but higher } \\
\text { specificity (reduced risk of false-positive classification). }\end{array}$ \\
$>16->19$ & $\begin{array}{l}\text { Combined cutoffs. Use scores from } 17 \text { to } 19 \text { as indicating possible feigning, or relatively } \\
\text { mild feigning. Follow-up testing is warranted. }\end{array}$ \\
& $\begin{array}{l}\text { Only recommended when the SIMS is employed as part of a test battery for conclusive } \\
\text { assessment in populations with particularly heightened SIMS scores due to genuine } \\
\text { psychopathology (e.g., schizophrenia, intellectual disability). It yields high specificity, but } \\
\text { low sensitivity (high risk of false-negative classification). }\end{array}$ \\
General & $\begin{array}{l}\text { Heightened SIMS scores do not necessarily reflect feigned psychopathology: They may } \\
\text { also be the result of irrelevant responding due to, for example, fatigue, frustration, } \\
\text { Caveat }\end{array}$ \\
& indifference, defiance, or incomprehension.
\end{tabular}




\section{Multi-method approach}

In general, people who feign psychopathology tend to overgeneralize: They might feign both psychiatric symptoms and cognitive deficits (i.e., they might overreport symptoms and underperform on cognitive tests). Moreover, feigners of psychopathology overgeneralize to cognitive impairments more frequently than the other way around (i.e., overreporters underperform more often than underperformers overreport; Alwes et al., 2008; see also Green, Rosenfeld, Belfi, Rohlehr, \& Pierson, 2012; Heinze \& Purisch, 2001). However, people might also be highly selective in the symptoms or impairments they feign. Astute or informed feigners will even limit their complaints to specific signs and symptoms of a particular disorder or disability. It is therefore essential that symptom validity assessment includes multiple measures covering diverse domains of symptomatology during various stages of the evaluation (Boone, 2009; Heilbronner et al., 2009).

Even though the SIMS taps into several areas of psychopathology, it is advisable to combine it with other SVTs, preferably PVTs, which tap underperformance, a dimension that is relatively independent of symptom overreporting as indexed by the SIMS (Nelson, Sweet, Berry, Bryant, \& Granacher, 2007; Ruocco et al., 2008; see also Table 4.5). Precisely because PVTs aim at another dimension of symptom validity testing, they are susceptible to other error sources than the SIMS (Dandachi-FitzGerald et al., 2011; Green et al., 2012).

Using the SIMS in conjunction with other validity tests allows for a significant reduction in false-positive risk; namely, through adherence to the rule that a respondent has to fail at least two validity tests in order to be classified as a feigner (Giger et al., 2010). Clinicians and researchers who decide to employ the SIMS are well-advised to bear this rule, also known as the two-failure rule (Victor et al., 2009), in mind. Concerns that the efficacy of the two-failure rule diminishes when more than two validity tests are administered (Berthelson, Mulchan, Odland, Miller, \& Mittenberg, 2013) are dispelled by recent empirical findings (Davis \& Millis, 2014; Larrabee, 2014a).

Because its administration is simple and brief, the SIMS is a fair candidate for inclusion in a multi-method approach to symptom validity assessment (see also Chapter 7). The original cut scores of the SIMS yield substandard specificity, which renders them inappropriate for confirming suspicious scores on other validity tests. On the other hand, the sensitivity of these cutoffs is relatively high. This makes them more suitable to rule feigning out, rather than rule it in. Hence, when using its original cutoffs, the SIMS is best used as first instrument in a multi-method approach. An advantage of using the SIMS as primary screen is that its subscales may provide an indication of the type of psychopathology a respondent might feign, which could facilitate the selection of validity tests that are tailored to specific (pseudo-)psychopathology.

\section{Alternatives}

Further proliferation of the SIMS comes with two risks. The first is that information about its cutoffs may become so prevalent that well-informed and calculating respondents will adapt 
their test behavior in order to pass the SIMS. It is true that the SIMS is presently robust against coaching. However, there might come a time when potential respondents can educate themselves (e.g., through the Internet; see Bauer \& McCaffrey, 2006; Ruiz, Drake, Glass, Marcotte, \& van Gorp, 2002) on how to feign psychiatric complaints while evading detection when confronted with the SIMS (for a recent example, see the Wikipedia entry on the $\mathrm{TOMM}^{7}$ ).

A second risk is that widespread use of the SIMS can lead to a form of thoughtless routine on the part of clinicians. Sociologists have termed this phenomenon the performance paradox (van Thiel \& Leeuw, 2002). It arises when examinees have learned to mask inferior performance by adjusting their response to performance indicators such that they obtain superior test results (Meyer \& Gupta, 1994). A similar scenario might unfold with instruments such as the SIMS. That is, respondents may come to learn how to obscure a sophisticated form of feigning by scoring reassuringly low on the SIMS.

Thus, the adequate sensitivity of the SIMS with cut scores of up to $>16$ is not likely to last forever. Bearing this in mind, it is sensible to consider alternatives to the SIMS. One candidate is the M Test (Beaber, Marston, Michelli, \& Mills, 1985; for reviews, see Boone, 2013, or Smith, 2008). The M Test is a 25-item self-report measure with a dichotomous response format that contains genuine symptoms of schizophrenia as well as absurd beliefs and bogus symptoms. The M Test focuses on feigned schizophrenia and is hence ill-suited to assess other types of feigned psychopathology. Nevertheless, the $\mathrm{M}$ Test might be valuable in a forensic context where blatant forms of feigning can be expected. In a direct comparison of their sensitivities, the M Test outperformed the SIMS in a sample of defendants suspected of feigning incompetence to stand trial, with detection rates being .93 and .87, respectively (Heinze \& Purisch, 2001). However, in samples where the psychopathology that respondents attempt to feign is relatively mild, the diagnostic qualities of the M Test are less satisfactory, especially with regard to specificity (Boone, 2013).

Another alternative is the Miller-Forensic Assessment of Symptoms Test (M-FAST; Miller, 2001; see also Smith, 2008). The M-FAST is a 25-item structured interview that (much like the vastly more extensive SIRS) probes into unusual and implausible symptomatology. In a known-groups comparison - with the SIRS serving as external criterion-of patients involved in competency to stand trial evaluations, the M-FAST held its ground as firmly as the SIMS did, producing very large effect sizes ( $d$ M-FAST: 2.7, d SIMS: 3.1; Vitacco et al., 2007). Similar effects were attained in a sample of claimants of personal injury or workers' compensation ( $d$ M-FAST: 3.0, d SIMS: 2.6; Alwes et al., 2008). The M-FAST might be a good alternative to the SIMS when patients or defendants have reading difficulties.

Of course, symptom validity assessment is not limited to freestanding screening measures such as the SIMS and the M-FAST. Obvious alternatives for comprehensive assessment of symptom validity include the SIRS, but also clinical inventories with embedded symptom validity scales (for a qualitative review, see Boone, 2013), such as the

${ }^{7}$ http://en.wikipedia.org/wiki/Test_of_Memory_Malingering (URL of August 2014). 
Minnesota Multiphasic Personality Inventory-2-Restructured Form (MMPI-2-RF; BenPorath \& Tellegen, 2008) and the Personality Assessment Inventory (PAI; Morey, 2007). A notable advantage of the SIMS over these more extensive instruments lies in its short administration time. As said before, however, the traditional cut scores of the SIMS are more suited to rule feigning out than to rule it in, while the cutoffs of these more comprehensive tools are geared toward the opposite.

\section{Conclusion}

In accordance with previous research, we found the SIMS to be a fairly sensitive test that is reasonably robust against coaching. A serious weakness of the SIMS is its poor specificity when the original cut scores ( $>14$ and $>16)$ are employed. These cutoffs are more effective in ruling feigning out than ruling it in, which is consistent with the SIMS' status as a screen for feigned psychopathology. The substandard specificity of the original cut scores of the SIMS can be worked around by combining the SIMS with PVTs and other SVTs, and by raising the cut score, although the latter solution sacrifices sensitivity for specificity. Furthermore, we advise clinicians to adopt a position of respectful skepticism toward respondents with a heightened SIMS score. Although an assumption of honesty might be naïve in, for example, a forensic context, the burden of proof for the conclusion that an individual feigns symptoms rests on the shoulders of diagnostic experts. A deviant SIMS score alone does not meet the burden of proof, but it should be an impetus for follow-up investigation. 


\section{Chapter 5}

\section{Detecting feigned cognitive impairment with Schretlen's Malingering Scale Vocabulary and Abstraction test}

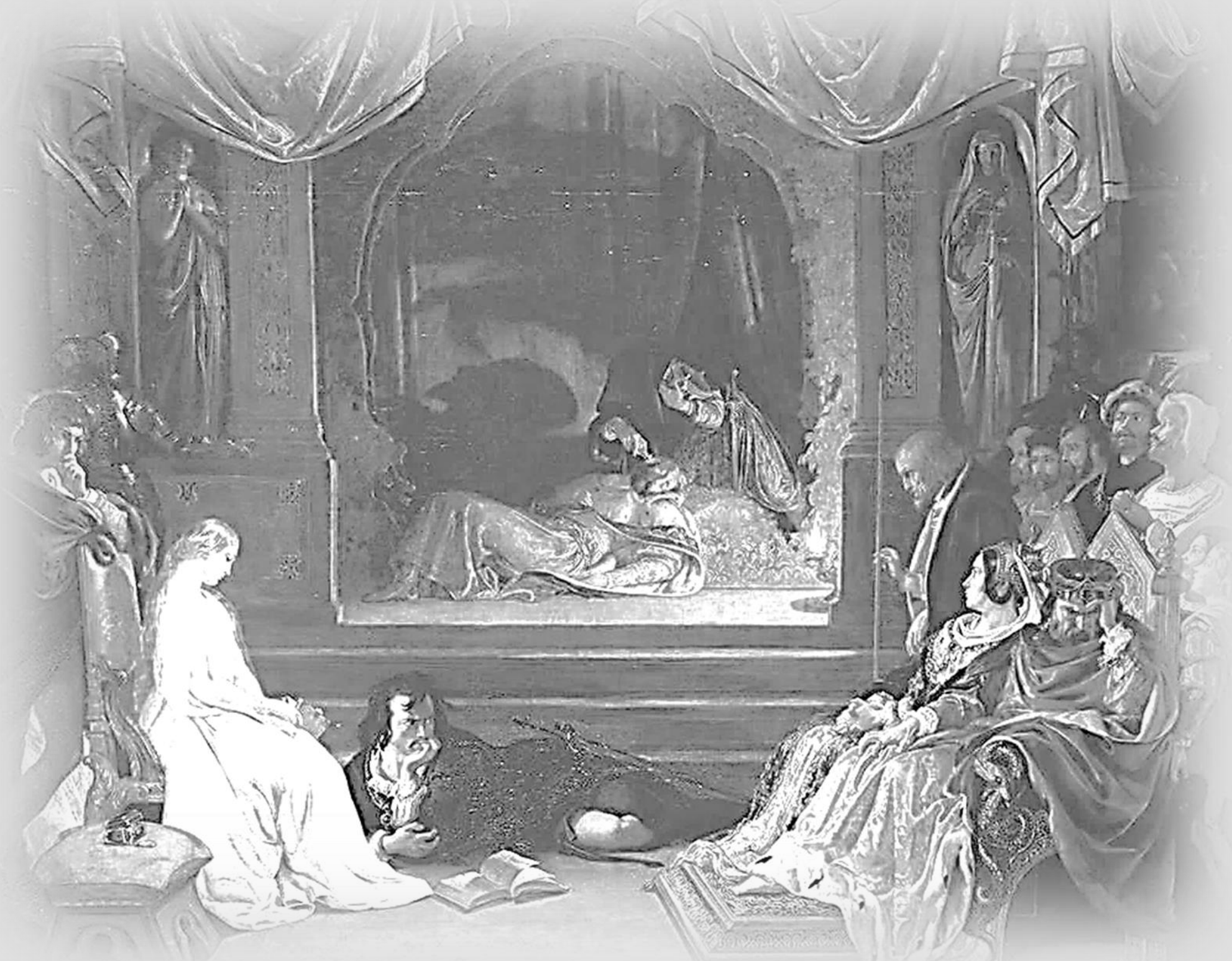

Published as:

van Impelen, A., Jelicic, M., Otgaar, H., \& Merckelbach, H. (2017). Detecting feigned cognitive impairment with Schretlen's Malingering Scale Vocabulary and Abstraction test. European Journal of Psychological Assessment. Advance online publication. 


\begin{abstract}
Schretlen's Malingering Scale Vocabulary and Abstraction test (MSVA) differs from the majority of performance validity tests in that it focuses on the detection of feigned impairments in semantic knowledge and perceptual reasoning rather than feigned memory problems. We administered the MSVA to children $(n=41)$, forensic inpatients with intellectual disability $(n=25)$, forensic inpatients with psychiatric symptoms $(n=57)$, and three groups of undergraduate students $(n=30, n=79$, and $n=90$, respectively), asking approximately half of each of these samples to feign impairment and the other half to respond honestly. With cutoffs chosen so as to keep false-positive rates below $10 \%$, detection rates of experimentally feigned cognitive impairment were high in children (90\%) and inpatients with intellectual disability (100\%), but low in adults without intellectual disability $(46 \%)$. The rates of significantly below-chance performance were low $(4 \%)$, except in children $(47 \%)$ and intellectually disabled inpatients (50\%). The reliability of the MSVA was excellent (Cronbach's $\alpha=.93-.97$ ) and the MSVA proved robust against coaching (i.e., informed attempts to evade detection while feigning). We conclude that the MSVA is not ready yet for clinical use, but that it shows sufficient promise to warrant further validation efforts.
\end{abstract}




\section{Introduction}

Neuropsychological evaluations are only valid to the extent that examinees follow instructions and perform to the best of their ability (Heilbronner et al., 2009). The validity of test performance can be assessed with performance validity tests (PVTs; Larrabee, 2012). Two recent surveys among North American neuropsychologists indicate that memoryoriented PVTs are by far the most popular (Brooks, Ploetz, \&Kirkwood, 2015; Martin, Schroeder, \& Odland, 2015). For example, Martin and colleagues (2015) found that five of the six most frequently used PVTs (e.g., the Medical Symptom Validity Test [MSVT]; Green, 2004, and the Test of Memory Malingering [TOMM]; Tombaugh, 1996) target feigned memory deficits.

The popularity of PVTs that are geared toward feigned memory deficits may inadvertently lead to the overapplication of such PVTs. Such overapplication may occur when it is overlooked that the validity of performance may vary across cognitive domains and throughout examinations (Boone, 2009). Thus, a PVT that masks as a memory test may be less suited to assess performance validity in other cognitive domains, such as attention, processing speed, language ability, and abstract reasoning. The relevance of a cognitive test and, arguably of a PVT as well, depends on the relation between the domain it taps and the complaints that a patient presents with; a memory-oriented PVT may not be effective in patients who deny having memory problems, but instead present with problems in other cognitive domains (e.g., reasoning).

Memory-related problems are not necessarily prime candidates for simulation when feigning is considered (Dandachi-FitzGerald \& Merckelbach, 2013). In their experimental feigning study, Dandachi-FitzGerald and Merckelbach (2013) presented undergraduate psychology students $(N=54)$ with case vignettes of a criminal trial and a civil lawsuit and asked them to imagine that they were the defendants or plaintiffs in these cases. Participants were then prompted to specify which symptoms they would feign and which symptoms they would specifically not feign in such situations. Only a minority $(7 \% ; n=4)$ had a preference for feigning a memory disorder and a similar percentage $(9 \% ; n=5)$ indicated that they would explicitly refrain from feigning memory deficits. Thus, memory-oriented PVTs may not always be suitable as default option to detect feigned cognitive problems in neuropsychological assessments.

The Malingering Scale (MgS) developed by Schretlen (1986; Schretlen \& Arkowitz, 1990 ) is an instrument that intends to assess feigned impairments in reasoning. It is a paperand-pencil tool that has the superficial appearance of an IQ test. The MgS contains two verbal tests with open-ended questions (Arithmetic, 20 items; and Information, 24 items) and two written tests that consist of two-alternative forced-choice items (Vocabulary, 26 items; and Abstraction, 20 items). The Vocabulary and Abstraction tests (but not the Arithmetic and Information tests) allow for the detection of below-chance performance (see below). Given their simple scoring format and considering that they are easily translatable, we focused on these two subtests. 
The Vocabulary test instructs respondents to "underline the word that means the same as the word in CAPITAL letters," for example: "THIEF: robber - driver." The Abstraction test asks respondents to "circle the answer that should go in the blank (_) space," for example: "2 $46 \ldots$ _ 5 - 8" and "Dog Bird Cat___: Tree - Horse." Items are nonhierarchical and correct answers are distributed equally among first and second alternatives. The two-alternative forced-choice response format results in a total score (0-46) that follows the binomial distribution.

Respondents whose vocabulary and abstract reasoning are severely limited may be expected to produce a total score that circles around 23. The exact criterion to determine whether a respondent responds with below-chance accuracy is open to debate (Frederick \& Speed, 2007; Greve, Binder, \& Bianchini, 2009). The generally accepted criterion is $p<.05$ (one-tailed, because the goal is to identify scores below chance level), although some authors endorse $p<.10$ (e.g., Binder, 2002) or even $p<.20$ (e.g., Binder, Larrabee, \& Millis, 2014; Reynolds \& Horton, 2012). The $p$ level corresponds to the likelihood that a respondent who responds randomly is incorrectly classified as responding nonrandomly (i.e., below chance level). For example, $p<.05$ entails that less than $5 \%$ of the respondents who respond at chance level are falsely classified as responding below chance level. For the combined Vocabulary and Abstraction tests of the Malingering Scale (the MSVA), the $p<.05$ criterion for below-chance responding corresponds to a cutoff of $<17$.

In an early study by Schretlen, Wilkins, van Gorp, and Bobholz (1992), the MgS was administered to prison inmates $(n=20)$ and psychiatric inpatients $(n=22$ veterans with substance abuse disorders) asked to "pretend that you are insane, that is, crazy" (p. 78). Using a more lenient cutoff to identify below-chance performance $(<18$ instead of $<17$, which corresponds to $p=.053$ ), Schretlen and colleagues (1992) found the rate of below-chance MSVA performance to be $10 \%(95 \%$ CI $[0 \%, 23 \%])$ among inmates and $41 \%$ (95\% CI [20\%, $61 \%]$ ) among inpatients, which amounts to a pooled detection rate of $26 \%$ (95\% CI [13\%, $39 \%]$ ). The accuracy in identifying credible performance was $100 \%$, as none of the participants who were asked to respond honestly (i.e., prison inmates, inpatient veterans, and inpatient veterans with schizophrenia; all groups $n=20$ ) scored below chance level. These results illustrate the main drawback as well as the main strength of below-chance cutoffs; low sensitivity (i.e., ability to detect feigned performance; Greve et al., 2009) but high specificity (i.e., accuracy in identifying credible performance; Rogers, 2008b). In fact, belowchance accuracy is considered to be the strongest indication currently available to substantiate (i.e., rule in) feigned cognitive performance (Greve et al., 2009).

An alternative strategy to detect feigned cognitive impairment with the MSVA is to find the lower boundaries of credible performance by impaired persons. This approach capitalizes on floor effects and the idea behind it is that feigners may not realize that simple cognitive tasks can be accomplished by most impaired individuals (Rogers, 2008b). A clinical floor (i.e., a cutoff below which credible patients rarely score) is typically far above belowchance criteria. For example, for the TOMM, the recommended cutoff is $<45$ ( $<90 \%$ correct in TOMM's Trial 2 or Retention Trial), whereas the $p<.05$ criterion corresponds to a cutoff of 
$<19(<38 \%$ correct in any trial). The chief advantage of using norm-referenced cutoffs over below-chance cutoffs is increased sensitivity. Interestingly, Schretlen, Neal, and Lesikar (2000) administered the MSVA to criminal defendants and found a sensitivity of .73 for a cutoff of $<80 \%$ correct (i.e., $<37$; the corresponding specificity was .92) in defendants who were judged to be malingering.

To explore its merits, we administered a translated version of the MSVA to several samples with the expectation that it would adequately distinguish between participants who feign cognitive impairment and those who respond honestly. We looked not only at belowchance performance, but also at various cutoffs above chance level to evaluate performance validity. Because children and patients with intellectual disability possess more limited cognitive abilities (i.e., less sophisticated feigning strategies), we expected the MSVA to be more effective in these samples than in the samples of adults without intellectual disabilities.

\section{Methods}

The various samples to whom we administered the Malingering Scale Vocabulary and Abstraction test (MSVA) included children $(n=41)$, forensic inpatients with intellectual disability $(n=25)$, forensic inpatients with psychiatric symptoms $(n=57)$, and three groups of undergraduate students, ( $n=30, n=79$, and $n=90$, respectively). The specific experimental manipulations that we used varied between these samples, but all manipulations served either to prompt participants to feign cognitive impairment or to ask them to respond honestly. In some samples, we employed well-researched validity tests in addition to the MSVA. We employed the Amsterdam Short-Term Memory test (ASTM; Schagen, Schmand, de Sterke, \& Lindeboom, 1997), the Structured Inventory of Malingered Symptomatology (SIMS; Smith \& Burger, 1997; see Chapter 4), and the Test of Memory Malingering (TOMM; Tombaugh, 1996) in undergraduate students asked to feign impairment. The SIMS was also administered to forensic inpatients with psychiatric symptoms who were asked to respond honestly. A more detailed account of the various samples and the experimental manipulations that were employed therein can be found below, followed by a description of the additional validity tests (ASTM, SIMS, and TOMM) that were used in some samples.

\section{Participants and Procedures}

\section{Primary school children.}

To investigate the lower bounds of credible MSVA performance, we administered the MSVA to 41 healthy primary school children (19 girls, 22 boys, Mage $=9.4$ years, age range: $7-13$ years) who were randomly assigned to one of two groups: one group ( $n=19)$ was asked to respond to the MSVA as if they lacked the mental capacity to do well on the test, the other group $(n=22)$ was asked to respond correctly to as many items as possible. Aside from inadequate test effort being a potential issue in children (see, e.g., Kirkwood, Yeates, Randolph, \& Kirk, 2012), we included this sample because the immature cognitive abilities of 
children provide a clinical floor below which adults with mild cognitive disabilities are not expected to score (see also Rienstra, Spaan, \& Schmand, 2010). Our expectation was that children who performed to the optimum of their ability would produce MSVA scores comparable to those of patients with intellectual disability (i.e., IQ below 70).

Forensic inpatients with intellectual disability.

As another test of the lower bounds of credible MSVA performance, we administered the MSVA to a group of 25 inmates (all men, age range: 18-65 years) of a medium security forensic psychiatric institution for intellectually disabled convicts. Typical crimes that inmates were convicted for included assault, battery, sexual assault, vandalism, and arson. All participants were diagnosed with intellectual disability: Twenty-one participants had an IQ below 70; four had an IQ below 50. Information about IQs was obtained from patient records, which contained Wechsler Adult Intelligence Scale (4th ed.; WAIS-IV; Wechsler, 2008) protocols. Participants were randomly allocated to a group $(n=10)$ that was asked to feign mental incapacity to do well on the test or to a control group $(n=15)$ that was asked to respond to the best of their ability. Only patients who were considered capable to participate by their treatment supervisors were approached to participate in the study. Treatment supervisors determined whether potential participants suffered from the following exclusion criteria; insufficient language proficiency, severe symptoms of drug withdrawal, extreme mental instability because of psychosis, acute problems with aggression, or incapacitating mental abilities due to severe intellectual disability. All patients were assisted in reading and comprehending the MSVA. Some patients (including those who had an IQ below 50) preferred the MSVA to be administered verbally. We decided to include the test results of these patients to maintain a representative sample of intellectually disabled forensic patients. The patients who had an IQ below 50 were all included in the control group; exclusion of these patients would inflate specificity values.

Forensic inpatients with psychiatric symptoms.

A diverse group of 57 inmates (all male, $M_{a g e}=40.0$ years, age range: $19-54$ years) of a medium security forensic psychiatric institution were asked to complete the MSVA and the SIMS optimally. Typical crimes that inmates were convicted for included burglary, robbery, assault, battery, and sexual assault. Mean IQ was 88.2 (SD IQ $=14.6)$. IQ information was gathered from patient records, which included WAIS-IV protocols. All but one patient were diagnosed with a substance disorder. Comorbid diagnoses included other specified personality disorder $(28 \%)$, antisocial personality disorder $(16 \%)$, autism spectrum disorder $(14 \%)$, attention deficit hyperactivity disorder $(7 \%)$, and schizophrenia $(7 \%)$. The same recruitment procedure and exclusion criteria were used as with the forensic inpatients with intellectual disability. We expected forensic inpatients with psychiatric symptoms to produce higher MSVA scores than children and patients with intellectual disability, but slightly lower than healthy undergraduate students. 


\section{Undergraduate students 1.}

Thirty undergraduate students (27 women, 3 men, $M_{\text {age }}=21.1$ years, age range: $18-31$ years) were asked to imagine being the perpetrator of pilferage in a restaurant. To this end, they were presented with a slideshow containing pictures (from the perpetrator's point of view) of the staged theft of a wallet. After the slideshow, participants were asked to feign amnesia for the imagined crime and were administered the MSVA and the Amsterdam Short-Term Memory test (ASTM; Schagen et al., 1997).

\section{Undergraduate students 2.}

We administered the MSVA, the ASTM, and the TOMM to 79 undergraduate students (56 women, 23 men, Mage $=22.2$ years, age range: 18-28 years). Participants were randomly allocated to one of four groups; an "honest" group $(n=20)$, which was asked to perform optimally, and three "feigning" groups; a "warned" group $(n=19)$ that was warned of the PVTs and was allowed to browse the Internet for 10 minutes to find information to help them pass the PVTs; a "coached" group $(n=20)$ that was forewarned and, in addition, received readymade information about head injury symptoms and how to pass PVTs; and a "naïve" group $(n=20)$ that was not forewarned and received no information about head injury symptoms or PVTs. Participants in the experimental feigning groups were asked to immerse themselves in a case vignette (adopted from Suhr \& Gunstad, 2000) describing a personal injury lawsuit following an accident, and imagine that they were the plaintiff, who, in order to obtain damages, decided to feign head injury symptoms.

\section{Undergraduate students 3.}

The MSVA and the SIMS were administered to 90 undergraduate students (60 women, 30 men, $M_{\text {age }}=23.2$ years, age range: 18-56 years) who were randomly assigned to a "feigning" group $(n=45)$ or an "honest" group $(n=45)$. Both groups were presented with a case vignette detailing the case of a loyal employee who, after being fired by a new manager, decided to feign illness to obtain workers' compensation (see Appendix A of DandachiFitzGerald \& Merckelbach, 2013). Participants in the feigning group were asked to imagine that they were the employee and would be undergoing court ordered neuropsychological assessment, while participants in the honest group were asked to indicate whether the case represented a social, a legal, or a medical problem. The feigning group was asked to consider the option to feign symptoms, whereas the honest group was asked to respond truthfully to the tests that were to be administered. Both the feigning and the honest groups comprised three subgroups: A "warned" group $(n=15)$ that was warned that certain tests could detect feigning; a "morally primed" group $(n=15)$ that was primed with questions about moral topics (for more details, see Merckelbach \& Collaris, 2012), and a "naïve" group $(n=15)$ that was not warned or morally primed. 


\section{Ethical approval and informed consent}

The study was approved by the Standing Ethics Committee of the Faculty of Psychology and Neuroscience of Maastricht University, Maastricht, the Netherlands. Tests were administered by graduate psychology students who were familiar with test protocols. The undergraduate samples received course points or a small financial compensation for participating in the study. The children could choose a small present (e.g., pen, coloring page). Forensic inpatients did not receive any incentive or compensation for their participation. Except for several inpatients with severe intellectual disability, all participants of all samples were verbally informed about the study and gave written informed consent only after reading handouts of the study information. The inpatients with intellectual disability who were insufficiently able to read gave verbal informed consent; written informed consent was obtained from their legal guardian. The primary school children provided their own assent while informed consent was obtained from their parents.

\section{Additional measures (used only in the samples indicated above)}

Amsterdam Short-Term Memory Test (ASTM).

The ASTM (Schagen et al., 1997) is a forced-choice word recognition PVT that is presented to participants as a memory test. It comprises 30 items that each consists of three parts; the first part is a set of five semantically related words that are to be read aloud and memorized; the second part is a simple addition or subtraction task that serves as distraction; and the third part is again a set of five related words; three from the first part and two new ones. Participants are asked to indicate which three words appeared in the first part. After every item, participants receive feedback on the number of words they correctly recognized. Correct words are totaled to arrive at a test score ranging from 30 to 90 . A score below 85 is indicative of feigned memory impairment (sensitivity .91, specificity .89; Schmand \& Lindeboom, 2005).

Structured Inventory of Malingered Symptomatology (SIMS).

The SIMS (Smith \& Burger, 1997) is a self-report symptom validity screen consisting of 75 true-false items that cover rare and improbable symptoms from various types of psychopathology. After recoding some items a total score is calculated by summing the number of endorsements. A score above 16 is indicative of noncredible self-reported symptomatology (sensitivity .92, specificity .66; see Chapter 4). To decrease the false-positive risk, we employed a cutoff of $>19$ (sensitivity .90, specificity .69; Clegg, Fremouw, \& Mogge, 2009).

Test of Memory Malingering (TOMM).

The TOMM (Tombaugh, 1996) consists of two learning trials and an optional retention trial. Both learning trials comprise (in different orders) 503 -second presentations of line-drawn 
objects, followed by a sequence of 50 pairs of line-drawn objects; each containing a new object and a previously presented object. Participants are asked to identify the previously presented objects. The retention trial consists of a different sequence of 50 pairs of line-drawn objects (each containing a prior and a new object) and can be administered after a 15-minute interval. A score less than 45 on Trial 2 or the retention trial is strongly associated with feigned memory impairment (sensitivity .50, specificity .97; Schroeder et al., 2013; sensitivity .42, specificity .96; Greve, Bianchini, \& Doane, 2006).

\section{Results}

\section{Mean MSVA scores and correlates}

Tables 5.1 and 5.2 summarize the main results. Note that some statistical estimates may be rather unprecise due to small sample size. The $95 \%$ confidence intervals serve to approximate the precision, with wider intervals indicating lower precision of the parameter estimate. To facilitate the interpretation of Cohen's $d$ as a measure of classificatory effectiveness, Table 5.1 displays the percentage of non-overlap (as derived from Cohen's $d$ ) between MSVA score distributions in each sample. Non-overlap percentages reflect the proportion of feigning participants who produced MSVA scores unlike any of those produced by participants who responded honestly. The non-overlap percentages offer a preview of the results of the receiver operating characteristic analysis presented in Table 5.2: the classificatory accuracy of the MSVA is adequate in children and forensic patients with intellectual disability, but unsatisfactory in adults without intellectual deficits.

Children who were asked to feign mental incapacity produced statistically lower scores $(M=14.3,95 \% \mathrm{CI}[10.5,18.1])$ than the group asked to respond honestly $(M=31.1,95 \%$ CI $[27.6,34.6]) ; t(39)=6.79, p<.01$, Cohen's $d=2.11(95 \%$ CI $[1.33,2.89])$. The rate of belowchance performance $(<17 ; p<.05)$ in experimental feigners was $47 \%(95 \%$ CI $[25 \%, 70 \%])$, compared with $0 \%$ in the control group. Cronbach's $\alpha$ were .93 for the combined tests, .90 for the Vocabulary test, and .83 for the Abstraction test. These alphas are somewhat lower - but still satisfactory - than those reported by Schretlen et al. (1992), who found values of .96 for the Vocabulary test and .94 for the Abstraction test.

In forensic inpatients with intellectual disability, the experimental feigning group scored statistically lower $(M=15.8,95 \%$ CI $[9.1,22.5])$ than the control group $(M=39.2,95 \%$ CI $[36.1,42.3]) ; t(23)=7.9, p<.01, d=3.32$ (95\% CI [1.98 4.42]). Furthermore, 50\% (95\% CI $[19 \%, 81 \%])$ of the experimental feigning group scored below chance $(<17)$, whereas none of the honest (i.e., nonfeigning) responders did. Cronbach's $\alpha$ values were .93 for the Vocabulary test, .93 for the Abstraction test, and .97 for the combined tests, values that come close to the ones reported by Schretlen et al. (1992). 
Chapter 5

Table 5.1

Means, corresponding 95\% confidence intervals, standard deviations, Cohen's ds, and non-overlap between distributions of Malingering Scale Vocabulary and Abstraction test scores in various samples.

\begin{tabular}{|c|c|c|c|c|c|}
\hline Sample & $N$ & $\begin{array}{c}M(S D) \\
{[95 \% \mathrm{CI}]}\end{array}$ & $\begin{array}{c}\text { Cohen's } d \\
{[95 \% \mathrm{CI}]}\end{array}$ & $\begin{array}{c}\text { Score } \\
\text { non-overlap } \\
{[95 \% \mathrm{CI}]}\end{array}$ & $\begin{array}{c}\text { Cohen's } d \\
\text { pooled data } \\
{[95 \% \mathrm{CI}]}\end{array}$ \\
\hline
\end{tabular}

Primary school children

- Honest $22 \quad 31.1(7.9)$ [27.6, 34.6]

- Feigning incapacity

$19.3(8.0)$
$[10.5,18.1]$

$2.11^{*}$

[1.33, 2.89]

$2.40^{*}$

$[1.79,3.00]$

$5.24^{*}$

$[10.5,18.1]$

$83 \%$

$[4.29,6.19]$

Forensic inpatients with intellectual disability

- Honest

- Feigning incapacity

Forensic inpatients with psychiatric symptoms

- SIMS $\leq 19$
- SIMS > 19

Undergraduate students I

- Feigning amnesia

Undergraduate students II

- Honest

- Feigning head injury ${ }^{b}$

(Naïve)

(PVT warned)

(PVT coached)

Undergraduate students III

- Honest

- Option to feign anything

(Naïve)

(PVT warned)

(Morally primed)
$15 \quad 39.2(5.6)$

[36.1, 42.3]

$10 \quad 15.8(9.3)$

$[9.1,22.5]$

$53 \quad 43.8(1.6)$

[43.4, 44.2]

$4 \quad 42.0(4.0)$

[35.6, 46.0]

0.99

[0.05, 2.02]

$30 \quad 33.6(14.2)$

[28.3, 38.9]

N/A

$3.22^{*}$
1.984 .42

$94 \%$

[81\%, 99\%]

$1.02^{*}$

[0.44, 1.61]

$4.99 *$

[3.94, 6.03]

0.24

$[-0.12,0.61]$

0.55

$[-0.47,1.56]$

[4\%, $81 \%$ ]

$1.97^{*}$

[1.45, 2.49]

$20 \quad 45.1(1.5)$

[44.4, 45.8]

59

40.1 (6.7)

[38.4, 41.8]

(20)

39.4 (7.5)

[35.9, 42.9]

(19)

40.4 (6.2)

[37.4, 43.4]

(20)

40.5 (6.6)

[37.4, 43.6]

$0.85^{*}$

[0.33, 1.38]

$1.05^{*}$

$[0.39,1.71]$

$1.06^{*}$

[0.38, 1.72]

$0.96^{*}$

$[0.30,1.61]$

N/A

N/A

$0.87^{*}$

$[21 \%, 68 \%] \quad[0.50,1.24]$

$57 \%$

[27\%, 75\%]

$57 \%$

[27\%, 75\%]

$54 \%$

[21\%, 73\%]
$45 \quad 45.3(1.1)$

$[44.9,45.6]$

45

$39.0(8.8)$

[36.3, 41.6]

(15)

$39.5(8.4)$

$[34.9,44.2]$

(15)

$37.9(9.4)$

[32.7, 43.1]

(15)

39.7 (9.2)

\section{$1.00^{*}$}

$[0.56,1.44]$

$1.37^{*}$

$[0.73,2.00]$

$1.57^{*}$

[0.91, 2.21]

$1.21^{*}$

[0.58, 1.83]
[34.6, 44.8]

\begin{tabular}{cc} 
& N/A \\
$55 \%$ & $1.06^{*}$ \\
{$[36 \%, 69 \%]$} & {$[0.65,1.46]$} \\
$67 \%$ & \\
{$[44 \%, 81 \%]$} & \\
$72 \%$ & \\
{$[52 \%, 84 \%]$} & \\
$62 \%$ & \\
{$[37 \%, 78 \%]$} & \\
\hline
\end{tabular}

(continued) 
Table 5.1 (continued)

Note. $\mathrm{CI}=$ confidence interval; SIMS = Structured Inventory of Malingered Symptomatology; N/A = not applicable; $\mathrm{PVT}=$ performance validity test.

aCalculated using the weighted standard deviation of the mean scores of the respective samples (5.90) and the weighted mean score of undergraduate students asked to respond honestly (45.24). bThis sample consists of the "Naïve,", "PVT warned" and "PVT coached" groups, whose mean scores did not statistically differ, $F(2,56)=0.16, p=.85$. cThis sample consists of the "Naïve", "PVT warned" and "Morally primed" groups, whose mean scores did not statistically differ, $F(2,42)=0.17, p=.84$.

*Means are statistically different from the honest control group at the $p<.01$ level.

In the sample of forensic inpatients with psychiatric symptoms, the Pearson productmoment correlation between the MSVA and the SIMS was -.39 (95\% CI $[-0.59,-0.14], p<.01)$, indicating that participants who scored lower on the MSVA tended to endorse more pseudosymptoms on the SIMS. Four patients scored beyond the cutoff $(>19)$ on the SIMS. As a group, these patients tended to score lower on the MSVA $(M=42.0,95 \%$ CI $[35.6,46.0])$ than patients with credible SIMS scores $(M=43.8,95 \%$ CI $[43.4,44.2]) ; t(55)=1.9, p=.06, d=.99$ $(95 \%$ CI $[0.05,2.02])$, but none of them scored below chance level $(<17)$.

In undergraduate students who were asked to feign amnesia (undergraduate sample 1), the mean MSVA score was 33.6 (95\% CI [28.3, 38.9]). Four participants (13\%; $95 \%$ CI [1\%, $25 \%])$ performed below chance $(<17)$ on the MSVA, while three $(10 \%$, including two who also scored below chance on the MSVA) did so on the ASTM (cutoff $<49 ; p<.05$ ). The Pearson product-moment correlation between the MSVA and the ASTM was statistically nonsignificant; $r=.26$ (95\% CI $[-.11, .57], p=.16)$. The majority of the participants $(83 \%)$ scored below the clinical cutoff $(<85)$ on the ASTM, which indicates that participants generally complied with the request to feign memory problems. Individuals who scored below the clinical ASTM cutoff did not have lower MSVA scores than those who scored above the clinical ASTM cutoff, means being 33.5 (95\% CI [21.8, 45.2]) and 34.0 (95\% CI [26.4, 41.6]), respectively; $t(28)=0.07, p=.94$.

In the second sample of undergraduate students, the three experimental feigning groups did not produce statistically different scores on any of the PVTs (MSVA, ASTM, and TOMM; all $F_{\mathrm{s}}(2,56)<2.80$, all $\left.p \mathrm{~s}>.07\right)$. While feigning participants attained statistically lower MSVA scores $(M=40.1,95 \%$ CI $[38.4,41.8])$ than honestly responding participants ( $M$ $=45.1,95 \% \mathrm{CI}[44.4,45.8]) ; t(77)=3.3, p<.01, d=0.85$ (95\% CI [0.33, 1.38]), none of them scored below chance on the MSVA $(<17)$. Neither did experimental feigners perform below chance on the ASTM $(<49 ; p<.05)$ or the TOMM $(<18, p<.05)$. The Pearson product-moment correlations between the MSVA and the TOMM and the ASTM were .77 (95\% CI [.66, .85]) and $.72(95 \% \mathrm{CI}[.59, .81])$, respectively (both $p<.01)$ : participants who produced lower scores on the MSVA also produced lower scores on the TOMM and the ASTM.

In undergraduate sample 3, neither forewarning nor moral priming had any statistical effect on MSVA or SIMS scores in the experimental feigning and honest groups (both $F s(2,42)<0.18$, $p s>.83)$. A comparison of the aggregated experimental feigning and honest groups reveals that feigners scored statistically lower on the MSVA $(M=39.0,95 \% \mathrm{CI}$ 
$[36.3,41.6])$ than the honest group $(M=45.3,95 \%$ CI $[44.9,45.6]) ; t(88)=4.7, p<.01, d=1.00$ $(95 \% \mathrm{CI}[0.56,1.44])$ and statistically higher on the SIMS; $t(88)=10.8, p<.01, d=1.50(95 \% \mathrm{CI}$ $[1.03,1.97])$. The Pearson product-moment correlation between the MSVA and the SIMS was -.69 (95\% CI $[-0.79,-0.56], p<.01)$, signifying that greater endorsement of pseudopsychopathology on the SIMS was associated with suppressed performance on the MSVA. In the experimental feigning group, one participant (2\%; 95\% CI [0\%, 7\%]) scored below chance level on the MSVA $(<17)$, while 24 participants $(53 \%)$ scored beyond the cutoff $(>19)$ on the SIMS. None of the honestly responding participants scored below chance on the MSVA or beyond the cutoff on the SIMS.

Diagnostic accuracy indices

Table 5.2 displays area under the receiver operating characteristic curve (AUC) ${ }^{8}$ values, which represent the overall diagnostic accuracy within the samples.

Table 5.2

Diagnostic accuracy of the Malingering Scale Vocabulary and Abstraction test in various samples

\begin{tabular}{|c|c|c|c|c|c|c|}
\hline Sample & $N$ & $\begin{array}{c}\text { AUC } \\
{[95 \% \mathrm{CI}]}\end{array}$ & Cutoff & $\begin{array}{c}\mathrm{SN} \\
{[95 \% \mathrm{CI}]^{\mathrm{a}}}\end{array}$ & $\begin{array}{c}\mathrm{SP} \\
{[95 \% \mathrm{CI}]^{\mathrm{a}}}\end{array}$ & $\begin{array}{c}\text { OCC } \\
{[95 \% \mathrm{CI}]^{\mathrm{a}}}\end{array}$ \\
\hline \multirow{7}{*}{$\begin{array}{l}\text { Primary school children } \\
\text { - Honest } \\
\text { - Feigning incapacity }\end{array}$} & & & $<17$ & $.47[.25, .70]$ & $1.00[1.00,1.00]$ & $.76[.62, .89]$ \\
\hline & 22 & .97 & $<23$ & $.89[.76,1.00]$ & $.91[.79,1.00]$ & $.90[.81, .99]$ \\
\hline & 19 & {$[.92,1.00]$} & $<35$ & $1.00[1.00,1.00]$ & $.41[.20, .61]$ & $.68[.54, .83]$ \\
\hline & & & $<41$ & $1.00[1.00,1.00]$ & $.09[.00, .21]$ & $.51[36 ., .67]$ \\
\hline & & & $<42$ & $1.00[1.00,1.00]$ & $.09[.00, .13]$ & $.51[36 ., .67]$ \\
\hline & & & $<44$ & $1.00[1.00,1.00]$ & $.05[.00, .00]$ & $.49[.33, .64]$ \\
\hline & & & $<45$ & $1.00[1.00,1.00]$ & $.00[.00, .00]$ & $.46[.31, .62]$ \\
\hline \multirow{7}{*}{$\begin{array}{l}\text { Forensic inpatients with } \\
\text { intellectual disability } \\
\text { - Honest } \\
\text { - Feigning incapacity }\end{array}$} & & & $<17$ & $.50[.19, .81]$ & $1.00[1.00,1.00]$ & $.80[.64, .96]$ \\
\hline & & & $<23$ & $.80[.55, .100]$ & $.93[.81,1.00]$ & $.88[.75,1.00]$ \\
\hline & 15 & .99 & $<35$ & $1.00[1.00,1.00]$ & $.93[.81,1.00]$ & $.96[.88,1.00]$ \\
\hline & 10 & {$[.95,1.00]$} & $<41$ & $1.00[1.00,1.00]$ & $.60[.35, .85]$ & $.76[.59, .93]$ \\
\hline & & & $<42$ & $1.00[1.00,1.00]$ & $.27[.04, .49]$ & $.56[.37, .75]$ \\
\hline & & & $<44$ & $1.00[1.00,1.00]$ & $.13[.00, .31]$ & $.48[.28, .68]$ \\
\hline & & & $<45$ & $1.00[1.00,1.00]$ & $.07[.00, .19]$ & $.44[.25, .63]$ \\
\hline \multirow{7}{*}{$\begin{array}{l}\text { Forensic inpatients with } \\
\text { psychiatric symptoms } \\
\text { - SIMS } \leq 19 \\
\text { - SIMS > } 19\end{array}$} & & & $<17$ & $.04[.00, .00]$ & $1.00[1.00,1.00]$ & $.93[.86,1.00]$ \\
\hline & & & $<23$ & $.08[.00, .00]$ & $1.00[1.00,1.00]$ & $.93[.86,1.00]$ \\
\hline & 53 & .62 & $<35$ & $.25[.00, .67]$ & $1.00[1.00,1.00]$ & $.95[.89,1.00]$ \\
\hline & 4 & {$[.38, .86]$} & $<41$ & $.42[.01, .99]$ & $.98[.94,1.00]$ & $.95[.89,1.00]$ \\
\hline & & & $<42$ & $.47[.01, .99]$ & $.92[.85,1.00]$ & $.89[.82, .97]$ \\
\hline & & & $<44$ & $.54[.01, .99]$ & $.58[.45, .72]$ & $.58[.45, .71]$ \\
\hline & & & $<45$ & $.63[.33,1.00]$ & $.40[.26, .53]$ & $.42[.29, .55]$ \\
\hline
\end{tabular}

\footnotetext{
${ }^{8}$ Area under the receiver operating characteristic curve values are a measure of overall accuracy. They are equivalent to the percentage of correct identifications in a paired comparison task (in which a decision maker is presented with trials containing a positive and a negative target and has to identify the positive target). Values from .50 to .70 indicate low accuracy, .70 to .90 moderate accuracy, and $>.90$ high accuracy (Swets, 1988).
} 
Table 5.2 (continued)

\begin{tabular}{|c|c|c|c|c|c|c|}
\hline Sample & $N$ & $\begin{array}{c}\text { AUC } \\
{[95 \% \mathrm{CI}]}\end{array}$ & Cutoff & $\begin{array}{c}\mathrm{SN} \\
{[95 \% \mathrm{CI}]^{\mathrm{a}}}\end{array}$ & $\begin{array}{c}\mathrm{SP} \\
{[95 \% \mathrm{CI}]^{\mathrm{a}}}\end{array}$ & $\begin{array}{c}\text { OCC } \\
{[95 \% \mathrm{CI}]^{\mathrm{a}}}\end{array}$ \\
\hline $\begin{array}{l}\text { Undergraduate students I } \\
\text { - Feigning amnesia }\end{array}$ & 30 & $\mathrm{~N} / \mathrm{A}$ & $\begin{array}{l}<17 \\
<23 \\
<35 \\
<41 \\
<42 \\
<44 \\
<45\end{array}$ & $\begin{array}{l}.13[.01, .25] \\
.20[.06, .34] \\
.37[.19, .54] \\
.50[.32, .68] \\
.57[.39, .74] \\
.67[.50, .84] \\
.70[.54, .86]\end{array}$ & $\mathrm{N} / \mathrm{A}$ & N/A \\
\hline Undergraduate students II $^{\mathrm{b}}$ & & & $<17$ & $.00[.00, .00]$ & $1.00[1.00,1.00]$ & $.25[.16, .35]$ \\
\hline - Honest & 20 & .76 & $<23$ & $.00[.00, .00]$ & $1.00[1.00,1.00]$ & $.25[.16, .35]$ \\
\hline $\begin{array}{l}\text { - Feigning head injuryc } \\
\text { (Naïve) } \\
\text { (PVT warned) } \\
\text { (PVT coached) }\end{array}$ & $\begin{array}{l}59 \\
(20) \\
(19) \\
(20)\end{array}$ & {$[.65, .86]$} & $\begin{array}{l}<35 \\
<41 \\
<42 \\
<44 \\
<45\end{array}$ & $\begin{array}{l}.19[.09, .29] \\
.39[.27,51] \\
.42[.30, .55] \\
.53[.40, .65] \\
.64[.52,77]\end{array}$ & $\begin{array}{c}1.00[1.00,1.00] \\
.95[.85,1.00] \\
.95[.85,1.00] \\
.95[.85,1.00] \\
.90[.77,1.00]\end{array}$ & $\begin{array}{l}.39[.28, .50] \\
.53[.42, .64] \\
.56[.45, .67] \\
.63[.53, .74] \\
.71[.61, .81]\end{array}$ \\
\hline $\begin{array}{l}\text { Undergraduate students III } \\
\text { - Honest } \\
\text { - Option to feign anythingd } \\
\text { (Naïve) } \\
\text { (PVT warned) } \\
\text { (Morally primed) }\end{array}$ & $\begin{array}{l}45 \\
45 \\
(15) \\
(15) \\
(15)\end{array}$ & $\begin{array}{c}.72 \\
{[.62, .83]}\end{array}$ & $\begin{array}{l}<17 \\
<23 \\
<35 \\
<41 \\
<42 \\
<44 \\
<45\end{array}$ & $\begin{array}{l}.02[.00,07] \\
.09[.01, .17] \\
.24[.12, .37] \\
.40[.26, .54] \\
.47[.32, .61] \\
.49[.34, .63] \\
.58[.43, .72]\end{array}$ & $\begin{array}{c}1.00[1.00,1.00] \\
1.00[1.00,1.00] \\
1.00[1.00,1.00] \\
.98[.93,1.00] \\
.98[.93,1.00] \\
.96[.90,1.00] \\
.87[.77, .97]\end{array}$ & $\begin{array}{l}.51[.41, .61] \\
.54[.44, .65] \\
.62[.52, .72] \\
.69[.59, .78] \\
.72[.63, .81] \\
.72[.63, .81] \\
.72[.63, .81]\end{array}$ \\
\hline
\end{tabular}

Note. $\mathrm{AUC}=$ area under the receiver operating characteristic curve; $\mathrm{CI}=$ confidence interval; $\mathrm{SN}=$ sensitivity; $\mathrm{SP}=$ specificity; $\mathrm{OCC}=$ overall correct classification; SIMS = Structured Inventory of Malingered Symptomatology; N/A = not applicable; PVT = performance validity test. Cutoffs in bold font are optimal cutoffs.

aFor computational simplicity, the asymptotic Gaussian approximation $(p \pm z \sqrt{ }[p\{1-p\} / n])$ was used to calculate $95 \%$ confidence intervals. ${ }^{b}$ Note that AUC, specificity, and overall correct classification (but not sensitivity) values may be overestimations of the values in clinical populations, because they are based on nonclinical controls (i.e., healthy undergraduates). "This sample consists of the "Naïve,", "PVT warned" and "PVT coached" groups, whose mean scores did not statistically differ, $F(2,56)=$ $0.16, p=.85$. dThis sample consists of the "Naïve", "PVT warned" and "Morally primed" groups, whose mean scores did not statistically differ, $F(2,42)=0.17, p=.84$.

In primary school children and forensic inpatients with intellectual disability, the MSVA was very accurate: AUC $=.97$ (95\% CI $[.92,1.00])$ and .99 (95\% CI [.95, 1.00]), respectively. The accuracy in undergraduates is moderate, but still at a level where the test may be useful: AUC = .77 (95\% CI [.70, .83]). The AUC for forensic psychiatric inpatients (with SIMS >19 as the criterion for feigning) is unprecise due to low sample size (95\% CI [.38, .86]). However, substituting the small sample of noncredible forensic psychiatric inpatients $(n=4)$ with the pooled sample of undergraduates who were asked to feign cognitive impairment $(n=134)$ results in an identical AUC parameter estimate: .62 (95\% CI [.56, .70]).

Table 5.2 also lists accuracy characteristics at separate cutoffs. Although the statistical estimates lack precision, it can be concluded that the sensitivity of below-chance cutoffs is 
very modest in children; .47 (95\% CI $[.25, .70])$ and inpatients with intellectual disability; .50 $(95 \%$ CI $[.19, .81])$, and practically absent in nonintellectually disabled adults; .04 (95\% CI $[.01, .07])$. Specificity, on the other hand, is perfect (1.00 in all groups). Sensitivity can be increased by using a clinical floor (i.e., a cutoff below the typical scores of credible patients) instead of a below-chance cutoff. A clinical floor cutoff is typically recommended to possess a specificity of at least .90 (i.e., $\leq 10 \%$ false-positive rate; Boone, 2007). Cutoffs that yield acceptable specificity values in intellectually disabled inpatients are $<35$ and lower; $7 \%$ (95\% CI $[0 \%, 19 \%])$ of intellectually disabled inpatients scored $<35$, see Table 5.2. The $<35$ cutoff is sensitive to experimental noncredible cognitive performance in primary school children and intellectually disabled inpatients (sensitivities of 1.00), but very much less so in groups with better developed cognitive abilities, with sensitivity ranging between .19 (95\% CI [.09, .29]) and .37 (95\% CI $[.19, .54])$.

Predictive power parameters at several base rates are shown in Table 5.3. Positive and negative predictive power (PPP and NPP) denote the probabilities of the presence or absence (respectively) of that which the test aims to capture (i.e., feigned cognitive impairment). Predictive power is dependent on sensitivity, specificity, and the base rate (i.e., prevalence of feigned impairment). Higher base rates translate to higher PPP and lower NPP, whereas lower base rates translate to lower PPP and higher NPP. Aside from the variance due to different base rates, the variance in PPP and NPP in Table 5.3 reflects the variance in sensitivity and specificity as displayed in Table 5.2.

\section{Table 5.3}

Positive and negative predictive power of the Malingering Scale Vocabulary and Abstraction test at different base rates in various samples

\begin{tabular}{|c|c|c|c|c|c|c|c|c|}
\hline \multirow[t]{2}{*}{ Sample } & \multirow[t]{2}{*}{$N$} & \multirow[t]{2}{*}{ Cutoff } & \multicolumn{3}{|c|}{$\begin{array}{l}\text { Positive predictive power } \\
\text { at base rate: }[95 \% \mathrm{CI}]^{\mathrm{a}}\end{array}$} & \multicolumn{3}{|c|}{$\begin{array}{l}\text { Negative predictive power } \\
\text { at base rate: }[95 \% \mathrm{CI}]^{\mathrm{a}}\end{array}$} \\
\hline & & & $10 \%$ & $30 \%$ & $50 \%$ & $10 \%$ & $30 \%$ & $50 \%$ \\
\hline \multirow{14}{*}{$\begin{array}{l}\text { Primary school } \\
\text { children } \\
\text { - Honest } \\
\text { - Feigning }\end{array}$} & \multirow{14}{*}{$\begin{array}{l}22 \\
19\end{array}$} & $<17$ & 1.00 & 1.00 & 1.00 & .94 & .81 & .65 \\
\hline & & & {$[1.00,1.00]$} & {$[1.00,1.00]$} & {$[1.00,1.00]$} & {$[.87,1.00]$} & {$[.69, .94]$} & {$[.49, .82]$} \\
\hline & & $<23$ & .53 & .81 & .91 & .99 & .96 & .90 \\
\hline & & & {$[.16, .90]$} & {$[.60,1.00]$} & {$[.78,1.00]$} & {$[.95,1.00]$} & {$[.88,1.00]$} & {$[.77,1.00]$} \\
\hline & & $<35$ & .16 & .42 & .63 & 1.00 & 1.00 & 1.00 \\
\hline & & & {$[.02, .30]$} & {$[.24, .60]$} & {$[.46, .79]$} & {$[1.00,1.00]$} & {$[1.00,1.00]$} & {$[1.00,1.00]$} \\
\hline & & $<41$ & .11 & .32 & .52 & 1.00 & 1.00 & 1.00 \\
\hline & & & {$[.01, .21]$} & {$[.17, .47]$} & {$[.37, .68]$} & {$[1.00,1.00]$} & {$[1.00,1.00]$} & {$[1.00,1.00]$} \\
\hline & & $<42$ & .11 & .32 & .52 & 1.00 & 1.00 & 1.00 \\
\hline & & & {$[.01, .21]$} & {$[.17, .47]$} & {$[.37, .68]$} & {$[1.00,1.00]$} & {$[1.00,1.00]$} & {$[1.00,1.00]$} \\
\hline & & $<44$ & .10 & .31 & .51 & 1.00 & 1.00 & 1.00 \\
\hline & & & {$[.01, .20]$} & {$[.17, .46]$} & {$[.36, .67]$} & {$[1.00,1.00]$} & {$[1.00,1.00]$} & {$[1.00,1.00]$} \\
\hline & & $<45$ & .10 & .30 & .50 & N/A & 1.00 & 1.00 \\
\hline & & & {$[.01, .19]$} & {$[.16, .44]$} & {$[.35, .65]$} & & {$[1.00,1.00]$} & {$[1.00,1.00]$} \\
\hline
\end{tabular}


Table 5.3 (continued)

\begin{tabular}{|c|c|c|c|c|c|c|c|c|}
\hline \multirow[t]{2}{*}{ Sample } & \multirow[t]{2}{*}{$N$} & \multirow[t]{2}{*}{ Cutoff } & \multicolumn{3}{|c|}{$\begin{array}{c}\text { Positive predictive power } \\
\text { at base rate: }[95 \% \mathrm{CI}]^{\mathrm{a}}\end{array}$} & \multicolumn{3}{|c|}{$\begin{array}{c}\text { Negative predictive power } \\
\text { at base rate: }[95 \% \mathrm{CI}]^{\mathrm{a}}\end{array}$} \\
\hline & & & $10 \%$ & $30 \%$ & $50 \%$ & $10 \%$ & $30 \%$ & $50 \%$ \\
\hline \multirow{8}{*}{$\begin{array}{l}\text { Forensic } \\
\text { inpatients w } \\
\text { intel. disabil } \\
\text { - Honest } \\
\text { - Feigning }\end{array}$} & & $<17$ & $\begin{array}{c}1.00 \\
{[1.00,1.00]}\end{array}$ & $\begin{array}{c}1.00 \\
{[1.00,1.00]}\end{array}$ & $\begin{array}{c}1.00 \\
{[1.00,1.00]}\end{array}$ & $\begin{array}{c}.95 \\
{[86 ., 1.00]}\end{array}$ & $\begin{array}{c}.82 \\
{[.66, .99]}\end{array}$ & $\begin{array}{c}.67 \\
{[.45, .88]}\end{array}$ \\
\hline & & $<23$ & .56 & .83 & .92 & .98 & .92 & .82 \\
\hline & 15 & & {$[.04 ., 1.00]$} & {$[.56,1.00]$} & {$[.76,1.00]$} & {$[.91,1.00]$} & {$[.79,1.00]$} & {$[.62,1.00]$} \\
\hline & 10 & $<35$ & $\begin{array}{c}.61 \\
{[.14,1.00]}\end{array}$ & $\begin{array}{c}.86 \\
{[.63,1.00]}\end{array}$ & $\begin{array}{c}.93 \\
{[.80,1.00]}\end{array}$ & $\begin{array}{c}1.00 \\
{[1.00,1.00]}\end{array}$ & $\begin{array}{c}1.00 \\
{[1.00,1.00]}\end{array}$ & $\begin{array}{c}1.00 \\
{[1.00,1.00]}\end{array}$ \\
\hline & & $<41$ & $\begin{array}{c}.22 \\
{[.00, .46]}\end{array}$ & $\begin{array}{c}.52 \\
{[.26, .77]}\end{array}$ & $\begin{array}{c}.71 \\
{[.50, .93]}\end{array}$ & $\begin{array}{c}1.00 \\
{[1.00,1.00]}\end{array}$ & $\begin{array}{c}1.00 \\
{[1.00,1.00]}\end{array}$ & $\begin{array}{c}1.00 \\
{[1.00,1.00]}\end{array}$ \\
\hline & & $<42$ & $\begin{array}{c}.13 \\
{[.00, .28]}\end{array}$ & $\begin{array}{c}.37 \\
{[.16, .58]}\end{array}$ & $\begin{array}{c}.58 \\
{[.37, .79]}\end{array}$ & $\begin{array}{c}1.00 \\
{[1.00,1.00]}\end{array}$ & $\begin{array}{c}1.00 \\
{[1.00,1.00]}\end{array}$ & $\begin{array}{c}1.00 \\
{[1.00,1.00]}\end{array}$ \\
\hline & & $<44$ & $\begin{array}{c}.11 \\
{[.00, .25]}\end{array}$ & $\begin{array}{c}.33 \\
{[.14, .52]}\end{array}$ & $\begin{array}{c}.53 \\
{[.33, .74]}\end{array}$ & $\begin{array}{c}1.00 \\
{[1.00,1.00]}\end{array}$ & $\begin{array}{c}1.00 \\
{[1.00,1.00]}\end{array}$ & $\begin{array}{c}1.00 \\
{[1.00,1.00]}\end{array}$ \\
\hline & & $<45$ & $\begin{array}{c}.11 \\
{[.00, .23]}\end{array}$ & $\begin{array}{c}.32 \\
{[.13, .50]}\end{array}$ & $\begin{array}{c}.52 \\
{[.32, .72]}\end{array}$ & $\begin{array}{c}1.00 \\
{[1.00,1.00]}\end{array}$ & $\begin{array}{c}1.00 \\
{[1.00,1.00]}\end{array}$ & $\begin{array}{c}1.00 \\
{[1.00,1.00]}\end{array}$ \\
\hline $\begin{array}{l}\text { Forensic } \\
\text { inpatients with }\end{array}$ & & $<17$ & $\begin{array}{c}1.00 \\
{[1.00,1.00]}\end{array}$ & $\begin{array}{c}1.00 \\
{[1.00,1.00]}\end{array}$ & $\begin{array}{c}1.00 \\
{[1.00,1.00]}\end{array}$ & $\begin{array}{c}.90 \\
{[.83, .98]}\end{array}$ & $\begin{array}{c}.71 \\
{[.59, .83]}\end{array}$ & $\begin{array}{c}.51 \\
{[.38, .64]}\end{array}$ \\
\hline $\begin{array}{l}\text { psych. symptoms } \\
\text { - SIMS } \leq 19\end{array}$ & 53 & $<23$ & $\begin{array}{c}1.00 \\
{[1.00,1.00]}\end{array}$ & $\begin{array}{c}1.00 \\
{[1.00,1.00]}\end{array}$ & $\begin{array}{c}1.00 \\
{[1.00,1.00]}\end{array}$ & $\begin{array}{c}.91 \\
{[.83, .98]}\end{array}$ & $\begin{array}{c}.72 \\
{[.60, .84]}\end{array}$ & $\begin{array}{c}.52 \\
{[.39, .65]}\end{array}$ \\
\hline \multirow[t]{5}{*}{ - SIMS > 19} & 4 & $<35$ & $\begin{array}{c}1.00 \\
{[1.00,1.00]}\end{array}$ & $\begin{array}{c}1.00 \\
{[1.00,1.00]}\end{array}$ & $\begin{array}{c}1.00 \\
{[1.00,1.00]}\end{array}$ & $\begin{array}{c}.92 \\
{[.85, .99]}\end{array}$ & $\begin{array}{c}.76 \\
{[.64, .87]}\end{array}$ & $\begin{array}{c}.57 \\
{[.43, .71]}\end{array}$ \\
\hline & & $<41$ & $\begin{array}{c}.70 \\
{[.21,1.00]}\end{array}$ & $\begin{array}{c}.90 \\
{[.69,1.00]}\end{array}$ & $\begin{array}{c}.95 \\
{[.84,1.00]}\end{array}$ & $\begin{array}{c}.94 \\
{[.87,1.00]}\end{array}$ & $\begin{array}{c}.80 \\
{[.69, .91]}\end{array}$ & $\begin{array}{c}.63 \\
{[.49, .77]}\end{array}$ \\
\hline & & $<42$ & $\begin{array}{c}.39 \\
{[.03, .76]}\end{array}$ & $\begin{array}{c}.72 \\
{[.45, .98]}\end{array}$ & $\begin{array}{c}.85 \\
{[.68,1.00]}\end{array}$ & $\begin{array}{c}.94 \\
{[.87,1.00]}\end{array}$ & $\begin{array}{c}.80 \\
{[.69, .92]}\end{array}$ & $\begin{array}{c}.63 \\
{[.49, .78]}\end{array}$ \\
\hline & & $<44$ & $\begin{array}{c}.13 \\
{[.00, .26]}\end{array}$ & $\begin{array}{c}.36 \\
{[.17, .54]}\end{array}$ & $\begin{array}{c}.56 \\
{[.38, .75]}\end{array}$ & $\begin{array}{c}.92 \\
{[.83,1.00]}\end{array}$ & $\begin{array}{c}.75 \\
{[.59, .90]}\end{array}$ & $\begin{array}{c}.56 \\
{[.38, .74]}\end{array}$ \\
\hline & & $<45$ & $\begin{array}{c}.10 \\
{[.00, .21]}\end{array}$ & $\begin{array}{c}.31 \\
{[.16, .46]}\end{array}$ & $\begin{array}{c}.51 \\
{[.35, .68]}\end{array}$ & $\begin{array}{c}.91 \\
{[.79,1.00]}\end{array}$ & $\begin{array}{c}.72 \\
{[.53, .90]}\end{array}$ & $\begin{array}{c}.52 \\
{[.31, .73]}\end{array}$ \\
\hline $\begin{array}{l}\text { Undergraduate } \\
\text { students II }{ }^{\mathrm{b}}\end{array}$ & & $<17$ & $\mathrm{~N} / \mathrm{A}$ & $\mathrm{N} / \mathrm{A}$ & N/A & $\begin{array}{c}.90 \\
{[.83, .97]}\end{array}$ & $\begin{array}{c}.70 \\
{[.60, .80]}\end{array}$ & $\begin{array}{c}.50 \\
{[.39, .61]}\end{array}$ \\
\hline - Honest & 20 & $<23$ & $\mathrm{~N} / \mathrm{A}$ & $\mathrm{N} / \mathrm{A}$ & $\mathrm{N} / \mathrm{A}$ & .90 & .70 & .50 \\
\hline - Feigning ${ }^{c}$ & 59 & & & & & {$[.83, .97]$} & {$[.60, .80]$} & {$[.39, .61]$} \\
\hline (Naïve) & $(20)$ & $<35$ & 1.00 & 1.00 & 1.00 & .92 & .74 & .55 \\
\hline (PVT warned) & (19) & & {$[1.00,1.00]$} & {$[1.00,1.00]$} & {$[1.00,1.00]$} & {$[.86, .98]$} & {$[.64, .84]$} & {$[.44, .67]$} \\
\hline \multirow[t]{5}{*}{ (PVT coached) } & $(20)$ & $<41$ & .46 & .77 & .89 & .93 & .78 & .61 \\
\hline & & & {$[.08, .84]$} & {$[.53,1.00]$} & {$[.74,1.00]$} & {$[.88, .99]$} & {$[.69, .88]$} & {$[.49, .73]$} \\
\hline & & $<42$ & $\begin{array}{c}.48 \\
{[.11, .86]}\end{array}$ & $\begin{array}{c}.78 \\
{[.56,1.00]}\end{array}$ & $\begin{array}{c}.89 \\
{[.75,1.00]}\end{array}$ & $\begin{array}{c}.94 \\
{[.88, .99]}\end{array}$ & $\begin{array}{c}.79 \\
{[.70, .89]}\end{array}$ & $\begin{array}{c}.62 \\
{[.50, .74]}\end{array}$ \\
\hline & & $<44$ & $\begin{array}{c}.54 \\
{[.19, .89]}\end{array}$ & $\begin{array}{c}.82 \\
{[.63,1.00]}\end{array}$ & $\begin{array}{c}.91 \\
{[.80,1.00]}\end{array}$ & $\begin{array}{c}.95 \\
{[.90,1.00]}\end{array}$ & $\begin{array}{c}.83 \\
{[.73, .92]}\end{array}$ & $\begin{array}{c}.67 \\
{[.55, .79]}\end{array}$ \\
\hline & & $<45$ & $\begin{array}{c}.42 \\
{[.14, .69]}\end{array}$ & $\begin{array}{c}.73 \\
{[.54, .92]}\end{array}$ & $\begin{array}{c}.86 \\
{[.74, .99]}\end{array}$ & $\begin{array}{c}.96 \\
{[.91,1.00]}\end{array}$ & $\begin{array}{c}.85 \\
{[.76, .94]}\end{array}$ & $\begin{array}{c}.71 \\
{[.59, .84]}\end{array}$ \\
\hline
\end{tabular}


Chapter 5

Table 5.3 (continued)

Positive and negative predictive power of the Malingering Scale Vocabulary and Abstraction test at different base rates in various samples

\begin{tabular}{|c|c|c|c|c|c|c|c|c|}
\hline \multirow[t]{2}{*}{ Sample } & \multirow[t]{2}{*}{$N$} & \multirow[t]{2}{*}{ Cutoff } & \multicolumn{3}{|c|}{$\begin{array}{l}\text { Positive predictive power } \\
\text { at base rate: }[95 \% \mathrm{CI}]^{\mathrm{a}}\end{array}$} & \multicolumn{3}{|c|}{$\begin{array}{l}\text { Negative predictive power } \\
\text { at base rate: }[95 \% \mathrm{CI}]^{\mathrm{a}}\end{array}$} \\
\hline & & & $10 \%$ & $30 \%$ & $50 \%$ & $10 \%$ & $30 \%$ & $50 \%$ \\
\hline \multirow{2}{*}{$\begin{array}{l}\text { Undergraduate } \\
\text { students III }\end{array}$} & & \multirow[t]{2}{*}{$<17$} & 1.00 & 1.00 & 1.00 & .90 & .70 & .51 \\
\hline & & & {$[1.00,1.00]$} & {$[1.00,1.00]$} & {$[1.00,1.00]$} & {$[.84, .96]$} & {$[.61, .80]$} & {$[.40, .61]$} \\
\hline - Honest & 45 & \multirow[t]{2}{*}{$<23$} & 1.00 & 1.00 & 1.00 & .91 & .72 & .52 \\
\hline - Feigningd & 45 & & {$[1.00,1.00]$} & {$[1.00,1.00]$} & {$[1.00,1.00]$} & {$[.85, .97]$} & {$[.63, .81]$} & {$[.42, .63]$} \\
\hline (Naïve) & (15) & \multirow[t]{2}{*}{$<35$} & 1.00 & 1.00 & 1.00 & .92 & .75 & .57 \\
\hline (PVT warned) & (15) & & {$[1.00,1.00]$} & {$[1.00,1.00]$} & {$[1.00,1.00]$} & {$[.87, .98]$} & {$[.66, .85]$} & {$[.46, .68]$} \\
\hline \multirow[t]{8}{*}{ (Morally primed) } & $(15)$ & \multirow[t]{2}{*}{$<41$} & .69 & .90 & .95 & .94 & .79 & .62 \\
\hline & & & {$[.29,1.00]$} & {$[72 ., 1.00]$} & {$[.86,1.00]$} & {$[.88, .99]$} & {$[.70, .88]$} & {$[.51, .73]$} \\
\hline & & \multirow[t]{2}{*}{$<42$} & .72 & .91 & .96 & .94 & .81 & .65 \\
\hline & & & {$[.26,1.00]$} & {$[.76,1.00]$} & {$[.88,1.00]$} & {$[.89, .99]$} & {$[.72, .90]$} & {$[.54, .76]$} \\
\hline & & \multirow[t]{2}{*}{$<44$} & .58 & .84 & .92 & .94 & .81 & .65 \\
\hline & & & {$[.23, .93]$} & {$[.66,1.00]$} & {$[.82,1.00]$} & {$[.89, .99]$} & {$[.73, .90]$} & {$[.54, .77]$} \\
\hline & & \multirow[t]{2}{*}{$<45$} & .33 & .66 & .82 & .95 & .83 & .67 \\
\hline & & & {$[.10, .56]$} & {$[.47, .85]$} & {$[.68, .95]$} & {$[.90,1.00]$} & {$[.74, .92]$} & {$[.55, .79]$} \\
\hline
\end{tabular}

Note. $\mathrm{CI}=$ confidence interval; N/A = not applicable; SIMS = Structured Inventory of Malingered Symptomatology; PVT = performance validity test. Cutoffs in bold font represent optimal cutoffs.

aFor computational simplicity, the asymptotic Gaussian approximation $(p \pm z \sqrt{ }[p\{1-p\} / n])$ was used to calculate $95 \%$ confidence intervals. ${ }^{\text {} N o t e ~ t h a t ~ n e g a t i v e ~ a n d ~ p o s i t i v e ~ p r e d i c t i v e ~ p o w e r ~ v a l u e s ~ m a y ~ b e ~}$ overestimations of the values in clinical populations, because they are based on nonclinical controls (i.e., healthy undergraduates). "This sample consists of the "Naïve,", "PVT warned" and "PVT coached" groups, whose mean scores did not statistically differ, $F(2,56)=0.16, p=.85$. dThis sample consists of the "Naïve", "PVT warned" and "Morally primed" groups, whose mean scores did not statistically differ, $F(2,42)=0.17, p=.84$.

\section{Comparisons with ASTM and TOMM}

Table 5.4 contrasts the diagnostic accuracy indices of the MSVA with that of the other validity tests that we administered in some samples. In the sample of undergraduate students who were asked to feign amnesia (undergraduate sample 1), the sensitivity of the ASTM (cutoff <85) was .83 (95\% CI [.70, .97]), whereas that of the MSVA (cutoff <42) was .57 $(95 \%$ CI $[.39, .74])$. Thus, the MSVA is outperformed by the ASTM, yet this is unsurprising considering that feigned memory problems are the target pathology of the ASTM, but not of the MSVA. The MSVA identified 3 (10\%) experimental feigners that remained undetected by the ASTM.

Participants in the undergraduate sample who either responded honestly or could opt to feign head injury symptoms (undergraduate sample 2) were given the MSVA, the ASTM, and the TOMM. The MSVA produced an AUC that was slightly lower than those of the ASTM and the TOMM; .76 (95\% CI $[.65, .86])$ versus .84 (95\% CI $[.75, .93])$ and $.83(95 \%$ CI $[.74, .92])$, respectively. The specificity of all three PVTs was excellent; the MSVA achieved 
.95 (95\% CI $[.85,1.00]$, cutoff <42), the ASTM .95 (95\% CI $[.85,1.00]$, cutoff <85), and the TOMM 1.00 (cutoff $<45$ at Trial 2). The sensitivity of the MSVA was moderate; .42 (95\% CI $[.30, .55])$, but comparable to that of the TOMM; .46 (95\% CI $[.33, .58])$, yet below that of the ASTM; .61 (95\% CI $[.49, .73])$. The MSVA detected 3 (5\%) experimental feigners that were missed by the ASTM and 4 (7\%) that were missed by the TOMM.

An interesting observation from Table 5.4 is that the MSVA is considerably less efficient than the SIMS when individuals are asked to consider the option to feign symptoms (i.e., choose to feign no symptoms or any symptoms of their choosing); AUC $=.72$ (95\% CI $[.62, .83])$ versus .96 (95\% CI $[.92,1.00])$. This difference may, in part, reflect the different domains that are tapped by PVTs (i.e., cognitive underperformance) and symptom validity tests such as the SIMS (i.e., symptom overreporting; see, e.g., van Dyke, Millis, Axelrod, \& Hanks, 2013).

\section{Table 5.4}

Comparison of diagnostic accuracy of the Malingering Scale Vocabulary and Abstraction test with several other validity tests

\begin{tabular}{|c|c|c|c|c|c|c|c|}
\hline Sample & $N$ & Test & $\begin{array}{c}\text { AUC } \\
{[95 \% \mathrm{CI}]}\end{array}$ & Cutoff & $\begin{array}{c}\mathrm{SN} \\
{[95 \% \mathrm{CI}]^{\mathrm{a}}}\end{array}$ & $\begin{array}{c}\mathrm{SP} \\
{[95 \% \mathrm{CI}]^{\mathrm{a}}}\end{array}$ & $\begin{array}{c}\text { OCC } \\
{[95 \% \mathrm{CI}]^{\mathrm{a}}}\end{array}$ \\
\hline $\begin{array}{l}\text { Undergraduate } \\
\text { students I } \\
\text { - Feigning }\end{array}$ & 30 & MSVA & N/A & $\begin{array}{l}<42 \\
<44\end{array}$ & $\begin{array}{l}.57[.39, .74] \\
.67[.50, .84]\end{array}$ & N/A & N/A \\
\hline $\begin{array}{l}\text { Undergraduate } \\
\text { students } \text { II }^{\mathrm{b}}\end{array}$ & & MSVA & $\begin{array}{c}.76 \\
{[.65, .86]}\end{array}$ & $\begin{array}{l}<42 \\
<44\end{array}$ & $\begin{array}{l}.42[.30, .55] \\
.53[.40, .65]\end{array}$ & $\begin{array}{l}.95[.85,1.00] \\
.95[.85,1.00]\end{array}$ & $\begin{array}{l}.56[.45, .67] \\
.63[.53, .75]\end{array}$ \\
\hline $\begin{array}{l}\text { - Honest } \\
\text { - Feigning } \\
\text { (Naïve) }\end{array}$ & $\begin{array}{l}20 \\
59 \\
(20)\end{array}$ & ASTM & $\begin{array}{c}.84 \\
{[.75, .93]}\end{array}$ & $<85$ & $.61[.49,73]$ & $.95[.85,1.00]$ & $.70[.59, .80]$ \\
\hline $\begin{array}{l}\text { (PVT warned) } \\
\text { (PVT coached) }\end{array}$ & $\begin{array}{l}(19) \\
(20)\end{array}$ & TOMM & $\begin{array}{c}.83 \\
{[.74, .92]}\end{array}$ & $<45$ & $.46[.33, .58]$ & $1.00[1.00,1.00]$ & $.59[.49, .70]$ \\
\hline $\begin{array}{l}\text { Undergraduate } \\
\text { students III }\end{array}$ & & MSVA & .72 & $<42$ & $.47[.32, .61]$ & $.98[.93,1.00]$ & $.72[.63, .81]$ \\
\hline $\begin{array}{l}\text { - Honest } \\
\text { - Feigningd } \\
\text { (Naïve) }\end{array}$ & $\begin{array}{c}45 \\
45 \\
(15)\end{array}$ & SIMS & {$[.62, .83]$} & $<44$ & $.49[.34, .63]$ & $.96[.90,1.00]$ & $.72[.63, .81]$ \\
\hline $\begin{array}{l}\text { (PVT warned) } \\
\text { (Morally primed) }\end{array}$ & $\begin{array}{l}(15) \\
(15)\end{array}$ & & {$[.92,1.00]$} & & & & \\
\hline
\end{tabular}

Note. $\mathrm{AUC}=$ area under the receiver operating characteristic curve; $\mathrm{CI}=$ confidence interval; $\mathrm{SN}=$ sensitivity; $\mathrm{SP}=$ specificity; $\mathrm{OCC}=$ overall correct classification; $\mathrm{MSVA}=$ Malingering Scale Vocabulary and Abstraction test; N/A = not applicable; ASTM = Amsterdam Short-Term Memory test; PVT = performance validity test; TOMM = Test of Memory Malingering; SIMS = Structured Inventory of Malingered Symptomatology. Cutoffs in bold font represent optimal cutoffs.

aFor computational simplicity, the asymptotic Gaussian approximation $(p \pm z \sqrt{ }[p\{1-p\} / n])$ was used to calculate 95\% confidence intervals. ${ }^{b}$ Note that AUC, specificity, and overall correct classification (but not sensitivity) values may be overestimations of the values in clinical populations, because they are based on nonclinical controls (i.e., healthy undergraduates). "This sample consists of the "Naïve,", "PVT warned" and "PVT coached" groups, whose mean scores did not statistically differ, $F(2,56)=$ $0.16, p=.85$. dThis sample consists of the "Naïve", "PVT warned" and "Morally primed" groups, whose mean scores did not statistically differ, $F(2,42)=0.17, p=.84$. 


\section{Discussion}

The main conclusions of our study can be summarized as follows. First, as can be seen in Table 5.1, the effect of experimentally feigned cognitive impairment on MSVA scores was moderate to very large; Cohen's $d=0.87$ (95\% CI $[0.50,1.24])$ to $1.97(95 \%$ CI $[1.45,2.49])$. The effect of authentic intellectual disability was moderate; $d=1.02$ (95\% CI $[0.44,1.61])$. Because these effects are close to each other in magnitude, the MSVA cannot sufficiently discriminate between intellectual disability and feigned cognitive impairment. This result echoes the results of the initial validation study of the MgS (Schretlen, 1986), where adults with intellectual disability (mean $I Q=47)$ produced MSVA scores $(M=32.4)$ similar to those of prison inmates (mean $\mathrm{IQ}=101)$ asked to feign insanity $(M=33.6)$ or intellectual disability $(M$ $=$ 18.3). Inadequacy in discriminating intellectual disability from feigned cognitive impairment is not unique to the MSVA; many other PVTs suffer from low specificity when their standard cutoffs are employed in intellectually disabled populations (for a review, see Victor \& Boone, 2007).

Second, to keep false-positive rates acceptably small in intellectually disabled populations one can rely on more stringent cutoffs. This typically diminishes sensitivity to feigned impairment in non-intellectually disabled populations. Table 5.2 illustrates this: a cutoff of $<35$ is needed to maintain a specificity above .90 in forensic inpatients with intellectual disability. While this cutoff provided great sensitivity in the intellectually disabled sample; 1.00, it yielded poor sensitivity in the non-intellectually disabled samples; $.19(95 \%$ CI $[.09, .29])$ to .37 (95\% CI $[.19, .54])$. The best approach would be to select a cutoff based on the intellectual disability status of a patient. In some cases, this can be feasible, because intellectual disability is a chronic and pervasive condition that manifests in early childhood (see American Psychiatric Association, 2013). As such, its presence can potentially be established through medical records and collateral sources.

Third, children (aged 7-13 years) produced considerably lower scores than young adults, lower even than intellectually disabled adults; means of 31.1 (95\% CI [27.6, 34.6]) versus 39.2 (95\% CI [36.1, 42.3]), which translates to a particularly strict cutoff. Acceptable specificity is attained with cutoffs of 23 and lower; $<23$ couples a specificity of $.91(95 \% \mathrm{CI}$ $[.79,1.00])$ with $.89(95 \%$ CI $[.76,1.00])$ sensitivity; <22 couples .95 (95\% CI [.86, 1.00]) specificity with .79 (95\% CI $[.61, .97])$ sensitivity, and $<21$ provides perfect specificity (1.00), albeit with unsatisfactory sensitivity; .58 (95\% CI [.36, .80]). A cutoff of $<21$ also yields perfect specificity among forensic patients with intellectual disability $(\mathrm{IQ}<70)$, which suggests that this cutoff is a clinical floor below which adults with mild cognitive disabilities are very unlikely to score.

Constraints in cognitive abilities, such as present in individuals with intellectual disability and children, clearly had a significant effect on MSVA scores; ds of 1.02 (95\% CI $[0.44,1.61])$ and 2.40 (95\% CI [1.79, 3.00]), respectively. By contrast, psychiatric symptomatology did not have a statistically significant impact; $d=0.24$ (95\% CI $[-0.12,0.61])$. Consequently, the cutoff to achieve a specificity above .90 in psychiatric inpatients was 
substantially higher $(<42)$ than among children $(<23)$ and inpatients with intellectual disability $(<35)$. The sensitivity that is associated with cutoff $<42$ in adults without intellectual disability is poor; .46 (95\% CI [.38, .55]) in the aggregated data. In comparison, Schretlen et al. (2000) attained superior accuracy statistics with a cutoff of $<37$ in a sample of malingering criminal defendants; a sensitivity of .73 coupled with .92 specificity.

Fourth, the results in Table 5.2 indicate that below-chance performance on the MSVA (i.e., scoring below 17) primarily occurs when children and inpatients with intellectual disability attempt to feign cognitive impairment (see also Schretlen \& Arkowitz, 1990). It occurs rarely among groups that are presumably more skillful in simulating cognitive impairment. Thus, outside intellectually disabled or juvenile populations, employment of below-chance cutoffs will result in a very low detection rate of feigned cognitive impairment. Yet, a below-chance cutoff has a specific utility; it can be used to rule in noncredible cognitive performance with great certainty (Merten \& Merckelbach, 2013a). The present studies attest to this, as the $<17$ cutoff had a zero percent false-positive rate in all groups, including children and intellectually disabled inpatients.

Recently, Binder and colleagues (2014) advocated the use of less stringent probability levels (e.g., $p<.20$, one tailed, calculated without correction for continuity) when determining below-chance performance on validated forced-choice tests. For the MSVA, $p<$ .20 (one tailed, without correction for continuity) corresponds to a cutoff of $<20$. In the present samples, this more lenient below-chance criterion yielded perfect specificity $(0 \%$ false positives), but did not provide greater sensitivity than the conservative $<17$ ( $p<.05$ ) cutoff.

Fifth, as can be seen in Table 5.2, forewarning that the MSVA can detect feigning does not lead experimental feigners to produce higher (i.e., more credible) MSVA scores. Even the provision of information about credible symptoms and how to pass PVTs (i.e., coaching) had little effect on the MSVA scores of experimental feigners. Incidentally, ASTM and TOMM scores were equally unaffected by coaching, which suggests that PVTs are fairly robust against educated attempts at feigning (for similar conclusions, see Jelicic, Ceunen, Peters, \& Merckelbach, 2011; Powell, Gfeller, Hendricks, \& Sharland, 2004).

Sixth, the MSVA did not correlate significantly with the ASTM in the sample of undergraduates who were asked to feign amnesia; $r=.26$ (95\% CI [-.11, .57], $p=.16)$, suggesting that the MSVA taps another cognitive domain than the memory-oriented ASTM. Nevertheless, the MSVA identified three experimental feigners (10\%) that evaded detection by the ASTM. In the sample of undergraduates who experimentally feigned head injury, the MSVA did correlate significantly with the ASTM; $r=.72$ (95\% CI [.59, .81], $p<.01)$, as well as with the TOMM; $r=.77$ (95\% CI [.66, .85], $p<.01)$, indicating that the MSVA captures largely the same variance of feigned head injury as the ASTM and the TOMM do. Still, the MSVA exposed three experimental feigners (5\%) that were not marked by the ASTM or the TOMM, and one $(2 \%)$ that was missed by the TOMM, underscoring that the MSVA can have incremental value when used in conjunction with other PVTs.

Undergraduates who were asked to feign amnesia ( $M=33.6,95 \%$ CI $[28.3,38.9])$ produced statistically lower MSVA scores than undergraduates who were asked to feign 
head injury $(M=40.1,95 \% \mathrm{CI}[38.4,41.8])$ or who were given the option to feign anything ( $M$ $=39.0,95 \% \mathrm{CI}[36.3,41.6]) ; t(87)=-2.96, p<.00$ and $t(73)=-2.06, p=.04$, respectively. Rather than indicating that the MSVA is more sensitive to feigned amnesia than to feigned head injury or other feigned symptoms, we believe this reflects the difference in experimental paradigms that were used. The undergraduates who were asked to feign head injury or were given the option to feign anything read civil case vignettes, whereas the undergraduates who were asked to feign amnesia read a criminal case vignette and were presented with pictures of the case. Our results are consistent with the finding by Merckelbach, Smeets, and Jelicic (2009) that, compared with civil case vignettes, criminal case vignettes elicit feigning behavior that is easier to detect.

The most prominent limitations of the present studies are the small sample sizes. The precision of accuracy indices diminishes as sample sizes decrease, because small samples may not reflect the full range or actual distribution of possible scores. Small sample sizes also restrict the precision of accuracy indices because they result in crude metric scales, with large units of measurement (i.e., fewer gradations): For example, in a sample of 20 persons, the smallest unit of measurement is $5 \%$ (i.e., each person represents $5 \%$ of the sample). Another restriction of small sample sizes is that they do not allow for the splitting of subsamples to cross-validate optimal cutoffs. Therefore, the cutoffs that are reported here need to be crossvalidated by larger psychometric studies.

Before the MSVA is to be used in clinical practice, it is highly recommended to put it to the test in various clinical populations. Moreover, we encourage the use of so-called "known-groups" designs (see Rogers, 2008a). The present studies employed an experimental design; they only include feigners who were asked to feign, not feigners who were classified as such under real-world conditions. In known-groups studies, the status of participants as credible or noncredible responders is established through independent assessment of performance and/or symptom validity. The validity test under investigation is then administered to see how well it classifies the "known groups."

In sum, because the MSVA is not geared toward simulated memory deficits, it has the potential to supplement PVTs that do primarily target feigned memory problems. The reliability of the MSVA, as quantified by Cronbach's $\alpha$, is excellent $(\alpha=.93-.97)$ and the MSVA appears not to be overly vulnerable to coaching (i.e., informed attempts to pass PVTs while feigning). Its diagnostic accuracy, on the other hand, is less satisfactory. The main issue is that intellectual disability suppresses MSVA scores to the extent that it is difficult to differentiate it from feigned impairment, a problem that plagues other PVTs as well (see Victor \& Boone, 2007).

The below-chance cutoff $(<17)$ yielded zero false positives, yet also few true positives, except in children and inpatients with intellectual disability. This confirms that below-chance cutoffs detect feigned impairment only sporadically, but when they do they provide strong evidence of feigned impairment. To increase the detection rate (sensitivity), candidates for clinical floor (i.e., norm-referenced) cutoffs should be considered. With such cutoffs, the corresponding sensitivities to experimentally feigned cognitive impairment are acceptable in 
children and inpatients with intellectual disability; .90 (95\% CI [.76, 1.00]) and 1.00, respectively), yet disappointingly low in adults without intellectual disability; .46 (95\% CI $[.38, .55])$. All in all, we believe that the MSVA is not ready yet for clinical use, but may add value to the existent array of PVTs and should be investigated further, especially in other clinical populations and with known-groups designs. 


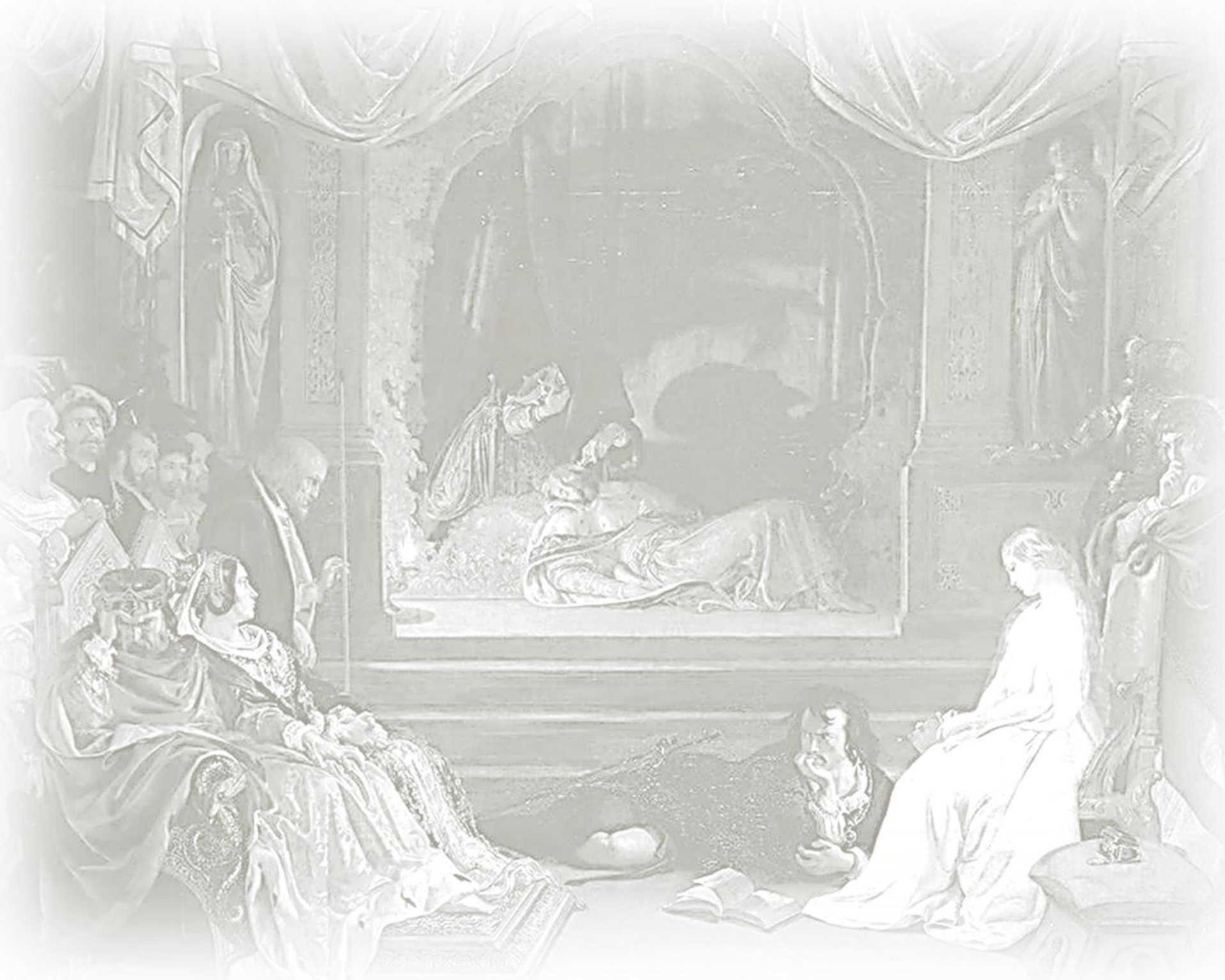




\section{Chapter 6}

\section{Differentiating factitious from malingered symptomatology: The development of a psychometric approach}

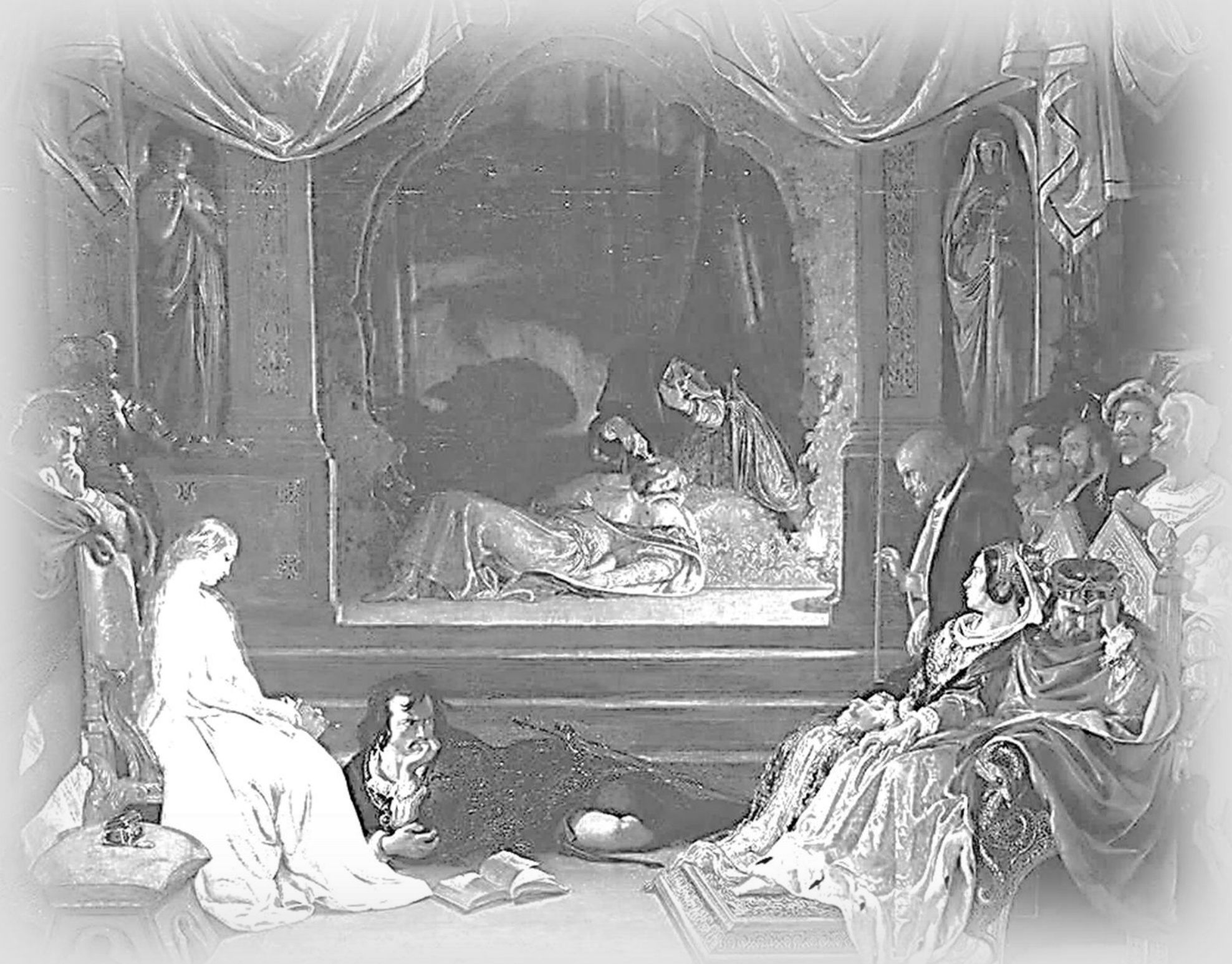

Published as:

van Impelen, A., Merckelbach, H., Jelicic, M., Niesten, I. J., \& à Campo, J. (2017). Differentiating factitious from malingered symptomatology: the development of a psychometric approach. Psychological Injury and Law, 10, 341-357. 


\begin{abstract}
Psychometric symptom validity assessment is becoming increasingly part and parcel of psychological and neuropsychological assessments. An unresolved and rarely addressed issue concerns the differentiation between factitious and malingered symptom presentations: present-day symptom validity tests can assess whether an examinee presents with noncredible symptomatology, but not why an examinee does so. We explored this issue by developing the Symptom and Disposition Interview (SDI); a symptom validity test that incorporates strategies intended to gauge internal incentives associated with factitious disorder. The merits of the SDI were explored and compared with a traditional symptom validity test (the Structured Inventory of Malingered Symptomatology) in two simulation studies, each with factitious and malingering conditions ( $n=24-30$ per condition) and a clinical control group $(n=34, n=40)$. Overall, the results were positive: The SDI was as effective in detecting feigned symptom presentations as a traditional symptom validity test and superior in differentiating factitious from malingered symptom presentations. We conclude that the SDI is not ready for clinical use, but that psychometric approaches to the assessment of factitious symptomatology, such as the SDI, appear sufficiently promising to warrant future research.
\end{abstract}




\section{Introduction}

Psychiatric, psychological, and neuropsychological evaluations are arguably incomplete if they do not entertain the possibility that examinees may present with feigned symptomatology. Indeed, the vast majority of North American neuropsychologists hold assessment of feigned symptomatology to be "mandatory in forensic evaluations and at least desirable in clinical evaluations" (Martin, Schroeder, \& Odland, 2015, p. 741). Assessment of feigned symptomatology is generally achieved through dedicated validity tests, which fall into two categories that each target a relatively independent dimension of assessment; performance validity tests (PVTs) assess the credibility of performance on cognitive tests, and symptom validity tests (SVTs) assess the credibility of symptom report (Larrabee, 2012). The effectiveness of validity tests to detect feigned symptomatology is well established to the point that their use is recommended by organizations such as the Association for Scientific Advancement in Psychological Injury and Law (Bush, Heilbronner, \& Ruff, 2014), the British Psychological Society (2009), and the Institute of Medicine (2015). Once feigned symptomatology has been established, "the next and equally important goal involves a careful assessment of multifaceted motivations for feigning" (Merten \& Rogers, 2017, p. 101). However, while current validity tests function well in detecting feigned symptom presentations, they do not address potential motivations for such symptom presentations.

Historically, validity tests were considered to be tools to detect malingering; a notion that was abandoned around the turn of the millennium in favor of the idea that validity tests capture noncredible symptom presentations, but not the underlying reasons for such presentations (Merten \& Merckelbach, 2013b; see also Chapter 4). Still, because validity tests originated from attempts to standardize the assessment of malingering (see Nies \& Sweet, 1994) and malingering is driven by external incentives - which, by virtue of being external, can often be identified independently of patients' self-report - there are no validity tests that address the motivations (external or internal) behind feigned symptom presentations.

Malingering is defined by the Diagnostic and Statistical Manual of Mental Disorders (5th ed.; DSM-5; American Psychiatric Association, 2013) as "the intentional production of false or grossly exaggerated physical or psychological symptoms, motivated by external incentives" (p. 726). To substantiate that a symptom presentation is malingered, three features of malingering must be established: these are (a) that the presented symptomatology is feigned; (b) that the feigning is intentional; and (c) that the intention is motivated by external incentives, such as avoiding work or duty, evading responsibility, or obtaining financial gain.

Another condition that may underlie feigned symptomatology is factitious disorder, which-in contrast to malingering-is considered to be a mental disorder (American Psychiatric Association, 2013). The determination of factitious disorder is similar to the detection of malingering, as both require the identification of (a) symptomatology that is feigned and (b) feigning that is intentional. The difference between factitious disorder and malingering lies in the third criterion, (c) the motivation behind intentional feigning: 
Whereas malingered symptom presentations are motivated by external incentives, factitious symptom presentations are motivated by internal incentives, such as seeking nurturance and sympathy for being ill; this has also been referred to as the need to "assume the sick role" (American Psychiatric Association, 2013, p. 727). To our knowledge, all validity tests bear on (a) symptomatology that is feigned; some validity tests-e.g., certain PVTs; see belowaddress (b) intentional feigning; yet no validity test taps (c) motivation by internal incentives.

Currently, the only validity tests that might contribute data to the assessment of intentionality of feigning are PVTs that can identify below-chance performance. The forcedchoice format of such PVTs allows for the calculation of the probability that a given score is obtained by chance: Test performances far below chance level imply deliberate avoidance of correct answers and are therefore equated with intentional underperformance (e.g., see Binder, Larrabee, \& Millis, 2014). However, below-chance performance is a fairly unsophisticated form of feigning that is relatively rare compared with more subtle feigned symptom presentations (Greve, Binder, \& Bianchini, 2009; see also Chapter 5). Moreover, being cognitive tasks, PVTs are ill-suited to address psychological constructs such as "incentives" and "motivation." SVTs, on the other hand, take the form of inventories, such as interviews and questionnaires of psychological symptoms and cognitive complaints. Examples include the Multiphasic Personality Inventory-2-Restructured Form (MMPI-2-RF; Ben-Porath \& Tellegen, 2008) and the Personality Assessment Inventory (PAI; Morey, 1991). The format of SVTs is suitable to be modified to include assessment of incentives related to feigned symptom presentations. For example, van Egmond and Kummeling (2002; see also van Egmond, Kummeling, \& van Balkom, 2005) developed a self-report checklist to explore incentives that patients anticipate when they enter treatment.

Although the presence of internal incentives to feign symptoms was deleted from the diagnostic criteria of factitious disorder when the DSM transitioned to its 5th edition, it has been retained as the main distinguishing feature between factitious disorder and malingering (American Psychiatric Association, 2013, p. 727). The removal of the internal incentives criterion likely reflects both the difficulties in determining the presence or absence of such incentives and the scarcity of research into the standardized assessment of factitious presentations. Virtually all published research into the assessment of factitious presentations is centered on individual cases (Bass \& Halligan, 2014).

To our knowledge, the only systematic data on differentiating factitious from malingered presentations was gathered by Rogers and colleagues, who compared the SVT profiles of patients with factitious disorder with those of suspected malingerers; they found no consistent differences between validity profiles (i.e., Structured Interview of Reported Symptoms profiles; Rogers, Bagby, \& Dickens, 1992; see also Rogers, Bagby, \& Vincent, 1994). Rogers, Jackson, and Kaminski (2005) conducted the only study to date that investigated the capacity of validity tests to differentiate between factitious and malingered presentations. More specifically, Rogers et al. (2005) administered a multiscale inventory of psychopathology with embedded validity scales (the PAI) and a symptom validity test (the Structured Inventory of Malingered Symptomatology, SIMS; Smith \& Burger, 1997) to four 
groups of doctoral students; two groups were asked to simulate factitious symptom presentations (i.e., with dependent and demanding interpersonal styles, respectively), one group was asked to simulate malingered disability, and one group to respond honestly. Discriminant functions aside, only the PAI Defensiveness Index and a newly developed SIMS index ( $A F$ minus $N$ ) evidenced capacity to distinguish between factitious and malingered presentations (Rogers et al., 2005). Specifically, Rogers and colleagues (2005) found that those instructed to present with factitious symptomatology scored significantly higher on an index that subtracts the Neurological impairment $(N)$ from the Affective disorders $(A F)$ SIMS scale score.

The lack of psychometric measures of internal incentives can be seen as a deficiency of contemporary symptom validity assessment, but the lack of contemporary symptom validity assessment in the diagnosis of factitious disorder is perhaps more alarming: Psychometric symptom validity assessment was not mentioned among the factors leading to the diagnosis of factitious disorder in any of the 455 cases that were included in a recent systematic review of the scholarly literature on factitious disorder (Yates \& Feldman, 2016). It may be that SVTs remained unmentioned in the review by Yates and Feldman (2016) because only cases with primarily physical symptoms were included. SVTs are typically used in psychological and neuropsychological evaluations and less so in medical domains that deal mainly with objective physical symptoms. However, given that SVTs are noninvasive and efficient, their informational value extends to practically any situation in which patients present with symptoms that are not readily or reliably assessed via physical examinations, including many cases reviewed by Yates and Feldman (2016).

Important goals of the current studies are to explore the potential of psychometric assessment of factitious symptom presentations and to address the lack of systematic research into the differentiation of factitious and malingered presentations. We endeavored to achieve these objectives through developing and testing the Symptom and Disposition Interview (SDI). We specifically designed the SDI to screen for feigned symptomatology and to gauge potential internal incentives for feigning (i.e., the need to assume the sick role). The utility of the SDI was examined in two studies using a simulation design with three experimental conditions, augmented with a clinical control group. The SIMS was employed as comparison for the ability of the SDI to detect feigned symptomatology (convergent validity) and to distinguish factitious from malingered symptom presentations (discriminant validity). Rather than serving to finalize the SDI for clinical use, the present studies function as exploratory steppingstones to improve the systematic assessment of factitious and malingered presentations. 


\section{Study 1}

\section{Method}

Study 1 used a simulation design with three experimental conditions, a nonclinical control condition, and a clinical control group. The three experimental conditions addressed presentations of factitious disorder, illness anxiety, and malingering, respectively. The nonclinical control condition was included to assess the susceptibility of the SDI to authentic symptomatology: This was realized by comparing the participants in the nonclinical control condition with the clinical control group. To avoid potential cases of feigning in the clinical control group, participants scoring $>16$ on the SIMS were treated as a separate group for all statistical analyses.

At the outset of Study 1, we had four hypotheses. First, we expected the accuracy of the SDI in classifying feigned symptoms presentations (i.e., the experimental conditions) to be satisfactory, comparable to that of the SIMS. Second, because the SDI includes a scale targeting the need to assume the sick role, we predicted that the SDI, but not the SIMS, would be able to differentiate between factitious symptom presentations and malingered symptom presentations. Third, we surmised that the SDI, which has a scale tapping somatic sensitivity and illness anxiety, would distinguish feigned illness anxiety from malingered symptom presentations. And fourth, because the SDI, in contrast to the SIMS, includes a scale containing items alluding to common, credible symptomatology, we expected the SDI Unlikely Symptom scale (which is a symptom validity scale; see below) to be less sensitive to authentic symptomatology than the SIMS. In other words, we anticipated that differences in SDI scores of clinical and nonclinical controls would mostly manifest in regular clinical items, not in unlikely or noncredible clinical items.

\section{Participants}

Participants for the three experimental conditions and the nonclinical control condition $(n=$ 24 per condition) were recruited at the faculty of Psychology and Neuroscience of Maastricht University (both graduate and undergraduate students were allowed to participate). The great majority of this portion of the sample was female $(90 \% ; n=86)$ and Caucasian $(94 \% ; n=$ 90). The mean age was 23.3 years (age range: 17-70). Because the study relied heavily on written materials, only native speakers of Dutch were eligible for participation. A history of severe mental illness was employed as exclusion criterion, but no participants disclosed such a history.

Participants for the clinical control group $(n=34)$ were recruited at three outpatient units of Radix Forensic Psychiatric Hospital, located in the Netherlands. This group was predominantly Caucasian $(85 \% ; n=29)$, consisted almost exclusively of males $(91 \% ; n=31)$, and had a mean age of 38.9 years (age range: $22-57$ years). Patients at Radix are in treatment for delinquent behavior, ranging from repeated misdemeanors to serious felonies, but not homicide. Typical delinquencies included drug offenses, crimes against property (e.g., 
burglary and robbery), and offenses against persons (e.g., assault, battery, and sexual assault). The most frequent types of psychopathology among patients were substance disorders (63\%) and personality disorders (53\%). Other forms of psychopathology included affective disorders (e.g., bipolar and depressive), thought disorders (e.g., schizophrenia spectrum), neurodevelopmental disorders (e.g., autism spectrum, intellectual disability), and posttraumatic stress disorder. Comorbid symptomatology was common and generally involved personality and substance disorders.

\section{Measures}

In addition to the SDI and the SIMS, which are described in more detail below, participants completed one other symptom validity test; the Miller Forensic Assessment of Symptoms Test (M-FAST; Miller, 2001; Cronbach's alpha $=.93$ ). The M-FAST is a brief structured interview that inquires about various rare, unusual, and extreme psychiatric symptoms. With permission of its publisher, Psychological Assessment Resources, we translated the MFAST into Dutch and included it in the current studies to investigate its psychometric properties. The M-FAST data were not used in the analyses presented in this report.

\section{Symptom and Disposition Interview (SDI)}

The SDI is a newly developed screen for feigned symptomatology and internal incentives for feigning. The development of the SDI commenced with the first author conceiving four scales that, at least theoretically, appear useful for symptom validity assessment; a symptom validity scale, a regular clinical scale, a scale addressing the need to assume the sick role, and a scale covering illness anxiety and sensitivity to somatoform symptomatology. For each scale, a superfluous number of potential items were drafted. Through multiple discussions with the other authors, items were selected and revised, and several new items were created. The version of the SDI that was used in the present studies consists of 42 items constituting four scales: Unlikely Symptoms (US, 14 items), Common Symptoms (CS, 7 items), Sick Role (SR, 14 items), and Illness Anxiety (IA, 7 items). The scale scores are calculated by summation, as is the total score, which is taken to be an overall indicator of feigned psychopathology. The language of the SDI is Dutch; the sample items given throughout the text below are translations of the original Dutch versions.

The Unlikely Symptoms (US) scale comprises rationally derived items based on wellestablished detection strategies for feigned symptomatology, such as improbable symptoms and symptom combinations (Rogers, 2008b). Items consist of a question followed by three answer-alternatives: often ( 2 points), sometimes ( 1 point), and never ( 0 points). Examples are "When you are suffering from anxiety or panic, how often do you get overly sensitive to light?" and "When you cannot remember something, how often do you develop a headache?"

The Common Symptoms (CS) scale contains items that inquire about different general symptoms whose mild variants occur frequently in nonclinical populations and whose 
severe variants are common in clinical populations. The answer and scoring format of $C S$ items is equivalent to that of the US items. The CS items serve a fourfold purpose: (1) they provide room to report genuine symptomatology; (2) they aid in the detection of feigned symptomatology because they tap different types of pathology (as per the indiscriminant symptom endorsement detection strategy) as well as the frequency of symptoms (as per the symptom severity strategy; Rogers, 2008b); (3) they provide an indication of symptom underreporting if patients largely deny any symptom manifestation; and (4) they veil the purpose of the SDI as an instrument to detect feigned symptomatology. Sample items are "How often do you suffer from depressive thoughts or feelings?" and "How often do you suffer from compulsive thoughts?"

The Sick Role (SR) scale includes items that query the willingness to engage in patient-related activities, such as participating in patient support groups or scientific studies and undergoing treatment or diagnostic procedures, even if these are unpleasant or have serious side effects. Because Rogers et al.'s (2005) simulation study found simulators of factitious presentations to endorse items that allude to low self-worth and resentment toward others, we decided to also include such items in the $S R$ scale (for example, "How often do you have the feeling that you are treated less well than other people?"). The answer and scoring format of the majority of SR items is divergent; $10 S R$ items provide only two answer alternatives, yes and no, which are scored as 2 or 0 points depending on the question. Typical $S R$ items are "Are you prepared to take medication for your symptoms even if it would have serious side effects?" and "Are you willing to participate in scientific studies into new treatments for your symptoms?" and "How often are you in need of psychological support?"

The Illness Anxiety (IA) scale consists of items covering distress over potential pathology and (self-perceived) sensitivity to somatic symptoms. The answer and scoring format mirrors that of the US and CS items. We included illness anxiety and somatic sensitivity items because they may aid in the detection of internal incentives or motivations for feigned symptomatology. The internal motivations that drive feigned symptom presentations in factitious disorder are similar to the internal motivations that underlie unconsciously distorted symptom presentations in somatic symptom and related disorders (including illness anxiety; see DSM-5; American Psychiatric Association, 2013, p. 309). Some authors (e.g., Krahn, Bostwick, \& Stonnington, 2008) have proposed to reclassify factitious disorder as a subtype of somatoform disorders, the argument being that factitious patients exaggerate their symptoms so as to convey to clinicians their belief that they are ill. Moreover, in the transition from $D S M-I V-T R$ to $D S M-5$, factitious disorder even ceased to be a discrete category of disorders and was subsumed under "somatic symptom and related disorders" (American Psychiatric Association, 2013, p. 813). Therefore, we reasoned that an assessment that is sensitive to somatoform symptomatology will also be sensitive to internal incentives or motivations for feigned symptomatology. Examples of IA items are "How often do you worry about your physical or mental well-being?" and "How often do you suffer from mildly allergic reactions?" 


\section{Structured Inventory of Malingered Symptomatology (SIMS)}

The SIMS (Smith \& Burger, 1997; see Merckelbach \& Smith, 2003 for the Dutch version, Cronbach's $\alpha=.72$ ) is a screen for feigned symptomatology. It consists of 75 true-false statements that refer to improbable and atypical symptoms of affective disorders, psychosis, neurological impairment, memory dysfunction, and low intelligence. The total number of endorsed statements serves as an indicator of feigned symptomatology; scores above 16 warrant further assessment of symptom validity (see Chapter 4 ).

We employed the SIMS because it is a well-researched instrument with respectable psychometric properties, which therefore could fulfill multiple functions: (a) to compare the accuracy of the SDI in detecting feigned symptomatology with; (b) to guarantee the validity of the clinical control group by identifying possible cases of feigning; and (c) to gauge the effectiveness of our experimental manipulation in inducing feigned symptomatology through comparison with previous research (e.g., Rogers et al., 2005; Chapter 4). Rogers et al. (2005) found that subtracting the Neurological impairment $(N)$ scale from the Affective disorders $(A F)$ scale of the SIMS resulted in an index that discriminated well between an experimental malingering condition, on the one hand, and two experimental factitious conditions, on the other hand. We included the SIMS $A F-N$ index in our analyses to see if we could replicate the findings of Rogers et al. (2005).

\section{Procedure}

Approval to commence the study was obtained from Radix Forensic Psychiatric Hospital as well as the standing Ethics Committee of the Faculty of Psychology and Neuroscience of Maastricht University. Data were gathered exclusively for research purposes and were not available to anyone but the researchers. With the exception of the informed consent, none of the study materials were signed with information other than participant numbers, thus guaranteeing the anonymity of the data that participants produced.

Nonclinical participants were quasi-randomly assigned to one of four conditions, which are outlined below; factitious, illness anxiety, malingering, and control. Both clinical and nonclinical participants were tested individually and in the presence of one of three researchers. The three researchers were advanced undergraduate psychology students who had completed supervised training in test administration and clinical interviewing. All information and instructions were conveyed via sets of written material, which contained the information facilitating informed consent, the instructions, and, in the experimental and nonclinical control conditions, a description of the experimental scenario. To increase the external validity of the experimental conditions, participants (including nonclinical controls) received instructional sets 2 days prior to the test session, leaving them with ample time to prepare themselves for participation in any way they saw fit. Exclusive employment of written materials allowed the experimenters to be blind to the conditions that participants were assigned to and hence avoid potential experimenter effects. Possible order effects were 
offset by administering all measures (i.e., SDI, SIMS, M-FAST) in counterbalanced order within each group. The total session time was around 50 minutes.

To ensure that the experimental materials were intelligible, plausible, and easy to identify with, we used the actually existing psychological support unit of Maastricht University as the setting for the scenarios and instructions (see below). After completion of the measures, participants were presented with several manipulation checks in the form of questions examining recall and compliance with the experimental manipulations. To safeguard the experimental procedures, participants were not debriefed until after all data were collected.

\section{Experimental Feigning Conditions}

The instructional sets that participants in the experimental feigning (i.e., factitious and malingering) conditions received, started by explaining to them that they were going to be asked to fill out a questionnaire and answer questions during two brief interviews and that they were to respond to all questions according to specific instructions that were detailed in the document they received. We refrained from directly instructing participants to act in a certain manner (e.g., feign a certain clinical presentation); rather, we prompted them to imagine themselves being in a certain setting and situation under particular circumstances with a specific background (which induced motives to feign symptomatology) and act as if they were in that situation and as if the described circumstances and background scenario were true.

Similar to Rogers et al. (2005), we employed the same setting and situation across all experimental conditions, thus controlling for "patient-role" effects (see, e.g., Kroger \& Turnbull, 1975). The setting that we used was the psychological support unit of Maastricht University, and the situation was an assessment by a student counselor. The psychological support unit of Maastricht University consists of psychologists ("student counselors") who are specialized in providing support to students with psychological problems. The circumstances and background scenario that we employed involved fictional information about (a) a prior meeting that the participant had with a student counselor; (b) the feelings that the participant subsequently had toward the counselor; (c) the participant's progress as a student (i.e., number of courses passed/failed) and their eligibility to complete the current academic year; and (d) the potential merits of feigning psychopathology during the upcoming "session" with the student counselor.

The experimental factitious condition was modeled after Rogers et al.'s (2005) instructional set for a dependency on staff factitious presentation, which is based on Cunnien's (1997) differentiation of dependency and demandingness as interpersonal motivations driving factitious disorders. The dependency motivation involves immoderate need for care and support; the demandingness motivation involves frustration and resentment for unmet treatment needs (Cunnien, 1997). Participants in the factitious condition were informed that (a) their previous meeting with the student counselor was an 
extremely pleasant and comforting experience; (b) they had come to quietly admire and feel sustained by the student counselor; (c) their progress as a student was fine (no courses failed) and they were eligible to complete the current academic year; and (d) the only way to be assigned to frequent sessions with the student counselor (which they hoped for) was to appear as if they were suffering from serious psychopathology.

The circumstances and background scenario of the illness anxiety condition paralleled that of the factitious condition, save that (a) the prior meeting with the student counselor was described as having been an ordinary session, which did not provoke specific feelings toward the counselor, and (b) sometime after seeing the counselor, the participant had developed increasing worries about their health and had grown fearful of incurring serious pathology. Contrary to the factitious and malingering conditions, which included the suggestion to feign symptomatology, the illness anxiety condition merely asked participants to behave in a manner so as to be taken serious by the student counselor.

In the experimental malingering condition, participants were not asked to suppose that the prior meeting with the student counselor had been particularly fulfilling and led them to long for frequent sessions with the counselor (the factitious condition) or to imagine that they developed pressing health concerns (the illness anxiety condition). Instead, participants were impelled to presume that they failed several exams and were therefore ineligible to complete the current academic year and that the only way to be allowed to partake in the resits of the failed exams in the current academic year (with privileged exam regulations) would be to feign serious psychopathology and convince the counselor that their academic failure was caused by psychopathology.

To stimulate participants to engage with the experimental material and subsequent tests, we offered them a small monetary incentive (a $€ 7.50$ gift voucher, equivalent to \$8.90). In addition, we stressed the importance of the research by pointing to the consequences of improper classification of feigned and genuine symptomatology (i.e., wrongfully allocated resources in healthcare, compensation, and damage claims). Participants in the three experimental conditions were informed that the questions they were to answer constituted tests designed to detect feigned symptomatology, and they were challenged to appear as credible as possible while striving to obtain their hypothetical incentive.

\section{Nonclinical Control Condition}

The nonclinical control condition was analogous to the experimental conditions, save that the scenario omitted incentives to feign symptoms (i.e., no dependency on student counselor, no denial to complete the current study year) and the instructions requested participants to answer all questions honestly.

\section{Clinical Control Group}

In contrast to the other groups, the clinical control group did not receive a monetary incentive to participate and did not undergo any experimental manipulation procedures: 
Instead, the importance of the research was highlighted and participants were implored to be completely truthful in answering all questions. Participants for the clinical control group were recruited via staff of the outpatient units of Radix Forensic Psychiatric Hospital, who alerted patients to the study and brought interested patients into contact with the researchers.

\section{Results}

Means and corresponding 95\% confidence intervals and standard deviations of SDI and SIMS scale scores of each group are summarized in Table 6.1. The mean SIMS scores indicate that the effect of our experimental manipulations to induce feigned symptomatology was similar across groups and comparable to that of earlier studies (see Chapter 4, Table 4.6). Six participants of the clinical control group produced a SIMS score above 16 (which calls the validity of reported symptoms into question). The data of these six participants may reflect real-world feigning and are therefore interesting to compare the data of the experimental groups with. To increase the statistical reliability of analyses with these data, we merged it with that of the clinical participants in Study 2 (see below) who also scored $>16$ on the SIMS $(n=5)$ : Together, these participants $(n=11)$ were treated as a single group in statistical analyses (see Study 2, Table 6.7). Mann-Whitney $U$ tests indicated that neither gender nor race (Caucasian vs. non-Caucasian) had a statistically significant effect on SDI or SIMS scale scores in any of the groups (all Us $>11.4$, all exact, two-tailed $p s>.14$ ). There was also no statistically significant relation between participants' age and SDI or SIMS scale scores in any of the groups (all Kendall rank correlation coefficients between -.27 and .23, all $p \mathrm{~s}>.11$ ). The main trend that emerges from Table 6.1 foretells the results that are reported below: The feigning groups generated higher SDI and SIMS scores than the clinical control group, and the factitious group yielded higher SDI (but not SIMS) scores than the other feigning groups.

Relevant comparisons between SDI and SIMS scale scores of each group were examined through Cohen's $d$ effect sizes. The results are shown in Table 6.2 and reveal several important findings. First, all SDI scales demonstrated large statistically significant group differences between the feigning groups (factitious, illness anxiety, and malingering) and the clinical control group ( $d$ s ranging from 1.1 to 3.0, all $p s<.001$ ). Second, the sensitivity to feigned symptomatology of the SDI Total scale compares favorably with that of the SIMS (SDI $d s, 1.6-2.9$ vs. SIMS ds, 1.4-2.3). Third, the SDI SR, IA (Illness Anxiety), and Total scales distinguished well between the factitious and the malingering condition ( $d \mathrm{~s} 1.0$ to $1.7, p \mathrm{~s}<$ .01). Fourth, in contrast to the SDI Total scale, the SIMS Total scale did not differentiate the factitious from the malingering condition $(d=0.2, p>.10)$. Fifth, no SDI scale evinced a statistically significant difference between the clinical and the nonclinical control group ( $d \mathrm{~s}$ -0.1 to 0.7 , ps $>.01$ ), which indicates that genuine symptomatology does not have an undue effect on the other SDI scales, also in comparison with the effect that genuine pathology had on the SIMS Total scale $(d=1.2, p<.001)$. 


\section{Table 6.1}

Symptom presentations on the Symptom and Disposition Interview and the Structured Inventory of Malingered Symptomatology in Study 1: Mean scores, corresponding [95\% confidence intervals], and (standard deviations)

Experimental groups

Factitious

Scale

(min-max)
Illness

anxiety

$n=24$

$$
n=24
$$

Malingering Nonclinical

SDI US

$(0-28)$

13.5

[11.3, 15.6]

(5.1)

\section{6}

SDI CS

(0-14)

$$
[7.5,9.7]
$$

20.6

[18.9, 22.4]

(4.1)

SDI $S R$

(0-28)

12.0

$[10.9,13.0]$

(2.4)

54.6

[50.1, 59.2]

(10.8)

$(0-84)$

SIMS $A F-N$

0.7

$[-0.9,2.3]$

(3.9)

SIMS Total

23.2

[19.7, 26.7]

(8.3)

\section{0}

[17.2, 20.9]

(4.5)

[8.3, 13.5]

(6.2)

\section{4}

$[6.5,8.3]$

(2.1)

45.3

[39.9, 50.8]

(13.0)

4.9

$[3.5,6.4]$

(3.4)

23.5

[18.6, 28.3]

(11.5) $n=24 \quad \begin{gathered}\text { control } \\ n=24\end{gathered}$

2.8

[1.6, 3.9]

(2.6)

(5.4)

\section{0}

[2.4, 3.7]

(1.5)

(2.4)

16.5

9.3

[7.4, 11.2]

(4.2)

(4.5)

\section{5}

[6.3, 8.8]

(3.0)

\section{7}

$[3.9,5.5]$

(1.9)

41.2

19.8

[16.5, 23.1]

(7.9)

(11.0)

\section{3}

$[2.7,6.0]$

(3.9)

\section{4}

[1.7, 3.1]

(1.7)

21.5

$[16.3,26.7]$

4.8

[3.3, 6.2]

(12.2)
Clinical control group ${ }^{a}$

$(\mathrm{SIMS} \leq 16) \quad($ SIMS $>16)$

$n=28$

$n=6$
7.2

$[1.6,4.6]$

(3.8)

[2.4, 11.9]

(4.5)

$\begin{array}{ll}4.8 & 8.8\end{array}$

$[3.7,6.0] \quad[5.1,12.6]$

(3.0)

$11.3 \quad 16.0$

$[9.6,13.1] \quad[11.7,20.4]$

(4.5)

\section{4}

6.3

$[3.4,5.4]$

(2.6)

[2.9, 9.8]

(3.3)

$23.6 \quad 38.3$

[19.6, 27.7]

[24.2, 52.5]

(10.4)

(13.5)

Note. SIMS = Structured Inventory of Malingered Symptomatology; SDI = Symptom and Disposition Interview; $U S=$ SDI Unlikely Symptoms scale; $C S$ = SDI Common Symptoms scale; $S R=$ SDI Sick Role scale; $I A=$ SDI Illness Anxiety scale; $A F-N=$ Affective disorders SIMS scale minus Neurological impairment SIMS scale score index.

aThe group of participants with a SIMS score $>16(n=6)$ were excluded from all analyses involving the clinical control group; instead, the data of this group were combined with those of the participants with a SIMS score $>16$ in Study 2 to form a supplemental group for comparison with the experimental groups (see Table 6.7). 
Chapter 6

Table 6.2

Differences in symptom presentation on the Symptom and Disposition Interview and Structured Inventory of Malingered Symptomatology in Study 1: Cohen's d effect sizes and corresponding [95\% Confidence Intervals]

\begin{tabular}{|c|c|c|c|c|c|c|c|}
\hline \multirow[b]{2}{*}{ Scale } & \multicolumn{3}{|c|}{$\begin{array}{c}\text { Feigning groups } \\
\text { vs. } \\
\text { Clinical control group }\end{array}$} & \multicolumn{3}{|c|}{$\begin{array}{c}\text { Feigning groups } \\
\text { vs. } \\
\text { each other }\end{array}$} & \multirow[b]{2}{*}{$\begin{array}{c}\text { Clinical } \\
\text { control } \\
\text { vs. } \\
\text { Nonclinical } \\
\text { control }\end{array}$} \\
\hline & $\begin{array}{c}\text { Factitious } \\
\text { vs. } \\
\text { Clinical } \\
\text { control }\end{array}$ & $\begin{array}{c}\text { Illness } \\
\text { anxiety } \\
\text { vs. } \\
\text { Clinical } \\
\text { control }\end{array}$ & $\begin{array}{c}\text { Malingering } \\
\text { vs. } \\
\text { Clinical } \\
\text { control }\end{array}$ & $\begin{array}{l}\text { Factitious } \\
\text { vs. } \\
\text { Malingering }\end{array}$ & $\begin{array}{c}\text { Illness } \\
\text { anxiety } \\
\text { vs. } \\
\text { Malingering }\end{array}$ & $\begin{array}{c}\text { Factitious } \\
\text { vs. } \\
\text { Illness } \\
\text { anxiety }\end{array}$ & \\
\hline SDI US & $\begin{array}{c}2.3^{* *} \\
{[1.6,3.0]}\end{array}$ & $\begin{array}{c}1.5^{* *} \\
{[0.9,2.1]}\end{array}$ & $\begin{array}{c}1.4^{* *} \\
{[0.8,2.0]}\end{array}$ & $\begin{array}{c}0.7 \\
{[0.1,1.3]}\end{array}$ & $\begin{array}{c}0.2 \\
{[-0.4,0.8]}\end{array}$ & $\begin{array}{c}0.5 \\
{[-0.1,1.1]}\end{array}$ & $\begin{array}{c}0.1 \\
{[-0.4,0.6]}\end{array}$ \\
\hline SDI CS & $\begin{array}{c}1.3^{* *} \\
{[0.7,1.9]}\end{array}$ & $\begin{array}{c}1.1^{* *} \\
{[0.5,1.7]}\end{array}$ & $\begin{array}{c}1.1^{* *} \\
{[0.5,1.7]}\end{array}$ & $\begin{array}{c}0.4 \\
{[-0.2,1.0]}\end{array}$ & $\begin{array}{c}0.1 \\
{[-0.5,0.7]}\end{array}$ & $\begin{array}{c}0.2 \\
{[-0.4,0.8]}\end{array}$ & $\begin{array}{c}0.7 \\
{[0.1,1.3]}\end{array}$ \\
\hline SDI $S R$ & $\begin{array}{c}2.2^{* *} \\
{[1.5,2.9]}\end{array}$ & $\begin{array}{c}1.7^{* *} \\
{[1.1,2.3]}\end{array}$ & $\begin{array}{c}1.2^{* *} \\
{[0.6,1.8]}\end{array}$ & $\begin{array}{c}1.0^{*} \\
{[0.4,1.6]}\end{array}$ & $\begin{array}{c}0.6 \\
{[0.0,1.2]}\end{array}$ & $\begin{array}{c}0.4 \\
{[-0.2,1.0]}\end{array}$ & $\begin{array}{c}0.4 \\
{[-0.2,0.9]}\end{array}$ \\
\hline SDI IA & $\begin{array}{c}3.0^{* *} \\
{[2.2,3.8]}\end{array}$ & $\begin{array}{c}1.3^{* *} \\
{[0.7,1.9]}\end{array}$ & $\begin{array}{c}1.1^{* *} \\
{[0.5,1.7]}\end{array}$ & $\begin{array}{c}1.7^{* *} \\
{[1.0,2.4]}\end{array}$ & $\begin{array}{c}0.0 \\
{[-0.6,0.6]}\end{array}$ & $\begin{array}{c}2.0^{* *} \\
{[1.3,2.7]}\end{array}$ & $\begin{array}{c}-0.1 \\
{[-0.6,0.4]}\end{array}$ \\
\hline SDI Total & $\begin{array}{c}2.9^{* *} \\
{[2.1,3.7]}\end{array}$ & $\begin{array}{c}1.9^{* *} \\
{[1.2,2.6]}\end{array}$ & $\begin{array}{c}1.6^{* *} \\
{[1.0,2.2]}\end{array}$ & $\begin{array}{c}1.2^{* *} \\
{[0.6,1.8]}\end{array}$ & $\begin{array}{c}0.3 \\
{[-0.3,0.9]}\end{array}$ & $\begin{array}{c}0.8 \\
{[0.2,1.4]}\end{array}$ & $\begin{array}{c}0.4 \\
{[-0.2,0.9]}\end{array}$ \\
\hline SIMS $A F-N$ & $\begin{array}{c}-0.7 \\
{[-1.3,-0.1]}\end{array}$ & $\begin{array}{c}0.7 \\
{[0.1,1.3]}\end{array}$ & $\begin{array}{c}0.5 \\
{[-0.1,1.1]}\end{array}$ & $\begin{array}{c}-0.9^{*} \\
{[-1.5,-0.3]}\end{array}$ & $\begin{array}{c}0.2 \\
{[-0.4,0.8]}\end{array}$ & $\begin{array}{c}-1.1^{*} \\
{[-1.7,-0.5]}\end{array}$ & $\begin{array}{c}0.2 \\
{[-0.3,0.7]}\end{array}$ \\
\hline SIMS Total & $\begin{array}{c}2.3^{* *} \\
{[1.6,3.0]}\end{array}$ & $\begin{array}{c}1.8^{* *} \\
{[1.1,2.4]}\end{array}$ & $\begin{array}{c}1.4^{* *} \\
{[0.8,2.0]}\end{array}$ & $\begin{array}{c}0.2 \\
{[-0.4,0.8]}\end{array}$ & $\begin{array}{c}0.2 \\
{[-0.4,0.8]}\end{array}$ & $\begin{array}{c}0.0 \\
{[-0.6,0.6]}\end{array}$ & $\begin{array}{c}1.2^{* *} \\
{[0.6,1.8]}\end{array}$ \\
\hline
\end{tabular}

Note. SDI $=$ Symptom and Disposition Interview; $U S=$ SDI Unlikely Symptoms scale; $C S=$ SDI Common Symptoms scale; $S R$ = SDI Sick Role scale; $I A$ = SDI Illness Anxiety scale; SIMS = Structured Inventory of Malingered Symptomatology.

${ }^{*}$ Cohen's $d$ is significant (i.e., $>0.0$ ) at the $p<.01$ level. ${ }^{* *}$ Cohen's $d$ is significant (i.e., $>0.0$ ) at the $p<$ .001 level.

Whereas the above findings are all confirmatory with regard to our hypotheses, two additional findings were not so: The first is that we expected the SDI, and its IA scale, in particular, to discriminate between the illness anxiety condition and the malingering condition, but this did not materialize ( $d \mathrm{~s} 0.0-0.6, p \mathrm{~s}>.01)$. The second is that the experimental factitious group scored significantly lower on the SIMS $A F-N$ index than the malingering group $(d=-0.9, p<.01)$, which is opposite to what Rogers et al. (2005) found.

Table 6.3 displays area under the receiver operating characteristic curve (AUC) ${ }^{9}$ values, which are a measure of overall diagnostic accuracy, with values from .50 to .70

\footnotetext{
${ }^{9}$ AUC values are the percentage of correct identifications in a paired comparison task (in which a decision maker is presented with trials containing a positive and a negative target and has to identify the positive target).
} 
signifying low accuracy, .70 to .90 moderate accuracy, and $>.90$ high accuracy (Swets, 1988). The SDI scales, like the SIMS, are moderately to highly effective in correctly classifying feigned and authentic symptom presentations (AUCs $=.75-.97, p \mathrm{~s}<.01$ ), with the Total scale appearing marginally superior over the subscales. Despite being dedicated to detecting feigned symptomatology, the US scale is not significantly more accurate than the $S R$ or $I A$ scales in this respect, and the CS scale lags slightly behind.

\section{Table 6.3}

Diagnostic utility of the Symptom and Disposition Interview and the Structured Inventory of Malingered Symptomatology in Study 1: Area's under the receiver operating characteristic curve and corresponding [95\% confidence intervals]

\begin{tabular}{|c|c|c|c|c|c|c|}
\hline \multirow[b]{2}{*}{ Scale } & \multicolumn{3}{|c|}{$\begin{array}{l}\text { Feigning groups } \\
\text { vs. } \\
\text { Clinical control group }\end{array}$} & \multicolumn{3}{|c|}{$\begin{array}{c}\text { Feigning groups } \\
\text { vs. } \\
\text { each other }\end{array}$} \\
\hline & $\begin{array}{c}\text { Factitious } \\
\text { vs. } \\
\text { Clinical } \\
\text { control }\end{array}$ & $\begin{array}{l}\text { Illness } \\
\text { anxiety } \\
\text { vs. } \\
\text { Clinical } \\
\text { control }\end{array}$ & $\begin{array}{c}\text { Malingering } \\
\text { vs. } \\
\text { Clinical } \\
\text { control }\end{array}$ & $\begin{array}{l}\text { Factitious } \\
\text { vs. } \\
\text { Malingering }\end{array}$ & $\begin{array}{c}\text { Illness } \\
\text { anxiety } \\
\text { vs. } \\
\text { Malingering }\end{array}$ & $\begin{array}{c}\text { Factitious } \\
\text { vs. } \\
\text { Illness } \\
\text { anxiety }\end{array}$ \\
\hline SDI US & $\begin{array}{c}.94^{* *} \\
{[.88,1.00]}\end{array}$ & $\begin{array}{c}.88^{* *} \\
{[.78, .97]}\end{array}$ & $\begin{array}{c}.85^{* *} \\
{[.74, .95]}\end{array}$ & $\begin{array}{c}.69 \\
{[.54, .84]}\end{array}$ & $\begin{array}{c}.55 \\
{[.38, .72]}\end{array}$ & $\begin{array}{c}.62 \\
{[.46, .79]}\end{array}$ \\
\hline SDI $C S$ & $\begin{array}{c}.83^{* *} \\
{[.71, .94]}\end{array}$ & $\begin{array}{c}.77^{*} \\
{[.65, .90]}\end{array}$ & $\begin{array}{c}.75^{*} \\
{[.62, .88]}\end{array}$ & $\begin{array}{c}.62 \\
{[.46, .78]}\end{array}$ & $\begin{array}{c}.53 \\
{[.36, .69]}\end{array}$ & $\begin{array}{c}.58 \\
{[.41, .74]}\end{array}$ \\
\hline SDI $S R$ & $\begin{array}{c}.93^{* *} \\
{[.87,1.00]}\end{array}$ & $\begin{array}{c}.88^{* *} \\
{[.79, .97]}\end{array}$ & $\begin{array}{c}.80^{* *} \\
{[.68, .92]}\end{array}$ & $\begin{array}{c}.76^{*} \\
{[.63, .90]}\end{array}$ & $\begin{array}{c}.67 \\
{[.51, .82]}\end{array}$ & $\begin{array}{c}.59 \\
{[.43, .75]}\end{array}$ \\
\hline SDI $I A$ & $\begin{array}{c}.97^{* *} \\
{[.90,1.00]}\end{array}$ & $\begin{array}{c}.81^{* *} \\
{[.70, .93]}\end{array}$ & $\begin{array}{c}.79^{* *} \\
{[.66, .91]}\end{array}$ & $\begin{array}{c}.88^{* *} \\
{[.76, .99]}\end{array}$ & $\begin{array}{c}.50 \\
{[.33, .66]}\end{array}$ & $\begin{array}{c}.93^{* *} \\
{[.85,1.00]}\end{array}$ \\
\hline SDI Total & $\begin{array}{c}.97^{* *} \\
{[.93,1.00]}\end{array}$ & $\begin{array}{c}.91^{* *} \\
{[.82, .99]}\end{array}$ & $\begin{array}{c}.88^{* *} \\
{[.79, .97]}\end{array}$ & $\begin{array}{c}.82^{* *} \\
{[.70, .94]}\end{array}$ & $\begin{array}{c}.58 \\
{[.41, .74]}\end{array}$ & $\begin{array}{c}.71 \\
{[.56, .86]}\end{array}$ \\
\hline SIMS $A F-N$ & $\begin{array}{c}.32 \\
{[.16, .47]}\end{array}$ & $\begin{array}{c}.70 \\
{[.55, .84]}\end{array}$ & $\begin{array}{c}.66 \\
{[.50, .82]}\end{array}$ & $\begin{array}{c}.25^{*} \\
{[.11, .39]}\end{array}$ & $\begin{array}{c}.52 \\
{[.35, .69]}\end{array}$ & $\begin{array}{c}.21^{*} \\
{[.08, .34]}\end{array}$ \\
\hline SIMS Total & $\begin{array}{c}.95^{* *} \\
{[.88,1.00]}\end{array}$ & $\begin{array}{c}.89^{* *} \\
{[.79, .99]}\end{array}$ & $\begin{array}{c}.83^{* *} \\
{[.70, .95]}\end{array}$ & $\begin{array}{c}.54 \\
{[.37, .71]}\end{array}$ & $\begin{array}{c}.55 \\
{[.38, .71]}\end{array}$ & $\begin{array}{c}.52 \\
{[.35, .68]}\end{array}$ \\
\hline
\end{tabular}

Note. SDI = Symptom and Disposition Interview; $U S=$ SDI Unlikely Symptoms scale; $C S=$ SDI Common Symptoms scale; $S R$ = SDI Sick Role scale; $I A$ = SDI Illness Anxiety scale; SIMS = Structured Inventory of Malingered Symptomatology; $A F-N=$ Affective disorders SIMS scale minus Neurological impairment SIMS scale score index.

*Area under the receiver operating characteristic curve is significantly greater than .5 (i.e., above chance level) at the $p<.01$ level. ${ }^{* *}$ Area under the receiver operating characteristic curve is significantly greater than .5 (i.e., above chance level) at the $p<.001$ level.

In line with our hypotheses, the SIMS performed at chance level when employed to tell participants in the factitious condition apart from those in the malingering condition $(\mathrm{AUC}=.54, p>.10)$. Although the SIMS $A F-N$ index displayed a discriminatory ability 
between the factitious and the malingering condition, this efficacy was not in the expected direction; instead of performing above chance level, the $A F-N$ index performed significantly below chance in classifying factitious and malingering participants $(\mathrm{AUC}=.25, p<.01)$.

\section{Study 2}

Past studies found the results of simulation studies to be dependent on the context and relevance of the scenario that is used as experimental manipulation to prompt noncredible symptom presentations (Merckelbach, Smeets, \& Jelicic, 2009; Rogers \& Cruise, 1998). In light of the encouraging outcomes of Study 1 , we decided to test to what extent the results would hold in a civil vs. a criminal law scenario, both of which are less familiar and relevant to participants than the student counselor scenarios used in Study 1. Factitious symptom presentations were instilled through a civil law scenario, and malingered presentations were elicited via a civil and a criminal law scenario, respectively (see below).

In Study 1, we provided participants in the experimental conditions with instructional sets 2 days before the test session would take place. For Study 2, we handed the instructional sets to participant at the start of the test session and allowed them only 20 minutes preparation time (with access to the Internet) before the study materials were administered. The reason for this modification is twofold: First, we wanted to align this part of the procedure more with previous studies, such as that by Rogers et al. (2005), and second, we wanted less variation in preparation time between participants, as some participants in Study 1 took considerable time to prepare while others did not take any time at all. Because real-world feigners typically have ample time to prepare for feigning, a short preparation time was retained to preserve some ecological validity in this regard.

Three participants in the experimental conditions of Study 1 produced very low SIMS scores (i.e., < 5, which is lower than clinical controls and comparable to nonclinical controls; see Table 6.1) despite passing all manipulation checks (i.e., they correctly recalled the scenario and instructions, and endorsed compliance). Such low SIMS scores raise the question whether these three participants genuinely tried to engage in symptom fabrication. This led us to realize that Study 1 lacked a fundamental manipulation check; a standard clinical measure of symptomatology with norm-referenced cut scores. We avoided this shortcoming in Study 2 by including the Brief Symptom Inventory (BSI; Derogatis \& Melisaratos, 1983) to check whether participants in the experimental conditions simulated clinically relevant levels of symptomatology.

The addition of the BSI and the 20-minute preparation prolonged the total session time with roughly 30 minutes. Therefore, we raised the value of the gift voucher that participants received for participating in one of the experimental conditions from $€ 7.50$ to $€ 12.50$ (equivalent to $\$ 14.90$ ). 
Another change is the elimination of the nonclinical control group: Although the scores of such a group are useful to quantify the sensitivity of an SVT to authentic symptomatology, they are not helpful in distinguishing authentic from feigned symptomatology. Akin to Study 1, we contrasted the scores of the experimental groups with those of a clinical control group in which SIMS scores above 16 served as exclusion criterion.

Aside from the changes just mentioned, Study 2 is an emulation of Study 1. Therefore, our general hypotheses remained the same; we predicted the SDI to approach the SIMS in classifying feigned presentations and exceed the SIMS in differentiating between factitious and malingered presentations. Based on Merckelbach et al. (2009), we expected the civil law scenario to prompt less perceptible feigning than the criminal law scenario.

\section{Method}

The method of Study 2 mirrored that of Study 1, save for the modifications outlined above, which include new experimental materials (civil and criminal law scenarios), 20 minutes preparation time during the session instead of two full days leading up to the session, inclusion of a measure of authentic symptomatology as manipulation check for the experimental conditions, and the exclusion of a nonclinical control group.

\section{Participants}

In addition to graduate and undergraduate psychology students at Maastricht University, members of the general population were recruited as participants for the three experimental conditions ( $n=32$ per condition). Only native Dutch speakers who did not partake in Study 1 were eligible for participation. None of the participants reported a history of severe mental illness. Eight participants were excluded from the statistical analyses because they did not simulate a significant level of symptomatology (see below). The remaining sample for the experimental conditions consisted of 64 students and 24 general population members (approximately evenly distributed over the three experimental conditions). The final sample for the experimental conditions $(n=88)$ was predominantly female $(74 \% ; n=65)$ and Caucasian $(93 \% ; n=82)$, with a mean age of 27.4 years (age range $18-65)$.

For the clinical control condition, participants $(n=40)$ were recruited at an inpatient unit $(n=25)$ and an outpatient unit $(n=15)$ of the same forensic psychiatric hospital that provided the clinical sample for Study 1; Radix Forensic Psychiatric Hospital (see the Method section of Study 1). All but one participant were male $(98 \% ; n=39)$. The majority was Caucasian $(83 \% ; n=33)$. The mean age was 36.5 years (age range $21-61$ years). Offenses for which participants were convicted often involved drugs, violence, theft, or sexual abuse. The most prevalent forms of psychopathology were substance disorders $(60 \%)$ and personality disorders $(60 \%)$, which occurred frequently with comorbid symptomatology, including schizophrenia, autism, depression, intellectual disability, or posttraumatic stress disorder. 


\section{Measures}

Identical to Study 1, the SDI, the SIMS, and the M-FAST were administered to participants; only the SDI and the SIMS are included in the present analyses.

\section{Brief Symptom Inventory (BSI)}

The BSI (Derogatis \& Melisaratos, 1983) is a 53-item self-report scale of psychopathology. It comprises nine subscales that represent various psychopathological domains, ranging from affective and anxiety disorders to cognitive impairments and somatic symptoms. Each item consists of a symptom description and a 5-point Likert-type scale (range: 0-4) that respondents use to indicate to what extent they felt distressed by the symptom during the past week. BSI Total and scale scores are computed by adding appropriate item scores and dividing the result by the number of items (i.e., scale scores are the means of their item scores). We employed the Dutch translation and norms constructed by De Beurs and Zitman (2006; Cronbach's $\alpha=.96$ ). To check whether participants in the experimental feigning conditions simulated clinically relevant levels of symptomatology, we used a Total (i.e., mean item) score of 0.50 as lower bound, which is associated with a sensitivity of .84 and a specificity of .70 (De Beurs \& Zitman, 2006).

\section{Procedure}

The procedures of Study 2 were equivalent to those of Study 1, except for the changes discussed earlier: We included the BSI in the test battery; we increased the compensation that participants in the experimental conditions received from $€ 7.50$ to $€ 12.50$ which is roughly \$14.90; and instead of sending the instructional sets to participants 2 days before their test session, we presented the instructional sets at the beginning of the test session and gave participants 20 minutes preparation time (with access to the Internet) after they studied the instructional materials.

\section{Experimental Feigning Conditions}

The instructional sets of Study 2 followed the same approach that was employed in Study 1: Participants were prompted to act as if they were in a certain setting, in a specific situation, under particular circumstances with a given background. We used the same hypothetical setting and situation in the three experimental conditions; all participants were asked to imagine that they were being evaluated by a court-ordered psychologist at a forensic clinic. The fictional circumstances and background of the psychological evaluation were similar across conditions, but varied in important aspects. Participants read a detailed description of how they had been provoked into a mildly violent altercation at a college party that they had attended 3 weeks prior. The outcome of the incident varied across conditions and served to incentivize factitious or malingered symptom presentations, as detailed below. 
In the experimental factitious condition, the outcome of the incident was that the participant sustained superficial injuries and started a civil lawsuit against their opponent. In the process of the lawsuit, which ended up being dismissed, the participant got into contact with a psychologist whom they soon came to revere and feel dependent on and were longing to keep into contact with; the only way to get into treatment and keep seeing the psychologist was to appear as if suffering from serious symptomatology. The "dependency on staff" factitious symptom presentation as formulated by Cunnien (1997) and interpreted by Rogers et al. (2005) served again as prototype of the interpersonal motivations behind factitious disorders.

The experimental civil law malingering condition featured the same outcome of the college party incident; participants were asked to suppose that they suffered only minor injuries but still instigated a civil lawsuit. Nevertheless, instead of being informed that the lawsuit was unsuccessful, participants were informed that the outcome of the lawsuit depended on the evaluation by the psychologist and that presenting as if suffering from serious symptomatology would lead to substantial damages being awarded to them.

In the criminal law malingering condition, the college party altercation resulted in severe (authentic) injuries for the adversary and an ensuing criminal trial for the participant. Analogous to the civil law malingering condition, the outcome of the trial depended on the evaluation by the psychologist, with a false presentation of serious symptomatology being the only way to a avoid criminal responsibility and corresponding punishment.

Other than the increased monetary incentive ( $€ 12.50$ gift voucher instead of $€ 7.50$ ), we did not change our methods to encourage participants to engage with and act according to the experimental materials: Thus, we emphasized the importance of the research and challenged participants to appear credible on the tests while attempting to obtain their hypothetical incentive.

\section{Clinical Control Group}

The recruitment and test session procedures for the clinical control group were identical to those of Study 1: Participants were recruited via personnel of the patient units of Radix Forensic Psychiatric Hospital, and were only requested to be completely honest during the test session. Participants' engagement and effort was not stimulated by any financial incentives, but by underscoring the importance of the research.

\section{Results}

Eight participants (two in the factitious condition, three in the civil law malingering condition, and three in the criminal law malingering condition) were excluded from the analyses because their BSI score was below 0.50, which suggests that they did not simulate a clinically relevant level of symptomatology. The remaining participants in the feigning conditions typically presented as patients on the BSI, generating mean scores between 1.4 and 2.0, which is slightly higher than the mean score of the heterogeneous clinical group $(N=$ 
992) of De Beurs and Zitman (2006; $M=1.2$ ). The mean SIMS scores of the experimental feigning groups are marginally lower than those of the feigning groups of Study 1, yet still similar to those of previous studies (see Chapter 4). Five participants of the clinical control group scored above 16 on the SIMS. These five participants were pooled with the clinical participants in Study 1 who also scored $>16$ on the SIMS $(n=6)$ : Together, these participants were handled as a single group $(n=11)$ for comparison with the factitious conditions of Studies 1 and 2 (see Table 6.7). Mann-Whitney $U$ tests showed that neither gender nor race (Caucasian vs. non-Caucasian) had a statistically significant effect on SDI or SIMS scale scores in any of the groups (all Us $>8.4$, all exact, two-tailed $p \mathrm{~s}>.09$ ). Likewise, age was not statistically related to SDI or SIMS scale scores in any of the groups (all Kendall rank correlation coefficients between -.25 and .24 , all $p s>.16$ ).

Table 6.4 displays group means and corresponding 95\% confidence intervals and standard deviations of SDI and SIMS scale scores. The pattern that can be observed is comparable to that in Study 1: The experimental feigning groups produced higher SDI and SIMS scores than the clinical control group, and the factitious group scored higher-albeit to a lesser extent - on the SDI, but not on the SIMS, than the other feigning groups.

Differences in scores on SDI and SIMS scales between the various groups were once more quantified through Cohen's $d$ effect sizes. The results are on display in Table 6.5 and corroborate many, but not all, findings of Study 1: While the SDI US and Total scales again performed in the same league as the SIMS by manifesting large group differences between the feigning groups (factitious, civil law malingering, and criminal law malingering) and the clinical control group ( $d \mathrm{~s}$ in the range of 1.2 to $2.1, p \mathrm{~s}<.001$ ), the other SDI scales were less effective in this regard.

In contrast to Study 1, the SDI failed to distinguish the factitious group from the malingering groups ( $d s-0.1-0.6, p s>.01)$. The potential that the SIMS $A F-N$ index showed in the factitious vs. malingering comparisons of Study $1(d=-0.9$, but cf. $d$ s $1.1-1.4$ of Rogers et al., 2005) did not replicate in Study 2, where the $A F-N$ index was as ineffective as the SIMS Total scale $(d s-0.3-0.3, p s>.10)$.

The diagnostic accuracy of the SDI (the US as well as the Total scale) and the SIMS for detecting feigned symptomatology, as represented by AUC values in Table 6.6, is slightly lower than in Study 1, yet still acceptable, with the SDI US scale now even performing on a par with the SDI and SIMS Total scales (AUCs: SDI US; .90-.92, SDI Total; .81-.90, SIMS Total; .78-.92, all $p s<.001)$. The efficacy of the other SDI scales $(C S, S R$, and $I A)$ in classifying feigned symptomatology fluctuated between poor and moderate (AUCs $=.43-.79$, $p$ s $>.10$ $<.001)$.

In Study 1, the SDI US and SR, and particularly the $I A$ and Total scales, achieved significant accuracy in differentiating participants in the factitious condition from those in the malingering condition (AUCs $=.69-.88$ ). The results of Study 2 are not corroborative: No scale was effective in differentiating the factitious condition from the civil malingering condition (AUCs $=.47-.65, \mathrm{ps}>.01$ ), and only the IA scale managed to discriminate the factitious from the criminal malingering condition $(\mathrm{AUC}=.75, p<.01)$. 


\section{Table 6.4}

Symptom presentations on the Symptom and Disposition Interview, the Structured Inventory of Malingered Symptomatology, and the Brief Symptom Inventory in Study 2: Mean scores, corresponding [95\% confidence intervals], and (standard deviations)

\begin{tabular}{|c|c|c|c|c|c|}
\hline \multirow[b]{2}{*}{$\begin{array}{l}\text { Scale } \\
\text { (min-max) }\end{array}$} & \multicolumn{3}{|c|}{ Experimental groups } & \multicolumn{2}{|c|}{ Clinical control group ${ }^{a}$} \\
\hline & $\begin{array}{c}\text { Factitious } \\
\text { (civil law) } \\
n=30\end{array}$ & $\begin{array}{c}\text { Malingering } \\
\text { (civil law) } \\
n=29\end{array}$ & $\begin{array}{c}\text { Malingering } \\
\text { (criminal law) } \\
n=29\end{array}$ & $\begin{array}{c}(\mathrm{SIMS} \leq 16) \\
n=35\end{array}$ & $\begin{array}{c}(\text { SIMS }>16) \\
n=5\end{array}$ \\
\hline $\begin{array}{l}\text { SDI US } \\
(0-28)\end{array}$ & $\begin{array}{c}13.0 \\
{[11.3,14.7]} \\
(4.5)\end{array}$ & $\begin{array}{c}11.1 \\
{[9.3,12.9]} \\
(4.7)\end{array}$ & $\begin{array}{c}12.4 \\
{[10.6,14.2]} \\
(4.7)\end{array}$ & $\begin{array}{c}3.7 \\
{[2.1,5.2]} \\
(4.4)\end{array}$ & $\begin{array}{c}11.4 \\
{[6.9,15.9]} \\
(3.6)\end{array}$ \\
\hline $\begin{array}{l}\text { SDI CS } \\
(0-14)\end{array}$ & $\begin{array}{c}7.0 \\
{[6.3,7.8]} \\
(2.0)\end{array}$ & $\begin{array}{c}6.0 \\
{[5.1,6.8]} \\
(2.2)\end{array}$ & $\begin{array}{c}6.8 \\
{[6.0,7.6]} \\
(2.1)\end{array}$ & $\begin{array}{c}4.5 \\
{[3.7,5.4]} \\
(2.5)\end{array}$ & $\begin{array}{c}8.2 \\
{[5.0,11.4]} \\
(2.6)\end{array}$ \\
\hline $\begin{array}{l}\text { SDI } S R \\
(0-28)\end{array}$ & $\begin{array}{c}17.0 \\
{[15.5,18.5]} \\
(4.0)\end{array}$ & $\begin{array}{c}14.8 \\
{[13.0,16.5]} \\
(4.5)\end{array}$ & $\begin{array}{c}14.4 \\
{[12.6,16.2]} \\
(4.8)\end{array}$ & $\begin{array}{c}11.8 \\
{[10.1,13.6]} \\
(5.1)\end{array}$ & $\begin{array}{c}15.2 \\
{[10.8,19.6]} \\
(3.6)\end{array}$ \\
\hline $\begin{array}{l}\text { SDI } I A \\
(0-14)\end{array}$ & $\begin{array}{c}6.0 \\
{[5.2,6.8]} \\
(2.2)\end{array}$ & $\begin{array}{c}6.3 \\
{[5.5,7.1]} \\
(2.1)\end{array}$ & $\begin{array}{c}4.0 \\
{[3.3,4.7]} \\
(1.8)\end{array}$ & $\begin{array}{c}4.7 \\
{[3.9,5.6]} \\
(2.3)\end{array}$ & $\begin{array}{c}6.2 \\
{[3.5,8.9]} \\
(2.2)\end{array}$ \\
\hline $\begin{array}{l}\text { SDI Total } \\
(0-84)\end{array}$ & $\begin{array}{c}43.0 \\
{[39.7,46.3]} \\
(8.7)\end{array}$ & $\begin{array}{c}38.1 \\
{[33.9,42.3]} \\
(11.0)\end{array}$ & $\begin{array}{c}37.6 \\
{[33.9,41.2]} \\
(9.7)\end{array}$ & $\begin{array}{c}24.7 \\
{[20.8,28.6]} \\
(11.4)\end{array}$ & $\begin{array}{c}41.0 \\
{[30.1,51.9]} \\
(8.7)\end{array}$ \\
\hline $\begin{array}{l}\text { SIMS } A F-N \\
(-15-15)\end{array}$ & $\begin{array}{c}3.3 \\
{[2.3,4.2]} \\
(2.5)\end{array}$ & $\begin{array}{c}2.5 \\
{[1.5,3.5]} \\
(2.6)\end{array}$ & $\begin{array}{c}4.1 \\
{[3.0,5.2]} \\
(2.9)\end{array}$ & $\begin{array}{c}3.2 \\
{[2.5,4.0]} \\
(2.2)\end{array}$ & $\begin{array}{c}2.8 \\
{[0.4,5.2]} \\
(1.9)\end{array}$ \\
\hline $\begin{array}{l}\text { SIMS Total } \\
(0-75)\end{array}$ & $\begin{array}{c}20.4 \\
{[16.8,24.1]} \\
(9.7)\end{array}$ & $\begin{array}{c}16.8 \\
{[12.2,21.4]} \\
(12.1)\end{array}$ & $\begin{array}{c}20.1 \\
{[16.6,23.6]} \\
(9.2)\end{array}$ & $\begin{array}{c}7.2 \\
{[5.9,8.5]} \\
(3.8)\end{array}$ & $\begin{array}{c}21.0 \\
{[15.7,26.3]} \\
(4.2)\end{array}$ \\
\hline $\begin{array}{l}\text { BSI Total } \\
(0.0-4.0)\end{array}$ & $\begin{array}{c}2.0 \\
{[1.8,2.2]} \\
(0.5)\end{array}$ & $\begin{array}{c}1.4 \\
{[1.1,1.6]} \\
(0.6)\end{array}$ & $\begin{array}{c}1.7 \\
{[1.5,1.9]} \\
(0.5)\end{array}$ & N/A & N/A \\
\hline
\end{tabular}

Note. SIMS = Structured Inventory of Malingered Symptomatology; SDI = Symptom and Disposition Interview; $U S=$ SDI Unlikely Symptoms scale; $C S=$ SDI Common Symptoms scale; $S R=$ SDI Sick Role scale; $I A=$ SDI Illness Anxiety scale; $A F-N=$ Affective disorders SIMS scale minus Neurological impairment SIMS scale score index; BSI = Brief Symptom Inventory; N/A = not applicable.

aThe group of participants with a SIMS score $>16(n=5)$ were excluded from all analyses involving the clinical control group; instead, the data of this group were combined with those of the participants with a SIMS score $>16$ in Study 1 to form a supplemental group for comparison with the experimental groups (see Table 6.7). 
Chapter 6

\section{Table 6.5}

Differences in symptom presentation on the Symptom and Disposition Interview and Structured Inventory of Malingered Symptomatology in Study 2: Cohen's d effect sizes and corresponding [95\% Confidence Intervals]

\begin{tabular}{|c|c|c|c|c|c|}
\hline \multirow[b]{2}{*}{ Scale } & \multicolumn{3}{|c|}{$\begin{array}{l}\text { Feigning groups } \\
\text { vs. } \\
\text { Clinical control group }\end{array}$} & \multicolumn{2}{|c|}{$\begin{array}{c}\text { Factitious group } \\
\text { vs. } \\
\text { other feigning groups }\end{array}$} \\
\hline & $\begin{array}{c}\text { Factitious } \\
\text { (civil law) } \\
\text { vs. } \\
\text { Clinical control }\end{array}$ & $\begin{array}{c}\text { Malingering } \\
\text { (civil law) } \\
\text { vs. } \\
\text { Clinical control }\end{array}$ & $\begin{array}{l}\text { Malingering } \\
\text { (criminal law) } \\
\text { vs. } \\
\text { Clinical control }\end{array}$ & $\begin{array}{c}\text { Factitious } \\
\text { (civil law) } \\
\text { vs. } \\
\text { Malingering } \\
\text { (civil law) } \\
\end{array}$ & $\begin{array}{c}\text { Factitious } \\
\text { (civil law) } \\
\text { vs. } \\
\text { Malingering } \\
\text { (criminal law) }\end{array}$ \\
\hline SDI US & $\begin{array}{c}2.1^{* *} \\
{[1.5,2.7]}\end{array}$ & $\begin{array}{c}1.6^{* *} \\
{[1.0,2.2]}\end{array}$ & $\begin{array}{c}1.9^{* *} \\
{[1.3,2.5]}\end{array}$ & $\begin{array}{c}0.4 \\
{[-0.1,0.9]}\end{array}$ & $\begin{array}{c}0.1 \\
{[-0.4,0.6]}\end{array}$ \\
\hline SDI $C S$ & $\begin{array}{c}1.1^{* *} \\
{[0.6,1.6]}\end{array}$ & $\begin{array}{c}0.6 \\
{[0.1,1.1]}\end{array}$ & $\begin{array}{c}1.0^{* *} \\
{[0.5,1.5]}\end{array}$ & $\begin{array}{c}0.5 \\
{[0.0,1.0]}\end{array}$ & $\begin{array}{c}0.1 \\
{[-0.4,0.6]}\end{array}$ \\
\hline SDI $S R$ & $\begin{array}{c}1.1^{* *} \\
{[0.6,1.6]}\end{array}$ & $\begin{array}{c}0.6 \\
{[0.1,1.1]}\end{array}$ & $\begin{array}{c}0.5 \\
{[0.0,1.0]}\end{array}$ & $\begin{array}{c}0.5 \\
{[0.0,1.0]}\end{array}$ & $\begin{array}{c}0.6 \\
{[0.1,1.1]}\end{array}$ \\
\hline SDI $I A$ & $\begin{array}{c}0.6 \\
{[0.1,1.1]}\end{array}$ & $\begin{array}{c}0.7^{*} \\
{[0.2,1.2]}\end{array}$ & $\begin{array}{c}-0.3 \\
{[-0.8,0.2]}\end{array}$ & $\begin{array}{c}-0.1 \\
{[-0.6,0.4]}\end{array}$ & $\begin{array}{c}1.0 \\
{[0.5,1.5]}\end{array}$ \\
\hline SDI Total & $\begin{array}{c}1.8^{* *} \\
{[1.2,2.4]}\end{array}$ & $\begin{array}{c}1.2^{* *} \\
{[0.7,1.7]}\end{array}$ & $\begin{array}{c}1.2^{* *} \\
{[0.7,1.7]}\end{array}$ & $\begin{array}{c}0.5 \\
{[0.0,1.0]}\end{array}$ & $\begin{array}{c}0.6 \\
{[0.1,1.1]}\end{array}$ \\
\hline SIMS $A F-N$ & $\begin{array}{c}0.0 \\
{[-0.5,0.5]}\end{array}$ & $\begin{array}{c}-0.3 \\
{[-0.8,0.2]}\end{array}$ & $\begin{array}{c}0.4 \\
{[-0.1,0.9]}\end{array}$ & $\begin{array}{c}0.3 \\
{[-2,0.8]}\end{array}$ & $\begin{array}{c}-0.3 \\
{[-0.8,0.2]}\end{array}$ \\
\hline SIMS Total & $\begin{array}{c}1.8^{* *} \\
{[1.2,2.4]}\end{array}$ & $\begin{array}{c}1.1^{* *} \\
{[0.6,1.6]}\end{array}$ & $\begin{array}{c}1.9^{* *} \\
{[1.3,2.5]}\end{array}$ & $\begin{array}{c}0.3 \\
{[-0.2,0.8]}\end{array}$ & $\begin{array}{c}0.0 \\
{[-0.5,0.5]}\end{array}$ \\
\hline
\end{tabular}

Note. SDI = Symptom and Disposition Interview; $U S=$ SDI Unlikely Symptoms scale; $C S=$ SDI Common Symptoms scale; $S R$ = SDI Sick Role scale; $I A$ = SDI Illness Anxiety scale; SIMS = Structured Inventory of Malingered Symptomatology; $A F-N=$ Affective disorders SIMS scale minus Neurological impairment SIMS scale score index.

${ }^{*}$ Cohen's $d$ is significant (i.e., $>0.0$ ) at the $p<.01$ level. ${ }^{* *}$ Cohen's $d$ is significant (i.e., $>0.0$ ) at the $p$ $<.001$ level.

As in Study 1, the SIMS Total scale did not demonstrate any precision in separating factitious from malingered experimental conditions. The promise that the SIMS $A F-N$ index showed in Study $1-\mathrm{AUC}=.25$, which translates to .75 if lower $A F-N$ index scores are taken to be indicative of the factitious condition, instead of higher scores as found by Rogers et al. (2005) - did not transpire in Study 2; AUCs were .41-.57, ps > .10. 


\section{Table 6.6}

Diagnostic utility of the Symptom and Disposition Interview and the Structured Inventory of Malingered Symptomatology in Study 2: Area's under the receiver operating characteristic curve and corresponding [95\% confidence intervals]

\begin{tabular}{|c|c|c|c|c|c|}
\hline \multirow[b]{3}{*}{ Scale } & \multicolumn{3}{|c|}{$\begin{array}{c}\text { Feigning groups } \\
\text { vs. } \\
\text { Clinical control group }\end{array}$} & \multicolumn{2}{|c|}{$\begin{array}{c}\text { Factitious group } \\
\text { vs. } \\
\text { other feigning groups }\end{array}$} \\
\hline & $\begin{array}{l}\text { Factitious } \\
\text { (civil law) }\end{array}$ & $\begin{array}{l}\text { Malingering } \\
\text { (civil law) }\end{array}$ & $\begin{array}{l}\text { Malingering } \\
\text { (criminal law) }\end{array}$ & $\begin{array}{l}\text { Factitious } \\
\text { (civil law) }\end{array}$ & $\begin{array}{l}\text { Factitious } \\
\text { (civil law) }\end{array}$ \\
\hline & $\begin{array}{c}\text { vs. } \\
\text { Clinical control }\end{array}$ & $\begin{array}{c}\text { vs. } \\
\text { Clinical control }\end{array}$ & $\begin{array}{c}\text { vs. } \\
\text { Clinical control }\end{array}$ & $\begin{array}{c}\text { vs. } \\
\text { Malingering } \\
\text { (civil law) }\end{array}$ & $\begin{array}{c}\text { vs. } \\
\text { Malingering } \\
\text { (criminal law) }\end{array}$ \\
\hline SDI US & $\begin{array}{c}.92^{* *} \\
{[85 ., 1.00]}\end{array}$ & $\begin{array}{c}.90^{* *} \\
{[.81, .98]}\end{array}$ & $\begin{array}{c}.91^{* *} \\
{[.84, .99]}\end{array}$ & $\begin{array}{c}.64 \\
{[.49, .78]}\end{array}$ & $\begin{array}{c}.54 \\
{[.39, .69]}\end{array}$ \\
\hline SDI $C S$ & $\begin{array}{c}.79^{* *} \\
{[.68, .90]}\end{array}$ & $\begin{array}{c}.67 \\
{[.54, .80]}\end{array}$ & $\begin{array}{c}.76^{* *} \\
{[.65, .88]}\end{array}$ & $\begin{array}{c}.63 \\
{[.49, .77]}\end{array}$ & $\begin{array}{c}.51 \\
{[.36, .66]}\end{array}$ \\
\hline SDI $S R$ & $\begin{array}{c}.78^{* *} \\
{[.67, .89]}\end{array}$ & $\begin{array}{c}.66 \\
{[.52, .79]}\end{array}$ & $\begin{array}{c}.65 \\
{[.52, .79]}\end{array}$ & $\begin{array}{c}.65 \\
{[.51, .79]}\end{array}$ & $\begin{array}{c}.66 \\
{[.52, .80]}\end{array}$ \\
\hline SDI $I A$ & $\begin{array}{c}.67 \\
{[.54, .80]}\end{array}$ & $\begin{array}{c}.70^{*} \\
{[.58, .83]}\end{array}$ & $\begin{array}{c}.43 \\
{[.29, .57]}\end{array}$ & $\begin{array}{c}.47 \\
{[.32, .62]}\end{array}$ & $\begin{array}{c}.75^{*} \\
{[.62, .87]}\end{array}$ \\
\hline SDI Total & $\begin{array}{c}.90^{* *} \\
{[.82, .98]}\end{array}$ & $\begin{array}{c}.81^{* *} \\
{[.70, .92]}\end{array}$ & $\begin{array}{c}.82^{* *} \\
{[.71, .92]}\end{array}$ & $\begin{array}{c}.63 \\
{[.49, .78]}\end{array}$ & $\begin{array}{c}.67 \\
{[.53, .81]}\end{array}$ \\
\hline SIMS $A F-N$ & $\begin{array}{c}.50 \\
{[.36, .64]}\end{array}$ & $\begin{array}{c}.44 \\
{[.30, .58]}\end{array}$ & $\begin{array}{c}.60 \\
{[.46, .75]}\end{array}$ & $\begin{array}{c}.57 \\
{[.42, .72]}\end{array}$ & $\begin{array}{c}.41 \\
{[.26, .56]}\end{array}$ \\
\hline SIMS Total & $\begin{array}{c}.90^{* *} \\
{[.83, .98]}\end{array}$ & $\begin{array}{c}.78^{* *} \\
{[.66, .90]}\end{array}$ & $\begin{array}{c}.92^{* *} \\
{[.85, .98]}\end{array}$ & $\begin{array}{c}.63 \\
{[.49, .77]}\end{array}$ & $\begin{array}{c}.51 \\
{[.37, .66]}\end{array}$ \\
\hline
\end{tabular}

Note. SDI = Symptom and Disposition Interview; $U S=$ SDI Unlikely Symptoms scale; $C S=$ SDI Common Symptoms scale; $S R=$ SDI Sick Role scale; $I A=$ SDI Illness Anxiety scale; SIMS = Structured Inventory of Malingered Symptomatology; $A F-N=$ Affective disorders SIMS scale minus Neurological impairment SIMS scale score index.

*Area under the receiver operating characteristic curve is significantly greater than .5 (i.e., above chance level) at the $p<.01$ level. ${ }^{* *}$ Area under the receiver operating characteristic curve is significantly greater than .5 (i.e., above chance level) at the $p<.001$ level.

Several participants in the clinical control groups of Study 1 and Study 2 scored above 16 on the SIMS, which compromises the validity of their symptom report and may reflect real-world feigning. Because these groups were recruited at the same forensic psychiatric hospital (at different points in time), received identical instructions (i.e., to respond honestly to all questions), and produced similar SIMS Total scores (means $23.3 \mathrm{vs.}$ $21.0 ; t(9)=0.57, p=.58)$, we grouped these participants together $(n=11)$ and employed them as an additional feigning group to compare the experimental factitious groups with. The results are on display in Table 6.7 and concur with the results from the experimental 
malingering-factitious comparisons: The SDI SR and Total scale, and above all the IA scale, distinguished well between the clinical group that produced SIMS scores $>16$ and the factitious group of Study 1 (ds 1.3 to 2.3, AUCs .83-.95, ps <.01), but not the factitious group of Study 2 ( $d \mathrm{~s}-0.1$ to 0.4 , AUCs .46-.59, $p \mathrm{~s}>.10$ ). The SIMS $A F-N$ index did not attain accuracy above chance level in discriminating the clinical SIMS $>16$ group from the factitious group of either study.

\section{Table 6.7}

Comparison of the factitious groups of Study 1 and Study 2 with the clinical groups of Study 1 and Study 2 who produced SIMS scores $>16$

\begin{tabular}{|c|c|c|c|c|c|}
\hline \multirow[b]{2}{*}{ Scale } & \multirow{2}{*}{$\begin{array}{c}M \\
{[95 \% \mathrm{CI}]} \\
(S D) \\
\\
\text { Clinical } \\
\text { (SIMS >16)a }\end{array}$} & \multicolumn{2}{|c|}{$\begin{array}{l}\text { Cohen's d } \\
{[95 \% \mathrm{CI}]}\end{array}$} & \multicolumn{2}{|c|}{$\begin{array}{l}\text { Area under the curve } \\
\qquad[95 \% \mathrm{CI}]\end{array}$} \\
\hline & & $\begin{array}{c}\text { Factitious } \\
\text { Study } 1 \\
\text { vs. } \\
\text { Clinical } \\
\text { SIMS }>16\end{array}$ & $\begin{array}{c}\text { Factitious } \\
\text { Study } 2 \\
\text { vs. } \\
\text { Clinical } \\
\text { SIMS }>16\end{array}$ & $\begin{array}{c}\text { Factitious } \\
\text { Study } 1 \\
\text { vs. } \\
\text { Clinical } \\
\text { SIMS }>16\end{array}$ & $\begin{array}{c}\text { Factitious } \\
\text { Study } 2 \\
\text { vs. } \\
\text { Clinical } \\
\text { SIMS }>16\end{array}$ \\
\hline SDI US & $\begin{array}{c}9.1 \\
{[6.1,12.1]} \\
4.5\end{array}$ & $\begin{array}{c}0.9 \\
{[0.1,1.6]}\end{array}$ & $\begin{array}{c}0.9 \\
{[0.2,1.6]}\end{array}$ & $\begin{array}{c}.74 \\
{[.57, .91]}\end{array}$ & $\begin{array}{c}.73 \\
{[.56, .90]}\end{array}$ \\
\hline SDI $C S$ & $\begin{array}{c}8.6 \\
{[6.5,10.6]} \\
3.0\end{array}$ & $\begin{array}{c}0.0 \\
{[-0.7,0.7]}\end{array}$ & $\begin{array}{c}-0.7 \\
{[-1.4,0.0]}\end{array}$ & $\begin{array}{c}.53 \\
{[.31, .74]}\end{array}$ & $\begin{array}{c}.34 \\
{[.13, .56]}\end{array}$ \\
\hline SDI $S R$ & $\begin{array}{c}15.6 \\
{[13.1,18.1]} \\
3.7\end{array}$ & $\begin{array}{c}1.3^{*} \\
{[0.5,2.1]}\end{array}$ & $\begin{array}{c}0.4 \\
{[-0.3,1.1]}\end{array}$ & $\begin{array}{c}.83^{*} \\
{[.70, .96]}\end{array}$ & $\begin{array}{c}.59 \\
{[.41, .78]}\end{array}$ \\
\hline SDI $I A$ & $\begin{array}{c}6.3 \\
{[4.5,8.1]} \\
2.7\end{array}$ & $\begin{array}{c}2.3^{* *} \\
{[1.4,3.2]}\end{array}$ & $\begin{array}{c}-0.1 \\
{[-0.8,0.6]}\end{array}$ & $\begin{array}{c}.95^{* *} \\
{[.87,1.00]}\end{array}$ & $\begin{array}{c}.46 \\
{[.24, .68]}\end{array}$ \\
\hline SDI Total & $\begin{array}{c}39.6 \\
{[32.1,47.0]} \\
11.1\end{array}$ & $\begin{array}{c}1.4^{*} \\
{[0.6,2.2]}\end{array}$ & $\begin{array}{c}0.4 \\
{[-0.3,1.1]}\end{array}$ & $\begin{array}{c}.86^{*} \\
{[.75, .98]}\end{array}$ & $\begin{array}{c}.57 \\
{[.36, .78]}\end{array}$ \\
\hline SIMS $A F-N$ & $\begin{array}{c}2.7 \\
{[1.0,4.5]} \\
2.6\end{array}$ & $\begin{array}{c}-0.6 \\
{[-1.3,0.1]}\end{array}$ & $\begin{array}{c}0.2 \\
{[-0.5,0.9]}\end{array}$ & $\begin{array}{c}.31 \\
{[.14, .49]}\end{array}$ & $\begin{array}{c}.57 \\
{[.38, .77]}\end{array}$ \\
\hline SIMS Total & $\begin{array}{c}22.3 \\
{[17.9,26.7]} \\
6.6\end{array}$ & $\begin{array}{c}0.1 \\
{[-0.6,0.8]}\end{array}$ & $\begin{array}{c}-0.2 \\
{[-0.9,0.5]}\end{array}$ & $\begin{array}{c}.55 \\
{[.35, .75]}\end{array}$ & $\begin{array}{c}.43 \\
{[.25, .60]}\end{array}$ \\
\hline
\end{tabular}

Note. $\mathrm{CI}=$ confidence interval; $\mathrm{AUC}=$ area under the receiver operating characteristic curve; $\mathrm{SDI}=$ Symptom and Disposition Interview; $U S=$ SDI Unlikely Symptoms scale; $C S=$ SDI Common Symptoms scale; $S R=$ SDI Sick Role scale; $I A=$ SDI Illness Anxiety scale; SIMS = Structured Inventory of Malingered Symptomatology; $A F-N=$ Affective disorders SIMS scale minus Neurological impairment SIMS scale score index.

${ }^{*}$ Cohen's $d$ is significant (i.e., $>0.0$ ) at the $p<.01$ level $/{ }^{*}$ Area under the receiver operating characteristic curve is significantly greater than .5 (i.e., above chance level) at the $p<.01$ level. ${ }^{* *}$ Cohen's $d$ is significant (i.e., $\left.>0.0\right)$ at the $p<.001$ level $/{ }^{* *}$ Area under the receiver operating characteristic curve is significantly greater than .5 (i.e., above chance level) at the $p<.001$ level.

aThis group consists of participants with a SIMS score $>16$ in the clinical control groups of Study $1(n=$ 6) and Study $2(n=5)$. 
We were also interested in the reliability of the SDI scales and, therefore, we computed Cronbach's alpha values over the pooled data of Studies 1 and $2(N=258)$. The reliability of the Total scale was high $(\alpha=.91)$, closely followed by that of the US scale $(\alpha=$ $.86)$; the alpha values of the other scales were acceptable (CS $\alpha=.70$, SR $\alpha=.71$, IA $\alpha=.74$ ).

\section{Discussion}

The present studies address an issue that is often overlooked in clinical practice and practically neglected in research: The structured assessment of internal incentives for feigned symptom presentations. We took a psychometric approach to this issue and developed the Symptom and Disposition Interview (SDI), which screens for feigned symptomatology and assesses potential internal incentives for feigning (i.e., the need to assume the sick role). The SDI consists of four scales: Unlikely Symptoms (US; 14 items measuring noncredible symptom reporting), Common Symptoms (CS; 7 items serving to disguise the symptom validity aspect of the Unlikely Symptom scale and lower its sensitivity to authentic symptomatology), Sick Role (SR; 14 items querying the readiness to engage in patient-related activities), and Illness Anxiety (IA; 7 items covering sensitivity to somatic symptoms and distress over potential pathology, which we included because the internal motivations that drive factitious symptom presentations are similar to those that underlie somatic symptomatology). To investigate the potential merits of the SDI, we compared it to a traditional symptom validity test (the SIMS) in two simulation studies, each with factitious and malingering conditions ( $n=24-30$ per condition) and a clinical control group ( $n=34, n=$ 40). The first and foremost point that can be taken from our two studies is that the assessment of internal incentives can be incorporated into a symptom validity test without sacrificing efficacy in detecting feigned symptomatology, as the SDI achieved parity with the SIMS in this respect.

The second conclusion that can be drawn is that the utility of the SDI in differentiating experimental factitious symptom presentations from malingered symptom presentations is sufficiently promising to justify future research: The diagnostic accuracy (i.e., AUC) of the $S R$ scale varied between .65 and .80. In designing the $S R$ scale, we assembled items that diverge widely with regard to their topic and approach, yet all approaches were taken to gauge the strength of an internal motive to feign symptomatology. In this light, the reliability of the $S R$ scale ( 14 items, $\alpha=.71$ ) is satisfactory.

Nonetheless, the assessment of factitious symptom presentations can be improved by advancing from rationally derived approaches to empirically established detection strategies. In this regard, future research may revolve around self-reported illness anxiety and somatic sensitivity. The rationale behind the development of the IA scale was that any measure of somatoform symptomatology would indirectly mark internal incentives for such symptomatology as well as for factitious symptomatology, because the incentives for both symptomatologies are thought to be similar (the main difference being that those of somatoform symptomatology largely reside outside awareness; see Krahn et al., 2008). The 
items of the $I A$ scale embody two potential detection-based strategies: The first encompasses sensitivity to, and frequency of, mild somatic symptomatology, and the second involves distress and anxiety over potential illnesses and health risks. More research on these strategies seems required.

The logical next step toward structured assessment of factitious symptom presentations is known-groups research (Rogers, 2008a). Rather than theorizing as to why some items or strategies work well and others do not in simulation research and attempting to gain more insight through additional simulation studies, it is pertinent to put positive findings in simulation research to the test in clinical group comparisons (i.e., patients with factitious disorder vs. real-world malingerers). For example, finding out why items referring to somatic sensitivity and illness anxiety worked (particularly well in Study 1) in differentiating experimental factitious symptomatology from experimental malingered symptomatology is of subsidiary importance to finding out what the value of such items is in forensic and clinical work. This is not to say that the theoretical foundation of a detection strategy is unimportant - in fact, it may well originate from there-but that the ultimate test of its adequacy is its utility in clinical practice (Meehl, 1945, but see Butcher, 2000).

The third outcome of the current studies is that the detection strategies described above did not consistently produce better results collectively than individually. For instance, the IA scale outperformed the Total scale in the majority of factitious vs. malingering comparisons (see Tables 6.3 and 6.6). Another example is the US scale attaining greater accuracy in discriminating feigned symptomatology from authentic symptomatology than the Total scale in Study 2 (see Table 6.6).

The fourth point that can be deduced from the data is that the CS scale of the SDI, which is an auxiliary scale referring to different (credible) psychiatric symptoms, succeeds in its functions that were tested in the present studies, these being (a) lowering the sensitivity of the US and IA scales to genuine symptomatology - by providing the opportunity to endorse such symptomatology - and (b) supporting the detection of feigned symptomatology. As can be seen in Table 6.2, the effect of authentic symptomatology on CS scale scores is substantially greater than on US and IA scale scores ( $d$ s 0.7 vs. 0.1 and -0.1 ). Tables 6.3 and 6.6 show that the CS scale possesses respectable diagnostic efficacy in classifying feigned symptomatology (AUCs $=.67-.83$ ). The latter result reflects the common finding that malingerers typically endorse a wider variety and higher severity of symptoms than do genuine patients (hence, the effectiveness of the indiscriminant symptom endorsement and symptom severity detection strategies; Rogers, 2008b).

The last conclusion that flows from the present data is that the SIMS $A F-N$ index, which yielded encouraging results in Rogers et al. (2005), does not hold up, as it delivered conflicting results. Although the $A F-N$ index had diagnostic value for the factitious vs. malingering comparison in Study 1, this was because the factitious condition induced low $A F-N$ scores, which is the inverse of what was reported by Rogers et al. (2005). In Study 2, the $A F-N$ index did not evidence any diagnostic utility. The most plausible explanation for 
the discrepant findings is one that Rogers et al. (2005) entertained: That the observed $A F-N$ differences between factitious and malingering groups are artifacts of the instructional sets.

An important constraint of the current studies is that it is not possible to establish to what extent the simulated factitious symptom presentations resemble real factitious symptom presentations; the clinical presentation of analogue simulators may differ considerably from that of genuine patients with factitious disorder. To some degree, this limitation is inherent in simulation designs, but the lack of published data on the standardized assessment of factitious disorders compounds this issue for the present studies. The only suitable data available for comparison are those of Rogers et al. (2005). The mean SIMS scores obtained by participants in the factitious conditions of Rogers et al. (2005) were 15.1 and 16.8, which is notably lower than the 23.2 and 20.4 that participants in our factitious conditions obtained. These discrepancies may stem from the fact that the samples of Rogers et al. (2005) consisted exclusively of doctoral psychology students, whereas our samples also included undergraduate students. Future research that samples actual patients with factitious disorder will have to establish whether the doctoral students of Rogers et al. (2005) were spot on sophisticated or too subtle in their feigning: The mean SIMS scores of malingerers (23.7-38.2; see Chapter 4) suggest the latter to be more likely. These data, however, only pertain to the feigned symptomatology part of factitious disorder and not to the motivational part (e.g., dependency or demandingness; see Cunnien, 1997), which is arguably more difficult to simulate. In addition to distilling the clinical characteristics of factitious symptom presentations, subsequent research in clinical populations may investigate whether the rationally derived detection strategies of the SDI represent welldefined dimensions (through, for example, factor analysis).

Another serious limitation of the present data is the unequal gender distribution. It may be considered tolerable that the samples for the experimental groups are predominantly female because the majority of patients with factitious disorder are also female (Bass \& Halligan, 2014; Yates \& Feldman, 2016), yet it is problematic that the samples for the clinical control groups are almost exclusively male. Although Mann-Whitney $U$ tests indicate that gender did not have a significant effect on SDI or SIMS scores, the small numbers of males in the experimental groups and females in the clinical control groups may be fatal to the reliability of these analyses. Nevertheless, the results of the Mann-Whitney $U$ tests square with previous research on the SIMS, which revealed that gender has no impact on SIMS scores (see Chapter 4). Other sample characteristics that impose considerable constraints are the restriction in age (mostly young adults in the experimental groups), race (nearly all participants were Caucasian, as were the researchers that administered the tests), and education (above average education in the experimental groups and below average education in the clinical control groups) and the forensic context of the clinical samples. Needless to say, the potential impact of demographic variables, such as age, gender, race/ethnicity, and education on SDI scores requires further examination.

The accuracy of the SDI in differentiating factitious from malingered symptom presentations differs noticeably between Studies 1 and 2 (AUCs Study 1 up to .88; AUCs 
Study 2 up to .75; see also Table 6.7). A conceivable factor in causing this divergence is the similarity of the situational background that was sketched in the factitious and malingering conditions of Study 2: All participants were prompted to imagine having been involved in a quarrel at a college party and an ensuing court case. The malingering condition asked participants to act as if they were still engaged in the court case, whereas the factitious condition required participants to suppose that the court case had been dismissed and that the psychological evaluation they were about to undergo was unrelated to the case. The experimental materials of the factitious condition of Study 1 did not contain any reference to a malingering scenario (court case or otherwise). It could be that some participants in the factitious condition of Study 2 did not completely disregard the relevance of the court case and thus simulated less factitious and more malingered symptom presentations as compared with participants in the factitious condition of Study 1.

The novelty of systematic and psychometric approaches to factitious symptom presentations implies that the conclusions derived from the present data are preliminary at best. Nevertheless, we hope they serve to highlight the potential of psychometric assessment of factitious symptom presentations and act as impetus for future research. Particularly encouraging is our finding that the SDI performed on a par with the SIMS in classifying feigned symptomatology, in that this suggests that items gauging internal incentives do not diminish the efficacy of regular SVT items. Other key findings of the present studies pertain to potential detection strategies for internal incentives associated with factitious disorder. In comparison with participants in the malingering conditions, as per the instrument results, participants in the factitious conditions expressed (a) greater willingness to discuss symptomatology outside professional examinations or treatment; (b) higher motivation to undergo disagreeable or distressful treatment or diagnostic procedures; (c) stronger feelings of resentment or dissatisfaction with previous proceedings concerning their alleged symptoms; (d) greater sensitivity and susceptibility to mild somatic symptomatology; and (e) higher levels of distress and anxiety over potential illnesses and health risks. In conclusion, the current studies demonstrate that the assessment of factitious disorder may benefit from psychometric investigations of symptom validity and that psychometric investigations of symptom validity may benefit from detection strategies for internal incentives associated with factitious disorder. 


\section{Chapter 7}

\section{General discussion}

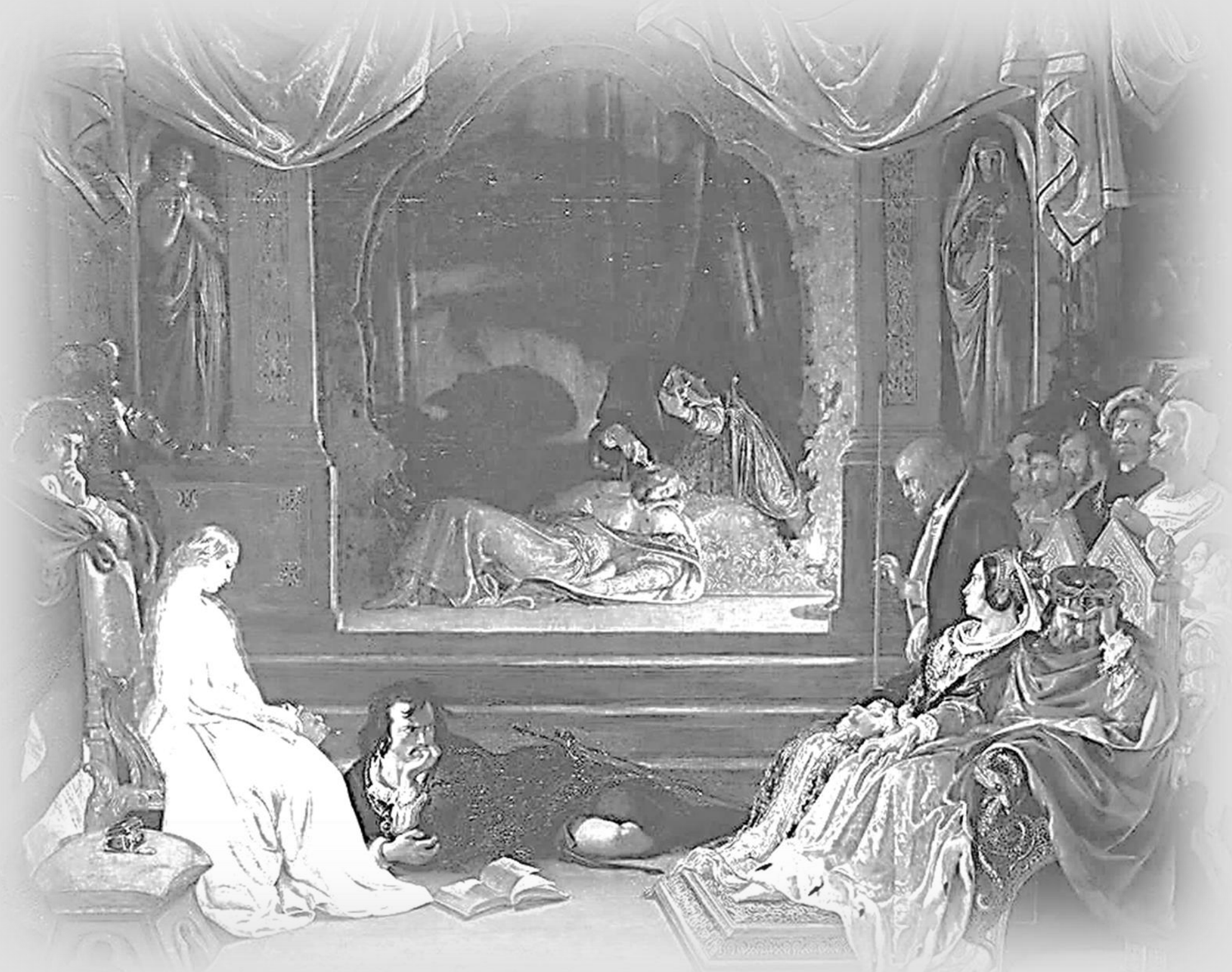




\section{Introduction}

The practice of diagnosis is an integral part of healthcare; the allocation of treatment resources and financial revenues for healthcare depend crucially upon it. The accuracy of diagnoses may be compromised when diagnosticians rely on erratic or inappropriate tests or procedures; when they err in their decision-making; or when patients are unable or unwilling to present or disclose their symptoms faithfully. All three of these domains (test validity, judgment validity, and assessment validity) can be quantified. Test validity can be estimated through research, such as that compiled in this thesis about validity tests, where the diagnostic qualities of tests are compared between groups of different diagnostic status (e.g., comparing SVT scores of noncredible patients with those of credible patients). Judgment validity can be guaranteed through actuarial decision-making, which is the use of decision rules of which the conclusions follow logically from empirically established knowledge. Assessment validity can be evaluated by means of validity tests; symptom validity tests (SVTs) gauge the accuracy with which patients present their symptoms, and performance validity tests (PVTs) appraise the adequacy of effort that patients give during cognitive testing.

Even though actuarial methods to combine data have long been shown to outperform clinical methods (Grove, Zald, Lebow, Snitz, \& Nelson, 2000; Meehl, 1954), the use of actuarial methods in validity assessment is not ubiquitous. In fact, interest in actuarial methods to combine the data of multiple validity tests has only just started to proliferate in the wake of expert consensus promoting the use of multiple measures in validity assessment (Martin, Schroeder, \& Odland, 2015). Statistical techniques to combine data are still evolving and typically involve complex calculations (e.g., Bayesian latent group analysis; Ortega, Wagenmakers, Lee, Markowitsch, \& Piefke, 2012). A technique that stands out because of its transparency and simplicity is the "chaining" of likelihood ratios (Larrabee, 2008; Meyers et al., 2014). To enhance the utility of this thesis for clinical practice and illustrate the value of the data that were obtained in the studies presented herein, the likelihood ratio technique for interpreting and combining test data will be explicated near the end of this chapter.

The furtherance of validity assessment that this thesis pursues is achieved through empirical investigations of indicators (Chapters 2-3) and tests (Chapters 4-6) that are taken to be measures of assessment validity. More specifically, Chapters 2 and 3 described studies that examined the assumption of the principal diagnostic manual for mental disorders, the Diagnostic and Statistical Manual of Mental Disorders (5th ed.; DSM-5; American Psychiatric Association, 2013), that antisocial features and behavior are indicators of assessment validity. Chapter 4 offered a meta-analysis and systematic review of all published data on a widelyused SVT (the Structured Inventory of Malingered Symptomatology; SIMS; Smith \& Burger, 1997). Chapter 5 summarized six studies in which the diagnostic accuracy of a revived PVT was evaluated (the Malingering Scale Vocabulary and Abstraction test; MSVA; Schretlen \& Arkowitz, 1990). Chapter 6 set out the development of an SVT with the innovative aim to distinguish between factitious and malingered symptom presentations and described two 
simulation studies in which the potential of this SVT was investigated. The present chapter discusses the key findings and conclusions of the studies that are recounted in previous chapters, and yields considerations of methodological issues, clinical implications, and directions for future research. As stated earlier, this chapter also provides a primer on likelihood ratios as an actuarial technique for interpreting and combining test data.

\section{Antisocial features as indicators of assessment validity}

The authoritative DSM-5 entertains the topic of assessment validity through entries on factitious disorder and malingering, with the former being viewed as a mental disorder, and the latter as plain deceit. The antisocial connotation of malingering may explain why the $D S M-5$ endorses the belief that antisocial features (as manifested in antisocial personality disorder; ASPD) are indicative of malingering. Chapters 2 and 3 detail three studies in which we explored the potential relation between antisocial features and noncredible symptom reporting. In short, we presented samples of forensic inpatients and prisoners with a wellvalidated SVT, the SIMS, as measure of assessment validity, and looked into various facets of their behavior and personality to see if antisocial features were predictive of infringed assessment validity.

In the first study, we evaluated the behavior of forensic inpatients by coding a behavioral observation scale based on the logs in patient records, which contain daily entries by various healthcare personnel. In the second study, we inferred antisocial behavior of prisoners from the length of their sentence, from whether or not they received the epithet "intensive offender", and from the number of disciplinary actions they incurred while incarcerated. The third study focused on deceitfulness, which is the antisocial trait that potentially is the strongest link between antisocial personality disorder and malingering. We captured deceitfulness by inquiring into therapists' and treatment supervisors' judgment on the extent to which patients denied their delinquency, and by checking the information that forensic inpatients reported during a semi-structured interview about their offense against the information in official offense records. In both the second and third study, we also administered a self-report instrument that charts specific antisocial features; lack of remorse and criminal blame externalization (the revised Gudjonsson Blame Attribution Inventory, BAI; Gudjonsson \& Singh, 1989).

Taken together, the results weigh heavily against the utility of antisocial traits or behavior as predictors of invalid symptom reporting. Across the three studies, the falsepositive predictions average $90 \%$ and the false-negative predictions $79 \%$. For example, only 1 out of 19 patients with antisocial personality disorder produced a deviant SIMS score $(>16)$, and this accounted for 1 out of 13 aberrant SIMS scores. In correlational terms, we found several modest relationships between symptom overreporting (but not symptom underreporting) and self-report measures of antisocial traits. Most notably, we found that symptom overreporting was associated with externalizing blame attribution styles, where blame for transgressions is attributed to mental disorders, social environments, victims, or 
society. These associations were more prominent in the punitive setting (i.e., prison) than in the therapeutic setting (i.e., forensic hospital), and, importantly, were only evident in selfreport measures of antisocial features; not in behavioral measures. Although such associations may be interesting from a clinical point of view, their strength does not suffice to provide diagnostically useful information.

A salient argument that can be raised against our failure to find support for the idea that antisocial behavior is tied with malingering, is that we equate invalid SVT (i.e., SIMS) scores with malingering. In principle, that argument rings true; invalid SVT scores do not amount to malingering per se, because SVTs do not measure the external incentives that motivate the feigning of symptoms in malingering. Similar doubts can validly be brought up concerning our use of only one SVT, and our employment of a liberal (i.e., false-positive prone) cutoff to designate noncredible respondents. We acknowledge the potential fatality of these flaws. Yet, our data do not leave much wiggle room even for such valid concerns, because they point so overwhelmingly in one direction. Even if, for the sake of argument, we would accept that many of the SIMS scores beyond 16 do not reflect malingering, and that several patients who malingered produced valid SIMS scores, then the false-positive and false-negative classification rates of antisocial features would still be unacceptable; dropping from $90 \%$ false positives and $79 \%$ false negatives to, for example, $50 \%$ false positives and $39 \%$ false negatives.

Other criticism that can be directed at our studies is that the sample sizes are small. Again, this is a serious concern. Nevertheless, the consistency of the findings between the two studies that were conducted at the same forensic psychiatric hospital, about two years apart, is reassuring. In both studies (each $N=57$ ), the prevalence of noncredible symptom reporting and most antisocial features was low (9-29\%). One could argue that the overlap between antisocial features and noncredible symptom reporting was so minimal that even when base rates would have been higher and overlap greater, the discriminatory utility of antisocial features for noncredible symptom presentations would still be meager at best. The other way around, if the relation between antisocial features and noncredible symptom reporting would have been strong enough to be diagnostically relevant, then the sample sizes would have sufficed to detect it. Lastly, it can be argued that low base rates of noncredible symptom presentations and antisocial features are representative of many settings, and that the DSM-5 remains silent on the impact of base rates on the predictive value of diagnostic criteria - an issue that is, in fact, germane to diagnostic accuracy; see the primer on likelihood ratios below.

A strong aspect of our studies is that we measured antisocial features in various ways, including self-report, behavioral observation, psychiatric diagnosis, and behavioral markers such as number of incurred disciplinary actions and classification as "intensive offender". Another asset is that we took positive distortions of symptom reporting into account. We reasoned that some patients might perceive merit in concealing or minimizing their psychopathology, and reckoned that antisocial features might predispose as much to 
symptom overreporting as they do to symptom underreporting, depending on which appears most profitable at a given time.

In the context of validity assessment, future research into the relation between antisocial features and noncredible symptom presentations is unwarranted for two reasons. The first reason is that the extant empirical data is consistent; the results of our studies correspond to those of similar studies (see, e.g., Niesten, Nentjes, Merckelbach, \& Bernstein, 2015), which found either no association or a weak, diagnostically trivial association (except Gacono, Meloy, Sheppard, Speth, \& Roske, 1995, who found ASPD and psychopathy to be strongly related to malingered insanity). The second reason is that psychometric approaches to validity assessment are considerably more promising (e.g., see Chapters 4-6), rendering trait-based approaches redundant and obsolete.

In the three studies described in Chapters $2-3$, the average error-rate of antisocial features as indicators of assessment validity was $85 \%$. Needless to say, this quashes any argument for the use of antisocial features in validity assessment, even as a risk factor or screening heuristic. Guidelines on the detection of response bias or malingering, such as those found in the DSM-5, should be disregarded in favor of the recommendations by professional organizations such as the Association for Scientific Advancement in Psychological Injury and Law (Bush, Heilbronner, \& Ruff, 2014), the American Academy of Clinical Neuropsychology (Heilbronner et al., 2009), the British Psychological Society (2009), and the Institute of Medicine (2015), who all advocate the psychometric approach to assessment validity. Thus, diagnosticians are well-advised to employ validity tests such as those that are described next.

\section{Symptom validity tests: The Structured Inventory of Malingered Symptomatology}

The entry on malingering in the DSM-5 is akin to the clinical method of diagnostics; it provides several rules of thumb without explicitly listing concrete or empirically based decision rules. The SIMS, on the other hand, is a psychometric instrument that embodies the actuarial method of diagnostics; it is a checklist of 75 rare, atypical, and extreme pathological symptoms that has a fixed scoring system and relies on empirically derived decision criteria. The diagnostic utility of a psychometric instrument, such as the SIMS, depends not only on the characteristics of the instrument itself, but also on the quality and quantity of the available data upon which its decision rules can be based. We charted the entire body of Anglo-Saxon, Dutch, German, and Spanish empirical research on the SIMS by gathering and reviewing all studies that had been published in the 17-year span from its conception in 1997 up to the year 2014, and performed the only meta-analysis of SIMS data to date. Specifically, we calculated weighted mean diagnostic accuracy and predictive power indices in various populations (based on 31 studies, 61 subsamples, and 4009 SIMS protocols) and weighted mean SIMS scores among patients, claimants, defendants, nonclinical adults, and various experimental feigners (based on 41 studies, 125 subsamples, and 4810 SIMS protocols). This section clusters and discusses the essentials of the findings catalogued in Chapter 4. 
The vast majority of studies using the SIMS involve comparisons of various groups for statistical differences in SIMS scores. Groups are typically simulated through random assignment of different experimental instructions (e.g., instructions to feign symptoms) or "known" via independent criteria (usually other validity tests) to classify participants in realworld conditions (e.g., respondents who feign symptoms). The strengths of simulation studies lie in their internal validity; most experimental parameters and procedures can be standardized or controlled for. The weaknesses of simulation research reside in its external validity; participants are not subjected to real-world incentives, conditions, or consequences, which are generally more extreme than experimental manipulations can simulate. These strengths and weaknesses are reversed in known-groups studies, where the possibilities for standardization and control are limited, but where participants and their circumstances are authentic.

The results of our meta-analysis indicate that experimental feigners produce SIMS scores that are similar to those of real-world feigners (with scores ranging roughly between 20 and 40; see Table 4.6); a finding that mitigates concerns about the external validity of simulation studies. Nevertheless, the results also reveal an important limitation of simulation research; healthy individuals score significantly lower on the SIMS than genuine patients do (scores are approximately 4-9 vs. 12-19; see Table 4.6), which entails that, in conditions where truthful responses are solicited, healthy individuals cannot be substituted for genuine patients. Neglect of this issue leads to overestimation of a validity tests' ability to classify honest responders correctly (i.e., specificity); a flaw that escaped scrutiny in various early simulation studies into the SIMS (e.g., Edens, Otto, \& Dwyer, 1999; Jelicic, Hessels, \& Merckelbach, 2006; Smith \& Burger, 1997).

The aggregated data substantiate the conclusion that the SIMS is a valuable symptom validity test. The diagnostic potential of the SIMS ranges from 59\% to $91 \%$ correct classifications (see Table 4.6), and is only moderately affected by coaching (i.e., informed attempts to pass validity tests while feigning). The bulk of the published SIMS data pertain to the traditional cut scores of the SIMS $(>14$ and $>16)$ and confirm that these are heavily geared toward screening purposes, providing high sensitivity (.91-.1.00; see Table 4.3) yet meager specificity (.37-.70; Table 4.3). Thus, these cutoffs are better suited to rule noncredible responding out than to rule such responding in; employing them in service of the latter incurs a sizable risk of false positives, which is exacerbated among patients with mentally incapacitating symptomatology, such as schizophrenia and intellectual disability.

The tendency of researchers-ourselves included-to focus exclusively on only a few cut scores has a considerable drawback; it severely limits the information that practitioners have at their disposal for the practice of diagnostics. Moreover, it may inadvertently lead practitioners to treat cut scores mistakenly as being laser-like accurate, or to regard noncredible responding erroneously as a categorical phenomenon, or to perceive sensitivity and specificity values as characteristics of an instrument, rather than as variables that depend on cut scores and the population in which the instrument is used. The key to evade these pitfalls is twofold; researchers should publish diagnostic accuracy data for all possible 
cut scores (in supplementary files, for instance), and practitioners should accustom themselves to employing likelihood ratios to quantify and combine the diagnostic value of test results (see below).

Another omission in publications about the SIMS is test-retest reliability data. With the exception of Merckelbach and Smith (2003; Dutch version) and Cima, Hollnack, and colleagues (2003; German version) there is no data at hand on the stability of SIMS scores over time. In the absence of other data, the disparity between the test-retest correlation coefficients that Merckelbach and Smith (2003) and Cima, Hollnack, and colleagues (2003) report, .72 in a 3-week interval versus .97 with a 6-week interim, is difficult to appraise, especially given the difference in language (Dutch versus German). Future research into the SIMS can raise its value markedly by simply addressing the test-retest reliability of the SIMS, particularly in clinical populations and in groups of noncredible respondents (Merckelbach \& Smith, 2003, and Cima, Hollnack, et al., 2003, employed undergraduates who were asked to respond credibly).

When reviewing the SIMS qualitatively, a substantial shortcoming becomes apparent; the SIMS lacks any means to differentiate symptom overreporting from irrelevant responding (i.e., indiscriminate affirmation or rejection of items). Because the SIMS is a truefalse paper-and-pencil questionnaire, its administration requires little practitioner-patient interaction and prompts little test behavior for practitioners to observe. Consequently, the possibilities to rule out disengaged or otherwise irrelevant responding are severely limited, which hampers the diagnostic prowess of the SIMS. This flaw can be amended by adding or incorporating items that tap disengaged responding, such as those of the Infrequency Scale by Chapman and Chapman (1983). The crux of such items is that they have only one sensible answer alternative. For example, the statement "Sometimes when walking down the sidewalk, I have seen children playing" is true for virtually anyone who is able to walk; failure to endorse this statement reflects disengaged responding in all save the rarest of cases. Prospective research can well enhance the value of the SIMS by augmenting it with "infrequency" items to address irrelevant responding.

Another weakness of the SIMS relates to items that cover genuine symptoms. The problem in this regard is twofold: First, the SIMS does not contain items that are intended to cover plausible symptoms; and second, the SIMS contains items that actually do refer to plausible symptoms. This is problematic because it leaves respondents-the majority of whom are, presumably, authentic patients - with a symptom inventory that does not contain any symptoms that can be endorsed credibly (i.e., endorsed without it being deemed noncredible symptom endorsement). For instance, the item "I have trouble sleeping" refers to a credible symptom, yet confirmation of it adds one point to the total SIMS score, which is taken to reflect noncredible symptom reporting. The presence of plausible symptoms within the SIMS is also reflected in the scores of authentic patients, who typically score in the range of 12-19, and even in the scores of healthy respondents, who generally produce scores around 4-9. The remedy for this weakness of the SIMS is not to purge all credible items from the SIMS; rather, it is to alter the scoring format of the SIMS in recognition of the items that 
do not warrant a point towards a noncredible SIMS score. In fact, the SIMS might even benefit from the inclusion of more plausible items-provided, of course, that these are recognized as such; a recent example of such an approach is the Self-Report Symptom Inventory (SRSI; Merten, Merckelbach, Giger, \& Stevens, 2016).

In sum, our comprehensive analysis of the SIMS allowed us to consider the strengths and weaknesses of the SIMS, and to identify potential gaps or flaws in knowledge about the SIMS. The strengths of the SIMS lie mainly in its respectable diagnostic potential and the efficiency with which that is attained (the SIMS being a brief paper-and-pencil test). Serious weaknesses of the SIMS are the absence of ways to distinguish symptom overreporting from irrelevant responding, and the failure to designate plausible items as such and adapt the scoring system accordingly. Looking forward, these shortcomings of the SIMS can be overcome by research dedicated to modify the SIMS or its scoring format (see, e.g., Rogers, Robinson, \& Gillard, 2014). Similarly, new research can lift the constraints on the diagnostic potential of the SIMS that are currently imposed by the lack of public data on cutoffs other than >14 and >16, and (to a lesser extent) on test-retest reliability. Despite these insufficiencies, the SIMS offers ample diagnostic utility to practitioners, particularly to those who are mindful of the aforementioned issues.

\section{Performance validity tests: The Malingering Scale Vocabulary and Abstraction test}

As stated earlier, validity tests come in two kinds; SVTs and PVTs. The SIMS exemplifies SVTs; psychometric instruments that take after symptom inventories and interviews, yet contain pseudo-symptoms to check respondents' inclination to endorse noncredible pathology. For example, feigned memory impairment could be gauged by items such as "When I can't remember something, hints do not help" (this statement is generally not true; hints and cues typically reinforce memory retrieval; see, e.g., Tulving \& Osler, 1968). PVTs take a different approach; they resemble cognitive tests, yet their difficulty level is deceptively low, allowing for the appraisal of respondents' effort during cognitive testing. For example, feigned memory impairment could be detected by presenting respondents with an exceedingly easy word list learning task (which can be completed well-nigh flawlessly by, e.g., children in second grade and patients with mild traumatic brain injury). The topic of Chapter 5 concerns a PVT; the Malingering Scale Vocabulary and Abstraction test (MSVA).

The MSVA stands out among PVTs because it is very brief (only 46 items, administered once) and does not imitate a memory test; instead, it is analogous to vocabulary and abstract reasoning tasks of IQ tests. Each items of the Vocabulary subtest consists of a target word followed by two response words, one of which is synonymous with the target word (e.g., HAT: coat - cap). Items of the Abstraction subtest each consist of a sequence of three words, letters, or numbers, which is complemented by one of two answer alternatives (e.g., Red Blue Green __ Yellow - Chair). The two-alternative forced-choice response format of the MSVA follows the binomial distribution, and therefore permits the calculation of the exact probability that a given score is obtained by chance. It appealed to us that MSVA 
is short, not memory-oriented, and can detect below-chance performance, and therefore we translated it into Dutch and investigated its potential in several experiments, recorded in Chapter 5.

We administered the MSVA to primary school children $(n=41)$, forensic inpatients with intellectual disability (IQ $<70, n=25)$, forensic inpatients with psychiatric symptoms ( $n$ $=57$ ), and undergraduate students ( $n=30, n=79$, and $n=90$, respectively). In most samples, we employed a simulation design; we assigned participants randomly to a condition in which they were asked to respond honestly or to a condition that prompted them to feign cognitive impairment. In the sample of forensic inpatients, we took a quasi-known-groups approach, with the SIMS as criterion to segregate participants who responded noncredibly. In the undergraduate samples, we employed the SIMS and two well-validated PVTs (the Amsterdam Short-Term Memory Test; ASTM; Schagen, Schmand, de Sterke, \& Lindeboom, 1997, and the Test of Memory Malingering; TOMM; Tombaugh, 1996) as benchmarks to compare the MSVA with.

The utility of the below-chance performance criterion (Total score $<17=p<.05$ ) was low among forensic psychiatric patients and undergraduate students ( $4 \%$ detection rate; see Table 5.2), yet high in children (47\%) and intellectually disabled inpatients $(50 \%)$. This suggests that below-chance performance may, at least partly, be a consequence of limits in cognitive capacity to deceive others convincingly and evade detection when attempting to mislead or outwit others. Because the below-chance criterion $(<17)$ did not yield false positives in any of the samples, it can be used to rule in noncredible cognitive performance with great confidence.

The diagnostic potential of the MSVA can be exploited more fully by capitalizing on floor effects. This is realized by identifying which cut scores genuinely impaired persons rarely score below. When cutoffs are selected to maintain a false-positive rate of less than $10 \%$, the detection rate of experimentally feigned cognitive impairment increases with 42 $50 \%$ (compared with the detection rates of below-chance cutoffs), becoming $90 \%$ in children, $100 \%$ among inpatients with intellectual disability, and $46 \%$ in adults without intellectual disability (see Table 5.2), which is mediocre.

In two undergraduate samples, we also examined the effect of coaching. Coaching amounts to warning respondents of validity tests and/or providing them with information that may help them pass such tests (e.g., information about credible symptoms or detection strategies). Neither warning of validity tests nor the provision of information about credible symptoms and validity testing had an undue effect on the diagnostic accuracy of the MSVA. The finding that coaching does not eliminate the usefulness of validity tests is not exceptional (e.g., see Chapter 4, Table 4.6), but the impact of coaching on the MSVA seems particularly small (see Table 5.1). It might be that the effect of coaching was trivial because the effect of noncredible responding in our samples (or rather; the effect of our experimental manipulations to provoke noncredible responding) was small compared with other studies (cf. Table 4.6). 
By the same token, the mediocrity of the diagnostic accuracy of the MSVA in our experiments may be explained partly by the nature of the experimental materials that we used in the groups of undergraduates. In the first group, participants were asked to feign amnesia for a fictional crime they saw pictures of; in the second group, participants read a case vignette about a plaintiff who feigns symptoms of head injury, and were prompted to act as if they were the plaintiff; and in the third group, participants immersed themselves in a case about an employee who decides to feign illness to obtain workers' compensation, and were left free to act however they would act if they would be the employee. Clearly, symptoms of amnesia and head injury are not equivalent to impairments in semantic knowledge and perceptual reasoning, and the option to feign any symptoms (including none) may not be a strong impetus to feign deficits in vocabulary or perceptual deduction skills. It may well be that the diagnostic accuracy of the MSVA will be higher in experiments where the materials are more tailored to elicit the feigned deficits that are targeted by the MSVA. Future research could address this supposition, and take into account the preferences that people may have when feigning symptoms (e.g., Dandachi-FitzGerald \& Merckelbach, 2013), and the various effects that experimental materials, such as case vignettes, have on the outcome of simulation studies (e.g., Merckelbach, Smeets, \& Jelicic, 2009).

The middling efficacy of our experimental manipulations to evoke feigning is also evident in the diagnostic accuracy of the ASTM and, especially, the TOMM; both tests fared better in other simulation studies (see the respective test manuals; Schmand \& Lindeboom, 2005; Tombaugh, 1996). The MSVA was about as effective as the TOMM in differentiating between honest and feigning respondents, and slightly less effective than the ASTM (see Table 5.4). Nevertheless, the MSVA still identified several noncredible respondents that the ASTM and TOMM failed to pick up, indicating that the MSVA has added value, and is worth investigating further.

In particular, it is recommended to examine the MSVA in studies where other PVTs are employed to group patients into credible and noncredible respondents (i.e., so-called "known-groups" studies). The purpose of such studies is not to compare the MSVA to other PVTs, but to investigate the MSVA in real-world conditions. Although we used clinical samples (i.e., forensic patients), we used them primarily as control groups for comparisons with experimental groups. Because the prevalence of noncredible responding is low in most populations, large sample sizes are required to gather groups of noncredible respondents that are substantial enough to conduct meaningful statistical analyses. Our comparison of credible and noncredible forensic inpatients with psychiatric symptoms is not a valid known-groups comparison for two obvious reasons; a) the size of the noncredible group is too small $(n=4)$, and b) the SIMS is an SVT, not a PVT, and as such, measures a different though closely related-phenomenon (i.e., symptom overreporting vs. cognitive underperformance; see Nelson, Sweet, Berry, Bryant, \& Granacher, 2007; van Dyke, Millis, Axelrod, \& Hanks, 2013).

The most notable issue that compromises the utility of the MSVA is, arguably, its sensitivity to genuine intellectual disability. The effect of authentic intellectual incapacity on 
MSVA scores is moderate ( $d=1.02$; see Table 5.1$)$, and can hardly be distinguished from the effect of feigned cognitive impairment $(d=0.87-1.97)$. Because this problem is common to validity tests, it does not necessarily devalue the MSVA compared with other validity tests (Victor \& Boone, 2007). Ideally, the problem of the MSVA being sensitive to intellectual disability is circumvented by ruling out severe intellectual disabilities on the basis of medical records and collateral information, which may be available in many cases because severe intellectual disabilities rarely occur in the absence of a developmental history or an acute medical trauma (Whitaker, 2013). Its susceptibility to intellectual disability does not preclude the MSVA from being used in populations with restricted intellectual abilities; on the contrary, when stringent cutoffs are being used (e.g., <23), the MSVA is very effective in differentiating between children or patients with intellectual disability who exert optimal effort and those who do not (see Table 5.2).

Taken together, our studies are an initiatory step towards the validation of the MSVA as a performance validity test that taps noncredible deficits in vocabulary and abstract reasoning rather than memory. We found the reliability of the MSVA to be excellent (Cronbach's $\alpha=.93-.97$ in the aggregated data). We established that cut scores chosen to keep false-positive rates below $10 \%$ yield high detection rates in children $(90 \%)$ and inpatients with intellectual disability $(100 \%)$, but low rates in adults without intellectual disability (on average $46 \%$ ), and we observed that the diagnostic efficacy of the MSVA was not significantly affected by forewarning of validity testing or by bestowal of information about validity testing. These findings solicit future research both because they indicate that the MSVA has potential and because they do not suffice to employ the MSVA in clinical practice.

\section{Discerning factitious disorder from malingering: The Symptom and Disposition Interview}

Symptom validity tests measure noncredible symptom reporting. Because there are multiple reasons that can underlie noncredible symptom reporting, the interpretation of noncredible symptom validity test scores can be complicated. For example, a crucial differentiation that must be dealt with is that between symptom fabrication and irrelevant responding. Some symptom validity measures are equipped for this task; for example, through the inclusion of specific items that assess indiscriminant endorsement (e.g., the Infrequency Scale by Chapman \& Chapman, 1983) or via algorithms that check for consistency or specific combinations across items (e.g., see the Minnesota Multiphasic Personality Inventory-2Restructured Form; Ben-Porath \& Tellegen, 2008; and the Structured Interview of Reported Symptoms; Rogers, Bagby, \& Dickens, 1992). Another fundamental distinction is that between factitious and malingered symptom presentations. The key difference between factitious and malingered symptomatology is that the former is motivated by internal incentives (i.e., the need for attention, affection, or care) whereas the latter is driven by external incentives (i.e., the desire to acquire material gain, or to escape duty or 
responsibility). Importantly, factitious disorder is, in contrast to malingering, considered to be a mental disorder (American Psychiatric Association, 2013).

The issue of differentiating factitious from malingered symptomatology has hitherto been all but ignored in the literature about validity assessment. The only published study in which a psychometric instrument was specifically adapted to distinguish factitious from malingered symptomatology was conducted by Rogers, Jackson, and Kaminski (2005). Rogers and colleagues (2005) devised a novel score index for the SIMS (AF scale minus $N$ scale) and ran a simulation study with doctoral students responding honestly or simulating either malingered or factitious symptom presentations: The $A F-N$ index discriminated well between the malingering and factitious conditions (Cohen's $d s=1.1-1.4)$. To address the lack of psychometric approaches to the differentiation of malingered and factitious symptom presentations, we developed the Symptom and Disposition Interview (SDI); a symptom validity test that deploys strategies to quantify internal incentives that impel factitious symptomatology.

The utility of the SDI is predicated on four scales: Unlikely Symptoms (US), Common Symptoms (CS), Sick Role (SR), and Illness Anxiety (IA). The US scale embodies traditional detection strategies for feigned symptomatology, such as improbable symptoms and symptom combinations (Rogers, 2008b). The CS scale serves to mask the symptom validity aspect of the SDI, lower its sensitivity to authentic symptomatology, and support the detection of feigned symptomatology through additional strategies (i.e., symptom severity and indiscriminant symptom endorsement; Rogers, 2008b). Items of the SR scale inquire into the willingness to assume the patient role, for example by undergoing additional or unpleasant treatment or diagnostic procedures, or by participating in scientific studies or patient support groups. The $I A$ scale surveys feelings of distress over potential pathology and sensitivity to somatic symptoms. The idea behind the $I A$ scale is that it augments the differentiation between malingered and factitious symptomatology by tapping internal incentives that incite unconsciously distorted symptom presentations, such as in somatic symptom disorders.

We explored the functionality of the SDI and compared it to that of the SIMS in two simulation studies with factitious and malingering conditions ( $n=24-30$ per condition) and a clinical control group $(n=34, n=40)$. The specifics of these studies and their outcomes are reported in Chapter 6. On the whole, the results suggest that our approach to distinguish between malingered and factitious symptom presentations merits further investment: The SDI performed satisfactory; on a par with the SIMS in detecting feigned symptom presentations, and surpassing the SIMS in differentiating factitious from malingered symptom presentations (i.e., in our studies, the SIMS $A F-N$ index did not produce useful results).

By and large, the SDI scales performed as intended: Tables 6.2 and 6.5 show that the US scale generated the largest effect sizes in comparisons of malingering groups with clinical control groups; the CS scale picked up the bulk of the authentic symptomatology in the clinical control group; the $S R$ scale was consistent in discerning factitious and illness anxiety 
conditions from malingering conditions; and the $I A$ scale was effective in differentiating between factitious and malingering conditions, albeit inconsistently. The SDI Total scale generally performed on the same level or better than individual SDI scales (e.g., in malingering vs. clinical control, and factitious vs. malingering comparisons), which demonstrates that the different scales complement each other.

The corpus of knowledge about the assessment of factitious disorder is restricted, and therefore the SDI is necessarily a pioneering attempt to psychometrically differentiate between factitious and malingered symptom presentations. And of course, the limited prior knowledge and experience that we could draw from to construct the SDI and set up suitable experiments limits the confidence with which conclusions can be drawn. Nonetheless, we rigorously adhered to the basic methodology of simulation research (see, e.g., Rogers, 2008a). Specifically, we kept differences between experimental groups to a minimum by assigning participants quasi-randomly to the experimental conditions; we negated experimenter effects by blinding experimenters to the conditions that participants were assigned to; we kept order effects constant across conditions by counterbalancing the order in which instruments were administered; we controlled for patient-role effects by using the same setting and situation in all experimental materials; we maximized the authenticity and intelligibility of the experimental materials by modeling them after actual events and facilities that participants were familiar with; we stimulated participants to engage with the experiment by offering them a monetary incentive, by explicating and stressing the importance of the research, and by challenging them to pass the validity tests while feigning; we secured the experimental manipulations by debriefing participants only after all data were collected; we included multiple manipulation checks to assess the effort and accuracy with which participants followed experimental procedures; and we identified potential cases of feigning in the clinical control group by employing a well-validated symptom validity test. Our methodological rigor notwithstanding, the results of Study 1 and Study 2 are not equivalent; the SDI performed better in Study 1. This underscores the volatile nature of experimental manipulations to illicit feigned symptomatology (e.g., see Chapter 4, Table 4.2) and highlights the importance of subjecting the SDI to additional research with different experimental materials.

The greatest weakness of our studies into the SDI is their questionable external validity: It is difficult to ascertain to which extent the factitious symptom presentations that our experimental manipulations brought about resemble factitious symptomatology. The feigned symptomatology aspect of factitious symptom presentations may differ from that of malingered symptom presentations. It may, for example, involve more physical symptoms (see, e.g., Yates \& Feldman, 2016). Yet, it is particularly the motivational aspect - which sets factitious disorders apart from malingering - that is challenging to simulate. We adapted our experimental materials from Rogers et al. (2005), who based theirs on Cunnien's (1997) account of dependency and demandingness as interpersonal motivations behind factitious disorders. The validity of these experimental materials can only be evaluated properly by 
employing the SDI in known-groups research, whereby real-world malingerers and patients with factitious disorder are identified through comprehensive validity assessment.

A related shortcoming pertains to the demographics of the samples that we recruited: The great majority of the experimental groups were female $(82 \%)$, in their twenties or younger $(88 \%)$, and higher educated $(94 \%)$. On the one hand, the fact that most experimental participants are young and bright may suggest that their ability to feign symptoms is in the upper echelons of sophistication, and thus represents a lower bound of the sensitivity of the SDI in detecting noncredible symptom presentations. On the other hand, the match of these groups with the clinical control groups is very poor: The clinical control groups were almost exclusively composed of males $(94 \%)$, who were in their thirties or older $(87 \%)$ and had not attended higher education (95\%). Another restriction to the generalizability of our results stems from the margins in race and ethnicity, as nearly all participants were Caucasian (experimental groups; 93\%, clinical control groups; 84\%), and descended from the Netherlands. Future research is advised to employ samples with different demographics, particularly with regard to clinical control groups, which, compared with our samples, should preferably include more women and more individuals who are higher educated and have no felonious background.

In the absence of psychometric data, the items of the SDI were rationally derived and not based on empirically established detection strategies. Future research ought to explore the detection strategies of the SDI further; either by inspecting the SDI itself or by incorporating the strategies of the SDI into other instruments. The items of the $S R$ scale reflect three potential detection-based strategies. The first covers the readiness to converse about symptomatology in situations where no essential or direct treatment, care, or diagnosis is provided, such as with coaches, counselors, or support groups. The second strategy taps the motivation to undergo alternative treatment or diagnostic procedures that are disagreeable or distressful. The third strategy is to target feelings of indignation for being disregarded, misunderstood, not taken seriously, or otherwise treated incorrectly. The items of the IA scale represent two strategies: The first involves susceptibility to moderate somatic symptomatology, and the second relates to apprehension about potential pathological symptoms. Examining the efficacy of these strategies is of paramount importance for the development of psychometric methods to assess factitious and malingered symptomatology.

The most important conclusion that can be drawn from our studies into the SDI is that psychometric approaches to the differentiation of factitious disorder and malingering can be realized by incorporating the assessment of internal incentives into SVTs. Reservations that such modifications may have an adverse effect on the efficacy of SVTs to detect noncredible symptomatology seem unfounded, as the SDI performed equal to the SIMS. Be that as it may, it is evident that additional research is indispensable to appraise the utility of the SDI and the soundness of the present experimental materials. Our discourse on the development of the SDI and the associated studies can be viewed as groundwork that may serve as catalyst for the progress of psychometric assessment of factitious disorder and malingering. 


\section{Interpreting and combining validity test data: The use of likelihood ratios}

The traditional modus operandi when employing validity tests is to use cut scores to determine whether or not respondents present with noncredible symptomatology. This routine is also evident in research into validity tests: The vast majority of published studiesthe ones that compose this thesis are no exception-provide diagnostic accuracy indices for only a handful of cut scores; typically cutoffs that yield optimal results or that have been promoted by previous research. Cut scores are best conceived as rules of thumb that guide the decision-making process during validity assessment; if a respondent stays at the safe side of cut scores with high specificity, then no further inquiry into assessment validity is necessary; if, however, a respondent produces scores beyond cutoffs with high specificity, then additional analyses are warranted, such as the chaining of likelihood ratios. Essentially, the likelihood ratio (LR) is a means to express the diagnostic value of test results; it combines sensitivity and specificity into a single number that indicates the extent to which a test result alters the likelihood that a condition of interest (e.g., noncredible symptomatology) is present.

The LR was first described as a technique to facilitate diagnostic decision-making in the 1950s (Swets, 1973). The LR contrasts the likelihood of a test result under two mutually exclusive hypotheses; under the one hypothesis the condition of interest is present, under the other hypothesis the condition of interest is absent. More precisely, the LR specifies how many times more likely a test result is under the first hypothesis than under the second, rival hypothesis. Likelihood ratios come in two versions: One for positive test results; the positive LR, and one for negative test results; the negative LR. The positive LR is the probability that a respondent with the target condition produces a positive test result (i.e., sensitivity, or truepositive rate) divided by the probability that a respondent without the target condition produces a positive test result (i.e., 1 - specificity, or false-positive rate). Likewise, the negative LR is the probability that a respondent with the target condition produces a negative test result divided by the probability that a respondent without the target condition produces a negative test result. In validity assessment, the negative LR is of lesser importanceprovided that the presumption of innocence is honored-because the consequences of negative test results need not be substantiated as meticulously as positive test results (i.e., the exclusion of false positives takes precedence over the exclusion of false negatives; Greve \& Bianchini, 2004). The remainder of this chapter will discuss the positive LR, which will be referred to simply as the "LR".

The goal of validity assessment is to deliver a judgment about assessment validity; that is, about the degree to which the symptom presentation of an examinee is credible. Cut scores fall short of this task, because they enforce a dichotomous outcome, and thus a loss of information, especially if respondents' scores are well below or above a cutoff. For example, if a respondent produces a validity test score above a cutoff, then we can calculate the LR based on the sensitivity and specificity of that cutoff (say, .70 and .90), but it would be more accurate to base the LR on the sensitivity and specificity of the actual score that was obtained 
(say, sensitivity .60 and specificity .95). This example reflects the fact that, for instruments where higher scores indicate a more positive test result, higher cutoffs yield higher specificity, yet lower sensitivity (with inversed scoring, lower cutoffs offer higher specificity, lower sensitivity).

The LR that corresponds to a sensitivity of .70 and a specificity of .90 is arrived at by dividing sensitivity by 1 minus specificity $(.70 /[1-.90]=7)^{10}$ The LR associated with .60 sensitivity and .95 specificity is 12 (.60 sensitivity/[1 - .95 specificity]). An LR of 12 means that the test score in question is 12 times more likely to be obtained if the symptom presentation is noncredible, than if the symptom presentation is credible. Thus, in our example, application of the LR on the basis of a cutoff results in an underestimation of the likelihood that the respondent presents with noncredible symptomatology; the cutoff yields an $\operatorname{LR}$ of 7 , while the actual score yields an LR of 12 .

LRs range from 1 to infinity.11 To some extent, the interpretation of LRs is intuitive; the higher the LR above 1, the greater the increase in the pre-test probability-i.e., the greater the post-test probability - that the hypothesis of interest is true. However, the effect of LRs on pre-test probabilities is not linear: An LR of 100 does not increase the pre-test probability 10 times more than an LR of 10 does (see Fagan's nomogram; Fagan, 1975; Grimes \& Schulz, 2005). Nonetheless, the change in pre-test probabilities between .10 and .90 is approximated by a constant; $.19 \times \log _{e}$ LR ( $\log _{e}$ refers to the natural logarithm; McGee, 2002). Table 7.1 displays the approximate changes in pre-test probabilities between .10 and .90 as effectuated by multiplying pre-test odds with an LR (adapted from McGee, 2002). As can be seen, an LR of 2 increases the pre-test probability by about $15 \%$; additional increases of $5 \%$ are produced by each LR integer after 2 , up to $6(+35 \%)$, after which $5 \%$ increases are brought about by LRs $8(+40 \%)$ and $10(+45 \%)$. For example, with a pre-test probability of $20 \%$ and an LR of 10 , the post-test probability is $20 \%+45 \%=65 \%$.

As illustrated above, the effect of LRs on pre-test probabilities is intelligible and fairly intuitive. However, the exact meaning of LRs is counterintuitive, and may be prone to misunderstanding (see, e.g., de Keijser \& Elffers, 2012). It would be a grave error to assume that a respondent presents with noncredible symptomatology solely on the basis of LRs. The LR expresses the relation between the probability of evidence (e.g., a test score) under two rival hypotheses (e.g., the symptom presentation is noncredible vs. the symptom presentation is credible). The finding that a particular test score is more likely if a symptom presentation is noncredible than if a symptom presentation is credible, should not be taken to mean the converse; that, given a particular test score, it is more likely that the symptom presentation is noncredible than that it is credible. The latter (conversed) inference is known as the "fallacy of the transposed conditional" or the "prosecutor's fallacy" (Thompson \& Schumann, 1987).

\footnotetext{
${ }^{10}$ If specificity is 1.00 , then the LR cannot be computed because sensitivity would be divided by zero, which is nonsensical. For the purpose of calculating LRs, a specificity of 1.00 should be assumed to be .99 instead.

${ }^{11}$ Note that we are considering only positive LRs; negative LRs range from 1 down to zero.
} 
Table 7.1

Approximate changes in pre-test probabilities between .10 and .90 as effectuated by multiplying pre-test odds with a likelihood ratio

\begin{tabular}{cc}
\hline Likelihood ratio & $\begin{array}{c}\text { Approximate change } \\
\text { in probability }\end{array}$ \\
\hline 1 & $0 \%$ \\
2 & $+15 \%$ \\
3 & $+20 \%$ \\
4 & $+25 \%$ \\
5 & $+30 \%$ \\
6 & $+35 \%$ \\
8 & $+40 \%$ \\
10 & $+45 \%$ \\
\hline
\end{tabular}

Note. The changes in pre-test probability are calculated via $.19 \times$ $\log _{e}$ LR, where $\log _{e}$ refers to the natural logarithm (McGee, 2002).

The prosecutor's fallacy can be difficult to notice in formal or sophisticated texts, yet it is easy to spot in simple examples: From the finding that, if an animal is a cat, it is likely to have four legs, it clearly cannot be inferred that, if an animal has four legs, it is likely to be a cat. One way to recognize the prosecutor's fallacy is to identify whether a statement is made about the probability of evidence (e.g., a test result) or about the probability of a hypothesis (e.g., a diagnosis). Statements about the probability of a test result given a diagnosis can validly be inferred from the sensitivity and specificity values of the test result. In contrast, statements about the probability of a diagnosis given a test result cannot be inferred solely from sensitivity and specificity. For example, the conclusion "the probability that the symptom presentation is noncredible is very high" does not logically follow from the fact that a score beyond the cutoff of a validity test has been produced. For such conclusions to be logically valid, it takes consideration of the base rate or prevalence of noncredible symptom presentations.

Failure to consider base rates is a serious concern in validity assessment (Rosenfeld, Sands, \& Van Gorp, 2000). Correct application of the LR approach prevents base rate neglect, because the LR is multiplied with the pre-test odds (i.e., base rate) of noncredible symptom presentations to arrive at the post-test odds that a respondent presents with noncredible symptomatology. The calculus of converting pre-test odds to post-test odds through multiplication with an LR is referred to as Bayes' Rule-the odds form of Bayes' Theorem; the LR is also known as Bayes' factor - so named after the Reverend Thomas Bayes (17011761), who first developed an equation to update hypotheses by taking into account new evidence.

If we return to our example where a respondent produces a validity test score with a sensitivity of .60 and a specificity of .95 , we can calculate the probability that the respondent 
presents with noncredible symptomatology if we know the base rate of noncredible symptom presentations. Assuming a base rate (i.e., pre-test probability) of .20, we can work out the post-test probability that the respondent presents with noncredible symptomatology by first converting the pre-test probability to odds. This conversion is necessary for the multiplication with the LR because LRs, like odds, but unlike probabilities, are not expressed as ratios to the whole. ${ }^{12}$ The conversion of a probability to odds can be accomplished by dividing the probability by 1 minus the probability (i.e., odds = probability/( 1 - probability) For example, a probability of .20 is equal to $.20 /(1-.20)=.25$ odds. ${ }^{13}$

The resultant (i.e., pre-test) odds are to be multiplied with the LR of the test result; in our example $12 ; .25 \times 12$, which is 3 odds. The post-test odds can be transformed back to probability by dividing them by 1 plus the post-test odds (i.e., probability = odds $/ 1+$ odds); in our case $3 /(1+3)=.75$ or $75 \%$. Thus, the probability that the symptom presentation of a respondent who belongs to a population in which the prevalence of noncredible symptomatology is .20 , and who produces a test score that is associated with .60 sensitivity and .95 specificity, is noncredible, is .75 or $75 \%$. In its entirety, the calculation runs as follows;

a) the LR of a validity test score with .60 sensitivity and .95 specificity $=.60$ sensitivity/[1 .95 specificity] $)=12$

b) the pre-test odds of noncredible symptomatology $=.20$ probability $/[1-.20$ probability $]=$ .25

c) the post-test odds of noncredible symptomatology $=$ LR $12 \times .25$ pre-test odds $=3$

d) the post-test probability of noncredible symptomatology $=3$ post-test odds/[ $1+3$ posttest odds] $=.75$ or $75 \%$

Table 7.2 also summarizes the consecutive calculations that are involved in applying the likelihood ratio approach to validity assessment.

Validity assessment preferably includes multiple measures of assessment validity (Slick, Sherman, \& Iverson, 1990). The primary reason for this is that false-positive rates decrease as a function of increase in the number of validity tests failed (Larrabee, 2014a; Victor, Boone, Serpa, Buehler, \& Ziegler, 2009). Another important reason is that all cognitive and psychological domains that are examined during an assessment should be covered by validity tests; ideally ones that blend in with other instruments and methods that are used (Boone, 2009; Heilbronner et al., 2009).

When multiple PVTs and SVTs are used, their results must be combined to render a verdict about assessment validity. The likelihood ratio approach offers a straightforward way to integrate the outcomes of multiple tests: LRs can be linked by means of Bayes' Rule, a process that is called "chaining" (Larrabee, 2008). When chaining LRs, the post-test odds of

\footnotetext{
12 Odds express the number of $X_{s}$ relative to the number of $Y_{S}$ (e.g., 1 to 4 ), whereas probabilities express the number of $X s$ relative to the number of $Y_{s}$ and $X s$, with the number of $Y_{s}$ and $X s$ standardized to 1 (e.g., 1 out of 5 ; standardized to .2 out of 1 ).

${ }^{13}$ Note that through this formula (probability/[1 - probability]), the latter number of the odds expression is standardized to 1, which, like in probabilities, is not recorded because such would be superfluous. For example, the formula transforms .20 probability to .25 odds, which is $.25: 1$ in odds form, and 1:4 in the odds expression with natural numbers.
} 
noncredible symptomatology after one validity test result are treated as the pre-test odds before a second validity test result. For instance, if the base rate of noncredible presentations is .20, and the LR of the first validity test result is 12 , then the post-test odds are $(.20 /[1-.20])$ $\times 12=3$; if the LR of the second validity test result is 3 , then the post-test odds become $3 \times 3=$ 9 , which, converted to probability, is .9 or $90 \%(9 /[1+9])$. Thus, multiplication of the post-test odds of the first test result with the LR of the second test result yields the post-test odds of the second test result, which in turn can be used as the pre-test odds for a third test result, and so forth.

An essential caveat that should be heeded when chaining LRs is that the test scores from which the LRs are obtained ought to be independent (Dujardin, Van den Ende, Van Gompel, Unger, \& Van der Stuyft, 1994). That is, the correlations between tests that are employed should not be significantly different than zero. If tests correlate significantly with each other, then post-test probabilities that are derived from chained LRs will be overestimated. In genuine clinical populations, PVTs are generally not significantly intercorrelated (see, e.g., Davis \& Millis, 2014; Larrabee, 2009; Meyers et al., 2014; Schroeder \& Marshall, 2011). The reason for this is that patients typically perform at ceiling on PVTs, which restricts the range of scores, and results in nonsignificant correlations between PVTs (Larrabee, 2014a). There is less data available on correlations between SVTs, yet it is plausible that, like in PVTs, boundaries of score ranges keep intercorrelations low in clinical populations. Correlations between PVTs and SVTs are minimal-at least in authentic clinical populations-owing to the clear difference in methodology between PVTs and SVTs (i.e., cognitive tests vs. symptom inventories; see, e.g., Copeland et al., 2016; Martin, Schroeder, Heinrichs, \& Baade, 2015). Note that correlations between validity tests among individuals who present with noncredible symptomatology are not problematic because positive test results in these populations are, by definition, not false positive.

Significant intercorrelations between validity tests are not the only route to overestimating post-test probabilities of noncredible symptomatology. Caution must also be exercised when deciding whether or not calculate LRs for the purpose of chaining: Chaining several scores with a considerable false-positive rate (i.e., with substandard specificity) could lead to a substantial post-test probability of noncredible symptomatology. It is vital to keep in mind that all test scores involved in the calculation of LRs are considered to be positive test outcomes (e.g., indicative of noncredible symptomatology). ${ }^{14}$ Thus, LRs of effective tests never yield exonerating outcomes: Even test results that are distinctly negative (e.g., a SIMS score of 3) do not decrease the pre-test probability of noncredible symptomatology; at best, they leave the pre-test probability unchanged. Therefore, it is imperative that LRs are only chained when at least two validity test results with high specificity are obtained (e.g., specificity $\geq$.90; Chafetz et al., 2015; Larrabee, 2014b).

\footnotetext{
14 Note, again, that we are only considering positive LRs; in negative LRs, test scores are considered to be negative, and they decrease pre-test probabilities.
} 
Chapter 7

Table 7.2

Consecutive calculations that constitute the likelihood ratio approach to interpreting validity test data

\begin{tabular}{|c|c|}
\hline Variable & Calculation \\
\hline Likelihood ratio & Sensitivity/(1 - Specificity) \\
\hline Pre-test odds (e.g., base rate) & Pre-test probability/(1 - Pre-test probability) \\
\hline Post-test odds & Pre-test odds $\times$ Likelihood ratio \\
\hline Post-test probability & Post-test odds/(1 + Post-test odds $)$ \\
\hline $\begin{array}{l}\text { Chaining Likelihood ratios } \\
\text { - Caveats }\end{array}$ & $\begin{array}{l}\text { Post-test odds from test A are Pre-test odds for test B, etc. } \\
\text { - Low specificity of test scores overestimates post-test probabilities. } \\
\text { - Dependence among tests overestimates post-test probabilities. }\end{array}$ \\
\hline
\end{tabular}

The product of the LR approach to validity assessment is the probability that a respondent presents with noncredible symptomatology. However, practice (clinical, forensic, or otherwise) often demands that a categorical decision is made on the credibility of an examinee's symptomatology. An advantage of the LR approach over the traditional use of cut scores is that it allows for the avoidance of the "ultimate issue" in validity assessment; it allows for the relegation of the final, qualitative judgment on noncredible symptomatology. Another advantage of LRs is that qualitative judgment can be facilitated by the calculation of 95\% confidence intervals for LRs. This does, however, require additional information; namely the samples sizes of the studies upon which the sensitivity and specificity of the validity tests are based. If this information is available, then $95 \%$ confidence intervals can be computed with the following formula, advanced by Simel, Samsa, and Matchar (1991):

$$
95 \% \text { CI LR }=\exp \left(\ln \left(\frac{\text { sensitivity }}{1-\text { specificity }}\right) \pm 1.96 \times \sqrt{\left(\frac{1-\text { sensitivity }}{\text { sensitivity } \times \mathrm{n} 1}\right)+\left(\frac{\text { specificity }}{(1-\text { specificity }) \times n 2}\right)}\right)
$$

where exp is the base of the natural logarithm, ln is the natural logarithm, $n 1$ is the sample size of noncredible respondents, and $\mathrm{n} 2$ is the sample size of credible respondents.

In sum, the LR approach prompts avoidance of several errors in validity assessment that may be fostered by the conventional use of cutoffs as ultimate decision criteria. Categorical decision-making based on cutoffs may inflate confidence in the diagnostic accuracy of the few cut scores that are used in clinical practice, and it might lure practitioners to rely on a single measure of assessment validity. Moreover, it could reinforce the incorrect notion that diagnostic accuracy indices (i.e., sensitivity and specificity) are static attributes of a psychometric instrument. More gravely, it could lead to neglect of the base rate of noncredible responding (Rosenfeld et al., 2000). Also, it possibly magnifies the erroneous impression that noncredible symptom presentations occur solely in the absence of genuine symptomatology (see, e.g., Merckelbach \& Merten, 2012). 
The above hazards are avoided when LRs are used to interpret and combine validity test data, because LRs are (ideally) calculated with actual test scores, and are multiplied with pre-test odds-i.e., the base rate in case of the first test, and the post-test odds of another test in the case of subsequent tests - to yield the exact probability that a respondent presents with noncredible symptomatology. An auxiliary advantage is that the LR approach does not enforce categorical decision-making and hence permits evasion of the "ultimate issue". Furthermore, LRs are preferable to positive and negative predictive values because they do not depend on base rates-and are thus transferable across populations-and because they can be computed from commonly available accuracy indices (i.e., sensitivity and specificity).

In conclusion, the LR can be conceived as the degree to which noncredible symptomatology is more probable after a validity test result is obtained compared with how probable it was before the validity test result was obtained. The chaining of LRs is a quantitative method of decision-making that, when employed with validated validity tests, caps off the actuarial approach to validity assessment. The method is simple enough to be calculated by hand, and its conclusions follow logically from empirically established knowledge. Thus, it encourages practitioners to work transparently and scientifically, and, in the process, increase diagnostic probability and decrease diagnostic error.

\section{Furthering validity assessment: Synthesis of the present studies}

As mentioned before, the quality of clinical assessment in healthcare rests on three pillars of validity; test validity, assessment validity, and judgment validity. Test validity is the capacity of tests to accurately measure what they are intended to measure; assessment validity is the accuracy with which examinees present their symptomatology; and judgment validity is extent to which diagnostic conclusions follow logically from clinical data. This thesis addresses the diagnostic qualities of indicators (Chapters 2-3) and tests (Chapters 4-6) that are meant to measure assessment validity. Because test validity and assessment validity are irrelevant if judgment validity is defective, this thesis also proffers a contemporary approach to safeguard judgment validity (likelihood ratios; see above).

The first goal of this thesis is to evaluate a diagnostic recommendation of the DSM-5; that antisocial features and behavior are useful indicators of assessment validity. We did not find antisocial behavior, as quantified through behavioral observations, self-report measures, and psychiatric diagnoses, to be associated with noncredible symptom reporting in a sample of forensic inpatients and a sample of young prisoners (Chapter 2). Subsequently, we deepened our investigation by zooming in on features that a re likely to underlie the potential relationship between antisocial features and noncredible symptomatology; namely deceitfulness, lack of remorse, and blame externalization, yet again we found no meaningful associations (Chapter 3). The main point that can be taken from these studies and the research that they follow up on is that antisocial features are not reliable markers of compromised assessment validity, and that they should not be used in any way in validity assessment lest they generate substantial proportions of misclassifications. 
The guideline that antisocial behavior signals feigned symptomatology is mainly predicated on clinical lore, as opposed to empirical fact. The dismissal of this guideline spurs the exploration alternative methods of validity assessment, which is the second goal of this thesis. We turned our attention to psychometric approaches to validity assessment and undertook a meta-analytic review of a commonly employed validity test; the SIMS (Chapter 4). The overarching conclusion that can be drawn from our meta-analysis is that the SIMS is effective in distinguishing credible from noncredible symptom presentations, and that its traditional cut scores are particularly tailored to screening purposes (i.e., offer high sensitivity, moderate specificity).

The SIMS represents one of two types of validity tests; SVTs. SVTs resemble symptom inventories or interviews, and are contrasted with PVTs, which mimic cognitive tests. We continued our exploration of psychometric approaches to validity assessment by testing the potential of a PVT that has not yet come into widespread use; the MSVA (Chapter 5). In contrast to most other PVTs, the MSVA does not target noncredible memory impairment; rather, it takes aim at noncredible deficits in vocabulary and abstract reasoning. We put the MSVA to the test in samples of children, forensic inpatients with intellectual disability, forensic inpatients with psychiatric symptoms, and undergraduate students. All in all, we found the performance of the MSVA to be insufficient to warrant clinical use, yet sufficiently promising to justify further validation research.

Neither SVTs nor PVTs gauge the motivations that drive noncredible symptom presentations. Because the distinction between factitious disorder and malingering - internal vs. external incentives - is highly significant (the former constitutes a mental disorder; the latter unadorned fraudulence), we set out to address this issue psychometrically. To this end, we developed an SVT with integrated strategies to tap internal incentives that are associated with factitious disorder; the SDI (Chapter 6). We investigated the qualities of the SDI in two simulation studies; each with factitious and malingering conditions and a clinical control group. The results were largely positive: The SDI detected noncredible symptom presentations as effectively as the SIMS, and exceeded the SIMS in distinguishing factitious from malingered symptom presentations.

Taken together, the studies and the scholarship laid out in this thesis advance the evaluation of symptom and performance validity in clinical and forensic assessments: They demonstrate that antisocial features and behavior are not, as the DSM-5 asserts, useful indicators of assessment validity. They establish that the SIMS is an effective SVT, and that its original cut scores emphasize high detection rates instead of low false-positive rates. They indicate that the MSVA is a potentially worthwhile PVT, which ought to be subjected to supplementary validation efforts. They substantiate that psychometric assessment of the internal motivations that distinguish factitious disorder from malingering is promising, and deserving of further consideration. And finally, they elucidate the likelihood ratio as coherent method to interpret and combine validity test data and avoid common pitfalls of validity assessment. 
This thesis started off with a brief sketch of the historical background of validity assessment by touching upon some of the myths and misconceptions that linger on from the nineteenth century to the present time. Validity assessment has come a long way since, evolving from pure clinical judgment to a largely psychometric enterprise. The last few decades, in particular, have witnessed an exponential growth in clinical and scholarly interest in validity assessment (e.g., see Bass \& Halligan, 2014; Berry \& Nelson, 2010; Rix \& Tracy, 2017). This thesis identified and addressed several issues where much progress is still to be made; the improvement of SVTs to be less susceptible to genuine pathology and better able to identify irrelevant responding; the proliferation of PVTs that target cognitive domains other than memory; the use of actuarial techniques to interpret and combine validity test data; and, above all, the psychometric differentiation of factitious and malingered symptomatology. 


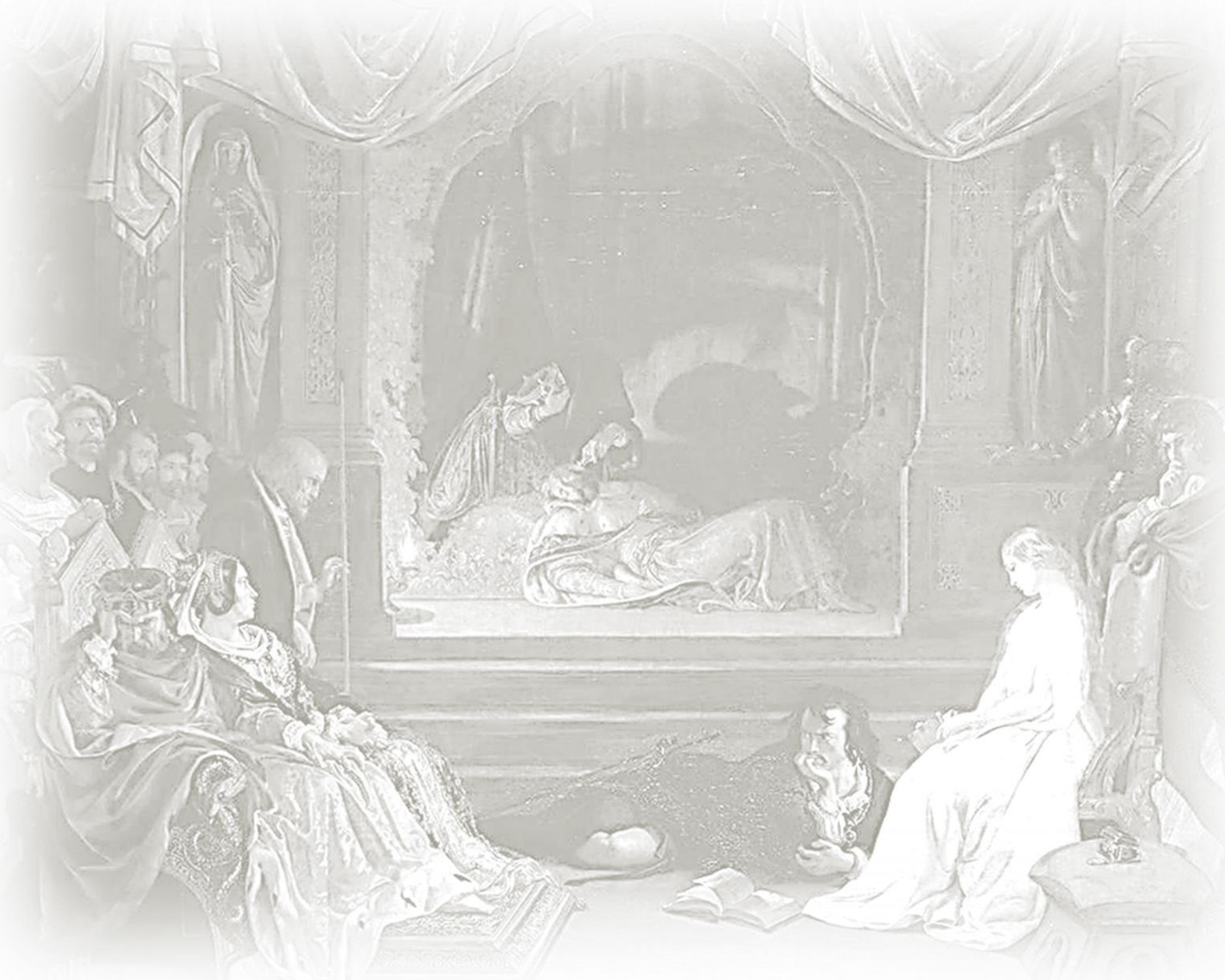




\section{References}

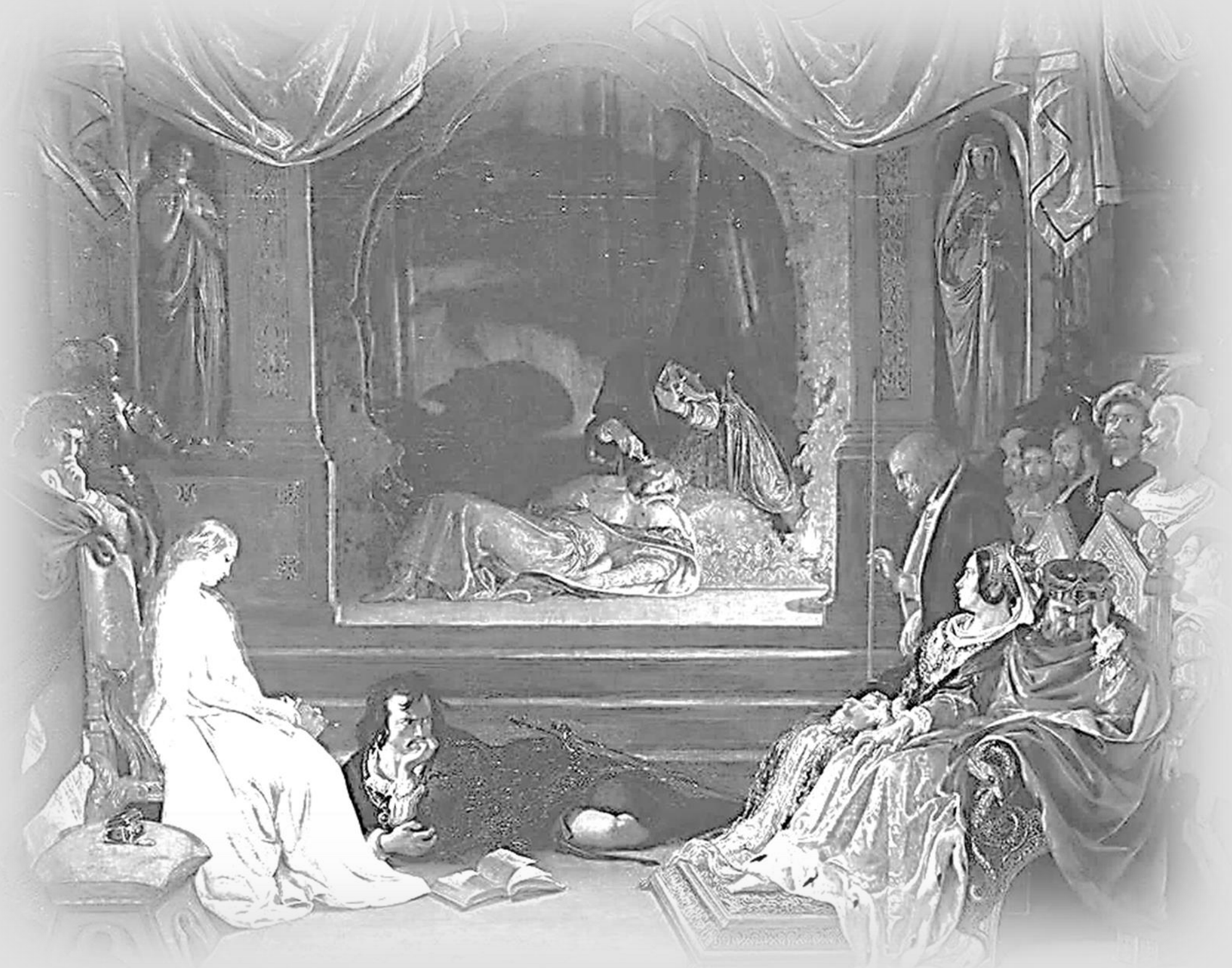


References marked with an asterisk indicate studies included in Table 4.6 (Chapter 4)

*Alwes, Y. R., Clark, J. A., Berry, D. T. R., \& Granacher, R. P. (2008). Screening for feigning in a civil forensic setting. Journal of Clinical and Experimental Neuropsychology, 30, 133-140.

Araujo, G. C., Antonini, T. N., Monahan, K., Gelfius, C., Klamar, K., Potts, M., ... Bodin, D. (2014). The relationship between suboptimal effort and post-concussion symptoms in children and adolescents with mild traumatic brain injury. The Clinical Neuropsychologist, 28, 786-801.

American Psychiatric Association. (1980). Diagnostic and statistical manual of mental disorders (3rd ed.). Washington, DC: Author.

American Psychiatric Association. (2000). Diagnostic and statistical manual of mental disorders (4th ed., text rev.). Washington, DC: Author.

American Psychiatric Association. (2013). Diagnostic and statistical manual of mental disorders (5th ed.). Arlington, Washington, DC: Author.

Asher, R. (1951). Munchausen's syndrome. The Lancet, 1, 339-341.

Bass, C., \& Halligan, P. (2014). Factitious disorders and malingering: challenges for clinical assessment and management. The Lancet, 383, 1422-1432.

Bauer, L., \& McCaffrey, R. J. (2006). Coverage of the Test of Memory Malingering, Victoria Symptom Validity Test, and Word Memory Test on the Internet: Is test security threatened? Archives of Clinical Neuropsychology, 21, 121-126.

Beaber, R. J., Marston, A., Michelli, J., \& Mills, M. J. (1985). A brief test for measuring malingering in schizophrenic individuals. American Journal of Psychiatry, 142, 1478-81.

Beck, A. T., Butler, A. C., Brown, G. K., Dahlsgaard, K. K., Newman, C. F., \& Beck, J. S. (2001). Dysfunctional beliefs discriminate personality disorders. Behaviour Research and Therapy, 39, 1213-1225.

Beck, A. T., Ward, C. H., Mendelson, M., Mock, J. E., \& Erbaugh, J. K. (1961). An inventory for measuring depression. Archives of General Psychiatry, 4, 561-571.

*Benge, J. F., Wisdom, N. M., Collins, R. L., Franks, R., Lemaire, A., \& Chen, D. K. (2012). Diagnostic utility of the Structured Inventory of Malingered Symptomatology for identifying psychogenic non-epileptic events. Epilepsy \& Behavior, 24, 439-444.

Ben-Porath, Y. S., \& Tellegen, A. (2008). The Minnesota Multiphasic Personality Inventory-2Restructured Form: Manual for administration, scoring, and interpretation. Minneapolis, MN: University of Minnesota Press.

Berry, D. T., \& Nelson, N. W. (2010). DSM-5 and malingering: A modest proposal. Psychological Injury and Law, 3, 295-303.

Berthelson, L., Mulchan, S. S., Odland, A. P., Miller, L. J., \& Mittenberg, W. (2013). False positive diagnosis of malingering due to the use of multiple effort tests. Brain Injury, 27, 909-916.

Bianchini, K. J., Mathias, C. W., \& Greve, K. W. (2001). Symptom validity testing: A critical review. The Clinical Neuropsychologist, 15, 19-45 
Bilder, R. M., Sugar, C. A., \& Hellemann, G. S. (2014). Cumulative false positive rates given multiple performance validity tests: Commentary on Davis and Millis (2014) and Larrabee (2014). The Clinical Neuropsychologist, 28, 1212-1223.

Binder, L. M. (2002). The Portland Digit Recognition Test: A review of validation data and clinical use. Journal of Forensic Neuropsychology, 2, 27-41.

Binder, L. M., Larrabee, G. J., \& Millis, S. R. (2014). Intent to fail: Significance testing of forced choice test results. The Clinical Neuropsychologist, 28, 1366-1375.

Boone, K. B. (2007). A reconsideration of the Slick et al. (1999) criteria for malingered neurocognitive dysfunction. In K. B. Boone (Ed.), Assessment of feigned cognitive impairment: A neuropsychological perspective (pp. 29-49). New York, NY: Guilford Press.

Boone, K. B. (2009). The need for continuous and comprehensive sampling of effort/response bias during neuropsychological examinations. The Clinical Neuropsychologist, 23, 729741.

Boone, K. B. (2013). Clinical Practice of Forensic Neuropsychology: An Evidence-Based Approach. New York, NY: Guilford Press.

Brennan, A. M., \& Gouvier, W. D. (2006). Are we genuinely studying malingering? A profile and comparison of feigned and suspected malingerers. Applied Neuropsychology, 13, 111 .

Brinkley, C. A., Schmitt, W. A., Smith, S. S., \& Newman, J. P. (2001). Construct validation of a self-report psychopathy scale: Does Levenson's Self-Report Psychopathy scale measure the same constructs as Hare's Psychopathy Checklist-Revised? Personality and Individual Differences, 31, 1021-1038.

British Psychological Society. (2009). Assessment of effort in clinical testing of cognitive functioning for adults. Leicester: Author.

Brooks, B. L., Ploetz, D. M., \& Kirkwood, M. W. (2016). A survey of neuropsychologists' use of validity tests with children and adolescents. Child Neuropsychology, 22, 1001-1020.

Brussel, J. A., \& Hitch, K. S. (1943). The military malingerer. Military Surgeon, 93, 33-44.

Bush, S. S., Heilbronner, R. L., \& Ruff, R. M. (2014). Psychological assessment of symptom and performance validity, response bias, and malingering: Official position of the Association for Scientific Advancement in Psychological Injury and Law. Psychological Injury and Law, 7, 197-205.

Butcher, J. N. (2000). Dynamics of personality test responses: the empiricist's manifesto revisited. Journal of Clinical Psychology, 56, 375-386.

Butcher, J. N., Graham, J. R., Ben-Porath, Y. S., Tellegen, A., Dahlstrom, W. G., \& Kaemmer, B. (2001). Minnesota Multiphasic Personality Inventory-2: Manual for administration, scoring and interpretation (rev. ed.). Minneapolis, MN: University of Minnesota Press.

Butler, M. (2008). What are you looking at? Prisoner confrontations and the search for respect. British Journal of Criminology, 48, 856-873. 
Capilla Ramírez, P., González Ordi, H., \& Santamaría Fernández, P. (2008). Detteción de simulación en dolor crónico. In H. González Ordi \& P. Santamaría Fernández (Eds.), Inventario Estructorado de Simulación de Sintomas - SIMS Manual [Structured Inventory of Malingered Symptomatology - SIMS Manual] (pp. 72-77). Madrid: Tea Ediciones.

Chafetz, M. D., Williams, M. A., Ben-Porath, Y. S., Bianchini, K. J., Boone, K. B., Kirkwood, M. W., ... Ord, J. S. (2015). Official position of the American Academy of Clinical Neuropsychology Social Security Administration policy on validity testing: Guidance and recommendations for change. The Clinical Neuropsychologist, 29, 723-740.

Chapman, L. J., \& Chapman, J. P. (1983). Infrequency Scale. Madison, WI: Unpublished test.

*Chen, D. K., Izadyar, S., Collins, R. L., Benge, J. F., LeMaire, A. W., \& Hrachovy, R. A. (2011). Induction of psychogenic nonepileptic events: Success rate influenced by prior induction exposure, ictal semiology, and psychological profiles. Epilepsia, 52, 1063 1070.

${ }^{*}$ Chen, D. K., Maheshwari, A., Franks, R., Trolley, G. C., Robinson, J. S., \& Hrachovy, R. A. (2014). Brief group psychoeducation for psychogenic nonepileptic seizures: A neurologist-initiated program in an epilepsy center. Epilepsia, 55, 156-166.

${ }^{*}$ Cima, M., Hollnack, S., Kremer, K., Knauer, E., Schellbach-Matties, R., Klein, B., \& Merckelbach, H. (2003). Strukturierter Fragebogen Simulierter Symptome [Structured Inventory of Malingered Symptomatology]. Nervenarzt, 74, 977-986.

Cima, M., Merckelbach, H., Butt, C., Kremer, K., Knauer, E., \& Schellbach-Matties, R. (2006). It was not me: Attribution of blame for criminal acts in psychiatric offenders. Forensic Science International, 168, 143-147.

Cima, M., Merckelbach, H., Hollnack, S., Butt, C., Kremer, K., Schellbach-Matties, R., \& Muris, P. (2003). The other side of malingering: Supernormality. The Clinical Neuropsychologist, 17, 235-243.

Cima, M., van Bergen, S., \& Kremer, K. (2008). Development of the Supernormality ScaleRevised and its relationship with psychopathy. Journal of Forensic Science, 53, 975-981.

${ }^{*}$ Cima, M., \& van Oorsouw, K. (2013). The relationship between psychopathy and crimerelated amnesia. International Journal of Law and Psychiatry, 36, 23-29.

Clark, C. R. (1997). Sociopathy, malingering, and defensiveness. In R. Rogers (Ed.), Clinical assessment of malingering and deception (2nd ed., pp. 68-84). New York, NY: Guilford Press.

Cleckley, H. (1941/1988). The mask of sanity. St. Louis: Mosby.

${ }^{*}$ Clegg, C., Fremouw, W., \& Mogge, N. (2009). Utility of the Structured Inventory of Malingered Symptomatology (SIMS) and the Assessment of Depression Inventory (ADI) in screening for malingering among outpatients seeking to claim disability. Journal of Forensic Psychiatry \& Psychology, 20, 239-254.

Cofer, C. N., Chance, J., \& Judson, A. J. (1949). A study of malingering on the Minnesota Multiphasic Personality Inventory. The Journal of Psychology, 27, 491-499.

Collie, J. (1913). Malingering and feigned sickness. London: Edward Arnold. 
Copeland, C. T., Mahoney, J. J., Block, C. K., Linck, J. F., Pastorek, N. J., Miller, B. I., ... Sim, A. H. (2016). Relative utility of performance and symptom validity tests. Archives of Clinical Neuropsychology, 31, 18-22.

Cumming, G. (2012). Understanding the new statistics: Effect sizes, confidence intervals, and metaanalysis. New York, NY: Routledge.

Cunnien, A. J. (1997). Psychiatric and medical syndromes associated with deception. In R. Rogers (Ed.), Clinical assessment of malingering and deception (2nd ed., pp. 23-46). New York, NY: Guilford Press.

*Dandachi-FitzGerald, B., \& Merckelbach, H. (2013). Feigning $\neq$ feigning a memory disorder: The Medical Symptom Validity Test as an example. Journal of Experimental Psychopathology, 4, 46-63.

Dandachi-FitzGerald, B., Merckelbach, H., \& Ponds, R. W. H. M. (2017). Neuropsychologists' ability to predict distorted symptom presentation. Journal of clinical and experimental neuropsychology, 39, 257-264.

Dandachi-FitzGerald, B., Ponds, R. W. H. M., Peters, M. J. V., \& Merckelbach, H. (2011). Cognitive underperformance and symptom over-reporting in a mixed psychiatric sample. The Clinical Neuropsychologist, 25, 812-828.

Davis, J. J., \& Millis, S. R. (2014). Examination of performance validity test failure in relation to number of tests administered. The Clinical Neuropsychologist, 28, 199-214.

Dawes, R. M., Faust, D., \& Meehl, P. E. (1989). Clinical versus actuarial judgment. Science, $243,1668-1674$.

de Beurs, E., \& Zitman, F. G. (2006). De Brief Symptom Inventory (BSI). Maandblad Geestelijke Volksgezondheid [Monthly Bulletin Mental Health], 61, 120-141.

de Keijser, J., \& Elffers, H. (2012). Understanding of forensic expert reports by judges, defense lawyers and forensic professionals. Psychology, Crime \& Law, 18, 191-207.

Delain, S. L., Stafford, K. P., \& Ben-Porath, Y. S. (2003). Use of the TOMM in a criminal court forensic assessment setting. Assessment, 10, 370-381.

DeMatteo, D., \& Edens, J. F. (2006). The role and relevance of the Psychopathy ChecklistRevised in court: A case law survey of U.S. courts (1991-2004). Psychology, Public Policy, and Law, 12, 214-241.

Derogatis, L. R. (1994) SCL-90-R: Administration, scoring and procedures manual. Minneapolis, MN: National Computer Systems.

Derogatis, L. R., \& Melisaratos, N. (1983). The Brief Symptom Inventory: An introductory report. Psychological Medicine, 13, 595-605.

Drane, D. L., Williamson, D. J., Stroup, E. S., Holmes, M. D., Jung, M., Koerner, E., ... Miller, J. W. (2006) Cognitive impairment is not equal in patients with epileptic and psychogenic nonepileptic seizures. Epilepsia, 47, 1879-1886.

Dujardin, B., Van den Ende, J., Van Gompel, A., Unger, J-P., \& Van der Stuyft, P. (1994). Likelihood ratios: a real improvement for clinical decision making? European Journal of Epidemiology, 10, 29-36. 
Edens, J. F., Kelley, S. E., Lilienfeld, S. O., Skeem, J. L., \& Douglas, K. S. (2015). DSM-5 antisocial personality disorder: Predictive validity in a prison sample. Law and Human Behavior, 39, 123-129.

*Edens, J. F., Otto, R. K., \& Dwyer, T. (1999). Utility of the Structured Inventory of Malingered Symptomatology in identifying persons motivated to malinger psychopathology. Journal of the American Academy of Psychiatry and the Law, 27, 387396.

Edens, J. F., Poythress, N. G., \& Watkins-Clay, M. M. (2007). Detection of malingering in psychiatric unit and general population prison inmates: A comparison of the PAI, SIMS, and SIRS. Journal of Personality Assessment, 88, 33-42.

Egeland, J., Andersson, S., Sundseth, Ø. Ø., \& Schanke, A-K. (2015). Types or modes of malingering? A confirmatory factor analysis of performance and symptom validity tests. Applied Neuropsychology: Adult, 22, 215-226.

Ekstrom, S. R. (2004). The mind beyond our immediate awareness: Freudian, Jungian, and cognitive models of the unconscious. Journal of Analytical Psychology, 49, 657-682.

Eysenck, H. J. (1985). Decline and fall of the Freudian empire. New York, NY, Viking Press.

Fagan, T. J. (1975). Nomogram for Bayes theorem [Letter]. The New England Journal of Medicine, 293, 257.

Faust, D., Hart, K., Guilmette, T. J., \& Arkes, H. R. (1988). Neuropsychologists' capacity to detect adolescent malingerers. Professional Psychology: Research and Practice, 19, 508515.

Fox, D. D. (2011). Symptom validity test failure indicates invalidity of neuropsychological tests. The Clinical Neuropsychologist, 25, 488-495.

Frederick, R. I., \& Speed, F. M. (2007). On the interpretation of below-chance responding in forced-choice tests. Assessment, 14, 3-11.

Freeman, T., Powell, M., \& Kimbrell, T. (2008). Measuring symptom exaggeration in veterans with chronic posttraumatic stress disorder. Psychiatry Research, 158, 374-380.

Freeman, J., \& Samson, F. (2012). Are you telling the truth? Psychopathy assessment and impression management in a community sample. The Open Criminology Journal, 5, 1623.

Gacono, C. B., Meloy, J. R., Sheppard, K., Speth, E., \& Roske, A. (1995). A clinical investigation of malingering and psychopathy in hospitalized insanity acquittees. Bulletin of the American Academy of Psychiatry and the Law, 23, 387-397.

Gavin, H. (1843) On Feigned and factitious diseases chiefly of soldiers and seamen. London: J. Churchill.

*Geraerts, E., Jelicic, M., \& Merckelbach, H. (2006). Symptom over-reporting and recovered memories of childhood sexual abuse. Law and Human Behavior, 30, 621-630.

*Giger, P., \& Merten, T. (2013). Swiss population-based reference data for six symptom validity tests. Clínica y Salud, 24, 153-159. 
*Giger, P., Merten, T., Merckelbach, H., \& Oswald, M. (2010). Detection of feigned crimerelated amnesia: A multi-method approach. Journal of Forensic Psychology Practice, 10, $440-463$.

Goldstein, H. (1945). A malingering key for mental tests. Psychology Bulletin, 42, 104-118.

*González Ordi, H., Capilla Ramírez, P., Santamaría Fernández, P., \& Casado Morales, M. I. (2012). Abordaje multidisciplinar para la detección de la simulación en lumbalgia crónica [A multidisciplinary approach to the detection of malingering in chronic lower back pain]. Trauma, 23, 145-154.

*González Ordi, H., \& Santamaría Fernández, P. (2008). Detection of malingering in clinical, medicolegal, and forensic settings. In H. González Ordi \& P. Santamaría Fernández (Eds.), Inventario Estructorado de Simulación de Síntomas - SIMS Manual [Structured Inventory of Malingered Symptomatology - SIMS Manual] (pp. 60-66). Madrid: Tea Ediciones.

González Ordi, H., \& Santamaría Fernández, P. (2009) Inventario Estructorado de Simulación de Sintomas - SIMS Manual [Structured Inventory of Malingered Symptomatology - SIMS Manual]. Madrid: Tea Ediciones.

*González Ordi, H., Santamaría Fernández, P., Blasco Saiz, J. L., \& Pallardó Durá, L. (2008). Estudio de patron de exageración de síntomas en contextos médico-legales [Study concerning the pattern of symptom exaggeration in medicolegal contexts]. In $\mathrm{H}$. González Ordi \& P. Santamaría Fernández (Eds.), Inventario Estructorado de Simulación de Sintomas - SIMS Manual [Structured Inventory of Malingered Symptomatology - SIMS Manual] (pp. 69-71). Madrid: Tea Ediciones.

*González Ordi, H., Santamaría Fernández, P., \& Fernández Marín, P. (2010). Precisión predictive del Inventario Estructurado de Simulación de Síntomas - SIMS en el contexto medicolegal [Predictive accuracy of the Structured Inventory of Malingered Symptomatology - SIMS in the medicolegal setting]. Edupsykhé, 9, 3-22.

*González Ordi, H., Santamaría Fernández, P., \& Matalobos Veiga, B. (2008). Inventario estructurado de simulatión de síntomas - SIMS. Una medida de screening de simulación de síntomas psicopatológicos y neuropsicológicos [Structured Inventory of Malingered Symptomatology - SIMS. A screening measure for feigned psychopathological and neuropsychological symptoms]. In H. González Ordi \& P. Santamaría Fernández (Eds.), Inventario Estructorado de Simulación de Síntomas - SIMS Manual [Structured Inventory of Malingered Symptomatology - SIMS Manual] (pp. 54-60). Madrid: Tea Ediciones.

*Graue, L. O., Berry, D. T. R., Clark, J. A., Sollman, M. J., Cardi, M., Hopkins, J., \& Werline, D. (2007). Identification of feigned mental retardation using the new generation of malingered detection instruments: Preliminary findings. The Clinical Neuropsychologist, 21, 929-942.

Green, P. (2003). Green's Word Memory Test for Windows: User's manual. Edmonton, Alberta, Canada: Green's Publishing. 
Green, P. (2004). Manual for the Medical Symptom Validity Test. Edmonton, Alberta, Canada: Green's Publishing.

Green, D., \& Rosenfeld, B. (2011). Evaluating the gold standard: A review and meta-analysis of the Structured Interview of Reported Symptoms. Psychological Assessment, 23, 95107.

Green, D., Rosenfeld, B., Belfi, B., Rohlehr, L., \& Pierson, A. (2012). Use of measures of cognitive effort and feigned psychiatric symptoms with pretrial forensic psychiatric patients. International Journal of Forensic Mental Health, 11, 181-190.

Greene, R. L. (1988). The relative efficacy of F-K and the obvious and subtle scales to detect overreporting of psychopathology on the MMPI. Journal of Clinical Psychology, 44, 152-159.

Greve, K. W., \& Bianchini, K. J. (2004). Setting empirical cut-offs on psychometric indicators of negative response bias: A methodological commentary with recommendations. Archives of Clinical Neuropsychology, 19, 533-541.

Greve, K. W., Bianchini, K. J., \& Doane, B. M. (2006). Classification accuracy of the Test of Memory Malingering in traumatic brain injury: Results of a known-groups analysis. Journal of Clinical and Experimental Neuropsychology, 28, 1176-1190.

Greve, K. W., Binder, L. M., \& Bianchini, K. J. (2009). Rates of below-chance performance in forced-choice symptom validity tests. The Clinical Neuropsychologist, 23, 534-544.

Greve, K. W., Ord, J. S., Bianchini, K. J., \& Curtis, K. L. (2009). Prevalence of malingering in patients with chronic pain referred for psychologic evaluation in a medico-legal context. Archives of Physical Medicine and Rehabilitation, 90, 1117-1126.

Grimes, D. A., \& Schulz, K. F. (2005). Refining clinical diagnosis with likelihood ratios. Lancet, 365, 1500-1505.

Grosz, H. J., \& Zimmerman, J. (1965). Experimental analysis of hysterical blindness: A follow-up report and new experimental data. Archives of General Psychiatry, 13, 255260.

Grove, W. M., Zald, D. H., Lebow, B. S., Snitz, B. E., \& Nelson, C. (2000). Clinical versus mechanical prediction: A meta-analysis. Psychological Assessment, 12, 19-30.

Gudjonsson, G. H., \& Singh, K. K. (1989). The Revised Gudjonsson Blame Attribution Inventory. Personality and Individual Differences, 10, 67-70.

Hare, R. D. (1991/2003). The Hare Psychopathy Checklist-Revised. Toronto: Multi-Health Systems.

Hare, R., Forth, A. E., \& Hart, S. D. (1989). The psychopath as prototype for pathological lying and deception. In J. C. Yuille (Ed.), Credibility assessment (pp. 25-49). Dordrecht: Kluwer Academic.

Hartman, D. E. (2002). The unexamined lie is a lie worth fibbing: Neuropsychological malingering and the Word Memory Test. Archives of Clinical Neuropsychology, 17, 709714 . 
Heilbronner, R. L., Sweet, J. J., Morgan, J. E., Larrabee, G. J., Millis, S. R., \& Conference participants. (2009). American Academy of Clinical Neuropsychology consensus conference statement on the neuropsychological assessment of effort, response bias, and malingering. The Clinical Neuropsychologist, 23, 1093-1129.

Heintz, C. E. J., van Tricht, M. J., van der Salm S. M. A., van Rootselaar, A. F., Cath, D., Schmand, B., \& Tijssen, M. A. J. (2013). Neuropsychological profile of psychogenic jerky movement disorders: Importance of evaluating noncredible cognitive performance and psychopathology. Journal of Neurology, Neurosurgery \& Psychiatry, $84,862-867$.

*Heinze, M. C., \& Purisch, A. D. (2001). Beneath the mask: Use of psychological tests to detect and subtype malingering in criminal defendants. Journal of Forensic Psychology Practice, 1, 23-52.

Heinze, M. C., \& Vess, J. (2005). The relationship among malingering, psychopathy, and the MMPI-2 validity scales in maximum security forensic psychiatric inpatients. Journal of Forensic Psychology Practice, 5, 35-53.

Henning, K., \& Holdford, R. (2006). Minimization, denial, and victim blaming by batterers: How much does the truth matter? Criminal Justice and Behavior, 33, 110-130.

Hunt, H. E (1948). The effect of deliberate deception on Minnesota Multiphasic Personality Inventory performance. Journal of Consulting Psychology, 12, 396-402.

Hunt, W. A., \& Older, H. J. (1943). Detection of malingering through psychometric tests. Naval Medical Bulletin, 41, 1318-1323.

Hyler, S. E., \& Spitzer, R. L. (1978). Hysteria split asunder. The American Journal of Psychiatry, $135,1500-1504$.

Inman, T. H., Vickery, C., Berry, D., Lamb, D., Edwards, C., \& Smith, G. (1998). Development and initial validation of a new procedure for evaluating adequacy of effort given during neuropsychological testing: The Letter Memory Test. Psychological Assessment, 10, 120-127.

Institute of Medicine. (2015). Psychological testing in the service of disability determination. Washington, DC: The National Academies Press.

*Jelicic, M., Ceunen, E., Peters, M. J. V., \& Merckelbach, H. (2011). Detecting coached feigning using the Test of Memory Malingering (TOMM) and the Structured Inventory of Malingered Symptomatology (SIMS). Journal of Clinical Psychology, 67, 850-855.

*Jelicic, M., Hessels, A., \& Merckelbach, H. (2006). Detection of feigned psychosis with the Structured Inventory of Malingered Symptomatology (SIMS): A study of coached and uncoached feigners. Journal of Psychopathology and Behavior Assessment, 28, 19-22.

*Jelicic, M., Merckelbach, H., Candel, I., \& Geraerts, E. (2007). Detection of feigned cognitive dysfunction using special malinger tests: A simulation study in naïve and coached malingerers. International Journal of Neuroscience, 117, 1185-1192. 
*Jelicic, M., Peters, M. J. V., Leckie, V., \& Merckelbach, H. (2007) Basic knowledge of psychopathology does not undermine the efficacy of the Structured Inventory of Malingered Psychopathology (SIMS) to detect feigned psychosis. Netherlands Journal of Psychology, 63, 107-110.

*Jelicic, M., van Gaal, M., \& Peters, M. J. V. (2013). Expert knowledge doesn't help: Detecting feigned psychosis in people with psychiatric expertise using the Structured Inventory of Malingered Symptomatology (SIMS). Journal of Experimental Psychopathology, 4, 3877.

Jones, A. B., \& Llewellyn, L. J. (1917). Malingering or the simulation of disease. London: Heinemann.

Jung, C. G. (1903). Über Simulation von Geistesstörungen [On feigning of mental disorders]. Journal für Psychologie und Neurologie [Journal of Psychology and Neurology], 5, 181-2012.

Kanaan, R. A. A., \& Wessely, S. C. (2010). The origins of factitious disorder. History of the Human Sciences, 23, 68-85.

Kelsey, K. R., Rogers, R., \& Robinson, E. V. (2014). Self-report measures of psychopathy: What is their role in forensic assessments? Journal of Psychopathology and Behavioral Assessment, 37, 380-391.

Kirkwood, M. W., \& Kirk, J. W. (2010). The base rate of suboptimal effort in a pediatric mild TBI sample: Performance on the Medical Symptom Validity Test. The Clinical Neuropsychologist, 24, 860-872.

Kirkwood, M. W., Yeates, K. O., Randolph, C., \& Kirk, J. W. (2012). The implications of symptom validity test failure for ability based test performance in a pediatric sample. Psychological Assessment, 24, 36-45.

Kobelt, A., Göbber, J., Bassler, M., \& Petermann, F. (2012). Beschwerdenvalidität im Rahmen stationärer psychosomatischer Rehabilitation [Symptom validity in psychosomatic rehabilitation]. Rehabilitation, 51, 349-355.

Krahn, L. E., Bostwick, J. M., \& Stonnington, C. M. (2008). Looking toward DSM-V: Should factitious disorder become a subtype of somatoform disorder? Psychosomatics, 49, 277-282.

Kroger, R. O., \& Turnbull, W. (1975). Invalidity of validity scales: the case of the MMPI. Journal of Consulting and Clinical Psychology, 43, 48-55.

Kucharski, L. T., Duncan, S., Egan, S. S., \& Falkenbach, D. M. (2006). Psychopathy and malingering of psychiatric disorder in criminal defendants. Behavioral Sciences and the Law, 24, 633-644.

Kucharski, L. T., Falkenbach, D. M., Egan, S. S., \& Duncan, S. (2006). Antisocial personality disorder and the malingering of psychiatric disorder: A study of criminal defendants. International Journal of Forensic Mental Health, 5, 195-204.

Kunst, M., Winkel, F. W., \& Bogaerts, S. (2011). Recalled peritraumatic reactions, selfreported PTSD, and the impact of malingering and fantasy proneness in victims of interpersonal violence who have applied for state compensation. Journal of Interpersonal Violence, 26, 2186-2210. 
Larrabee, G. J. (2008). Aggregation across multiple indicators improves the detection of malingering: Relationship to likelihood ratios. The Clinical Neuropsychologist, 22, 666679.

Larrabee, G. J. (2009). Malingering scales for the Continuous Recognition Memory Test and Continuous Visual Memory Test. The Clinical Neuropsychologist, 23, 167-180.

Larrabee, G. J. (2012). Performance validity and symptom validity in neuropsychological assessment. Journal of the International Neuropsychological Society, 18, 625-631.

Larrabee, G. J. (2014a). False-positive rates associated with the use of multiple performance and symptom validity tests. Archives of Clinical Neuropsychology, 29, 364-373.

Larrabee, G. J. (2014b). Minimizing false positive error with multiple performance validity tests: Response to Bilder, Sugar, and Hellemann (2014 this issue). The Clinical Neuropsychologist, 28, 1230-1242.

Larrabee, G. J. (2015). The multiple validities of neuropsychological assessment. American Psychologist, 70, 779-788.

Larrabee, G. J., Millis, S. R., \& Meyers, J. E. (2009). 40 plus or minus 10, a new magical number: Reply to Russell. The Clinical Neuropsychologist, 23, 841-849.

Levenson, M., Kiehl, K., \& Fitzpatrick, C. (1995). Assessing psychopathic attributes in a noninstitutionalized population. Journal of Personality and Social Psychology, 68, 151158.

*Lewis, J. L., Simcox, A. M., \& Berry, D. T. R. (2002). Screening for feigned psychiatric symptoms in a forensic sample by using the MMPI-2 and the Structured Inventory of Malingered Symptomatology. Psychological Assessment, 14, 170-176.

Lilienfeld, S. O., \& Andrews, B. P. (1996). Development and preliminary validation of a selfreport measure of psychopathic personality traits in noncriminal populations. Journal of Personality Assessment, 66, 488-524.

Lynam, D. R., Whiteside, S., \& Jones, S. (1999). Self-reported psychopathy: A validation study. Journal of Personality Assessment, 73, 110-132.

MacNeil, B. M., \& Holden, R. R. (2006). Psychopathy and the detection of faking on selfreport inventories of personality. Personality and Individual Differences, 41, 641-651.

Marion, B. E., Sellbom, M., Salekin, R. T., Toomey, J. A., Kucharski, L. T., \& Duncan, S. (2013). An examination of the association between psychopathy and dissimulation using the MMPI-2-RF validity scales. Law and human behavior, 37, 219-230.

Martin, P. K., Schroeder, R. W., Heinrichs, R. J., \& Baade, L. E. (2015). Does true neurocognitive dysfunction contribute to Minnesota Multiphasic Personality Inventory-2nd Edition-Restructured Form cognitive validity scale scores? Archives of Clinical Neuropsychology, 30, 377-386.

Martin, P. K., Schroeder, R. W., \& Odland, A. P. (2015). Neuropsychologists' validity testing beliefs and practices: A survey of North American professionals. The Clinical Neuropsychologist, 29, 1-36.

Maruna, S., \& Mann, R. E. (2006). A fundamental attribution error? Rethinking cognitive distortions. Legal and Criminological Psychology, 11, 155-177. 
McDermott, B. E., Dualan, I. V., \& Scott, C. L. (2013). Malingering in the correctional system: Does incentive affect prevalence? International Journal of Law and Psychiatry, 36, 287292.

McGee, S. (2002). Simplifying likelihood ratios. Journal of General Internal Medicine, 17, 647650.

Meade, A. W., \& Craig, S. B. (2012). Identifying careless responses in survey data. Psychological Methods, 17, 437-455.

Meehl, P. E. (1945). The dynamics of "structured" personality tests. Journal of Clinical Psychology, 1, 296-303.

Meehl, P. E. (1954). Clinical versus statistical prediction: A theoretical analysis and a review of the evidence. Minneapolis, MN: University of Minnesota Press.

Meijer, E. H., Verschuere, B., Gamer, M., Merckelbach, H., \& Ben-Shakhar, G. (2016). Deception detection with behavioral, autonomic, and neural measures: Conceptual and methodological considerations that warrant modesty. Psychophysiology, 53, 593604.

*Merckelbach, H., \& Collaris, J. (2012). Mother Theresa doesn't help here: Lack of moral priming effects on malingered symptom reports and what we can learn from it. Psychologica Belgica, 52, 201-215.

*Merckelbach, H., Jelicic, M., \& Pieters, M. (2011). The residual effect of feigning: How intentional faking may evolve into a less conscious form of symptom reporting. Journal of Clinical and Experimental Neuropsychology, 33, 131-139.

Merckelbach, H., \& Merten, T. (2012). A note on cognitive dissonance and malingering. The Clinical Neuropsychologist, 26, 1217-1229.

Merckelbach, H., Smeets, T., \& Jelicic, M. (2009). Experimental feigning: Type of malingering scenario makes a difference. The Journal of Forensic Psychiatry \& Psychology, 20, 378386.

*Merckelbach, H., \& Smith, G. P. (2003). Diagnostic accuracy of the Structured Inventory of Malingered Symptomatology (SIMS) in detecting instructed malingering. Archives of Clinical Neuropsychology, 18, 145-152.

Merten, T., Dandachi-FitzGerald, B., Hall, V., Schmand, B.A., Santamaría, P., \& GonzálezOrdi, H. (2013). Symptom validity assessment in European countries: Development and state of the art. Clínica y Salud, 24, 129-138.

*Merten, T., Diederich, C., \& Stevens, A. (2008). Vorgetäuschte Beschwerden nach Distorsionstrauma der Halswirbelsäule: Eine experimentelle Feigningsstudie [Feigned symptoms after whiplash injury: An experimental feigning study]. Aktuelle Neurologie, 35, 8-15.

*Merten, T., Friedel, E., Mehren, G., \& Stevens, A. (2007). Über die Validität von Persönlichkeitsprofilen in der nervenärztlichen Begutachtung [On the validity of personality profiles in psychiatric assessment]. Nervenarzt, 78, 511-520. 
Merten, T., Friedel, E., \& Stevens, A. (2007) Die Authentizität der Beschwerdenschilderung in der neurologisch-psychiatrischen Begutachtung: eine Untersuchung mit dem Strukturierten Fragebogen Simulierter Symptome [Authenticity of symptom report in independent neurological and psychiatric examinations: A study with the Structured Inventory of Malingered Symptomatology]. Praxis der Rechtspsychologie, 17, 140-154.

*Merten, T., Lorenz, R., \& Schlatow, S. (2010). Posttraumatic Stress Disorder can easily be faked, but faking can be detected in most cases. German Journal of Psychiatry, 13, 140149.

Merten, T., \& Merckelbach, H. (2013a). Forced-choice tests as single-case experiments in the differential diagnosis of intentional symptom distortion. Journal of Experimental Psychopathology, 4, 20-37.

Merten, T., \& Merckelbach, H. (2013b). Symptom validity testing in somatoform and dissociative disorders: A critical review. Psychological Injury and Law, 6, 122-137.

Merten, T., Merckelbach, H., Giger, P., \& Stevens, A. (2016). The Self-Report Symptom Inventory (SRSI): A new instrument for the assessment of distorted symptom endorsement. Psychological Injury and Law, 9, 102-111.

Merten, T., \& Rogers, R. (2017). An international perspective on feigned mental disabilities: conceptual issues and continuing controversies. Behavioral Sciences $\mathcal{E}$ the Law, 35, 97112.

Merten, T., Thies, E., Schneider, K., \& Stevens, A. (2009). Symptom validity testing in claimants with alleged posttraumatic stress disorder: Comparing the Morel Emotional Numbing Test, the Structured Inventory of Malingered Symptomatology, and the Word Memory Test. Psychological Injury and Law, 2, 284-293.

Meyer, M. W., \& Gupta, V. (1994). The performance paradox. Research in Organizational Behavior, 16, 309-369.

Meyers, J. E., Miller, R. M., Thompson, L. M., Scalese, A. M., Allred, B. C., Rupp, Z. W., ... Lee, A. J. (2014). Using likelihood ratios to detect invalid performance with performance validity measures. Archives of Clinical Neuropsychology, 29, 224-235.

Miller, H. A. (2001). M-FAST: Miller-Forensic Assessment of Symptoms Test professional manual. Odessa, FL: Psychological Assessment Resources.

Mittenberg, W., Patton, C., Canyock, E. M., \& Condit, D. C. (2002). Base rates of malingering and symptom exaggeration. Journal of Clinical and Experimental Neuropsychology, 24, 1094-1102.

Morel, K. R. (1998). Development and preliminary validation of a forced-choice test of response bias for posttraumatic stress disorder. Journal of Personality Assessment, 70, 299-314.

Morey, L. C. (2007). The Personality Assessment Inventory professional manual (2nd ed.). Odessa, FL: Psychological Assessment Resources. 
Nelson, N. W., Sweet, J. J., Berry, D. T. R., Bryant, F. B., \& Granacher, R. P. (2007). Response validity in forensic neuropsychology: Exploratory factor analytic evidence of distinct cognitive and psychological constructs. Journal of the International Neuropsychological Society, 13, 440-449.

Nies, K. J., \& Sweet, J. J. (1994). Neuropsychological assessment and malingering: A critical review of past and present strategies. Archives of Clinical Neuropsychology, 9, 501-552.

Niesten, I. J. M., Nentjes, L., Merckelbach, H., \& Bernstein, D. P. (2015). Antisocial features and "faking bad": A critical note. International Journal of Law and Psychiatry, 41, 34-42.

Ortega, A., Wagenmakers, E-J., Lee, M. D., Markowitsch, H. J., \& Piefke, M. (2012). A Bayesian latent group analysis for detecting poor effort in the assessment of malingering. Archives of Clinical Neuropsychology, 27, 453-465.

Pankratz, L. (1979). Symptom validity testing and symptom retraining: Procedures for the assessment and treatment of functional sensory deficits. Journal of Consulting and Clinical Psychology, 47, 409-410.

Pankratz, L., Fausti, S. A., \& Peed, S. (1975). A forced-choice technique to evaluate deafness in the hysterical or malingering patient. Journal of Consulting and Clinical Psychology, $43,421-422$.

Pareés, I., Kassavetis, P., Saifee, T. A., Sadnicka, A., Bhatia, K. P., Fotopoulou, A., \& Edwards, M. J. (2012). 'Jumping to conclusions' bias in functional movement disorders. Journal of Neurology, Neurosurgery \& Psychiatry, 83, 460-463.

Pareés, I., Saifee, T. A., Kassavetis, P., Kojovic, M., Rubio-Agusti, I., Rothwell, J. C., ... Edwards, M. J. (2012). Believing is perceiving: Mismatch between self-report and actigraphy in psychogenic tremor. Brain, 135, 117-123.

*Peters, M. J. V., Jelicic, M., Moritz, S., Hausschildt, M., \& Jelinek, L. (2013). Assessing the boundaries of symptom over-reporting using the Structured Inventory of Malingered Symptomatology in a clinical schizophrenia sample: Its relation to symptomatology and neurocognitive dysfunctions. Journal of Experimental Psychopathology, 4, 64-77.

Pierson, A. M., Rosenfeld, B., Green, D., \& Belfi, B. (2011). Investigating the relationship between antisocial personality disorder and malingering. Criminal Justice and Behavior, 38, 146-156.

Plohmann, A. M., \& Merten, T. (2013). The Third European Symposium on Symptom Validity Assessment - Facts and controversies. Clínica y Salud, 24, 197-203.

Pollock, P. H., Quigley, B., Norley, K. O., \& Bashford, C. (1997). Feigned mental disorders in prisoners referred to forensic mental health services. Journal of Psychiatry and Mental Health Nursing, 4, 9-15.

Porter, S., \& Woodworth, M. (2007). "I'm sorry I did it... but he started it": A comparison of the official and self-reported homicide descriptions of psychopaths and nonpsychopaths. Law and Human Behavior, 31, 91-107.

Powell, M. R., Gfeller, J. D., Hendricks, B. L., \& Sharland, M. (2004). Detecting symptom- and test-coached simulators with the Test of Memory Malingering. Archives of Clinical Neuropsychology, 19, 693-702. 
Radaelli, D., Benedetti, F., Cavallaro, R., Colombo, C., \& Smeraldi, E. (2013). The reality monitoring deficit as a common neuropsychological correlate of schizophrenic and affective psychosis. Behavioral Sciences, 3, 244-252.

Ray, J. V., Hall, J., Rivera-Hudson, N, Poythress, N. G., Lilienfeld, S. O., \& Morano, M. (2013). The relation between self-reported psychopathic traits and distorted response styles: A meta-analytic review. Journal of Personality Disorders, 4, 1-14.

Rey, A. (1941). L'examen psychologique dans les cas d'encéphalopathie traumatique [The psychological examination in cases of traumatic encephalopathy]. Archives de Psychologie, 28, 286-340.

Rey, A. (1958). L'examen clinique en psychologie [The clinical examination in psychology]. Paris: Presses Universitaires de France.

Reynolds, C. R., \& Horton, A. M. Jr. (2012). Clinical acumen, common sense, and data-based decision making in the assessment of dissimulation during head injury litigation. In C. R. Reynolds \& A. M. Horton Jr. (Eds.), Detection of malingering during head injury litigation (pp. 351-370). New York, NY: Springer.

Rienstra, A., Spaan, P. E. J., \& Schmand, B. (2010). Validation of symptom validity tests using a "child model" of adult cognitive impairments. Archives of Clinical Neuropsychology, $25,371-382$.

Rix, K. J. B., \& Tracy, D. K. (2017). Malingering mental disorders: Medicolegal reporting. BJPsych Advances, 23, 115-122.

Rogers, R. (1990a). Development of a new classificatory model of malingering. Bulletin of the American Academy of Psychiatry \& the Law, 18, 323-333.

Rogers, R. (1990b). Models of feigned mental illness. Professional Psychology: Research and Practice, 21, 182-188.

Rogers, R. (1992). Classification of malingering: Will DSM IV rise to the challenge? Psychiatric Times, 54-55.

Rogers, R. (2008a). An introduction to response styles. In R. Rogers (Ed.), Clinical assessment of malingering and deception (3rd ed., pp. 3-13). New York, NY: Guilford Press.

Rogers, R. (2008b). Detection strategies for malingering and defensiveness. In R. Rogers (Ed.), Clinical assessment of malingering and deception (3rd ed., pp. 14-35). New York, NY: Guilford Press.

Rogers, R., Bagby, R. M., \& Dickens, S. E. (1992). The Structured Interview of Reported Symptoms (SIRS). Odessa, FL: Psychological Assessment Resources.

Rogers, R., Bagby, R. M., \& Vincent, A. (1994). Factitious disorders with predominantly psychological signs and symptoms: a conundrum for forensic experts. Journal of Psychiatry and Law, 22, 99-106.

Rogers, R., \& Cruise, C. R. (1998). Assessment of malingering with simulation designs: Threats to external validity. Law and Human Behavior, 22, 273-285.

Rogers, R., Hinds, J. D., \& Sewell, K. W. (1996). Feigning psychopathology among adolescent offenders: Validation of the SIRS, MMPI-A, and SIMS. Journal of Personality Assessment, 67, 244-257. 
*Rogers, R., Jackson, R. L., \& Kaminski, P. L. (2005). Factitious psychological disorders: The overlooked response style in forensic evaluations. Journal of Forensic Psychology Practice, 5, 21-41.

${ }^{*}$ Rogers, R., Robinson, E. V., \& Gillard, N. D. (2014). The SIMS screen for feigned mental disorders: The development of detection-based scales. Behavioral Sciences and the Law, 32, 455-466.

Rogers, R., \& Shuman, D. W. (2005). Fundamentals of forensic practice: Mental health and criminal law. New York, NY: Springer.

Rogers, R., Sewell, K. W., \& Goldstein, A. (1994). Explanatory models of malingering: A prototypical analysis. Law and Human Behavior, 18, 543-552.

Rosen, G. M., \& Phillips, W. R. (2004). A cautionary lesson from simulated patients. Journal of the American Academy of Psychiatry and the Law, 32, 132-133.

Rosenfeld, B., Sands, S. A., \& Van Gorp, W. G. (2000). Have we forgotten the base rate problem? Methodological issues in the detection of distortion. Archives of Clinical Neuropsychology, 15, 349-359.

Rosenhan, D. L. (1973). On being sane in insane places. Science, 179, 250-258.

Ross, L. (1977). The intuitive psychologist and his shortcomings: Distortions in the attribution process. In L. Berkowitz (Ed.), Advances in experimental social psychology (Vol. 10, pp. 173-220). New York, NY: Academic Press.

Ruiz, M. A., Drake, E. B., Glass, A., Marcotte, D., \& van Gorp, W. G. (2002). Trying to beat the system: Misuse of the Internet to assist in avoiding the detection of psychological symptom dissimilation. Professional Psychology: Research and Practice, 33, 294-299.

Ruocco, A. C., Swirsky-Sacchetti, T., Chute, D. L., Mandel, S., Platek, S. M., \& Zillmer, E. A. (2008). Distinguishing between neuropsychological malingering and exaggerated psychiatric symptoms in a neuropsychological setting. The Clinical Neuropsychologist, 22, 547-564.

Santamaría Fernández, P. (2013, June). The Structured Inventory of Malingered Symptomatology (SIMS) in civil forensic evaluations. Paper presented at the Third European Symposium on Symptom Validity Assessment, Würzburg, Germany.

Schaefer, J., Giangrande, E., Weinberger, D. R., \& Dickinson, D. (2013). The global cognitive impairment in schizophrenia: Consistent over decades and around the world. Schizophrenia Research, 150, 42-50.

Schagen, S., Schmand, B., de Sterke, S., \& Lindeboom, J. (1997). Amsterdam Short-Term Memory Test: A new procedure for the detection of feigned memory deficits. Journal of Clinical and Experimental Neuropsychology, 19, 43-51.

Schmand, B., \& Lindeboom, J. (2005). Amsterdam Short-Term Memory test manual. Leiden, the Netherlands: PITS.

Schretlen, D. (1986). Malingering: Use of a psychological test battery to detect two kinds of simulation. Ann Arbor, MI: University Microfilms International.

Schretlen, D., \& Arkowitz, H. (1990). A psychological test battery to detect prison inmates who fake insanity or mental retardation. Behavioral Sciences and the Law, 8, 75-84. 
Schretlen, D., Neal, J., \& Lesikar, S. (2000). Screening for malingered mental illness in a court clinic. American Journal of Forensic Psychology, 18, 5-16.

Schretlen, D., Wilkins, S. S., van Gorp, W. G., \& Bobholz, J. H. (1992). Cross-validation of a psychological test battery to detect faked insanity. Psychological Assessment, 4, 77-83.

Schroeder, R. W., Buddin, W. H. Jr., Hargrave, D. D., VonDran, E. J., Campbell, E. B., Brockman, C. J., ... Baade, L. E. (2013). Efficacy of Test of Memory Malingering Trial 1, Trial 2, the Retention Trial, and the Albany Consistency Index in a criterion group forensic neuropsychological sample. Archives of Clinical Neuropsychology, 28, 21-29.

Schroeder, R. W., \& Marshall, P. S. (2011). Evaluation of the appropriateness of multiple symptom validity indices in psychotic and non-psychotic psychiatric populations. The Clinical Neuropsychologist, 25, 437-453.

Shad, M. U., Tamminga, C. A., Cullum, M., Haas, G. L., \& Keshavan, M. S. (2006). Insight and frontal cortical function in schizophrenia: A review. Schizophrenia Research, 86, $54-70$.

Siemens, F. (1883). Zur Frage der Simulation der Seelenstörungen [On the simulation of mental disorders]. Archiv für Psychiatrie und Nervenkrankheiten [Archive of Psychiatry and Neurological Disorders], 14, 40-86.

Sijtsma, K. (2009). On the use, the misuse, and the very limited usefulness of Cronbach's alpha. Psychometrika, 74, 107-120.

Simel, D. L., Samsa, G. P., \& Matchar, D. B. (1991). Likelihood ratios with confidence: Sample size estimation for diagnostic test studies. Journal of Clinical Epidemiology, 44, 763-770.

Slick, D. J., Hopp, G., Strauss, E., \& Thompson, G. B. (1997). Victoria Symptom Validity Test professional manual. Odessa, FL: Psychological Assessment Resources.

Slick, D. J., Sherman, E. M. S., \& Iverson, I. (1999). Diagnostic criteria for malingered neurocognitive dysfunction: Proposed standards for clinical practice and research. The Clinical Neuropsychologist, 13, 545-561.

Smith, G. P. (2008). Brief screening measures for the detection of feigned psychopathology. In R. Rogers (Ed.), Clinical assessment of malingering and deception (3rd ed., pp. 323-339). New York, NY: Guilford Press.

*Smith, G. P., \& Burger, G. K. (1997). Detection of malingering: Validation of the Structured Inventory of Malingered Symptomatology (SIMS). Journal of the American Academy on Psychiatry and Law, 25, 180-183.

Solomon, R. E., Boone, K. B., Miora, D., Skidmore. S., Cottingham, M., Victor, T., ... Zeller, M. (2010). Use of the WAIS-III Picture Completion Subtest as an embedded measure of response bias. The Clinical Neuropsychologist, 24, 1243-1256.

Stevens, A., Friedel, E., Mehren, G., \& Merten, T. (2008). Malingering and uncooperativeness in psychiatric and psychological assessment: Prevalence and effects in a German sample of claimants. Psychiatry Research, 157, 191-200.

Stevens, A., Schneider, K., Liske, B., Hermle, L., Huber, H., \& Hetzel, G. (2014). Is subnormal cognitive performance in schizophrenia due to lack of effort or to cognitive impairment? German Journal of Psychiatry, 17, 1-9. 
Stöber, J. (2001). The Social Desirability Scale-17 (SDS-17): Convergent validity, discriminant validity, and relationship with age. European Journal of Psychological Assessment, 17, 222-232.

Suhr, J. A., \& Gunstad, J. (2000). The effects of coaching on the sensitivity and specificity of malingering measures. Archives of Clinical Neuropsychology, 15, 415-424.

Sumanti, M., Boone, K. B., Savodnik, I., \& Gorsuch, R. (2006). Noncredible psychiatric and cognitive symptoms in a workers' compensation "stress" claim sample. The Clinical Neuropsychologist, 20, 754-765.

Swets, J. A. (1973). The relative operating characteristic in psychology: A technique for isolating effects of response bias finds wide use in the study of perception and cognition. Science, 182, 990-1000.

Swets, J. A. (1988). Measuring the accuracy of diagnostic systems. Science, 240, 1285-1293.

Tavakol, M., \& Dennick, R. (2011). Making sense of Cronbach's alpha. International Journal of Medical Education, 2, 53-55.

Thompson, W. C, \& Schumann, E. L. (1987) Interpretation of statistical evidence in criminal trials: The prosecutor's fallacy and the defense attorney's fallacy. Law and Human Behavior, 11, 167-187.

Tombaugh, T. N. (1996). Test of Memory Malingering (TOMM). Toronto: Multi-Health Systems.

Tulving, E., \& Osler, S. (1968). Effectiveness of retrieval cues in memory for words. Journal of Experimental Psychology, 77, 593-601.

*van Beilen, M., Griffioen, B. T., Gross, A., \& Leenders, K. L. (2009). Psychological assessment of malingering in psychogenic neurological disorders and non-psychogenic neurological disorders: Relationship to psychopathology levels. European Journal of Neurology, 16, 1118-1123.

van Dyke, S. A., Millis, S. R., Axelrod, B. N., \& Hanks, R. A. (2013). Assessing effort: Differentiating performance and symptom validity. The Clinical Neuropsychologist, 27, 1234-1246.

van Egmond, J., \& Kummeling, I. (2002). A blind spot for secondary gain affecting treatment outcome. European Psychiatry, 17, 46-54.

van Egmond, J., Kummeling, I., \& van Balkom, T. (2005). Secondary gain as hidden motive for getting psychiatric treatment. European Psychiatry, 20, 416-421.

van Thiel, S., \& Leeuw, F. L. (2002). The performance paradox in the public sector. Public Performance \& Management Review, 25, 267-281.

Victor, T. L., \& Boone, K. B. (2007). Identification of feigned mental retardation. In K. B. Boone (Ed.), Assessment of feigned cognitive impairment (pp. 310-345). New York, NY: Guilford Press.

Victor, T. L., Boone, K. B., Serpa, J. G., Buehler, J., \& Ziegler, E. A. (2009). Interpreting the meaning of multiple symptom validity test failure. The Clinical Neuropsychologist, 23, 297-313. 
*Vitacco, M. J., Rogers, R., Gabel, J., \& Munizza, J. (2007). An evaluation of malingering screens with competency to stand trial patients: A known-groups comparison. Law and Human Behavior, 31, 249-260.

*Vossler-Thies, E., Stevens, A., Engel, R. R., \& Licha, C. (2013). Erfassung negativer Antwortverzerrungen mit der deutschen Fassung des "Personality Assessment Inventory", dem "Verhaltens- und Erlebensinventar" [Capturing negative response distortion with the German version of the Personality Assessment Inventory]. Diagnostica, 59, 73-85.

Walczyk, J. J., Harris, L. L., Duck, T. K., \& Mulay, D. (2014). A social-cognitive framework for understanding serious lies: Activation-decision-construction-action theory. New Ideas in Psychology, 34, 22-36.

Walters, G. D., Berry, D. T. R., Rogers, R., Payne, J. W., \& Granacher, R. P., Jr. (2009). Feigned neurocognitive deficit: Taxon or dimension? Journal of Clinical and Experimental Neuropsychology, 31, 584-593.

Walters, G. D., Brinkley, C. A., Magaletta, P. R., \& Diamond, P. M. (2008). Taxometric analysis of the Levenson Self-Report Psychopathy Scale. Journal of Personality Assessment, 90, 491-498.

Walters, G. D., Rogers, R., Berry, D. T. R., Miller, H. A., Duncan, S. A., McCusker, P. J., ... Granacher, R. P., Jr. (2008). Malingering as a categorical or dimensional construct: The latent structure of feigned psychopathology as measured by the SIRS and MMPI-2. Psychological Assessment, 20, 238-247.

Watts, A. L., Lilienfeld, S. O., Edens, J. F., Douglas, K. S., Skeem, J. L., Verschuere, B., \& LoPilato, A. C. (2016) Does response distortion statistically affect the relations between self-report psychopathy measures and external criteria? Psychological Assessment, 28, 294-306.

Wechsler, D. (2008). Wechsler Adult Intelligence Scale (4th ed.). San Antonio, TX: Pearson.

Wedding, D., \& Faust, D. (1989). Clinical judgment and decision making in neuropsychology. Archives of Clinical Neuropsychology, 4, 233-265.

Wessely, S. (2003). Malingering: historical perspectives. In P. W. Halligan, C. Bass, \& D. A. Oakley (Eds.), Malingering and illness deception (pp. 31-41). Oxford: Oxford University Press.

Whitaker, S. (2013). Intellectual disability: An inability to cope with an intellectually demanding world. Palgrave Macmillan, London.

Widder, B. (2011). Beurteilung der Beschwerdenvalidität [Evaluation of symptom validity] In B. Widder \& P. W. Gaidzik (Eds.), Begutachtung in der Neurologie (2nd ed., pp. 6492). Stuttgart, Germany: Thieme.

Widows, M. R., \& Smith, G. P. (2005). Structured Inventory of Malingered Symptomatology professional manual. Odessa, FL: Psychological Assessment Resources.

*Wisdom, N. M., Callahan, J. L., \& Shaw, T. G. (2010). Diagnostic utility of the Structured Inventory of Malingered Symptomatology to detect malingering in a forensic sample. Archives of Clinical Neuropsychology, 25, 118-125. 
Wistedt, B., Rasmussen, A., Pederson, L., Malm, U., Traskman-Bendz, L., Wakelin, J., \& Bech, P. (1990). The development of an observer-scale for measuring social dysfunction and aggression. Pharmacopsychiatry, 23, 249-252.

World Health Organization. (1990). International statistical classification of diseases and related health problems (10th ed.). Geneva: Author.

Yates, G. P., \& Feldman, M. D. (2016). Factitious disorder: a systematic review of 455 cases in the professional literature. General Hospital Psychiatry, 41, 20-28.

Young, G. (2015). Malingering in forensic disability-related assessments: Prevalence $15 \pm 15 \%$. Psychological Injury and Law, 8, 188-199.

Young, S., Jacobson, R., Einzig, S., Gray, K., \& Gudjonsson, G. H. (2016). Can we recognise malingerers? The association between malingering, personality traits and clinical impression among complainants in civil compensation cases. Personality and Individual Differences, 98, 235-238.

Zakzanis, K. K. (2001). Statistics to tell the truth, the whole truth, and nothing but the truth: Formulae, illustrative numerical examples, and heuristic interpretation of effect size analyses for neuropsychological researchers. Archives of Clinical Neuropsychology, 16, 653-667.

*Zimmermann, P., Kowalski, J. T., Alliger-Horn, C., Danker-Hopfe, H., Engers, A., Meermann, R., \& Hellweg, R. (2013). Detection of malingering in the assessment of occupational disability in the military. German Journal of Psychiatry, 16, 54-60. 


\section{Summary}

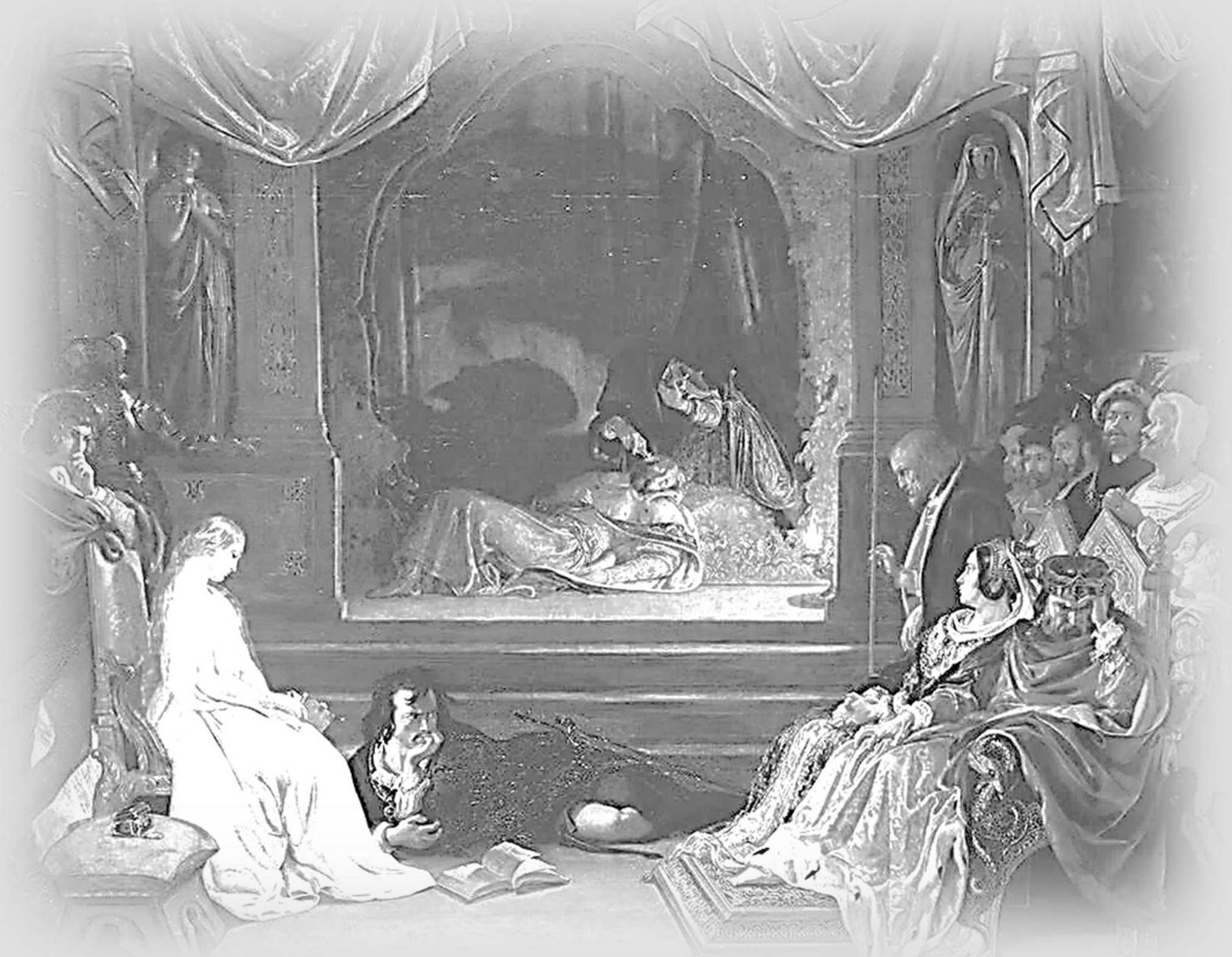


The research presented in this thesis aims to advance the evaluation of assessment validity. This goal was pursued through empirical investigations of indicators (Chapters 2-3) and tests (Chapters 4-6) that are considered to be measures of assessment validity. By way of introduction, Chapter 1 touches upon the historical context of validity testing and brings up several common myths and misconceptions. Chapter 7 discusses the main findings of the studies presented throughout this thesis and offers considerations of methodological issues, clinical implications, and directions for future research. To enhance the utility of this thesis and advance the practice of validity assessment, Chapter 7 also includes a primer on a quantitative method for interpreting and combining validity test data; the likelihood ratio.

\section{Chapter 1}

Chapter 1 introduces the validity triumvirate that determines the accuracy of diagnoses; test validity, assessment validity, and judgment validity. Test validity refers to the alignment between what a test measures and what it is designed and employed to measure. Assessment validity concerns the accuracy and openness with which patients present their symptoms. Judgment validity denotes the extent to which diagnostic conclusions follow logically from clinical data. Chapter 1 also conveys that diagnostic decision-making can be accomplished through two methodological approaches that are fundamentally different; the clinical method and the actuarial method: A decision-making process is clinical if it depends on human cognition; it is actuarial if it solely rests upon empirically derived decision rules.

Before divulging the present state of play in validity assessment, Chapter 1 serves up historical highlights relevant to some of the myths and misconceptions that vex psychological and neuropsychological assessments still. Foremost amongst these myths and misconceptions are the ungrounded belief in the potency of clinical judgment in validity assessment; the incorrect notion that feigned symptom presentations are rare; the false idea that feigned symptomatology must be underlain by authentic symptomatology; and the faulty perception that antisocial features are associated with feigned symptomatology.

Finally, Chapter 1 describes how the modern-day approach to validity assessment originated from attempts to use two-alternative forced-choice tests to identify functional neurological deficits. Nowadays, the evaluation of assessment validity is realized by means of "performance validity test" (PVTs) and "symptom validity tests" (SVTs): PVTs resemble cognitive tests and are used to appraise the adequacy of effort that examinees give during cognitive testing. SVTs are similar to symptom inventories or interviews, and serve to estimate the accuracy with which patients present their symptoms. An important constraint of validity test is that they cannot identify why assessment validity is insufficient; they can only indicate whether it is insufficient.

\section{Chapter 2}

Chapter 2 covers two studies, both of which were designed to examine the idea, as articulated in the Diagnostic and Statistical Manual of Mental Disorders (5th ed.), that antisocial 
features and behavior are predictive of feigned symptom presentations. In the first study, we administered an SVT and a measure of symptom minimization to 57 forensic psychiatric inpatients, and rated the behavior of participants by coding a behavioral observation scale based on the daily logs in patient records. In the second study, we presented 45 inmates of a youth prison with an SVT, and with self-report scales for psychopathy and criminal blame attribution. We inferred antisocial behavior of prisoners from the length of their sentence, from whether or not they were officially considered to be intensive offenders, and from the number of disciplinary actions they incurred while incarcerated.

The key findings of these studies are: 1) the association between symptom overreporting and antisocial features is a) present in self-report measures, but not in behavioral measures, and b) stronger in the punitive setting than in the therapeutic setting; and 2) participants who overreport symptoms a) are prone to attribute blame for their offense to mental disorders, and b) tend to report heightened levels of antisocial traits, but the reverse is not true. In the aggregate, the data do not endorse the use of antisocial features as indicators of assessment validity, on the contrary; they suggest that such practice leads to large proportions of misclassifications.

\section{Chapter 3}

With the study described in Chapter 3, we turned our attention from general antisocial behavior to specific features that may underlie the possible link between antisocial traits and noncredible symptom presentations; namely deceitfulness, lack of remorse, and blame externalization. We found 57 forensic psychiatric inpatients willing to complete an SVT, a self-report instrument measuring lack of remorse and criminal blame externalization, and a semi-structured interview about their most recent offense. To quantify patients' deceitfulness, we checked the information collected via the semi-structured interview against the official records of patients' offenses, and we gathered therapists' and treatment supervisors' judgment on the extent to which patients denied their delinquency.

The results echo those from the two earlier studies: The main finding was that patients who were inaccurate when reporting their delinquency, or who showed little regret for their offenses, or who tended to blame their offenses on external factors, had similar levels of symptom exaggeration as those without these tendencies. As in the first study involving forensic psychiatric inpatients, antisocial personality disorder had no predictive value for noncredible symptom presentations. These results square with previous research into the relationship between antisocial traits and feigned symptomatology. The most important point that can be taken from our studies and the ones that preceded them is that the relationship between antisocial features and noncredible symptom presentations is not sufficiently strong for antisocial features to be useful markers of assessment validity. The presence or absence of antisocial traits should therefore have no bearing on validity assessment. 


\section{Chapter 4}

The research detailed in Chapter 4 encompasses a meta-analytic review of all published studies that used the Structured Inventory of Malingered Symptomatology (SIMS) to detect feigned psychopathology. The SIMS is an SVT that presents respondents with 75 pseudopathological symptoms that are to be endorsed or rejected via a true-false response format.

The accumulated data show that the diagnostic potential of the SIMS ranges from $59 \%$ to $91 \%$ correct classifications, and that coaching (i.e., education to pass validity tests while feigning) only has a moderately suppressing effect on SIMS scores. The greater part of the published SIMS data pertain to the traditional cut scores of the SIMS $(>14$ and $>16)$ and confirm that these are heavily geared toward screening purposes, providing high sensitivity (.91-.1.00) yet meager specificity (.37-.70; which corresponds to a false-positive rate of .30.63). The false-positive risk is exacerbated in patients who suffer from mentally disabling pathology, such as schizophrenia, intellectual disability, and psychogenic non-epileptic seizures.

When reviewing the SIMS qualitatively, two significant shortcomings become apparent. First, the SIMS lacks any means to distinguish symptom overreporting from irrelevant responding (i.e., indiscriminate affirmation or rejection of items). Second, the SIMS does not contain items that are intended to cover plausible symptoms, yet it does contain items that actually do refer to plausible symptoms. This may well explain the sensitivity of the SIMS to authentic symptomatology, which is discernable in the aggregated data. These two flaws of the SIMS could be amended by incorporating items that tap disengaged responding, and by altering the scoring format to account for items that refer to authentic symptomatology.

Our meta-analysis also yielded two interesting subsidiary findings: Experimental feigners produce SIMS scores that are similar to the scores of real-world feigners; and healthy individuals produce scores that are significantly lower than those of patients. The former finding alleviates concerns about the external validity of experimentally impelled feigning, whereas the latter underscores that healthy individuals cannot be substituted for genuine patients to form control groups.

\section{Chapter 5}

Chapter 5 chronicles our research into a PVT; the Malingering Scale Vocabulary and Abstraction test (MSVA). The MSVA is an atypical PVT in that it does not mimic a memory test, as most PVTs do; rather, it is analogous to vocabulary and abstract reasoning tasks of IQ tests. We translated the MSVA and examined its diagnostic utility by administering it to primary school children $(n=41)$, forensic inpatients with intellectual disability $(n=25)$, forensic inpatients with psychiatric symptoms $(n=57)$, and undergraduate students $(n=30, n$ $=79$, and $n=90$, respectively). In most samples, we employed a simulation design; we assigned participants randomly to a condition in which they were asked to respond honestly or to a condition that prompted them to feign cognitive impairment. In the sample of 
forensic inpatients, we took a quasi-known-groups approach, with the SIMS as criterion to segregate participants who responded noncredibly. In the undergraduate samples, we employed the SIMS and two well-validated PVTs (the Amsterdam Short-Term Memory Test; ASTM, and the Test of Memory Malingering; TOMM) as benchmarks to compare the MSVA with.

With cutoffs chosen so as to keep false-positive rates below $10 \%$, detection rates of experimentally feigned cognitive impairment were high in children $(90 \%)$ and inpatients with intellectual disability (100\%), but low in adults without intellectual disability (46\%). The rates of significantly below-chance performance were low (4\%), except in children (47\%) and intellectually disabled inpatients (50\%). The reliability of the MSVA was excellent, and its diagnostic efficacy was not significantly affected by forewarning of validity testing or by provision of information about validity testing. The MSVA was about as effective as the TOMM in differentiating between honest and feigning respondents, and slightly less effective than the ASTM. Nevertheless, the MSVA still identified several noncredible respondents that the ASTM and TOMM failed to pick up, indicating that the MSVA has added value, and is worth investigating further. Taken together, our studies are an initiatory step towards the validation of the MSVA as a performance validity test that taps noncredible deficits in vocabulary and abstract reasoning rather than memory.

\section{Chapter 6}

Chapter 6 revolves around an SVT of our own making; the Symptom and Disposition Interview (SDI). By developing the SDI, we explored an unresolved and rarely addressed issue in validity assessment; the differentiation between factitious and malingered symptom presentations. Over and above measuring noncredible symptomatology, the SDI aims to quantify internal incentives that are associated with factitious disorder (i.e., the need for sympathy, attention, and care that comes with the "sick role"). This is effectuated through items that inquire into the willingness to assume the patient role. For example, various items gauge the readiness to undergo additional or unpleasant treatment or diagnostic procedures, to participate in scientific studies or patient support groups, or to vent feelings of indignation for being disregarded, misunderstood, not taken seriously, or otherwise treated incorrectly.

We investigated the qualities of the SDI and compared them with those of a traditional SVT (the SIMS) in two simulation studies, each with factitious and malingering conditions ( $n=24-30$ per condition) and a clinical control group ( $n=34, n=40)$. The first study yielded more favorable results than the second, yet, overall the results were positive: The SDI was as effective in detecting feigned symptom presentations as the SIMS, and superior in differentiating factitious from malingered symptom presentations. Nonetheless, it is evident that additional research, particularly in clinical samples, is indispensable to appraise the utility of the SDI and the detection strategies upon which it is predicated. Our discourse on the development of the SDI and the associated studies can be viewed as 
groundwork that may serve as catalyst for the progress of psychometric assessment of factitious disorder and malingering.

\section{Chapter 7}

In addition to discussing the main findings and conclusions that are presented in the foregoing chapters, Chapter 7 explicates the likelihood ratio (LR) as an actuarial technique for interpreting and combining validity test data. The LR can be conceived as the degree to which a particular validity test score fits better with the hypothesis that a symptom presentation is noncredible than with the hypothesis that a symptom presentation is credible, or put differently; the degree to which the hypothesis of noncredible symptomatology is more probable after a particular validity test score is obtained compared with how probable it was before the score was obtained.

Every validity test result is associated with a certain sensitivity and specificity value. The LR is calculated by dividing sensitivity by 1 minus specificity (LR = sensitivity/[1 specificity]). LRs range from 1 to infinity; the higher the LR above 1, the greater the increase in the pre-test probability of noncredible symptomatology. The pre-test probability is equal to the base rate noncredible symptomatology, or, if other validity tests have already been administered, to the post-test probability of the previous tests. The post-test probability of noncredible symptomatology can be arrived at by first converting the pre-test probability to odds (i.e., pre-test probability/[1 - pre-test probability $]=$ pre-test odds), then multiplying the result with the LR, and then converting the outcome back to probability (i.e., post-test odds $/[1+$ post-test odds $]=$ post-test probability).

LRs can be "chained" by using the post-test odds from the first test as pre-test odds for the second test, and so forth. When chaining LRs, two caveats must be kept in mind. These are that post-test probabilities of noncredible symptom presentations are overestimated if validity test results are dependent (i.e., correlated) in clinical populations, and if test results are chained without at least two results being associated with high specificity (e.g., specificity $\geq .90$ ).

In sum, the chaining of LRs is a quantitative method of decision-making that, when employed with validated validity tests, caps off the actuarial approach to validity assessment. The method involves simple calculations and its conclusions follow logically from empirically established knowledge. Thus, it encourages practitioners to work transparently and scientifically, and, in the process, increase diagnostic probability and decrease diagnostic error. 


\section{Samenvatting}

(Summary in Dutch)

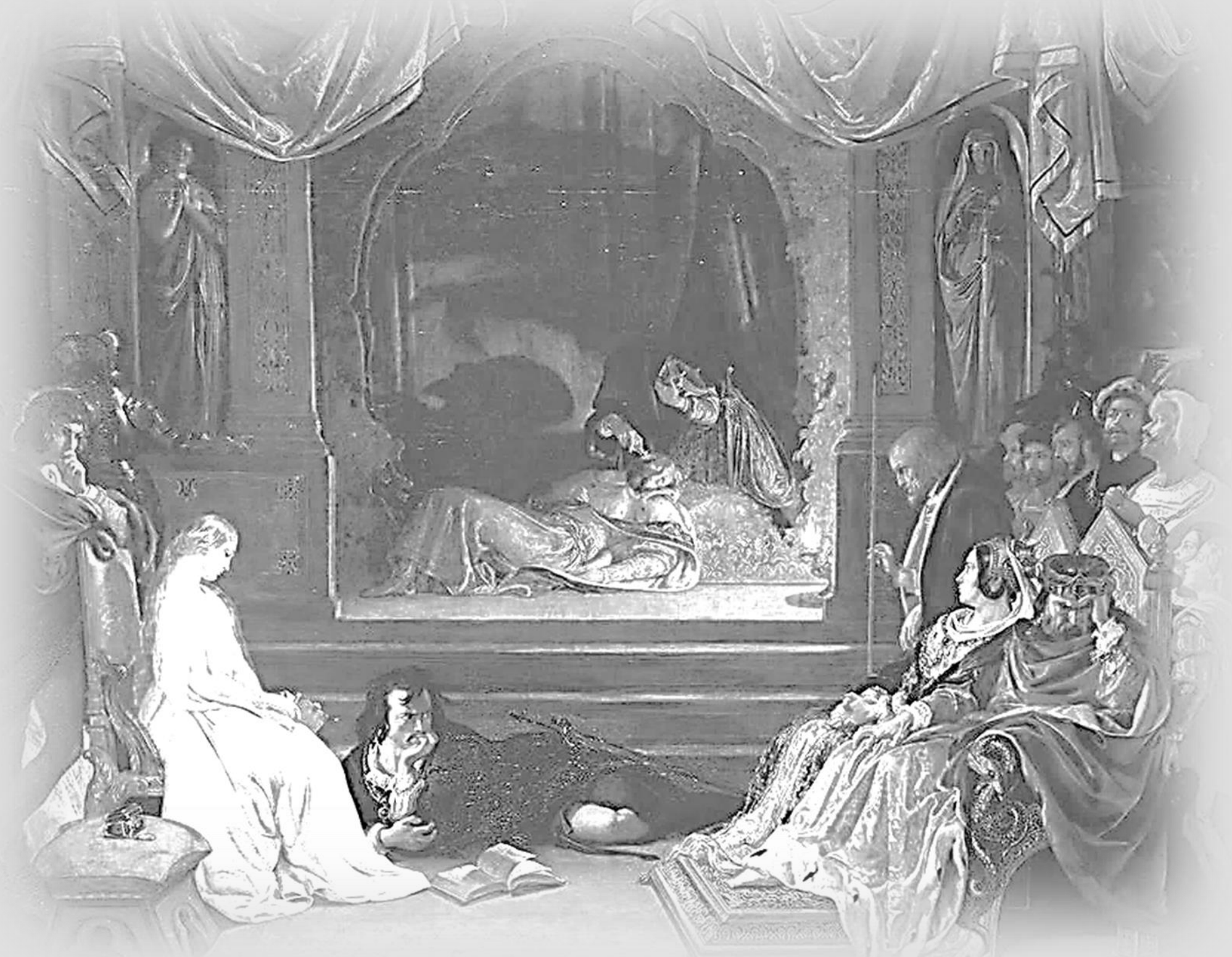


Het onderzoek dat in deze dissertatie gepresenteerd wordt, is uitgevoerd om artsen en psychologen beter in staat te stellen om een inschatting te maken van de accuraatheid waarmee patiënten symptomen presenteren. De mate waarin mensen hun symptomatologie accuraat presenteren aan clinici wordt ook wel "symptoomvaliditeit" genoemd. Hoofdstukken 2 en 3 gaan over antisociale gedragskenmerken als voorspellers van gebrekkige symptoomvaliditeit. Hoofdstukken 4, 5 en 6 handelen over psychometrische tests om symptoomvaliditeit te meten (zogenaamde "validiteitstests"'). Bij wijze van inleiding wordt in hoofdstuk 1 kort stilgestaan bij de geschiedenis van validiteitstests en bij enkele veel voorkomende mythes en misverstanden over symptoomvaliditeit. Hoofdstuk 7 omvat een discussie van de belangrijkste bevindingen van de studies uit de voorgaande hoofdstukken en beschrijft methodologische overwegingen, klinische implicaties en aanbevelingen voor toekomstig onderzoek. Om de praktische toepasbaarheid van dit proefschrift te vergroten, wordt in hoofdstuk 7 ook uitleg gegeven over de likelihood ratio ("aannemelijkheidsquotiënt") als kwantitatieve methode om validiteitstest-scores te combineren en te interpreteren.

\section{Hoofdstuk 1}

Hoofdstuk 1 introduceert de drie typen validiteit die tezamen de accuratesse van diagnoses bepalen; testvaliditeit, symptoomvaliditeit en oordeelsvaliditeit. Testvaliditeit is de mate waarin een test datgene meet wat men ermee beoogt te meten. Symptoomvaliditeit is de mate waarin patiënten hun symptomatologie accuraat (d.w.z., open en consciëntieus) presenteren tijdens klinisch onderzoek. Oordeelsvaliditeit is de mate waarin diagnostische conclusies gestoeld zijn op logica en empirische gegevens. Hoofdstuk 1 beschrijft tevens dat besluitvorming in de diagnostiek via twee diametrale methodes plaats kan vinden; de klinische methode en de actuariële methode. Bij de klinische methode worden besluiten genomen of conclusies getrokken op basis van menselijke cognitie (bijv., "klinische intuïtie"); bij de actuariële methode wordt uitsluitend gebruik gemaakt van empirische beslisregels.

De voornaamste mythes en misverstanden die in hoofdstuk 1 de revue passeren zijn het onterechte geloof in de effectiviteit van de klinische methode om symptoomvaliditeit te evalueren; het onjuiste idee dat geveinsde symptomatologie een zeldzaam fenomeen is; de foute aanname dat geveinsde symptomatologie een indicatie is van authentieke symptomatologie; en het verkeerde idee dat antisociale gedragskenmerken samenhangen met het veinzen van symptomen.

Verder beschrijft hoofdstuk 1 dat validiteitstests voortkwamen uit pogingen om functionele neurologische symptomen te detecteren met two-alternative forced-choice tests. Tegenwoordig worden twee typen validiteitstests onderscheiden; "prestatievaliditeitstests" (PVTs) en "symptoomvaliditeitstest" (SVTs). PVTs zijn quasi-cognitieve tests en worden gebruikt om de inzet van respondenten tijdens cognitieve taken te bepalen (d.w.z., PVTs meten cognitief onderpresteren). SVTs zijn vragenlijsten of gestructureerde interviews waarin pseudo-symptomatologie is opgenomen om daarmee de accuraatheid van zelf- 
rapportage over symptomatologie in te schatten (d.w.z., SVTs meten het overrapporteren van symptomen). De prominentste beperking van validiteitstests is dat ze niet duidelijk kunnen maken waarom er bij een psychologische evaluatie mogelijk iets schort aan symptoomvaliditeit; ze kunnen slechts aangeven of er iets schort aan symptoomvaliditeit.

\section{Hoofdstuk 2}

Hoofdstuk 2 handelt over twee studies die opgezet zijn om een idee te toetsen dat duidelijk in de Diagnostic and Statistical Manual of Mental Disorders ("diagnostisch en statistisch handboek voor psychische stoornissen" 5de ed.) naar voren komt; namelijk dat antisociale gedragskenmerken indicatief zijn voor gebrekkige symptoomvaliditeit (d.w.z., dat antisociale gedragskenmerken samenhangen met het veinzen van symptomen). In de eerste studie namen we bij 57 forensisch-psychiatrische patiënten een SVT en een instrument voor symptoom-minimalisatie (het onderrapporteren van symptomen) af. Daarnaast kwantificeerden we antisociaal en disruptief gedrag van deelnemers door middel van een gedragsobservatie-instrument dat we scoorden op basis van logboeken die door behandelend en verplegend personeel dagelijks werden bijgehouden. In de tweede studie vulden 45 gedetineerde jongeren een SVT en zelf-rapportage instrumenten voor psychopathie en schuld-attributie in. We bepaalden antisociale gedragskenmerken aan de hand van de zwaarte van opgelegde straffen, het al dan niet aangemerkt zijn als "veelpleger", en het aantal opgelegde disciplinaire maatregelen gedurende detentie.

De belangrijkste bevindingen van deze studies zijn: 1) de samenhang tussen het overrapporteren van symptomen en antisociale gedragskenmerken is a) aanwezig in zelfrapportage instrumenten voor antisociale gedragskenmerken, maar niet in gedragsobservatie-instrumenten, en b) sterker in de punitieve setting dan in de therapeutische setting; en 2) deelnemers die symptomen overrapporteren zijn geneigd om a) schuld voor hun delictgedrag te attribueren aan psychische problemen, en b) meer antisociale gedragskenmerken te rapporteren, maar het tegenovergestelde geldt niet (deelnemers die bovenmatig antisociale gedragskenmerken rapporteren zijn niet bovenmatig geneigd om symptomen over te rapporteren). Bij elkaar genomen leveren de data geen bewijs voor het bestaan van een duidelijk verband tussen antisociale gedragskenmerken en symptoomvaliditeit; integendeel: het aannemen van zulk een verband leidt tot grote aantallen misclassificaties van symptoomvaliditeit.

\section{Hoofdstuk 3}

Met de studie die in hoofdstuk 3 beschreven wordt verschuift onze aandacht van algemeen antisociaal gedrag naar de vormen van antisociaal gedrag die het grootste raakvlak hebben met het veinzen van symptomen; namelijk leugenachtigheid, gebrek aan berouw of schuldgevoel, en schuld-externalisatie. We vonden wederom 57 forensisch-psychiatrische patiënten bereid om een SVT en een zelf-rapportage instrument over schuldgevoel en schuld-attributie in te vullen en om vragen te beantwoorden tijdens een semigestructureerd 
interview over het indexdelict. Om de leugenachtigheid van deelnemers in te schatten legden we hun antwoorden tijdens het interview over hun indexdelict naast de informatie uit de justitiële documentatie van hun indexdelict en vroegen we naar het oordeel van behandelaren over de mate waarin deelnemers hun indexdelict ontkenden of minimaliseerden.

De resultaten weerspiegelen de uitkomsten van de twee voorgaande studies: de voornaamste bevindingen zijn dat het overrapporteren van symptomen evenveel voorkomt onder patiënten die de neiging hebben om niet accuraat te zijn bij het beschrijven van hun indexdelict, of weinig berouw te tonen over hun indexdelict, of de schuld voor hun delictgedrag te externaliseren, als onder patiënten die zulke neigingen niet vertonen. Zowel in deze als in de eerste studie waaraan forensisch-psychiatrische patiënten deelnamen had de diagnose "antisociale persoonlijkheidsstoornis" geen voorspellende waarde voor het overrapporteren van symptomen. Deze resultaten stroken met de uitkomsten van eerder onderzoek naar de mogelijke samenhang tussen antisociale gedragskenmerken en symptoomvaliditeit: het belangrijkste punt dat voortvloeit uit de bevindingen van de studies op dit gebied is dat de samenhang tussen antisociale gedragskenmerken en symptoomvaliditeit dermate zwak is dat de voorspellende waarde van antisociale gedragskenmerken voor symptoomvaliditeit te verwaarlozen is. De aan- of afwezigheid van antisociale gedragskenmerken zou geen invloed moeten hebben op de evaluatie van symptoomvaliditeit.

\section{Hoofdstuk 4}

Hoofdstuk 4 is een meta-analyse van alle gepubliceerde studies die de Structured Inventory of Malingered Symptomatology (SIMS) gebruikten om het overrapporteren van symptomen te meten. De SIMS is een SVT die bestaat uit 75 stellingen die pseudo-pathologie beschrijven; respondenten dienen bij elke stelling aan te geven of die op hen van toepassing is.

De geaggregeerde data laten zien dat het diagnostische potentieel van de SIMS tussen de 59\% en 91\% correcte classificaties ligt, en dat coaching (d.w.z., aanwijzingen hoe men kan slagen voor validiteitstests terwijl men symptomen veinst) slechts een beperkt drukkend effect heeft op SIMS scores. Het overgrote deel van de gepubliceerde SIMS data heeft betrekking op de traditionele afkapscores van de SIMS (>14 en $>16$ ) en bevestigt dat deze toegespitst zijn op screening; ze genieten hoge sensitiviteit (.91-.1.00) maar lage specificiteit (.37-.70; wat overeenkomt met een fout-positief kans van .30-.63). Het risico op foutpositieve classificatie is zelfs nog hoger bij patiënten met beperkte of verstoorde mentale capaciteiten, zoals het geval is bij schizofrenie, verstandelijke beperking, en psychogene nietepileptische aanvallen.

Een kwalitatieve beschouwing van de SIMS brengt twee majeure tekortkomingen aan het licht. Ten eerste ontbreekt het de SIMS aan mogelijkheden om onderscheid te maken tussen het overrapporteren van symptomen en het willekeurig reageren op items. Ten tweede bevat de SIMS geen items die bedoeld zijn om authentieke symptomatologie te meten, 
maar wel items die in zekere mate aan authentieke symptomatologie refereren. Dit verklaart mogelijk waarom de SIMS, zoals blijkt uit de geaggregeerde data, gevoelig is voor authentieke symptomatologie. Deze twee gebreken van de SIMS zouden geredresseerd kunnen worden door items aan de SIMS toe te voegen die willekeurige antwoordtendensen detecteren en door de score formule aan te passen zodat de items die feitelijk aan authentieke symptomen refereren niet meer meegenomen worden in de bepaling van symptoomvaliditeit.

Onze meta-analyse leverde nog twee interessante bevindingen op: studiedeelnemers die gevraagd worden om symptomen te simuleren produceren SIMS scores die vergelijkbaar zijn met die van échte simulanten, en gezonde deelnemers die gevraagd worden om symptomen accuraat te rapporteren produceren SIMS scores die lager zijn dan die van patiënten. De eerste bevinding vermindert zorgen over de externe validiteit van experimentele simulanten, en de tweede bevinding onderstreept dat gezonde mensen niet thuis horen in klinische controle groepen van experimenteel simulatie-onderzoek.

\section{Hoofdstuk 5}

Het onderwerp van hoofdstuk 5 is een PVT; de Malingering Scale Vocabulary and Abstraction test (MSVA). De MSVA is een atypische PVT omdat het niet, zoals de meeste PVTs, lijkt op een geheugentest, maar aandoet als vocabulaire- en abstract-redeneren-taken van IQ tests. We vertaalden de MSVA en onderzochten de diagnostische slagkracht ervan in verschillende experimentele studies met kinderen $(n=41)$, forensische patiënten met een verstandelijke beperking $(n=25)$, forensisch-psychiatrische patiënten $(n=57)$, en studenten (respectievelijk $n=30, n=79$ en $n=90$ ). In het merendeel van de groepen hanteerden we een experimentele opzet; we verdeelden deelnemers willekeurig over een conditie waarin gevraagd werd om optimaal te presteren en een conditie waarin getracht werd om deelnemers cognitieve beperkingen te laten veinzen. Bij de forensisch-psychiatrische patiënten gebruikten we de SIMS om de groep te splitsen in deelnemers die mogelijk cognitieve beperkingen veinsden en deelnemers die dat niet deden. In de groepen studenten zetten we naast de SIMS tevens twee gevalideerde maten voor cognitief onderpresteren in (de Amsterdamse Korte Termijn Geheugen test; AKTG, en de Test of Memory Malingering; TOMM) om de MSVA mee te vergelijken.

Met afkappunten waarbij het risico op fout-positieve classificatie minder dan $10 \%$ is, was de detectie ratio van experimenteel gesimuleerde cognitieve beperkingen hoog bij kinderen (90\%) en forensische patiënten met een verstandelijke beperking (100\%), maar laag bij volwassenen zonder verstandelijke beperking (46\%). Het aantal gevallen van prestatie onder kansniveau was klein (4\%), behalve bij kinderen $(47 \%)$ en forensische patiënten met een verstandelijke beperking (50\%). De betrouwbaarheid van de MSVA was goed en de diagnostische effectiviteit werd niet significant ondermijnd door waarschuwingen voor validiteitstest of door het verstrekken van informatie over validiteitstests. De MSVA was ongeveer even effectief als de TOMM in het maken van onderscheid tussen eerlijke en 
simulerende deelnemers, en iets minder effectief dan de AKTG. Desalniettemin detecteerde de MSVA verscheidene simulerende deelnemers die door de AKTG en de TOMM over het hoofd werden gezien; dit geeft aan dat de MSVA toegevoegde waarde heeft en daarom verder onderzocht zou moeten worden. Bij elkaar genomen vormen onze studies een eerste stap richting de validatie van de MSVA als PVT die zich richt op gesimuleerde beperkingen in vocabulaire en abstract redeneren in plaats van geheugen.

\section{Hoofdstuk 6}

Hoofdstuk 6 draait om een SVT die we zelf ontwikkeld hebben; de Symptom and Disposition Interview (SDI). Met de SDI exploreerden we een onopgelost en nauwelijks onderzocht probleem in de evaluatie van symptoomvaliditeit; namelijk het maken van onderscheid tussen simulatie en nagebootste stoornissen ("malingering" en "factitious disorder"). Bij simulatie veinzen mensen symptomen omwille van externe voordelen; ze trachten er tastbaar gewin mee te behalen, zoals financiële toekenningen of het ontlopen van plichten of verantwoordelijkheden; bij nagebootste stoornissen wordt het veinzen van symptomen gedreven door interne motieven; bijvoorbeeld om aandacht, hulp of sympathie te verkrijgen. In tegenstelling tot simulatie worden nagebootste stoornissen beschouwd als psychiatrische aandoeningen. Naast het detecteren van symptoom-overrapportage dient de SDI om verschillende interne motieven te peilen die geassocieerd worden met nagebootste stoornissen. Dit wordt bewerkstelligd door items die aftasten in hoeverre respondenten bereid zijn patiënt-gerelateerde activiteiten te ondernemen; bijvoorbeeld om niet-essentiële of onprettige procedures te ondergaan ter diagnose of behandeling; om deel te nemen aan praatgroepen of wetenschappelijke studies; of om frustratie te uiten over niet begrepen of serieus genomen of anderszins niet correct behandeld worden.

We onderzochten de kwaliteiten van de SDI en vergeleken deze met die van een traditionele SVT (de SIMS) in twee experimentele studies; elk met simulatie- en nagebootste stoornis-condities ( $n=24-30$ per conditie) en een klinische controle groep ( $n=34, n=40)$. De eerste studie leverde mooiere resultaten op dan de tweede, maar over het geheel genomen waren de resultaten positief. De SDI was even effectief als de SIMS in het detecteren van symptoom-overrapportage en superieur in het differentiëren tussen de simulatie- en nagebootste stoornis-condities. Uiteraard is verder onderzoek, in het bijzonder in klinische populaties, nodig om de kenmerken van de SDI en de effectiviteit van de gebruikte detectiestrategieën beter in kaart te brengen. Ons onderzoek naar de SDI kan het best beschouwd worden als exploratief voorwerk dat als basis kan dienen voor vervolgonderzoek naar de psychometrische evaluatie van simulatie en nagebootste stoornissen.

\section{Hoofdstuk 7}

Naast een discussie van de belangrijkste resultaten en conclusies van de studies die beschreven werden in voorgaande hoofdstukken biedt hoofdstuk 7 een uiteenzetting van de likelihood ratio (LR) als kwantitatieve methode om validiteitstestscores te combineren en te 
interpreteren. De LR kan bezien worden als de mate waarin een bepaalde validiteitstestscore meer strookt met de hypothese dat een symptoompresentatie niet accuraat is dan met de hypothese dat een symptoompresentatie wel accuraat is. Anders gezegd kan de LR gezien worden als de mate waarin de hypothese dat een symptoompresentatie niet accuraat is meer aannemelijk wordt nadat een bepaalde validiteitstestscore bekend is.

Elke validiteitstestscore is geassocieerd met een bepaalde sensitiviteit en specificiteit; sensitiviteit is de kans op een positieve testuitslag bij positieve respondenten en specificiteit is de kans op een negatieve testuitslag bij negatieve respondenten. De LR wordt berekend door sensitiviteit te delen door 1 minus specificiteit (LR = sensitiviteit/[1 - specificiteit]). LRs variëren van 1 tot oneindig; hoe verder boven 1, hoe groter de toename in waarschijnlijkheid dat een symptoompresentatie niet accuraat is.

De pre-test kans dat een symptoompresentatie niet accuraat is, is gelijk aan de prevalentie van niet-accurate symptoompresentaties, of, indien er reeds validiteitstests zijn afgenomen, aan de post-test kans behorende bij de afgenomen validiteitstests. De post-test kans dat een symptoompresentatie niet accuraat is, wordt berekend door eerst de pre-test kans om te rekenen naar odds ("kansverhouding"); pre-test kans/[1 - pre-test kans] = pre-test odds. De pre-test odds kan vervolgens vermenigvuldigd worden met de LR, waarna de uitkomst weer terug kan worden gerekend naar kans via post-test odds/[1 + post-test odds].

Het combineren van testresultaten wordt bewerkstelligd door het aaneenschakelen ("chaining") van LRs: dit houdt in dat de post-test odds van de eerste test gebruikt worden als pre-test odds van de tweede test, enzovoorts. Bij het aaneenschakelen van LRs dienen twee zaken in het oog gehouden te worden; dat de post-test kans op niet-accurate symptoompresentaties overschat wordt indien de resultaten van validiteitstests samenhangen (d.w.z., met elkaar correleren) in klinische populaties, en indien testresultaten aaneengeschakeld worden zonder dat er tenminste twee resultaten geassocieerd zijn met een hoge specificiteit (d.w.z., $\geq .90$ ).

Samenvattend kan gesteld worden dat het aaneenschakelen van LRs een kwantitatieve methode is om diagnostische beslissingen te nemen en dat deze methode de actuariële benadering van symptoomvaliditeitstoetsing completeert. De berekeningen zijn eenvoudig (zie blz. 160, tabel 7.2) en de beslissingen die ermee genomen worden stoelen volledig op logica en empirische kennis; kortom, het gebruik van LRs bevordert de transparantie en de wetenschappelijke insteek van diagnostiek en helpt om de diagnostische foutenmarge te reduceren. 


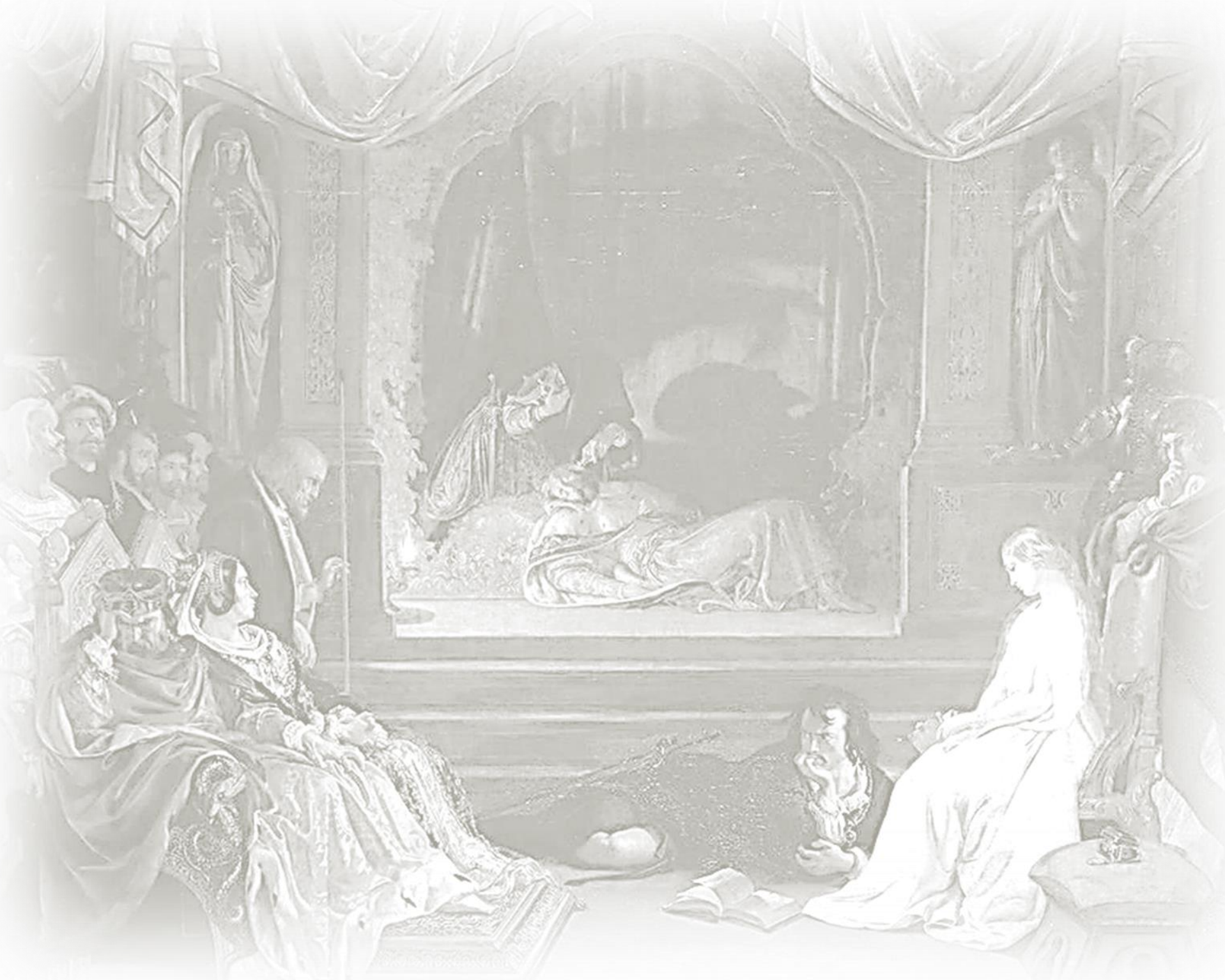




\section{Valorization addendum}

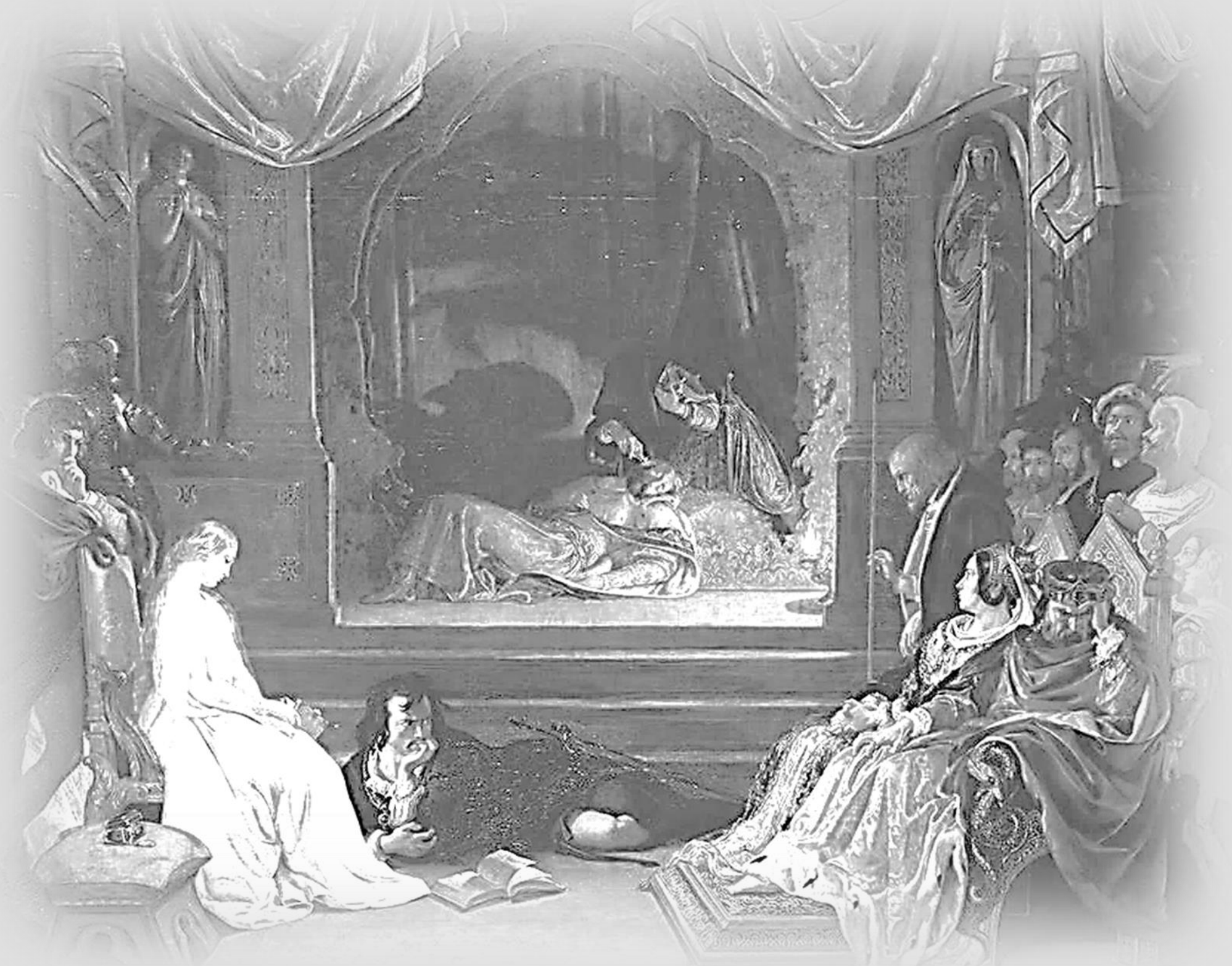




\section{Relevance}

Validity assessment is an essential component of psychological and neuropsychological evaluations: Without it, there is no way to ascertain the validity of diagnostic data and the conclusions that are based thereon. This thesis presents and discusses data about the utility of several validity tests and indicators, and offers guidelines for the application of current methods of validity assessment, and recommendations on how to improve upon these methods.

Validity tests serve to pinpoint the extent to which a patient's symptom presentation accurately reflects their clinical condition. If there is a significant mismatch between a patient's symptom presentation and their clinical condition, and this mismatch remains undetected, then the patient will receive an incorrect diagnosis and a correspondingly inappropriate treatment. As a result, the patient's clinical condition may persist, or even worsen. Therefore, validity assessment, and, by extension, research into validity assessment, such as presented in this dissertation, is first and foremost in the interest of patients themselves.

Because the well-being of patients is a primary concern for healthcare practitioners, and validity assessment aids in the diagnosis of health problems, research on how to carry out and improve validity assessment is relevant for healthcare practitioners. In fact, the leading objective in writing this thesis has been to provide practitioners with empirically based recommendations as to the use of various validity tests and indicators. Moreover, the final part of Chapter 7, about the use of likelihood ratios to interpret and combine validity test data, was written primarily to present practitioners with a simple yet scientifically tenable approach to process validity test data.

Next to clinical settings, validity assessment is useful in settings where patients experience incentives to distort their symptom presentation, such as in legal and insurance contexts. Studies that aim to improve the accuracy and reliability of validity assessment are relevant to all stakeholders in such settings, because faulty validity assessment (i.e., falsepositive or false-negative identifications of noncredible symptom presentations) may have severe consequences, such as erroneous verdicts or improper endowments of benefits.

Validity assessment can also improve the outcome of proceedings in research where the symptom presentations of patients are a crucial factor. For example, studies into causes, effects, or treatments of psychological or neuropsychological symptoms are critically dependent on the accuracy of the diagnoses of its participants: If a minority of participants misrepresents their clinical condition (e.g., feigns the condition that is being studied), then study results may be distorted. For instance, the effects of medication or therapeutic interventions may be resisted by individuals who feign or exaggerate symptomatology. Similarly, dose-response relationships may be obscured in samples that include individuals who present with symptoms in the (relative) absence of causal factors (e.g., present with cognitive impairment in the absence of brain injury). 
In addition to being valuable to those directly involved in validity assessment (i.e., patients and practitioners), validity assessment has considerable consequences that are beneficial to society at large. These consequences are essentially financial: Feigned symptomatology that goes unnoticed leads to losses in labor productivity, wrongfully allocated healthcare resources, wasted healthcare research funds, unjustly awarded claims, and escalations in disability benefits and insurance compensations, which, ultimately, trigger increases in healthcare insurance premiums and taxes. The tripartite of productivity loss, resource waste, and rise in compensation costs, entails that even when the prevalence of feigned symptomatology is assumed to be low, the associated monetary burden for society is still considerable; in the order of billions: For example, in 2016, the expenditure of the United States on healthcare alone was 3.3 trillion dollars; a number in which productivity loss and compensation costs have yet to be factored in.

\section{Innovation}

Chapters 2 and 3 describe studies in which we investigated the assumption of the Diagnostic and Statistical Manual of Mental Disorders (5th ed.) that antisocial features are predictive of noncredible symptom presentations. These studies are among the first that address this issue in Europe. Moreover, they are the first in which a signal detection theory approach is used to quantify the diagnostic utility of antisocial features for noncredible symptom presentations. The two studies reported in Chapter 2 also stand out because, unlike previous research, they involved contrasting settings; a therapeutic forensic setting (Study 1) and a punitive forensic setting (Study 2), and because they covered symptom underreporting (Study 1) and social desirability (Study 2) in addition to symptom overreporting. These are important assets because the association between biased symptom reporting and antisocial features may be context dependent, and because, depending on contextual factors, positively biased symptom presentations are equally plausible to be related with antisocial features. The study presented in Chapter 3 improves on earlier research by explicitly targeting specific features that may underlie the potential link between noncredible symptom presentations and antisocial personality disorder; namely deceitfulness, lack of remorse, and blame externalization.

Chapter 4 relates the only meta-analysis and systematic review of published Structured Inventory of Malingered Symptomatology (SIMS) data to date. To update and improve the guidelines of the official manual, which dates from 2005, we compiled and calculated diagnostic accuracy indices and normative scores of patients, claimants, defendants, nonclinical adults, and various experimental feigners. Based on the results of our meta-analysis and on a qualitative review of all published studies, we evaluated the strengths and weaknesses of the SIMS, and put forward amended guidelines for clinical practice.

The innovation of Chapter 5 lies in the translation and revival of the Malingering Scale Vocabulary and Abstraction test (MSVA). In contrast to most other performance 
validity tests (PVTs), the MSVA does not target noncredible memory impairment; instead, it focusses on noncredible deficits in semantic knowledge and perceptual reasoning. After a few initial publications in the early 1990s, the MSVA failed to come into regular use and was not published about again. The lack of alternatives to memory-oriented PVTs drove us to translate the MSVA and examine its diagnostic potential through experiments in various samples, including children, forensic inpatients with intellectual disability, forensic inpatients with psychiatric symptoms, and undergraduate students.

In terms of novelty, Chapter 6 is the pinnacle of this dissertation; it chronicles our development of the Symptom and Disposition Interview (SDI). The SDI is a symptom validity test (SVT) with the unprecedented aspiration to distinguish between factitious and malingered symptom presentations. The differentiation between factitious and malingered symptomatology is imperative because the former constitutes a mental disorder, whereas the latter is mere deception. The two studies described in Chapter 6 are one of the first attempts to investigate the capacity of validity tests to differentiate between factitious and malingered presentations, and certainly the very first attempt to develop strategies to gauge the internal incentives that are associated with factitious disorder (i.e., the "need to assume the sick role").

Finally, Chapter 7 includes a primer on an unconventional technique to combine and interpret validity test data; the likelihood ratio. The use of likelihood ratios has still to catch on in practice, yet it offers multiple advantages over cut scores - the traditional method-to determine whether or not respondents present with noncredible symptomatology. Chiefly, it encourages practitioners to work transparently and scientifically, and, in the process, increase diagnostic probability and decrease diagnostic error. Therefore, we promoted the likelihood ratio approach to validity assessment by adding an explanation of the technique and its merits to Chapter 7.

\section{Valorization}

The knowledge that was generated through the studies presented in this dissertation serves to advance the clinical practice of validity assessment and the research that informs it. Our guiding principle in seeking out the avenues of research that this thesis showcases, was ever to maximize the clinical usefulness of the information that would be generated. We endeavored to gather data to improve the application and interpretation of existing methods, and to develop new insights and approaches to current practices. These ambitions are manifested in, for example, our focus on statistical analyses that capture the practical utility of a method (e.g., signal detection theory and receiver operating characteristic) and our extensive discussions of practical implications and guidelines. We also advanced our aspiration to further the practice of validity assessment by publishing the scholarship collected in this thesis in international, peer-reviewed journals, and by disseminating it through presentations and posters at international and national symposia, and via academic lectures, workshops, and tutorials. 


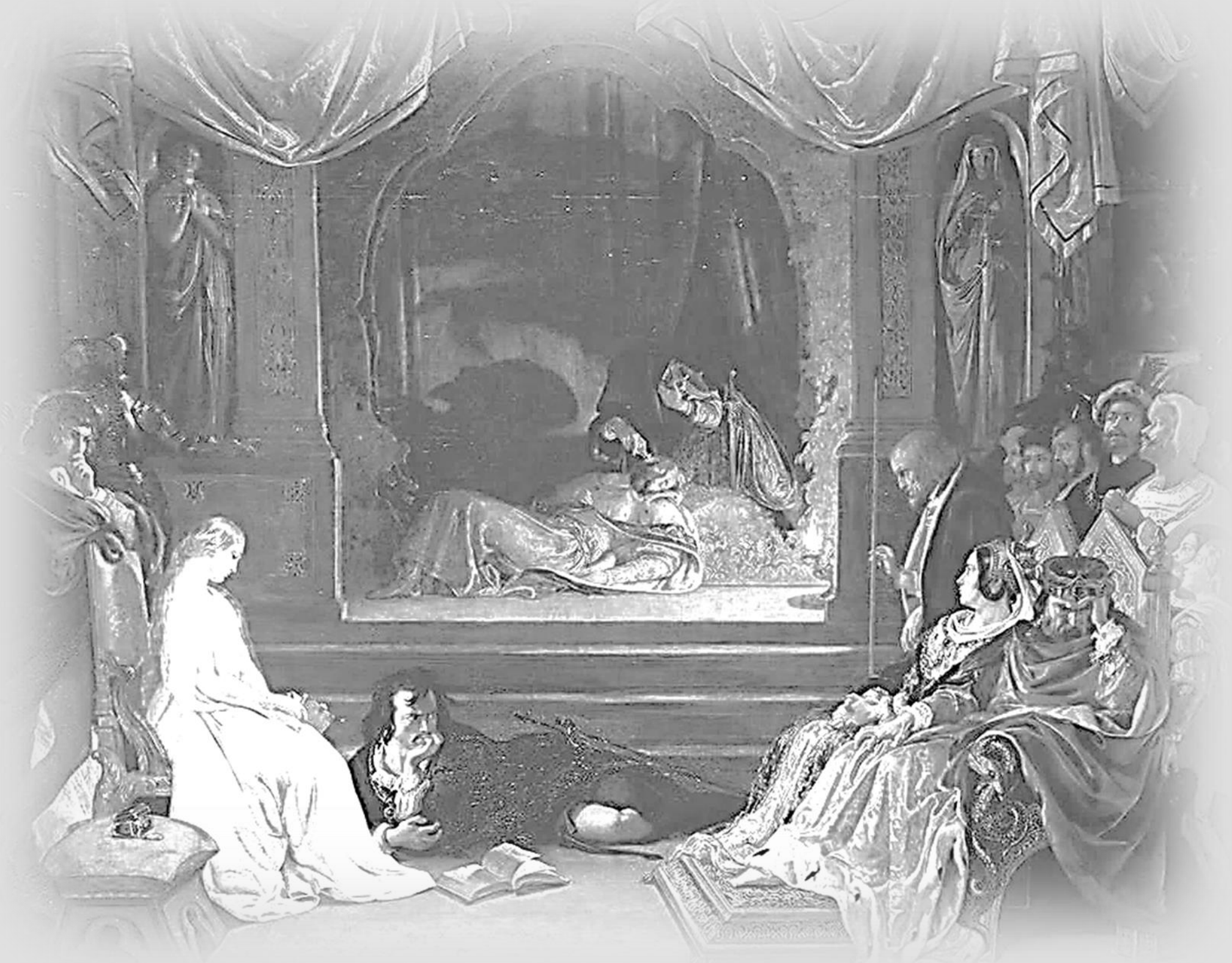




\section{Acknowledgements}

First and foremost, I express deep gratitude to my supervisors Joost à Campo, Marko Jelicic, and Harald Merckelbach, for their invaluable support and guidance and their profound contributions to this dissertation; Joost, Marko, and Harald, your erudition, insight, and diligence were ever a blessing; it was a privilege and a pleasure to work with you and learn from you. Next, I thank Isabella Niesten for the multitude of constructive conversations and productive collaborations; Isabella, working with you was delightful and inspiring.

I am highly thankful for the valuable input of my co-authors Benno Huhnt, Thomas Merten, and Henry Otgaar. I am similarly grateful to Jessica Alleva, Thomas Meyer, Maarten Peters, and Wouter van Impelen for their important contributions to various research projects. I am beholden to the secretarial and information technology staff of the Clinical Psychological Science department for their splendid and timely support. I also give thanks to all students who played a significant part in mutually fruitful research endeavors, and I am very appreciative of all participants who partook in my studies.

Hearty thanks to my office mates; Jessica Alleva, Glynis Bogaard, Irena Boskovic, Ivan Manguilli, Anna Sagana, Manuela Schols, Maartje Schreuder, Ghislaine Schyns, and Pim Wetzelaer; your assorted and greatly appreciated humor, counsel, and moral support rendered me all the merrier and wiser, and greatly facilitated the composition of this dissertation. A big thank you also to all other colleagues from Clinical Psychological Science, especially the Forensic Psychology section, for the myriad of positives that enriched my journey toward a doctoral degree; the retreats, in particular, were a treat.

Last, yet by no means least, I thank those who provided me with vital support in various ways: Frans Leeuw and David Roef for being magnificent mentors at the Faculty of Law; Conny Quaedflieg and Anna Sagana for being scintillating paranymphs; Brecht Debor and Wouter van Impelen for the epic trips and diversions; Josee van Atteveld and Anja Wanders for the precious care and love for my daughters; Mincke Frederix-van Impelen for the splendid support that only a singularly devoted partner in life and love can provide; and Isolde and Séralin for being the most beautiful, brilliant, and delightful daughters a father could ever wish for. 


\begin{abstract}
About the author
Alfons van Impelen was born in Maastricht, the Netherlands, on 11 December 1983. He received primary and secondary education in Maastricht. After dropping out of secondary school at age 16, he alternated between holding minor jobs and pursuing various travel dreams. Upon his return from a journey on foot across the Himalayas, Alfons enrolled in adult high school to complete his secondary education and become eligible for higher education. In 2007, he obtained a VWO ("preuniversity secondary education") degree and successfully sought admission to Maastricht University's bachelor's program in Psychology. A year into the program, he received an award for belonging to the top 3\% of Maastricht University students and accepted an invitation to participate in the bachelor's honors program of the Faculty of Psychology and Neuroscience. After being awarded a Bachelor of Science degree in Psychology cum laude, Alfons was admitted to the two-year Forensic Psychology master's program of Maastricht University. As part of this master's program, he completed a combined clinical and research internship at Radix Forensic Psychiatric Hospital, Heerlen, the Netherlands. Subsequent to earning his Master's degree, Alfons spent 5 years pursuing a doctorate at Maastricht University; the result of which is this dissertation.
\end{abstract}




\section{Publications}

van Impelen, A., Merckelbach, H., Jelicic, M., \& à Campo, J. (2018). Antisocial features are not predictive of symptom exaggeration in forensic patients. Legal and Criminological Psychology, 23, 135-147.

van Impelen, A., Jelicic, M., Otgaar, H., \& Merckelbach, H. (2017). Detecting feigned cognitive impairment with Schretlen's Malingering Scale Vocabulary and Abstraction test. European Journal of Psychological Assessment. Advance online publication.

van Impelen, A., Merckelbach, H., Jelicic, M., Niesten, I. J., \& à Campo, J. (2017). Differentiating factitious from malingered symptomatology: the development of a psychometric approach. Psychological Injury and Law, 10, 341-357.

van Impelen, A., Merckelbach, H., Niesten, I. J., Jelicic, M., Huhnt, B., \& à Campo, J. (2017). Biased symptom reporting and antisocial behaviour in forensic samples: A weak link. Psychiatry, Psychology and Law, 24, 530-548.

van Impelen, A., Merckelbach, H., Jelicic, M., \& Merten, T. (2014). The Structured Inventory of Malingered Symptomatology (SIMS): A systematic review and meta-analysis. The Clinical Neuropsychologist, 28, 1336-1365.

van Impelen, A., Niesten, I. J., Jelicic, M., \& Merckelbach, H. (in press). Simulatie: Enkele misvattingen nader belicht [Feigning: Shedding light on several misconceptions]. In K. Goethals, G. Meynen, A. Popma (Eds.), Leerboek forensische psychiatrie [Textbook forensic psychiatry]. De Tijdstroom Uitgeverij.

van Impelen, A., \& Niesten, I. J. (2015) Als patiënten overdrijven: de valkuilen in het achterhalen van bedrog [When patients exaggerate: the pitfalls of detecting deceit]. In-Mind magazine, 2015, issue 2.

Niesten, I. J., van Impelen, A., \& Merckelbach, H. (2018). Decreasing invalid symptom reporting: A comment on Horner, Turner, Van Kirk, and Denning (2017). Archives of Clinical Neuropsychology. Advance online publication.

Niesten, I. J., Merckelbach, H., van Impelen, A., Jelicic, M., Manderson, A., \& Cheng, M. (2017). A lab model for symptom exaggeration: What do we need? Journal of Experimental Psychopathology, 8, 55-75.

Merckelbach, H., Otgaar, H., van Kan, N., \& van Impelen, A. (2014). De Schretlen Malingering Scale $(\mathrm{MgS})$ als maat voor onderpresteren [The Schretlen Malingering Scale (MgS) as measure of underperformance]. Tijdschrift voor Neuropsychologie, 9, 239-249.

Merckelbach, H., Jelicic, M., \& van Impelen, A. (2013). De Structured Inventory of Malingered Symptomatology: Een update [The Structured Inventory of Malingered Symptomatology: An update]. Tijdschrift voor Neuropsychologie, 8, 170-178. 


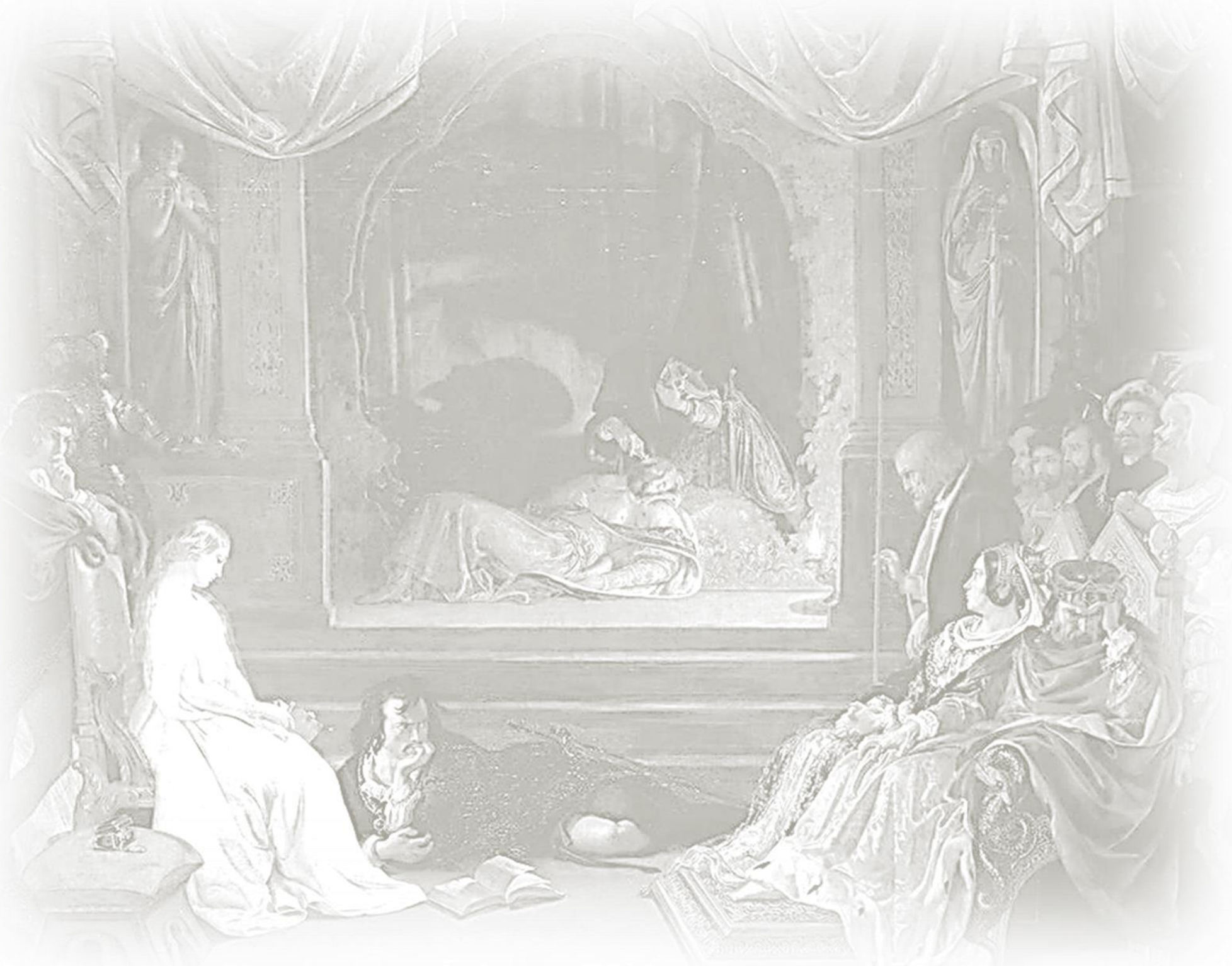




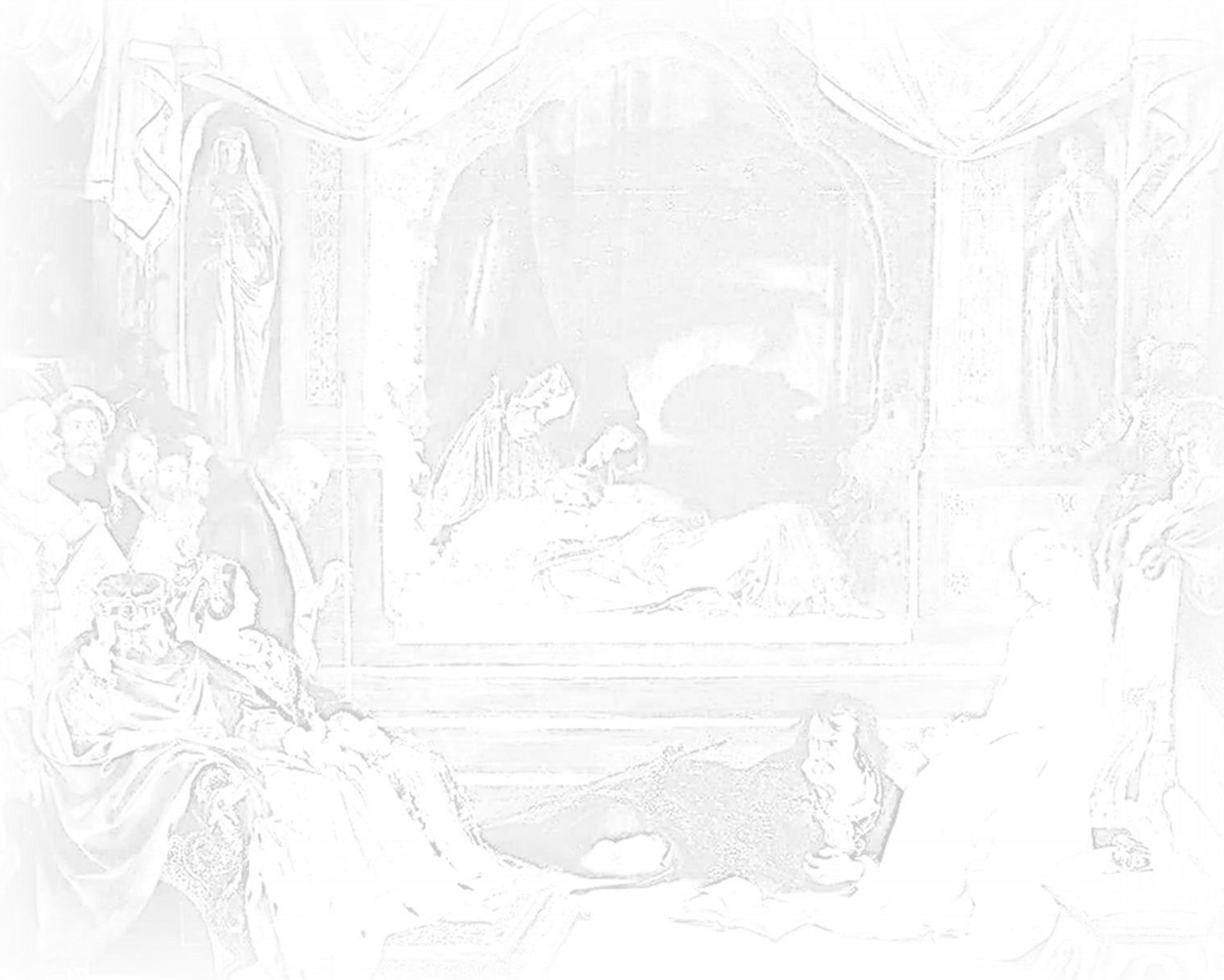

